Check for updates

Cite this: RSC Adv., 2017, 7, 25897

Received 23rd December 2016

Accepted 5th April 2017

DOI: $10.1039 / \mathrm{c} 6 \mathrm{ra} 28598 \mathrm{~h}$

rsc.li/rsc-advances

\section{The evolution of comprehensive strategies for furanoid glycal synthesis and their applications $\uparrow$}

\author{
Pinki Palț and Arun K. Shaw (D)* \\ Cyclic enol ether frameworks, especially stereochemically pure furanoid and pyranoid glycals are well \\ known highly functionalized chiral building blocks. Furanoid glycals have been shown to possess great \\ potential, as they have been used as key intermediates for the synthesis of structurally diverse molecules
}

Division of Medicinal \& Process Chemistry, CSIR-Central Drug Research Institut, Sector 10, Jankipuram Extension, Sitapur Road, Lucknow-226 031, India. E-mail: akshaw55@yahoo.com; Tel: +91-9415403775

+ CDRI Communication Number is 9482 .
I Present address: Department of Chemistry, Mount Carmel College Autonomous, 58, Palace Road, Bangalore-560052, India. E-mail: pinkipal@ gmail.com; Tel: +91-7760512715

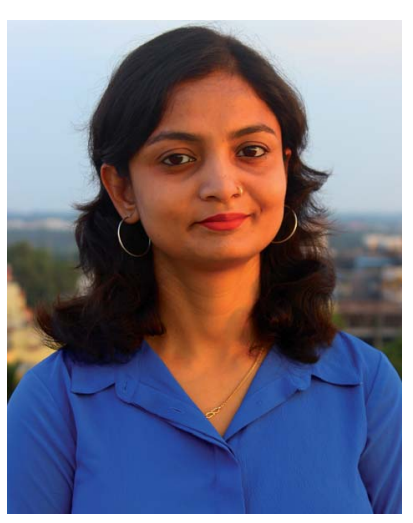

Pinki Pal was born in the state of West Bengal, India. She obtained her B.Sc. in Chemistry (Hons.) from The University of Burdwan, India and M.Sc. in Organic Chemistry from University of Kalyani, India in 2002 and 2004 respectively. She received her Ph.D. degree in 2011 jointly from CSIR-Central Drug Research Institute, Lucknow, and Jadavpur University, Kolkata, India, under the supervision of Dr Arun $K$.

Shaw (CSIR-CDRI) and co-supervision of Prof. Gourhari Maiti (Jadavpur University). In her doctoral research, she worked on 'chiron' approach to total stereoselective synthesis of bioactive natural product and natural product like molecules starting from commercially available monosaccharides. After working as a Project Associate at the Indian Institute of Science, India, with Prof. N. Jayaraman and Postdoctoral Fellow at National Taiwan University, Taiwan, with Prof. YaChing Shen, she joined as Associate Scientist at GVK Biosciences Pvt. Ltd., Hyderabad, India. Later she worked as a Consultant at Jawaharlal Nehru Centre for Advanced Scientific Research (JNCASR), Bangalore in Dr Jayanta Haldar's Research Group. At present, she is Lecturer at Department of Chemistry, Mount Carmel College Autonomous, Bangalore, India.

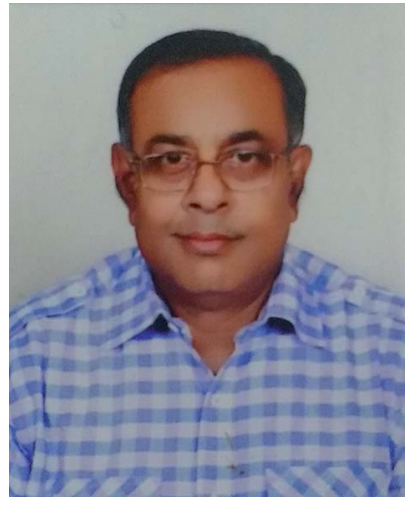

Arun K. Shaw was born in Raniganj, West Bengal. He received his B.Sc. (Hons.) degree in Chemistry from Scottish Church College, Calcutta University, in 1975, his M.Sc. degree in Chemistry from Calcutta University in 1977, and his Ph.D. in Natural Product Chemistry under the supervision of Professor S. N. Ganguly from Bose Institute, Calcutta University, in 1985. After his doctoral work, he worked with Professors S. K. Talapatra and B. Talapatra in the Department of Pure Chemistry, Calcutta University, during 19851986. In 1987 he joined as a Scientist Gr. IV (1) in the Department of Food Chemistry, CSIR-Central Food Technological Research Institute, Mysore. He moved in the same capacity to the Division of Medicinal Chemistry, CSIR-Central Drug Research Institute, Lucknow, in 1991. His research interests centred around isolation, purification characterization of natural products of plant origin, syntheses of bioactive natural product or natural product like molecules using carbohydrates as chiral pool. He is also interested in development of new methodology/synthetic reagents and investigation of new reaction pathways in organic synthesis. He has published over 78 papers in peer reviewed international journals including a review article in Chemical Review. He held the visiting scientist positions at University of Rostock, Germany under CSIR-DAAD Exchange Programme of scientists in April-June, 2000 and at University of Glasgow, Glasgow, Scotland in March, 2013 under INSA, New Delhi International Collaboration/Exchange Programme during 2011-2012. He superannuated in 2015 from Division of Medicinal Chemistry, CSIR-Central Drug Research Institute, Lucknow from the position of Chief Scientist and Professor AcSIR. 


\section{Introduction}

Carbohydrates represent one of the most privileged classes of naturally occurring versatile building blocks in synthetic organic chemistry due to their wealth of unique functional, conformational, and stereochemical information. The diversity and availability of these relatively cheap chiral compounds has led to their use as starting materials for the design and syntheses of naturally occurring compounds and biologically important molecules. ${ }^{1}$ The preparation of attractive building blocks from carbohydrates and their use for the synthesis of various biologically active simple or complex natural products has received considerable attention from organic chemists. Therefore, the stereocontrolled synthesis of chiral building blocks (CBBs) is an important objective in organic chemistry. Over the last several years our group has been working toward the synthesis of enantiomerically pure sugar derived building blocks and their utilization to accomplish the total synthesis of target biologically relevant natural products ${ }^{2 \boldsymbol{b}, \boldsymbol{d}, \boldsymbol{g}, \boldsymbol{h}}$ and natural product like molecules. ${ }^{2 \boldsymbol{a}, \boldsymbol{c}, \boldsymbol{e}, \boldsymbol{f}, \boldsymbol{i}}$ Recently our research group has reviewed glycal derived $\delta$ hydroxy $\alpha, \beta$-unsaturated aldehydes (Perlin aldehydes). ${ }^{3 a}$

While there are many carbohydrate derivatives, monosaccharides occupy a significant place among them as starting materials. Glycals, prepared from hexoses and pentoses, are most important and well known highly functionalized CBBs and find their huge applications in 'chiron' approach synthesis. ${ }^{3 b, c}$ They are highly reactive due to their enol ether geometry (a double bond between the carbon atoms 1 and 2 of the ring). There are two kinds of glycals: (i) pyranoid glycal I (derived from hexose), (ii) furanoid glycal II (derived from pentose) (Fig. 1).

A considerable effort has been dedicated toward the synthesis of pyranoid glycals and furanoid glycals. In recent years, interest has been devoted to synthesis of furanoid glycals, owing to the fact that they have been used as key intermediates

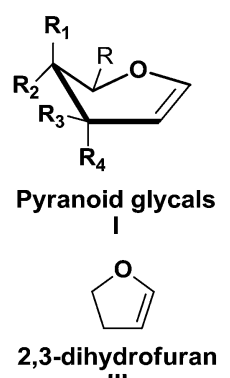

III

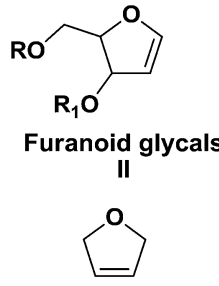

2,5-dihydrofuran
Fig. 1 General structures of pyranoid glycals (I), furanoid glycals (II), 2,3-dihydrofuran (III) and 2,5-dihydrofuran (IV). in syntheses of structurally diverse compounds with various biological activities such as polyether antibiotics, ${ }^{4}$ 6-epi-leukotrienes $\mathrm{C} \& \mathrm{D},{ }^{5}$ palladium-mediated coupling reaction leading to $C$-nucleosides, ${ }^{6}$ antiviral and antitumour $C$-nucleosides, ${ }^{7}$ $\alpha$-arabino nucleosides, ${ }^{8} 2^{\prime}, 3^{\prime}$-dideoxynucleosides ${ }^{9}$ and more recently $2^{\prime}$-deoxynuleosides. ${ }^{10}$

There are a large number of reports on the synthesis and uses of furanoid glycals. The versatile application of furanoid glycals inspired us to compile the wholesome work centered around their synthesis and applications since the inception to date in the form of a review. This review mainly focuses on various synthetic routes for the preparation of furanoid glycals and their applications toward synthesis of important 'chiral building blocks', various kinds of natural and unnatural products of biological importance and $C$ - \& $N$-nucleosides. We have tried to include many recent examples in this review that covers our studies till date, and any omissions on this wide topic are unintentional. It should be noted that, only synthesis and applications of furanoid glycals are described here. Other reactions, in which 2,3- and 2,5-dihydrofurans (III, IV) involve are not described here (Fig. 1).

\section{Literature reports on synthesis of furanoid glycals (FGs)}

Glycals (pyranoid and furanoid glycals) are important intermediates in the synthesis of a variety of carbohydrate derivative. In 1913, Fischer and Zach ${ }^{\mathbf{1 1}}$ first synthesized 3,4,6-tri-O-acetyl-1,5-anhydro2-deoxy-D-arabino-hex-1-enitol. Inspired by the reactivities of glycals and to report the first synthesis of furanoid glycal (FG), Ness and Fletcher tried to synthesise furanoid glycal from tri-O-benzoyl$\alpha$-D-arabinofuranosyl bromide after several modification of Fisher and Zach's method. ${ }^{12}$ But they failed to achieve their goal.

However, they successfully synthesised 1,4-anhydro-3,5-di-Obenzoyl-2-deoxy-D-erythro-pent-1-enitol 4 in 1963, known to be the first glycal derivative with a furanose structure, starting from 3,5-di-O-benzoyl-2- $O$ - $p$-nitrophenylsulfonyl- $\beta$-D-ribosyl bromide 3 , which was easily prepared from 1,3,5-tri-O-benzoyl- $\alpha$-D-ribose 1 in two steps. ${ }^{13}$ The free hydroxyl group in $\mathbf{1}$ was nosylated with $\mathrm{NsCl}$ in the presence of pyridine to obtain nosyl derivative 2 . It was brominated at $\mathrm{C}-1$ with $\mathrm{HBr}$ in $\mathrm{AcOH}$ to afford 3,5-di-Obenzoyl-2- $O-p$-nitrophenylsulfonyl- $\beta$-D-ribosyl bromide 3 , which was ultimately treated with $\mathrm{NaI}$ in acetone solution at a low temperature to obtain crystalline FG 4 in $72 \%$ yield (Scheme 1). While its reaction in DCM with $\mathrm{MeOH}$ at room temperature gave the dihydro furan 5, the fufuryl benzoate 6 was obtained when 4 in acetone was allowed to react with water. 
<smiles>O=C(O)OC[C@H]1O[C@@H](OC(=O)c2ccccc2)[C@H](O)[C@@H]1O</smiles>

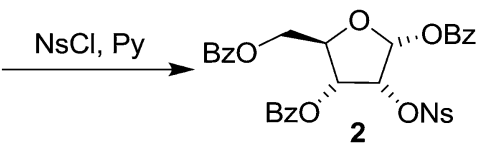<smiles>CC(Br)CCCCCC(=O)O</smiles><smiles>O=C(O)OC[C@H]1OC(Br)[C@@H](O[N+](=O)[O-])[C@@H]1OC(=O)O</smiles>

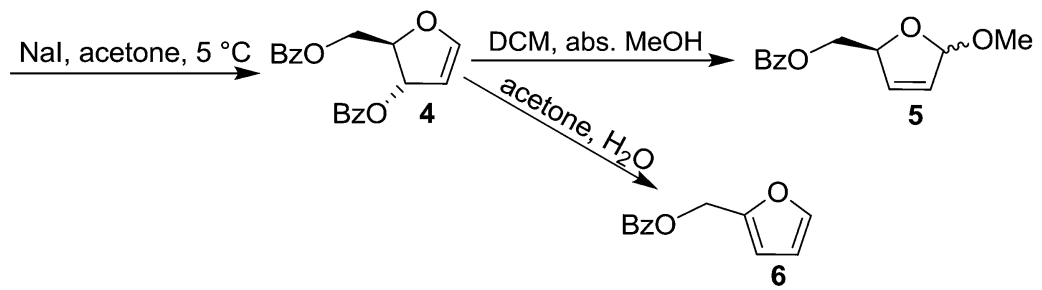

Scheme 1

After the synthesis of labile furanoid glycal 4, Ness et al. synthesised 3,5-di-O-p-anisoyl-1,2-dideoxy-D-erythro-pentofuranos-1ene 14 and showed that greater the nucleophilicity of the substituent at C-3 of furanoid glycal 14, the lesser would be the tendency to form aromatic products. Its synthesis was started from methyl- $\beta$-D-ribofuranoside 7 . It was first acylated with $p$ anisoyl chloride to obtain 8 followed by its bromination with $32 \%$ $\mathrm{HBr}$ in $\mathrm{AcOH}$ to give bromoderivative 9. Its hydrolysis and subsequently crystallization of the resulting product mixture with acetone and water $(7: 1)$ in DCM yielded isomeric hemiacetals 1,3,5-tri-O- $p$-anisoyl- $\alpha$-D-ribofuranose 10 and 2,3,5-tri- $O$ - $p$-anisoyl$\beta$-D-ribofuranose 11. Compound 10 was nosylated with $p$-nitrophenyl sulphonyl chloride $(\mathrm{NsCl})$ in pyridine at $0{ }^{\circ} \mathrm{C}$ to give 12 in good yield. It was brominated with $32 \% \mathrm{HBr}$ in acetic acid to furnish 13, which was treated with $\mathrm{NaI}$ in acetone solution at $5{ }^{\circ} \mathrm{C}$ to obtain crystalline furanoid glycal 14 in $67 \%$ yield (Scheme 2). ${ }^{\mathbf{1 4}}$
Bischofberger and Hall attempted to prepare the stable $\mathrm{FGs}^{\mathbf{1 5}}$ by the modification of Fischer and Zach's method in the year 1976. ${ }^{13}$ However, their method failed to deliver the desired glycals due to the tendency of C-3 substituent to undergo allylic rearrangement. To get rid of this problem, a series of differently substituted furanose derivatives (15a-d) were prepared, where C3 substituents were less susceptible to allylic rearrangement. ${ }^{15 a, b}$ Having these precursors in their hand, they prepared FGs (19a-d) by modifying Fischer and Zach's method for the preparation of glycals (Scheme 3 , Table 1). ${ }^{15 c}$ The modified method involved the highly reactive cationic species $(\mathbf{1 7 a}-\mathbf{d})$, which can either accept two electrons and lose an acetoxyl anion to form the glycals (19a-d), or can combine with hydroxyl or acetoxyl anions to give the free aldoses $(\mathbf{1 8 a}-\mathbf{d})$ or starting materials (15a-d). The glycals 19a and 19b were obtained in moderate yields whereas 19c and 19d in low yields. All of them were stable on silica gel and stored under $\mathrm{N}_{2}$ at $-5{ }^{\circ} \mathrm{C}$ for 6 months. Compounds 20a and 5 were<smiles>CO[C@H]1O[C@H](CO)[C@@H](O)[C@H]1O</smiles>

7

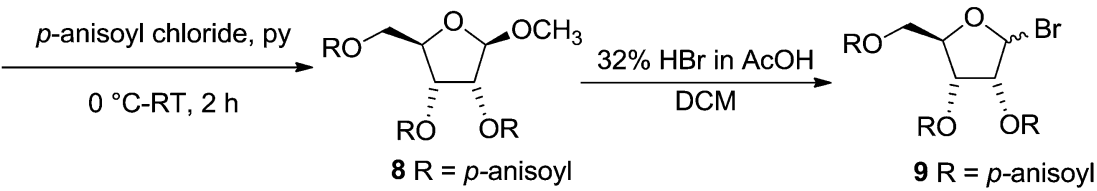

RO OR

11

$\mathrm{R}=p$-anisoyl, $\mathrm{R}^{1}=\mathrm{H}$

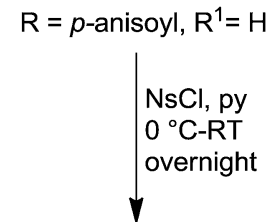

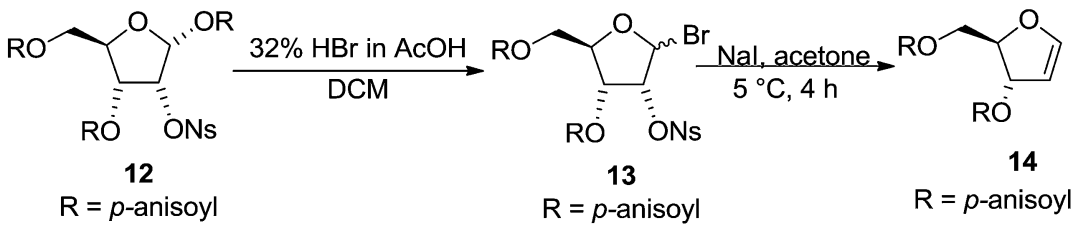

Scheme 2 


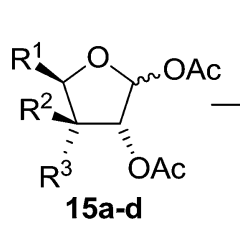<smiles></smiles><smiles>[R16]O[C@H]1[C@H](Br)O[C@@H]([R10])C1([R])[R]</smiles>

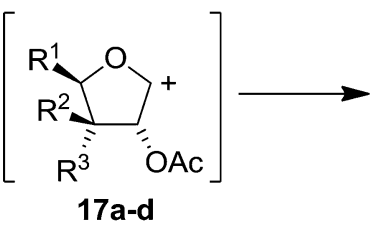<smiles>[R]C1O[C@H](O)[C@@H](OC(C)=O)C1([R])[R]</smiles>

a $\mathrm{R}^{1}=\mathrm{CHOAc} . \mathrm{CH}_{2} \mathrm{OAc}, \mathrm{R}^{2}=\mathrm{OMe}, \mathrm{R}^{3}=\mathrm{H}$

b $\mathrm{R}^{1}=\mathrm{CH}_{2} \mathrm{OBz}, \mathrm{R}^{2}=\mathrm{OMe}, \mathrm{R}^{3}=\mathrm{H}$

c $\mathrm{R}^{1}=\mathrm{CH}_{2} \mathrm{OBz}, \mathrm{R}^{2}=\mathrm{H}, \mathrm{R}^{3}=\mathrm{OMe}$

d $^{1}=\mathrm{CH}_{2} \mathrm{OAc}, \mathrm{R}^{2}=\mathrm{H}, \mathrm{R}^{3}=\mathrm{NHAc}$

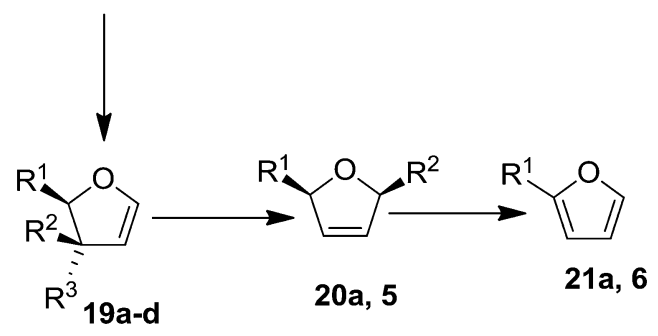

Scheme 3

Table 1 Product yields of furanoid glycals $(19 a-d)$ by modified Fischer and Zach's method from substituted furanose derivatives (15a-d)

\begin{tabular}{|c|c|c|c|c|c|}
\hline Starting material & \multicolumn{5}{|c|}{ Yields of products (\%) } \\
\hline $15 \mathbf{a}$ & 1 & 26 & 2 & 3 & 51 \\
\hline $15 b$ & 2 & 20 & 5 & 5 & 48 \\
\hline $15 c$ & & 6 & & 5 & 83 \\
\hline
\end{tabular}

generated from their respective glycals $\mathbf{1 9 a}, \mathbf{b}$ by 1,3 -sigmatropic shift of the methoxy groups, whereas the furans $21 \mathrm{a}$ and $\mathbf{6}$ were produced by the decomposition of $19 \mathrm{a}$ and $19 \mathrm{~b}$, respectively (Scheme 3)..$^{15 d}$

In 1977 Jordaan et al. reported an alternative method for the preparation of furanoid glycals by the reduction of suitably protected furanosyl bromides with sodium or potassium in aprotic solvents. ${ }^{\mathbf{1 6 a}}$ 2,3:5,6-di- $O$-isopropylidene- $\alpha$-D-mannofuranose 22 derived bromo derivative 23 (ref. 16b) on treatment with an excess of sodium in dry THF at $20{ }^{\circ} \mathrm{C}$ for $3 \mathrm{~h}$ gave furanoid glycal 24 in 59\% yield and a trace of 1,1'-disaccharide 25 ( $2 \%$ yield). Treatment of the mannofuranosyl bromide 23 with

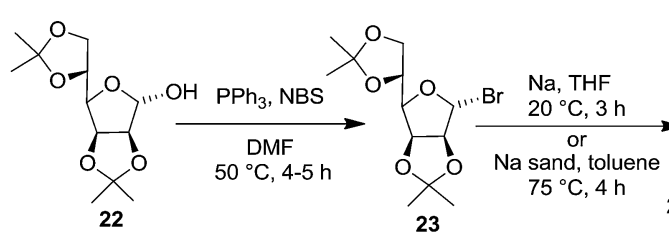

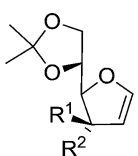<smiles>[R]C1OC2OC(C)(C)OC2OC1C1COC(C)(C)O1</smiles>

$24 \mathrm{R}^{1}=2,3: 5,6$-di-O-isopropylidene $25 \mathrm{R}=2,3: 5,6$-di-O-isopropylidene $-\alpha$-D-mannofuranosyloxy, $\mathrm{R}^{2}=\mathrm{H} \quad-\alpha$-D-mannofuranosyl $26 \mathrm{R}^{1}=\mathrm{OH}, \mathrm{R}^{2}=\mathrm{H}$
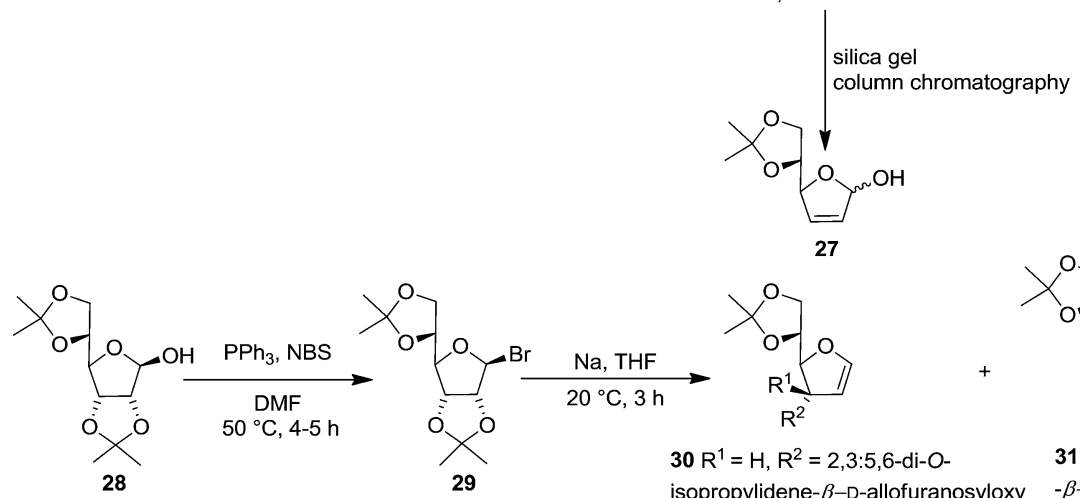<smiles>CC1(C)OCCO1</smiles><smiles>[R]C1([R])C=COC1C1OCOC1(C)C</smiles>

$30 \mathrm{R}^{1}=\mathrm{H}, \mathrm{R}^{2}=2,3: 5,6$-di-O-

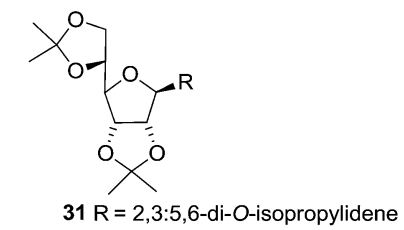
isopropylidene- $\beta$-D-allofuranosyloxy $\quad-\beta$-D-allofuranosyl 
sodium sand in toluene at $75{ }^{\circ} \mathrm{C}$ for $4 \mathrm{~h}$ gave low yields of 24 (9\%) as well as the 1,4-anhydrohex-1-enitol 26 (11\%). The glycal 26 was unstable and rearranged during chromatography on silica gel to the isomeric compound 27 (Scheme 4).

In the similar way, reduction of 2,3:5,6-di- $O$-isopropylidene$\beta$-D-allofuranosyl bromide 29 , derived from $28,{ }^{16 b}$ with sodium in THF $\left(20^{\circ} \mathrm{C}, 3 \mathrm{~h}\right)$ gave furanoid glycal 30 in $69 \%$ yield and 1,1'disaccharide 31 (2\% yield) (Scheme 4 ).

In 1978, the same group discussed an alternative route for the synthesis of furanoid and pyranoid glycals. ${ }^{17 a}$ While treating 2,3:5,6-di- $O$-isopropylidene- $\alpha$-D-mannofuranose 22 derived furanosyl chloride 32 (ref. 17b) with sodium naphthalide in THF followed by acetic acid furnished FG 26 in 59\% yield, under the identical reaction condition furanosyl chloride $\mathbf{3 5}$ (derived from 28) yielded FG 36 in 54\% yield (Scheme 5).

On the other hand, treatment of furanosyl chloride $\mathbf{3 2}$ and furanosyl bromide 23 each with $\mathrm{Na}$ or $\mathrm{K}$ metal in THF instead of sodium naphthalide gave 3-O-furanosyl furanoid glycal 24 as the major product along with glycoside 33 and disaccharides 25 , 34 as by-products. Similarly, the furanosyl chloride 35 (ref. 17c) and the analogous bromide $\mathbf{2 9}$, gave only the 3-O-furanosyl glycal $30(69 \%)$ and a trace of the disaccharide 31 (Scheme 5).
Further, warming furanosyl bromide 23 with sodium sand in toluene at $70{ }^{\circ} \mathrm{C}$ afforded the glycal 26 in low yield along with its isomeric 2,5-dihydro derivative 27 (Scheme 5).

In the same year, Ireland and co-workers developed a general procedure for the synthesis of high yielding 3-hydroxylated FGs, in 4 steps, starting from D-erythronolactone $37 \mathbf{a}$ and from $\mathrm{D}^{-}$ ribonic acid- $\gamma$-lactone $\mathbf{3 7 \mathbf { b }}$ in 5 steps, involving the reductive fragmentation of 2,3-O-isopropylidene protected furanosyl chloride with $\mathrm{Li}$ in liquid ammonia as a key step (Scheme 6).,18

The starting material 2,3-O-isopropylidene- $\beta$-D-erythro-furanosyl chloride 39a was prepared from D-erythronolactone 37a in $79 \%$ overall yield by a sequence of reactions that involves acetonide formation of D-erythronolactone 37 a followed by partial reduction of the resulting acetonide 38a with DIBALH in $\mathrm{Et}_{2} \mathrm{O}$ at $-78{ }^{\circ} \mathrm{C}$ to an intermediate 2,3-O-isopropylidene-Derythrose, which was immediately treated with $\mathrm{CCl}_{4}$ and $\mathrm{Ph}_{3} \mathrm{P}$ in THF to obtain furanosyl chloride 39a. Its reduction with 4 equiv. of $\mathrm{Li}$ in liquid $\mathrm{NH}_{3}$ in the presence of 6 equiv. of $\mathrm{NH}_{4} \mathrm{Cl}$ afforded a mixture containing glycal 40a and THF 41a in a ratio of $6: 1$ (NMR) with $60 \%$ yield. They also used D-ribonic-acid- $\gamma$-lactone 37b as the starting material in their study to achieve the synthesis of furanoid glycal $\mathbf{4 0 b}$. The acetonide protection of the

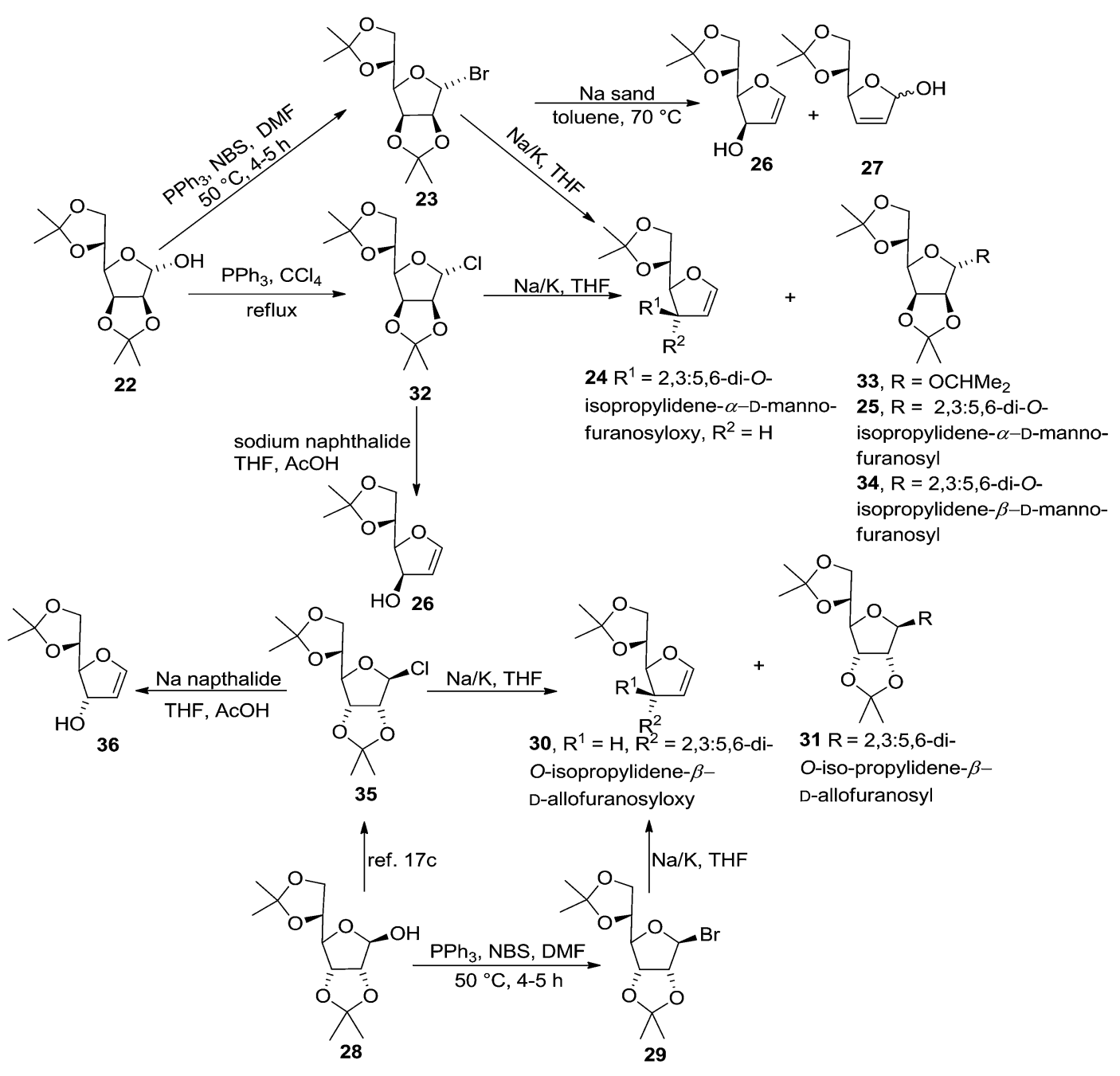

Scheme 5 


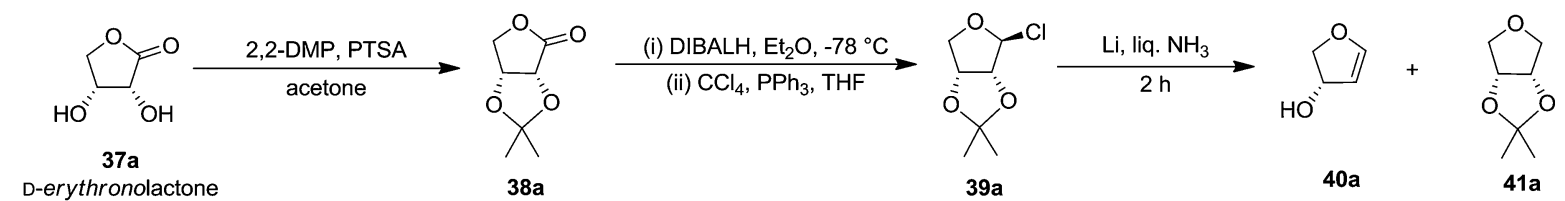

D-erythronolactone

$38 \mathrm{a}$

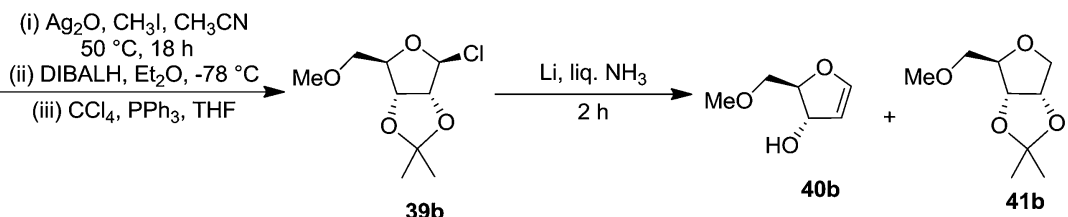

D-ribonicacid- $\gamma$-lactone

Scheme 6

lactone was done by adopting the standard process to obtain acetonide 38b. Methylation of its primary hydroxyl group with $\mathrm{Ag}_{2} \mathrm{O} / \mathrm{CH}_{3} \mathrm{I} / \mathrm{CH}_{3} \mathrm{CN}$ at $50{ }^{\circ} \mathrm{C}$ for $18 \mathrm{~h}$, followed by reduction of the resulting $\mathrm{O}$-methyl derivative with DIBALH in $\mathrm{Et}_{2} \mathrm{O}$ at $-78^{\circ} \mathrm{C}$ for $1 \mathrm{~h}$ gave hemiacetal in $90 \%$ overall yield, which on treatment with $\mathrm{CCl}_{4} / \mathrm{PPh}_{3} / \mathrm{THF}$ resulted furanosyl chloride 39b in $90 \%$ yield. Its reduction with $\mathrm{Li}$ in liquid $\mathrm{NH}_{3}$ as described above, afforded a mixture of glycal $\mathbf{4 0 b}$ and the corresponding THF derivative $41 \mathrm{~b}$ in a ratio of $6: 1$ (NMR) with $75 \%$ yield. It was also reported there that the mixture was not separated by silica gel column chromatography because the furanoid glycal resulted poor recovery after purification (Scheme 6).

This group again utilized acetonide $\mathbf{3 8 b}$ for the synthesis of furanoid glycal $45 .{ }^{4}$ The MOM protected lactone 42 , prepared from 38b by treating with chloromethyl methyl ether (MOMCl) in the presence of diisopropylethylamine $\left(\left({ }^{\mathrm{B}} \mathrm{Pr}\right)_{2} \mathrm{EtN}\right)$ in DCM, on reduction with DIBAL-H at $-78{ }^{\circ} \mathrm{C}$ provided lactol 43. Its chlorination with $\mathrm{PPh}_{3}$ and $\mathrm{CCl}_{4}$ in THF gave the chloride 44. Its reduction with $\mathrm{Li}$ in liquid $\mathrm{NH}_{3}$ at $-78{ }^{\circ} \mathrm{C}$ yielded a mixture of glycal 45 and THF 46 in the ratio $6: 1$ with 93\% overall yield (Scheme 7).

Under identical reaction condition furanosyl chlorides 32 yielded furanoid glycal 26 in 75\% yield along with THF 47 in 9\% yield (Scheme 7).
Due to the instability of the intermediate chlorides formed in this process, this group further examined an alternative method for the transformation of lactols to glycals. Hexamethylphosphorus triamide (tris-(dimethylamino)phosphine, TDAP) reacts at very low temperatures with $\mathrm{CCl}_{4}$ in the presence of alcohols to form adducts of type $\mathbf{4 8}$ (Fig. 2).

First TDAP was added to a solution of lactol 43 and $\mathrm{CCl}_{4}$ in THF at $-78{ }^{\circ} \mathrm{C}$. The resulting reaction mixture was warmed to $0{ }^{\circ} \mathrm{C}$ and then immediately it was added to a solution of excess $\mathrm{Li}$ in liquid $\mathrm{NH}_{3}$ to afford a mixture of 45 and 46 in $6: 1$ with 93\% yield after passing the crude product mixture through silica gel to remove HMPA (Scheme 7).

After that, they showed ester enolate Claisen rearrangement on furanoid glycal esters 48 and 50 derived from 45 and 26 respectively. These esters were prepared by the reaction of a lithium alcoholate with the appropriate butanoyl chloride and propanoyl chloride respectively, and the resulting solution of ester was used immediately for the Claisen rearrangement. Silyl

\section{$\mathrm{ROP}^{+}\left(\mathrm{NMe}_{2}\right)_{3} \mathrm{Cl}^{-}$}

Fig. 2 Adduct 48.

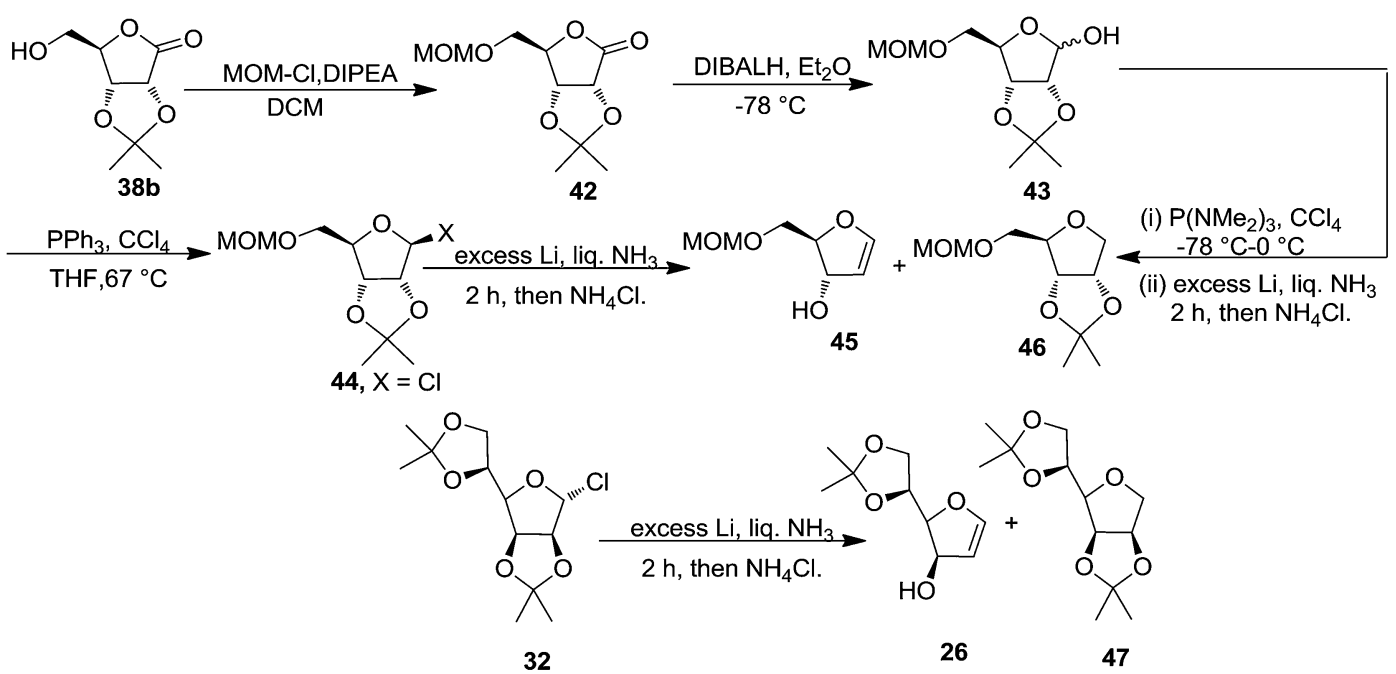

Scheme 7 


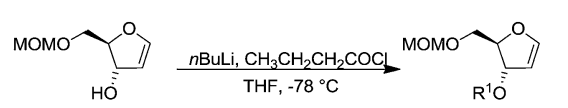
$48 \mathrm{R}^{1}=\mathrm{COCH}_{2} \mathrm{CH}_{2} \mathrm{CH}_{3}$
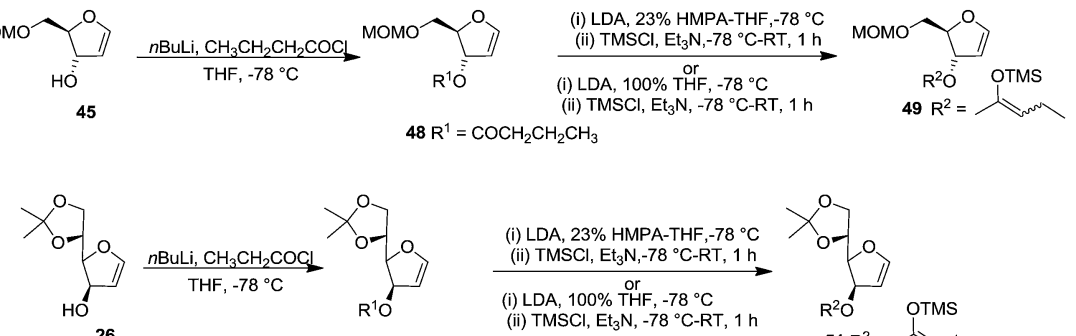

$50 \mathrm{R}^{1}=\mathrm{COCH}_{2} \mathrm{CH}_{3}$

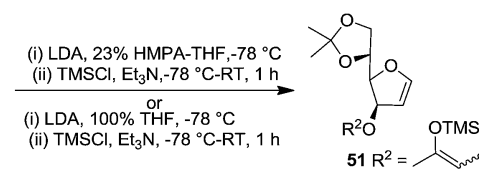

Scheme 8

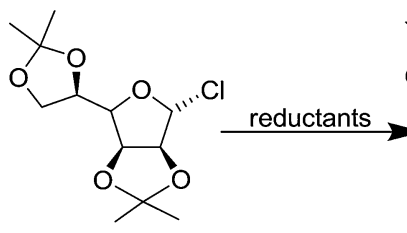

32

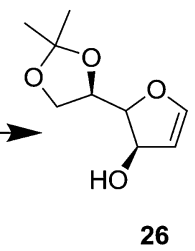

Scheme 9
Table 2 Reductive fragmentation of the model furanosyl chloride 32 to obtain glycal 26

\begin{tabular}{lll}
\hline Reductants & Yield of 26 (\%) & $26: 47$ \\
\hline $\mathrm{Li} / \mathrm{NH}_{3}{ }^{a}$ & $75 \%$ & $7.9: 1$ \\
$\mathrm{Na} \mathrm{NH}_{3}{ }^{a}$ & $77 \%$ & $10.7: 1$ \\
$\mathrm{~K}_{\mathrm{NH}}{ }^{a}$ & $79 \%$ & $15.0: 1$ \\
$\mathrm{SmI}_{2}{ }^{b}$ & $0 \%$ & - \\
Sodium naphthalene $^{c}$ & $82 \%$ & $>50: 1$ \\
Lithium benzophenone $^{d}$ & $\mathrm{NR}$ & - \\
Sodium anthracene $^{e}$ & $\mathrm{NR}$ & - \\
Sodium trimesitylborane $^{f}$ & $70 \%$ & $>50: 1$ \\
Lithium $^{h}, 4^{\prime}$-di-tert-butylbiphenyl & \\
& $94 \%$ & $>50: 1$
\end{tabular}

${ }^{a} 35$ equiv. of metal, $0.5 \mathrm{M}, 1: 10 \mathrm{THF} / \mathrm{NH}_{3},-78^{\circ} \mathrm{C}, 30 \mathrm{~min}$, then $\mathrm{NH}_{4} \mathrm{Cl}$. ${ }^{b} 2$ equiv. $0.07 \mathrm{M} \mathrm{THF}, 25{ }^{\circ} \mathrm{C}, 3 \mathrm{~h} .{ }^{c} 6$ equiv. $0.21 \mathrm{M} \mathrm{THF},-35{ }^{\circ} \mathrm{C}, 20 \mathrm{~min}$, then $\mathrm{H}_{2} \mathrm{O} .{ }^{d} 5$ equiv. $0.50 \mathrm{M}$ THF, $25^{\circ} \mathrm{C} .{ }^{e} 5$ equiv. $0.25 \mathrm{M}$ THF, $25^{\circ} \mathrm{C} .{ }^{f} 5$ equiv. $0.25 \mathrm{M} \mathrm{THF},-20{ }^{\circ} \mathrm{C} \rightarrow 0{ }^{\circ} \mathrm{C}, 1 \mathrm{~h}$, then $\mathrm{H}_{2} \mathrm{O} .{ }^{g} 5$ equiv. $0.20 \mathrm{M}$ THF, $-78{ }^{\circ} \mathrm{C}, 15 \mathrm{~min}$, then $\mathrm{H}_{2} \mathrm{O} \cdot{ }^{h}$ No reaction. ketene acetals 49 and 51, derived from the furanoid glycal esters $(48,50)$ by deprotonation with LDA in a $23 \mathrm{vol} \%$ mixture of hexamethylphosphoric triamide (HMPA) in THF or in $100 \%$ THF at $-78^{\circ} \mathrm{C}$ followed by silylation of enol ether with TMSCl (Scheme 8). Protected furanoid glycal $\mathbf{4 9}$ was further converted to natural product Lasalocid A (X537A) 174 after several steps (Schemes 31 and 33).

To obtain high yielding furanoid glycal 26, they further extended their studies on reductive fragmentation of furanosyl chloride 32 with various reductants like metal/ $/ \mathrm{NH}_{3}$ systems, sodium napthalene and lithium di-tert-butylbiphenyl (Table 2) and found that lithium di-tert-butylbiphenyl afforded the furanoid glycal 26 in high yields (Scheme 9, Table 2). ${ }^{19}$

The same reaction protocol was latter followed by Daves et al. in 1985 to synthesize 3-hydroxy furanoid glycals $(\mathbf{4 5}, \mathbf{5 3 a}-\mathbf{c})$, and also a series of symmetrically (54a, $\mathbf{5 4 f}$ ) and differentially protected (54b-e, 54g, 54h) 3,5-bis-O-substituted furanoid glycals from 2,3-isopropylidene protected ribolactone $\mathbf{3 8 b}$. They also synthesized 1,4-anhydro-2-deoxy-D-erythro-pent-1-enitol 55 and 3-O-derivatized 5-hydroxy glycals $\mathbf{5 6}$ from their corresponding starting materials by removal of the silyl protecting groups (Scheme 10). ${ }^{20 a}$

In the same year, Schlosser and coworkers described the synthesis of furanoid glycal of threo configuration from Dmannose (Scheme 11). ${ }^{21}$ The free hydroxyl group at anomeric position of D-mannose 57 derived intermediate 1,2:5,6-di-O-

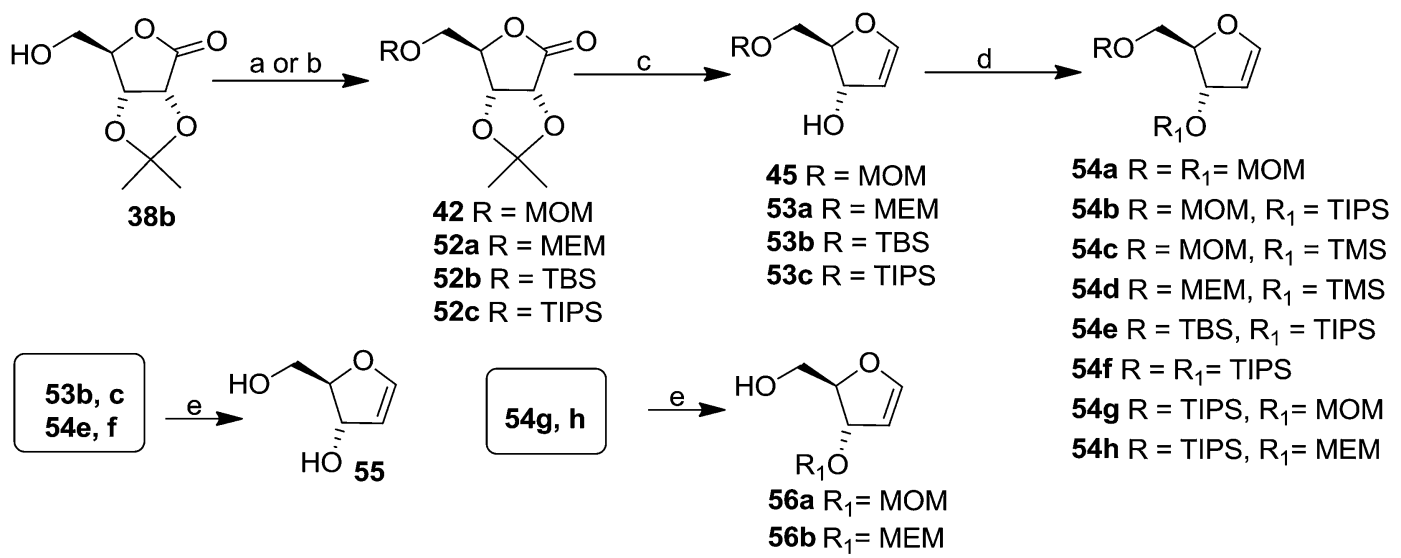

Scheme 10 Reagents and conditions: (a) To obtain 42 and 52a: (i) MOMCl, ${ }^{\mathrm{P}} \mathrm{rr}_{2} \mathrm{EtN}, \mathrm{DCM}$; (ii) MEMCl, 'Pr ${ }_{2} \mathrm{EtN}, \mathrm{DCM}$; (b) to obtain 52b and 52c: (i) TBSCl, imidazole, DMF; (ii) TIPSCl, imidazole, DMF; (c) ref. 4, 18 and 19; (d) ref. 20a; (e) ref. 20b. 


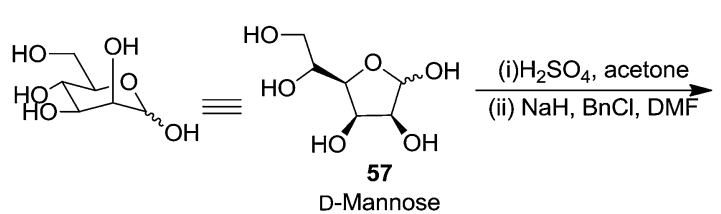<smiles>CC1(C)OCC([C@H]2O[C@H](OCc3ccccc3)C3OC(C)(C)OC32)O1</smiles>

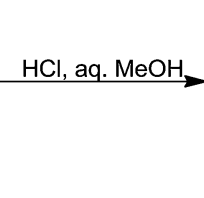<smiles>CC1(C)OC2C(OCc3ccccc3)OC(C(O)CO)C2O1</smiles>

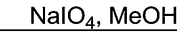<smiles>CCCCOC1O[C@H](C=O)C2OC(C)(C)OC12</smiles>

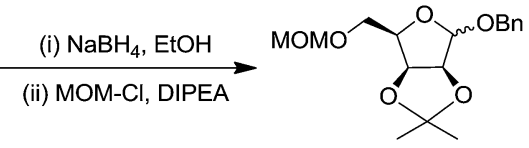

61

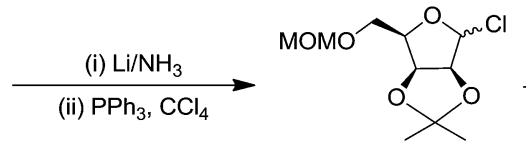

62

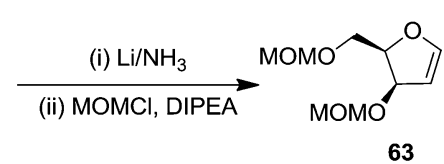

63

Scheme 11

isopropylidene-D-mannofuranose was benzylated with $\mathrm{BnCl}$ in the presence of $\mathrm{NaH}$ in dry DMF to afford benzyl protected compound 58 in good yield. The globally $-\mathrm{OH}$ protected compound 58 was treated with $\mathrm{HCl}$ in aq. $\mathrm{MeOH}$ to form diol 59 in 92\% yield, which on treatment with $\mathrm{NaIO}_{4}$ in $3: 1$ $\mathrm{MeOH}: \mathrm{H}_{2} \mathrm{O}$ mixture gave aldehyde 60 in $70 \%$ yield. Its reduction with $\mathrm{NaBH}_{4}$ in EtOH followed by $\mathrm{MOMCl}$ protection of the resulting primary alcohol produced $\mathbf{6 1}$ in $89 \%$ yield. Its debenzylation with $\mathrm{Li}$ in liq. $\mathrm{NH}_{3}$ followed by chloride formation with $\mathrm{PPh}_{3}$ and $\mathrm{CCl}_{4}$ in THF afforded 62 in $64 \%$ yield. Finally, it was reduced with $\mathrm{Li} / \mathrm{liq} . \mathrm{NH}_{3}$ and the free $2^{\circ}$ alcohol was protected with $\mathrm{MOMCl}$ to give threo furanoid glycal 63 in $56 \%$ yield (Scheme 11). It was utilized as key intermediate for the synthesis of erythro- $(2 S, 3 R)$-sphingosine 232 which has been discussed in Scheme 39.

Pederson et al. reported the synthesis of erythro furanoid glycals from commercially available free thymidine 64a or $5^{\prime}-O$ (tert-butyldiphenylsilyl)thymidine $\mathbf{6 4 b}$ in a single step. ${ }^{22}$ The nucleosides 64a \& 64b were refluxed with 1,1,1,3,3,3-hexamethyldisilazane (HMDS) in the presence of $\left(\mathrm{NH}_{4}\right)_{2} \mathrm{SO}_{4}$ for $2 \mathrm{~h}$ under $\mathrm{N}_{2}$ atmosphere to afford furanoid glycals 65a \& 65b in 7595\% yields (Scheme 12).

This approach was further followed by Hammer et al. in 1997 to synthesize gram quantities of furanoid glycals (Scheme 13). ${ }^{23}$ They synthesized wide range of $O$-silyl protected furanoid glycals. They also included $5^{\prime}$-ester (toluoyl) protected glycals as well as various combinations of $5^{\prime}$-ester and 3- and 5-TBS and TBDPS protected furanoid glycals (Table 3 ).

In 1994 Kassou and Castillón synthesized both erythro and threo furanoid glycals from easily available 2-deoxyribose 67 by using a key selenoxide elimination. ${ }^{24}$ Methyl furanoside 68 was easily synthesized from 2-deoxyribose 67 by reaction with

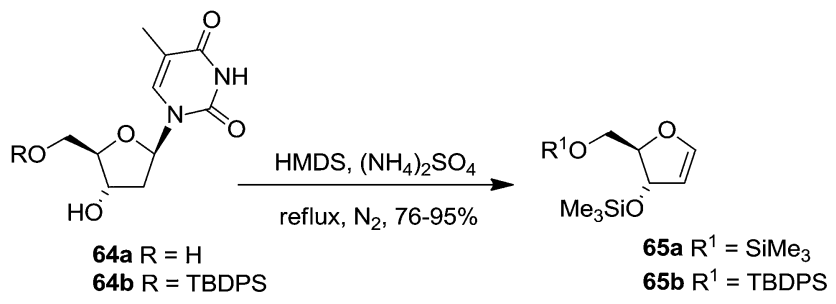

Scheme 12
$\mathrm{HCl} / \mathrm{MeOH}(0.05 \%)$, which was benzylated with $\mathrm{BnBr} / \mathrm{NaH}$ to obtain 69a. Similarly compounds $69 \mathrm{~b}$ and 72 were prepared by treating methyl furanoside 68 with PivCl and TBDPSCl respectively. The methyl 2-deoxy furanosides 69a, 69b and 72 were treated with $\mathrm{PhSeH}$ and $\mathrm{BF}_{3} / \mathrm{Et}_{2} \mathrm{O}$ to afford phenyl-2deoxy-1-selenofuranosides 70a, 70b and $73(\alpha / \beta$ mixtures) in $85 \%, 71 \%$ and $75 \%$ yields respectively. For the synthesis of threo furanoid glycals, inversion of the $3-\mathrm{OH}$ in compound 73 was achieved by its treatment with $\mathrm{Tf}_{2} \mathrm{O} / \mathrm{Py}$ followed by $\mathrm{KNO}_{2} /$ 18-crown-6/DMF to afford threo derivative 74a in 75\% yield for the two steps (Scheme 14). Protection of the secondary alcohol with TBSCl led to compound $\mathbf{7 4 b}$. Treatment of $\mathbf{7 4 a}$ with

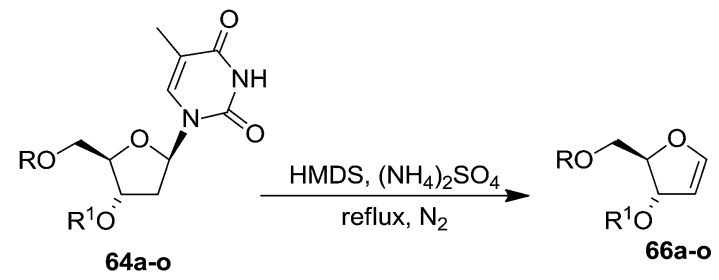

Scheme 13

Table 3 Product yields for furanoid glycals

\begin{tabular}{llllll}
\hline Thymidine & Glycal & $\mathrm{R}$ & $\mathrm{R}^{1}$ & Yield (\%) & $\begin{array}{l}\text { Yield (\%) } \\
\text { from 64a }\end{array}$ \\
\hline $\mathbf{6 4 a}$ & $\mathbf{6 6 a}$ & $\mathrm{H}$ & $\mathrm{H}$ & 80 & $80(1)$ \\
$\mathbf{6 4 b}$ & $\mathbf{6 6 b}$ & TBDPS & $\mathrm{H}$ & 91 & $70(2)$ \\
$\mathbf{6 4 c}$ & $\mathbf{6 6 c}$ & TBS & $\mathrm{H}$ & 74 & $53(2)$ \\
$\mathbf{6 4 d}$ & $\mathbf{6 6 d}$ & Tol & $\mathrm{H}$ & 52 & $38(2)$ \\
$\mathbf{6 4 e}$ & $\mathbf{6 6 e}$ & TBS & TBS & 69 & $47(2)$ \\
$\mathbf{6 4 f}$ & $\mathbf{6 6 f}$ & TBDPS & TBDPS & 80 & $76(2)$ \\
$\mathbf{6 4 9}$ & $\mathbf{6 6 g}$ & Tol & Tol & No glycal & No glycal \\
$\mathbf{6 4 h}$ & $\mathbf{6 6 h}$ & TBS & TBDPS & 79 & $55(3)$ \\
$\mathbf{6 4 i}$ & $\mathbf{6 6 i}$ & TBS & Tol & No glycal & No glycal \\
$\mathbf{6 4 j}$ & $\mathbf{6 6 j}$ & TBDPS & TBS & 59 & $40(3)$ \\
$\mathbf{6 4 k}$ & $\mathbf{6 6 k}$ & TBDPS & Tol & No glycal & No glycal \\
$\mathbf{6 4 1}$ & $\mathbf{6 6 1}$ & Tol & TBS & 74 & $39(3)$ \\
$\mathbf{6 4 m}$ & $\mathbf{6 6 m}$ & Tol & TBDPS & 94 & $64(3)$ \\
$\mathbf{6 4 n}$ & $\mathbf{6 6 n}$ & H & TBS & 36 & $18(4)$ \\
$\mathbf{6 4 0}$ & $\mathbf{6 6 0}$ & H & TBDPS & 79 & $53(4)$
\end{tabular}

${ }^{a}$ The number in parentheses indicates the number of steps required to prepare the glycal from commercially available free thymidine $\mathbf{6 4 a}$. 

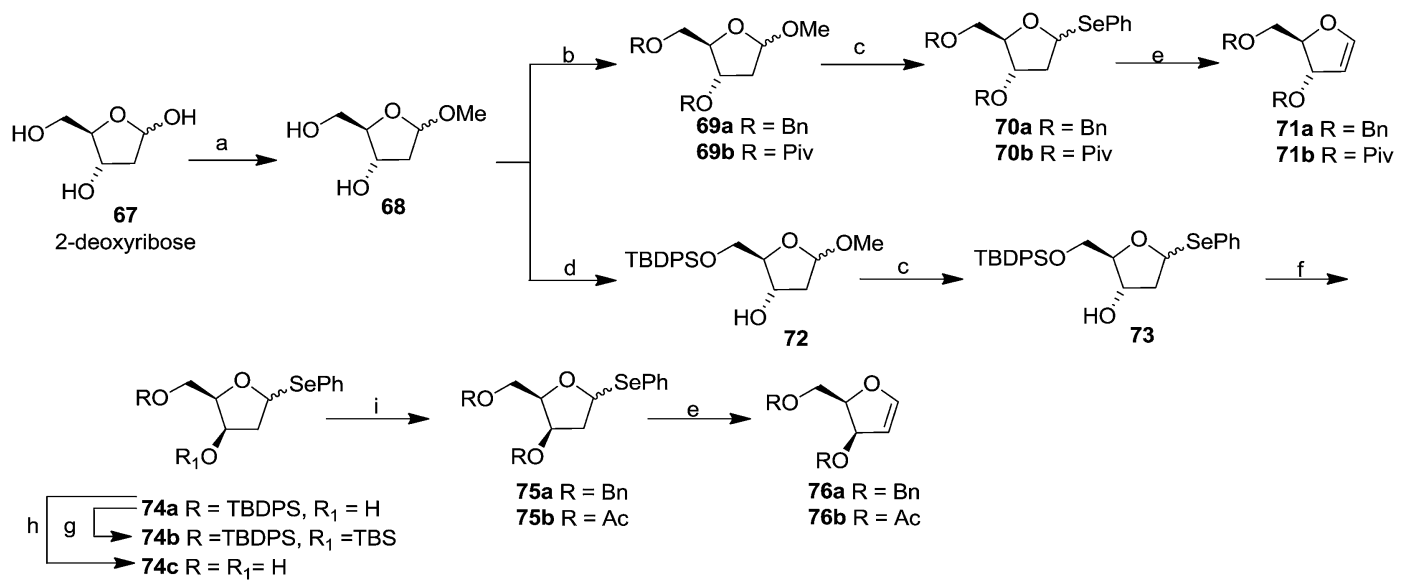

Scheme 14 Reagents and conditions: (a) $\mathrm{HCl} / \mathrm{MeOH}$ (0.05\%); (b) (i) $\mathrm{BnBr}$. NaH, THF (69a); (ii) $\mathrm{PivCl}, \mathrm{Py}(69 \mathrm{~b}) ;(\mathrm{c}) \mathrm{PhSeH} \mathrm{BF}_{3} / \mathrm{Et}_{2} \mathrm{O}, \mathrm{DCM},-5^{\circ} \mathrm{C}$

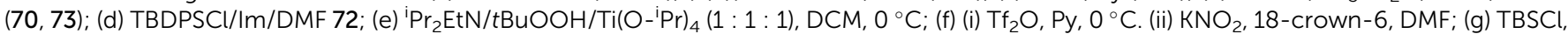
$\mathrm{DBU}$, benzene; (h) $n \mathrm{Bu}_{4} \mathrm{NF}, \mathrm{THF}$; (i) (i) $\mathrm{BnBr}$. NaH, THF (75a), (ii) $\mathrm{Ac}_{2} \mathrm{O}$, py (75b).

$n \mathrm{Bu}_{4} \mathrm{NF}$ led silyl deprotection to give $74 \mathrm{c}$ whose phenylseleno derivatives $\mathbf{7 5 a}$ and $\mathbf{7 5 b}$ were easily obtained by usual benzyl and acyl protections respectively. Oxidation followed by thermal elimination of these phenyl-2-deoxy-selenofuranosides 70a, 70b and 75a, 75b with ${ }^{\mathrm{i}} \mathrm{Pr}_{2} \mathrm{EtN} / \mathrm{tBuOOH} /$ $\mathrm{Ti}\left(\mathrm{O}^{\mathrm{i}}{ }^{\mathrm{i}} \mathrm{Pr}\right)_{4}(1: 1: 1)$ system in DCM at $0{ }^{\circ} \mathrm{C}$ afforded corresponding furanoid glycals $71 \mathrm{a}, 71 \mathrm{~b}$ and $76 \mathbf{a}, 76 \mathrm{~b}$ in good yields.

Their work was further continued to synthesize differently protected erythro and threo furanoid glycals from 4-pentene1,2,3-triol involving selenium induced 5-endo-trig cyclization followed by selenoxide elimination..$^{25}$ They utilized inexpensive D-mannitol derived D-glyceraldehyde 77 as the starting material which on treatment with vinylmagnesium chloride in ether/THF furnished the alcohol 78 (1:1 mixture). Benzylation of free hydroxyl group followed by isopropylidene deprotection afforded separable diols $\mathbf{7 9}$ and $\mathbf{8 0}$. The primary hydroxyl group of compounds $\mathbf{7 9}$ and $\mathbf{8 0}$ were selectively protected with $\mathrm{BnBr}$ via the stannylidene procedure to give alcohols 81 and 83. In another set of experiments, 79 and 80 were selectively protected with TBDPSCl to obtain their respective alcohols $\mathbf{8 2}$ and $\mathbf{8 4}$ (Scheme 15). The protected alkenic alcohols 81-84 on treatment with $N$-phenylselenophthalimide ( $N$-PSP) in the presence of CSA in DCM preferencially gave $\alpha / \beta$ mixture of 4-phenylselenenyl tetrahydrofurans 85-88 in different ratio through unusual 5-endo-trig cyclization. These were oxidised with $\left(t \mathrm{BuOOH},{ }^{\mathrm{i}} \mathrm{Pr}_{2} \mathrm{EtN}\right.$, $\mathrm{Ti}\left(\mathrm{O}-{ }^{\mathrm{i}} \mathrm{Pr}\right)_{4}$ in $\left.\mathrm{DCM}\right)$ to obtain the corresponding selenoxides, which on prolong heating in DCM or DCE gave isolated erythro furanoid glycals $(\mathbf{8 9}, \mathbf{9 0})$ and threo furanoid glycals $(\mathbf{9 1}$, 92) respectively in good yields.

They further extended their work to synthesize differently protected erythro and threo furanoid glycals by oxidative elimination of 1-phenylselenenyl furanosides and 2-phenylselenenyl1,4-anhydroalditol in the presence of $t \mathrm{BuOOH}, \mathrm{Ti}\left(\mathrm{O}-{ }^{\mathrm{i}} \mathrm{Pr}\right)_{4}$ and ${ }^{\mathrm{i}} \mathrm{Pr}_{2} \mathrm{EtN}$ system. ${ }^{26}$

In 1995 Florent and co-workers reported the synthesis of $2^{\prime}$ $C$-acetoxymethylfuranoid glycal $\mathbf{9 7 a}$ by reductive elemination of glycosyl phenyl sulfone 96 with $\mathrm{SmI}_{2}-\mathrm{HMPA},{ }^{27}$ which was obtained in four steps as discussed below from readily available $\alpha$-D-isosaccharino-1,4-lactone 93 (Scheme 16). The sequential reduction-acetylation of the lactone $\mathbf{9 3}$ afforded peracetyl derivative $\mathbf{9 4}$, which on treatment with $\mathrm{PhSH} / \mathrm{BF}_{3}-$ $\mathrm{Et}_{2} \mathrm{O} / \mathrm{DCM}$ gave thiophenyl glycoside 95 . Its oxidation with $m$ CPBA produced phenyl sulfone 96 whose reductive samariation with $\mathrm{SmI}_{2}$ in THF in the presence of HMPA, followed by elimination of the acetate, afforded the furanoid glycal 97a. It was then converted into 97b via a six membered cyclic

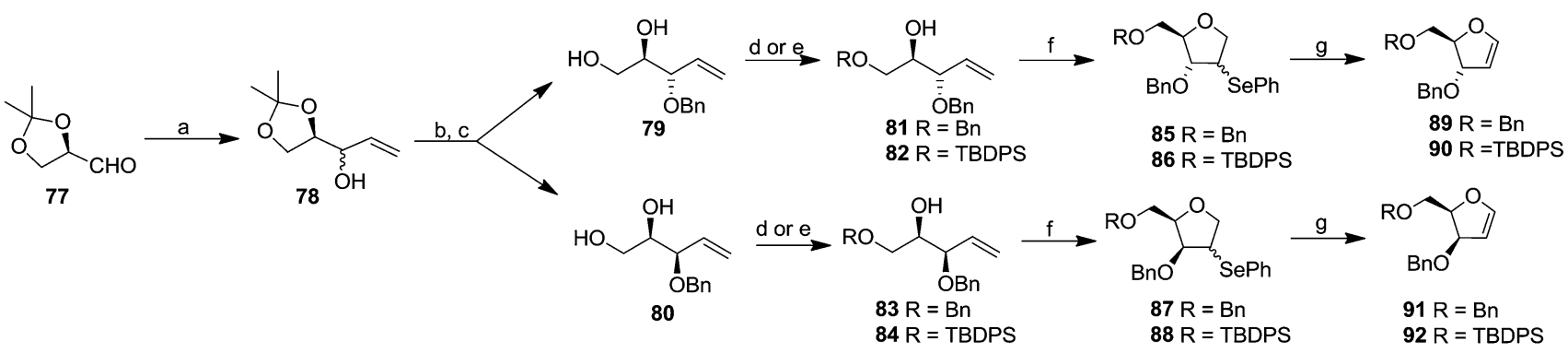

Scheme 15 Reagents and conditions: (a) vinylmagnesium chloride, ether/THF; (b) NaH, BnBr; separation of isomers; (c) $\mathrm{H}^{+}, \mathrm{MeOH}$; (d) to obtain 81 and 83 (i) $\mathrm{Bu}_{2} \mathrm{SnO}$, toluene, $4 \AA$ MS; (ii) $\mathrm{BnBr}, \mathrm{Bu}_{4} \mathrm{NBr}$; (e) to obtain 82 and 84: TBDPSCl, imidazole, DMF; (f) N-PSP, CSA, DCM; (g) tBuOOH (2.5 equiv.), ${ }^{i} \operatorname{Pr}_{2} \operatorname{EtN}\left(1.7\right.$ equiv.) and $\operatorname{Ti}\left(\mathrm{O}-{ }^{i} \mathrm{Pr}\right)_{4}$, (1 equiv.) in $\mathrm{DCM}(48 \mathrm{~h})$ or $\mathrm{DCE}(4 \mathrm{~h})$, reflux. 


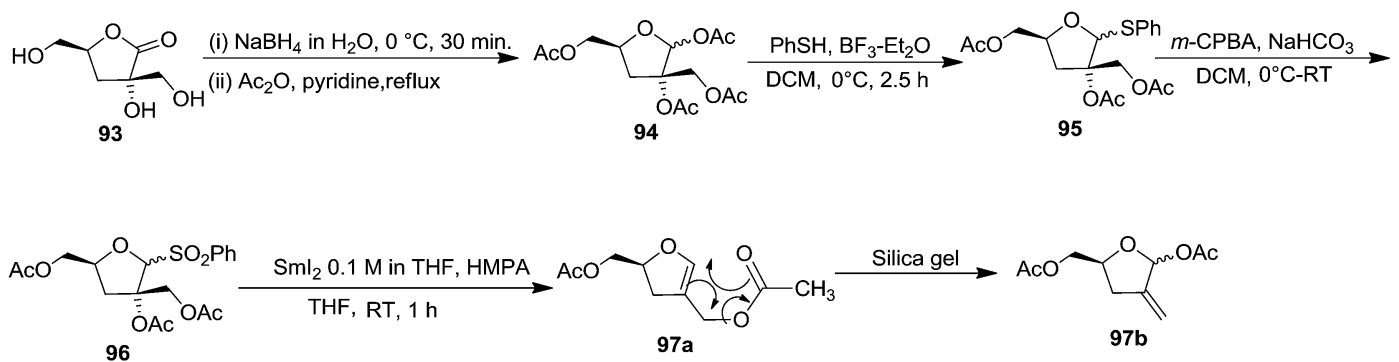

Scheme 16

rearrangement during purification by silica gel column chromatography. The formation of $N$-nucleosides $2^{\prime}, 3^{\prime}$ dideoxy-2'-C-methylidene-5-methyl uridine 623 and $3^{\prime}$-deoxy analog of DMDC 626 and 627 from furanoid glycal 97a has been discussed in Scheme 105.

In 1996 Townsend et al. synthesized ribofuranoid glycals in multigram scale from 2-deoxy-ribose derived 2-deoxy-D-ribono1,4-lactone $98,{ }^{28}$ which was bis-silylated at 3 - and 5-positions with different silyl chloride in DMF in the presence of imidazole to give the 3,5-bis- $O$-silylated products 99a-c. These silyl protected compounds 99a-c were reduced with DIBALH at $-78{ }^{\circ} \mathrm{C}$ to their corresponding 2-deoxy-D-erythro-pentofuranose derivatives 100a-c $(\alpha / \beta=1: 1)$. Its mesylation followed by in situ elimination of $\mathrm{MsOH}$ furnished ribofuranoid glycals 102a-c (Scheme 17).

Furanoid glycals were also synthesized by McDonald and Gleason through trialkylamine-molybdenum pentacarbonylcatalyzed alkynol endo cycloisomerizations, ${ }^{29}$ which were easily prepared in chiral nonracemic form by short synthetic sequences featuring asymmetric epoxidations of commercially available allylic alcohols (Schemes 18 and 19).

Furanoid glycal 106 was prepared by asymmetric epoxidation of allyl alcohol 103 followed by in situ esterification with pivaloyl chloride to give $\mathbf{1 0 4}$ (Scheme 18). Regioselective addition of
$\mathrm{LiC} \equiv \mathrm{CH} / \mathrm{BF}_{3} \cdot \mathrm{Et}_{2} \mathrm{O}$ to 104 at low temperature $\left(-78^{\circ} \mathrm{C}\right.$ to $\left.-20{ }^{\circ} \mathrm{C}\right)$ provided the homopropargylic secondary alcohol 105. Treatment of 105 with $\mathrm{Mo}(\mathrm{CO})_{6}$ and trimethylamine-N-oxide in ether/ $\mathrm{Et}_{3} \mathrm{~N}$ at room temperature gave 106 in $80 \%$ isolated yield (Table 4). ${ }^{29}$

They also reported the asymmetric synthesis of alkynols having propargylic nitrogen substituents. These substrates were prepared from (E)-2-penten-4-yn-1-ol 107 (Scheme 19). Asymmetric epoxidation of 107 furnished 108 which on treatment with $\operatorname{Ti}\left(\mathrm{O}-{ }^{\mathrm{i}} \mathrm{Pr}\right)_{2}\left(\mathrm{~N}_{3}\right)_{2}$ in toluene followed by the selective protection of the resulting primary alcohol 109 formed the azide 110. Its reduction with tin(II) chloride in $\mathrm{MeOH}$ yielded the amine $\mathbf{1 1 1}$ which was acylated with $\mathrm{Ac}_{2} \mathrm{O}$ and $\mathrm{Tf}_{2} \mathrm{O}$ to obtain the respective 3-amidoalkynols 112 and 113 respectively.

The various alkynols were subjected to Mo-catalyzed alkynol cyclization to obtain furanoid glycal and THF derivatives as shown in Table 4.

Here it is worth mentioning that the Mo-catalyzed alkynol cyclization method was compatible with alkynol substrates containing propargylic nonbasic, ester and amide functional groups $(\mathbf{1 0 5}, \mathbf{1 1 6}, \mathbf{1 1 2}, \mathbf{1 1 3})$ for synthesis of furanoid glycals $(106,117,121,122)$. Whereas, alkynol substrates bearing good leaving groups (i.e., $\mathrm{N}_{3}$ group) and basic groups (i.e. $\mathrm{NH}_{2}, \mathrm{OR}$ ) at

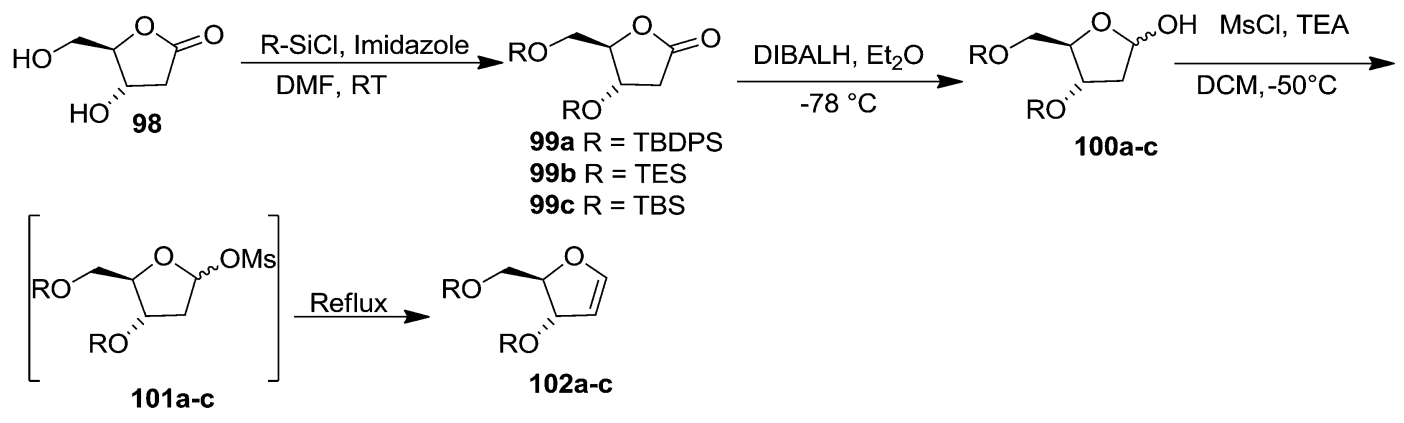

Scheme 17

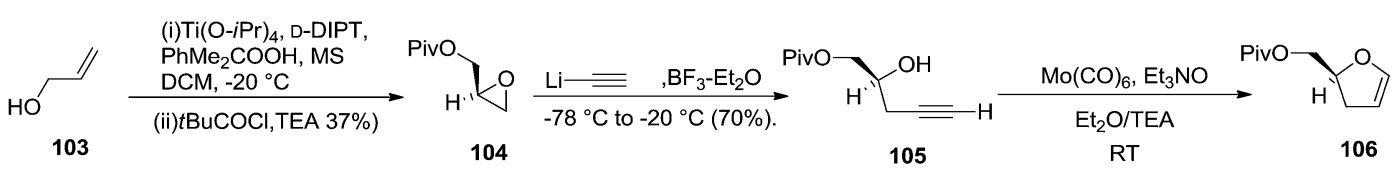

Scheme 18 

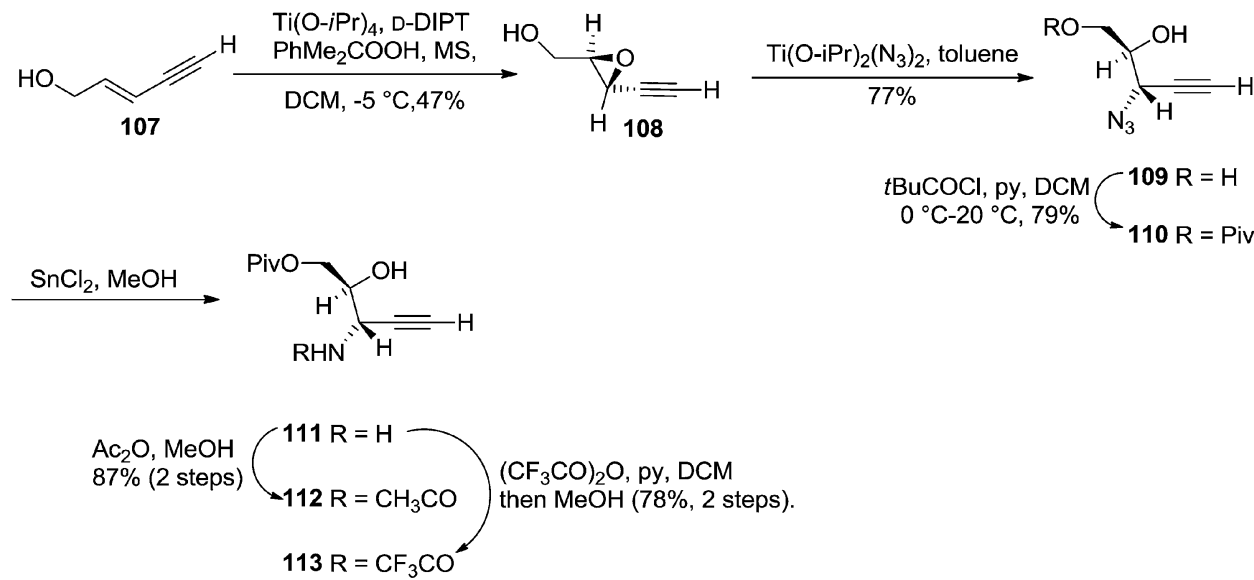

Scheme 19

Table 4 Cyclization of alkynols with trialkylamine-molybdenum pentacarbonyl

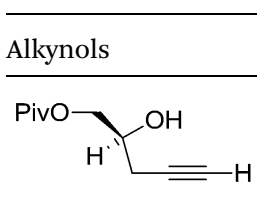

105<smiles>C#C[C@H](O)[C@@H](O)COC(C)(C)C</smiles>

114

TBSO-

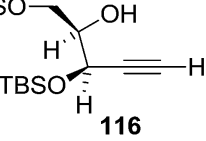

TBSO<smiles>C#CC(C(O)CC)C(O)CC</smiles>

118<smiles>C#CC(O)CO</smiles>

109

Pivo<smiles>C#CC(C)O</smiles>

110

Pivo<smiles>C#C[C@H](N)CC</smiles>

111

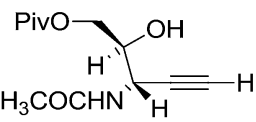

112

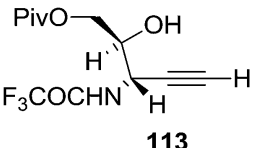

Products (isolated yields)

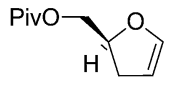

106

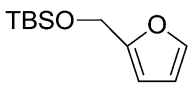

115

TBSO

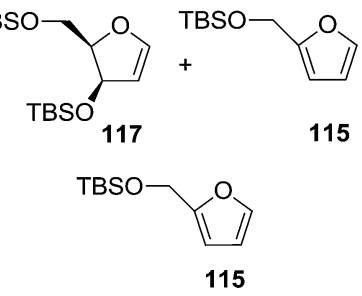<smiles>OCc1ccco1</smiles>

119<smiles>CCCOCc1ccco1</smiles>

120<smiles>Oc1ccco1</smiles>

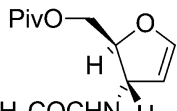
$\mathrm{H}_{3} \mathrm{COCHN}$

121<smiles>CCCCON=P</smiles>
$\mathrm{F}_{3} \mathrm{COCHN}$

122

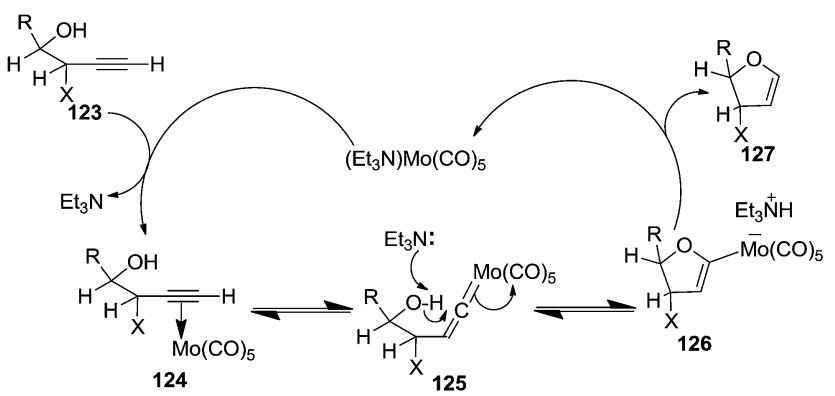

Scheme 20 Mechanism for alkynol cycloisomerization ( $\mathrm{X}=$ non basic group, $\mathrm{H}, \mathrm{NH}(\mathrm{CO}) \mathrm{R})$.

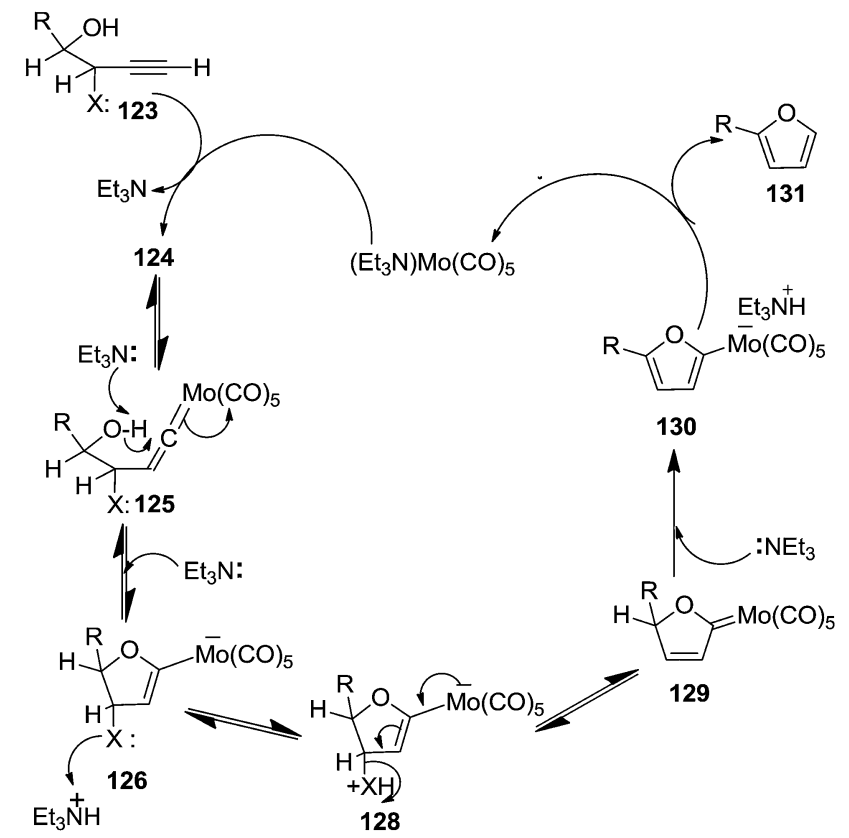

Scheme 21 Mechanism for furan formation $\left(X=N_{3}\right.$, or basic groups i.e. $\left.\mathrm{NH}_{2}, \mathrm{OR}\right)$. 
the propargylic position $(\mathbf{1 1 4}, \mathbf{1 1 8}, \mathbf{1 0 9}, \mathbf{1 1 0})$ underwent cyclization followed by elimination afforded furan derivatives (115, 119, 120). The mechanistic explanations for their formation are delineated below (Schemes 20 and 21). These furanoid glycals further utilized for synthesis of deoxynucleosides (Schemes 106-111).

In 1997 Diaz et al. described two synthetic procedures for $C$ 3,4-D-threo and D-erythro furanoid glycals from protected 1,2dihydroxy pento- and hexo-furanose derivatives with the $\mathrm{D}^{-x y l o}$, D-gluco and D-ribo, D-allo configurations as starting materials. ${ }^{30}$

The first one referred to the Garegg-Samuelsson reaction on vic-diols (132a-138a) in the presence of $\mathrm{I}_{2}-\mathrm{PPh}_{3}$-Im caused substitution followed by elimination of unstable vic-diiodide intermediate to the corresponding furanoid glycals $(\mathbf{1 3 2 c - 1 3 8 c})$ (Scheme 22).

The second one was modified Corey's dideoxygenation of 1,2-thiocarbonates (132b-138b) which were derived from the reaction of 1,2-diols (132a-138a) with thiophosgene in alkaline medium in good yields. These 1,2-thiocarbonates (132b-138b) on treatment with 1,3-dimethyl-2-phenyldiazaphospholidine
(DMPD) in dry toluene at $70{ }^{\circ} \mathrm{C}$ underwent elimination to give furanoid glycals (132c-138c) (Scheme 22).

In 1999 Theodorakis and co-workers disclosed a short and efficient enantioselective synthesis of norrisane side chain $\mathbf{2 4 4}$ from furanoid glycal 139 (Scheme 41) derived from D-mannose 57. ${ }^{31}$ They followed Ireland's method to synthesize furanoid glycal 139 from D-mannose 57 in good yield. D-Mannose 57 was treated with acetone in presence of iodine as a catalyst to deliver bis-acetonide 22 in $85 \%$ yield, after a simple filtration and crystallization. Its treatment with $p$-TsCl and $\mathrm{Et}_{3} \mathrm{~N}$ afforded glycosyl chloride 32, which upon slow addition to a stirring mixture of sodium naphthalenide in THF gave furanoid glycal 26 in $48 \%$ overall yield (for two steps). Due to its labile nature, it was immediately benzylated $(\mathrm{BnBr}, \mathrm{NaH}$, TBAI) to produce the glycal 139 in 90\% yield (Scheme 23) which was utilized to achieve the synthesis of norrisane side chain 244 in 6 steps discussed in Scheme 41.

In 2000, Knaus et al. reported the synthesis of analogues of deoxy- $\beta$-L-cytidine via furanoid glycal as key intermediates. They followed Garegg Samuelsson reaction for the synthesis
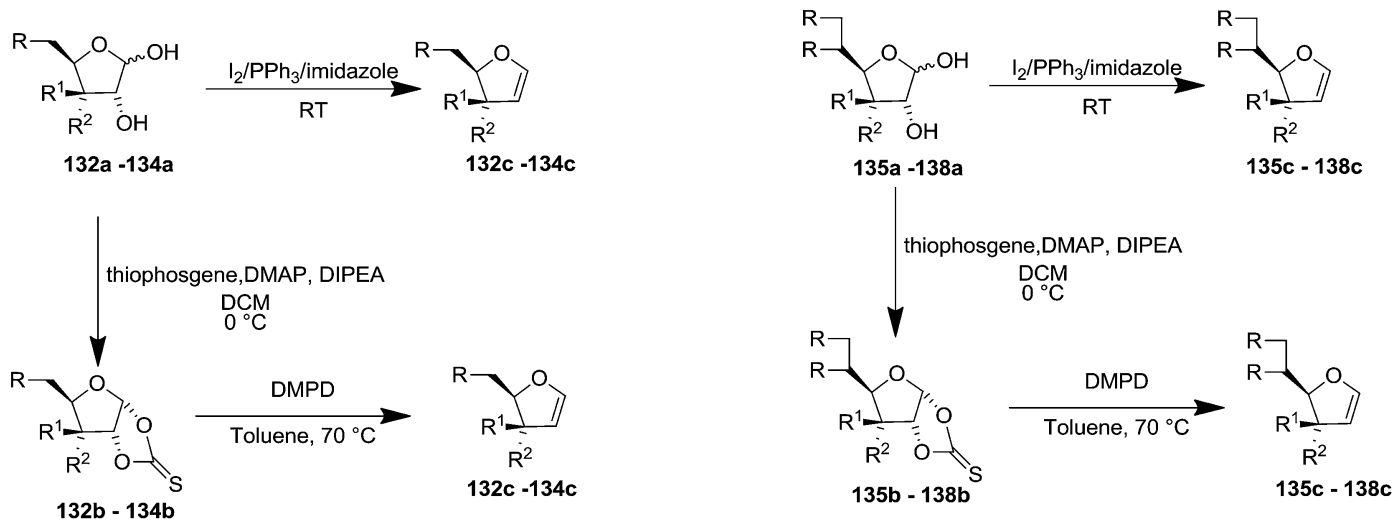

132 and $135 \mathrm{R}=\mathrm{R}^{1}=\mathrm{OBn} ; \mathrm{R}^{2}=\mathrm{H}$

133 and $136 \mathrm{R}=\mathrm{R}^{1}=\mathrm{OBz} ; \mathrm{R}^{2}=\mathrm{H}$

$134 \mathrm{R}=\mathrm{OPiv} ; \mathrm{R}^{1}=\mathrm{H} ; \mathrm{R}^{2}=\mathrm{OBz}$

$137 \mathrm{R}=\mathrm{OBz} ; \mathrm{R}^{1}=\mathrm{OAll} ; \mathrm{R}^{2}=\mathrm{H}$

$138 \mathrm{R}=\mathrm{R}^{2}=\mathrm{OBz} ; \mathrm{R}^{1}=\mathrm{H}$

Scheme 22<smiles>OC[C@H]1O[C@H](O)[C@H](O)[C@H](O)[C@H]1O</smiles>

57

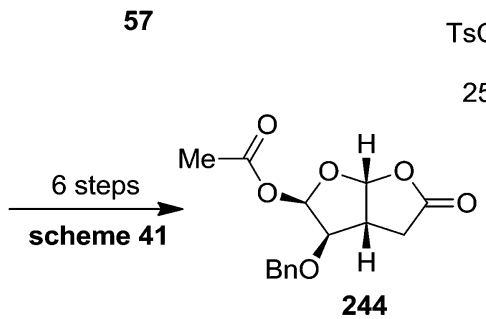

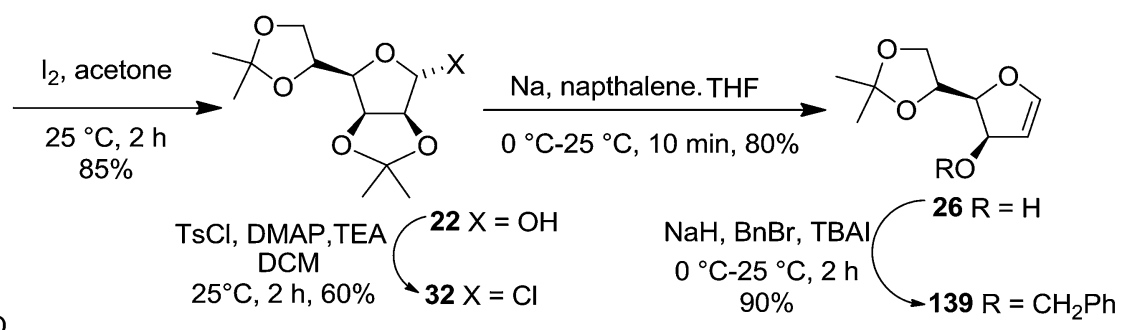

$90 \%$ 

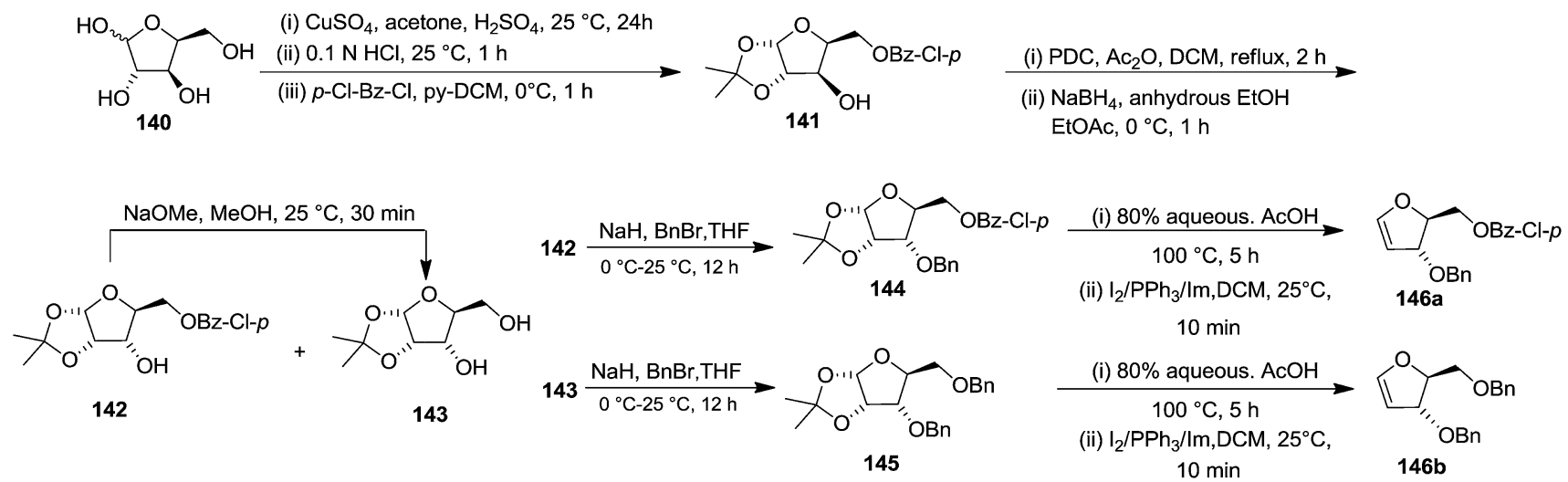

Scheme 24

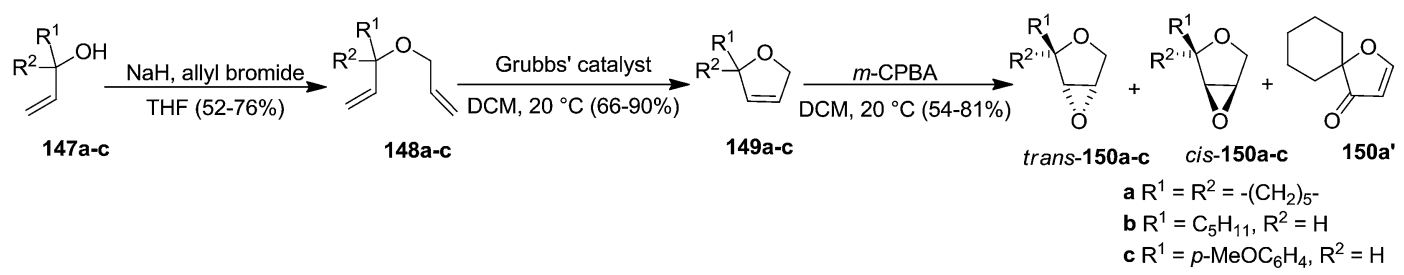

Scheme 25

of ribo furanoid glycals from vic-diols intermediate, easily derived from L-xylose 140. ${ }^{32}$ Acetonide protection of L-xylose 140 followed by selective acid hydrolysis with $0.1 \mathrm{~N} \mathrm{HCl}$ afforded intermediate 1,2-O-isopropylidene- $\alpha$-L-xylofuranose whose primary hydroxyl group was selectively protected with $p$-Cl-Bz-Cl in pyridine-DCM at $0{ }^{\circ} \mathrm{C}$ to obtain 141. Its free hydroxyl group was oxidised with PDC in DCM, and the resulting ketone was reduced with $\mathrm{NaBH}_{4}$ to afford a mixture of ribose derivatives 142 (68\% yield) and 151 (28\% yield). The sugar derivative 142 was converted into compound 143 with $\mathrm{NaOMe}$ in $\mathrm{MeOH}$. It was benzylated with $\mathrm{BnBr}$ in THF in the presence of $\mathrm{NaH}$ to afford the 3,5-di-O-benzyl-L-ribose derivative 145 in good yields. The similar protocol was adopted to obtain the 5-O-( $p$-chlorobenzoyl)-3-benzyl-L-ribose derivative 144 from its precursor 142. The 1,2-O-isopropylidenyl groups in 144 and 145 were readily removed by treating each with $80 \%$ aqueous $\mathrm{AcOH}$ at $100{ }^{\circ} \mathrm{C}$ to give the vic-diols. Their debenzylation with the $\mathrm{I}_{2}-\mathrm{PPh}_{3}$-Im system in dry DCM at $25{ }^{\circ} \mathrm{C}$ afforded the desired ribofuranoid glycals 146a and 146b in $62 \%$ and $45 \%$ yield respectively (Scheme 24 ). These were used as key intermediates for synthesis of unnatural C-aryl $2^{\prime}$ deoxy- $\beta$-L-cytidine mimics (529a, b) (Scheme 92).

In the same year Schmidt and Wildemann developed the synthesis of 2,3-dihydropyrans or 2,3-dihydrofurans (furanoid glycals) utilizing ring closing methathesis as one of the key reaction steps. The allylic alcohols $(\mathbf{1 4 7 a - c )}$ were subjected to allylation with allyl bromide in the presence of $\mathrm{NaH}$ in THF to obtain the diallyl ethers $(\mathbf{1 4 8 a}-\mathbf{c})$. Their ring-closing metathesis yielded 3,4-dihydrofurans (149a-c) followed by their epoxidation with $m$-CPBA gave dihydrofuran oxides $(\mathbf{1 5 0 a}-\mathbf{c})$. In the case of 150a, spiro dihydrofuranone $150 a^{\prime}$ was obtained along with cis, trans-150a (Scheme 25). ${ }^{33}$

The base-induced rearrangement of 150a with LDA in THF at ambient temperature gave a crude product whose NMR spectra identified it as 151a. It was rearranged to hemiacetal 152 during its silica gel column purification. However, this was supressed when free hydroxyl group in $\mathbf{1 5 1}$ was protected as a benzyl ether 153 (Scheme 26).

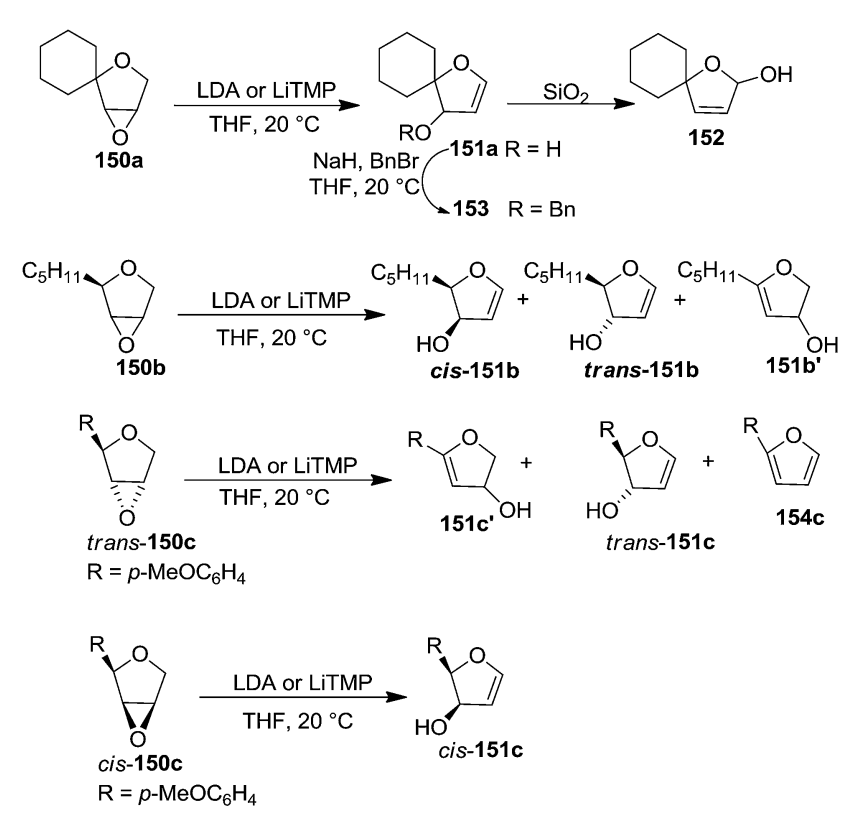

Scheme 26 
The rearrangement of inseparable diastereoisomeric mixture of dihydrofuran oxide 150b underwent the rearrangement reaction with LDA or LiTMP to give a $4: 3: 1$ mixture of isomers cis-151b, trans $\mathbf{- 1 5 1 b}$ and $\mathbf{1 5 1} \mathbf{b}^{\prime}$ which were characterized by NMR spectroscopy of crude reaction mixture.

The dihydrofuran oxides trans- and cis-150c were separable. While the treatment of trans-150c with LiTMP gave three products in a ratio of $9: 3: 1$ which were identified as furanoid glycals 151c', trans-151c and furan 154c, the cis-150c yielded only one rearrangement product cis-151c.

Recently the furanoid glycal 26 was synthesised by Gómez and López et al. from 155. Its thioglycosylation followed by controlled oxidation of the resulting thioglycoside with $m$-CPBA afforded furanosyl sulfoxide 156 which on treatment with $n$ BuLi furnished column pure furanoid glycal 26 in good yield (Scheme 27). ${ }^{34}$
As mentioned above, several methods are available for synthesis of furanoid glycals or 4,5-dihydrofurans but difficulties are generally encountered with the formation of unstable glycals, ${ }^{13}$ usage of expensive starting materials ${ }^{22,23}$ and, in some cases, low yield of the desired products and that is why improvements in the existing methods are still desirable. To overcome all these limitations and encouraged by the literature reports on various applications of furanoid glycals in organic synthesis, our research group reported a simple protocol for the synthesis of stereochemically pure different furanoid glycals 162a (1,4-anhydro-2-deoxy-5,6-O-isopropylidene-3-O-benzyl-Larabino-hex-1-enitol), 162b (1,4-anhydro-2-deoxy-5,6-O-isopropylidene-3-O-benzyl-L-ribo-hex-1-enitol), 162c (1,4-anhydro2-deoxy-5,6-O-isopropylidene-3-O-benzyl-D-ribo-hex-1-enitol), ${ }^{17 a}$ 139 (1,4-anhydro-2-deoxy-5,6-O-isopropylidene-3-O-benzyl-Darabino-hex-1-enitol) $)^{17 a, 31,36,37}$ and also highly functionalized 2,5dihydrofurans (163a, b) (Fig. 3) from easily accessible

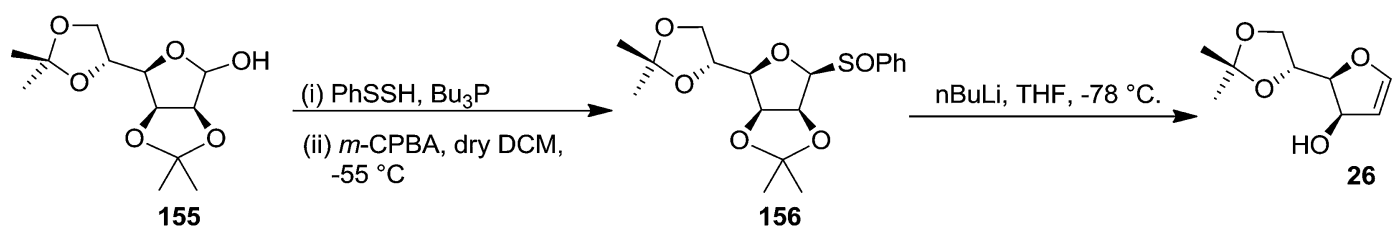

Scheme 27

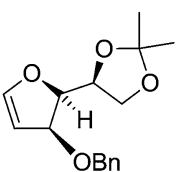

$162 a$

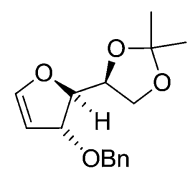

$162 b$

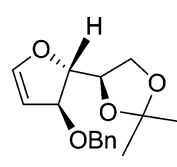

162c<smiles></smiles>

139<smiles>CC1(C)OCC(C2OCC=C2OCc2ccccc2)O1</smiles>

163a

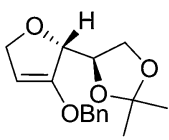

163b

Fig. 3 Structures of furanoid glycals (162a-c, 139) and highly functionalized 2,5-dihydrofurans (163a, b).

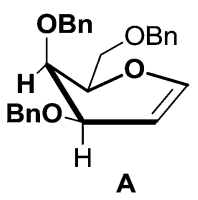

A
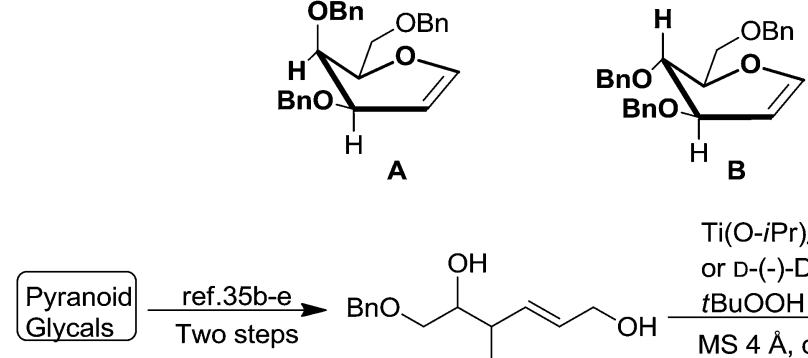

157

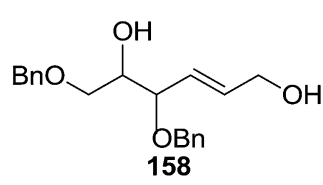

$\mathrm{Ti}(\mathrm{O}-\mathrm{iPr})_{4}(1.0$ equiv. $), \mathrm{L}-(+)$

or D-(-)-DET(1.2 equiv.)

$t \mathrm{BuOOH}(2.0$ equiv.)

MS $4 \AA$, dry DCM, $2.5 \mathrm{~h}$

$-25{ }^{\circ} \mathrm{C}$ to $0{ }^{\circ} \mathrm{C}$, saturated citric

acid in acetone, $2 \mathrm{~h}$

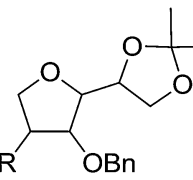<smiles>CC1(C)OC[C](C2OCC=C2OCc2ccccc2)O1</smiles>

162a-c, 139

163a,b

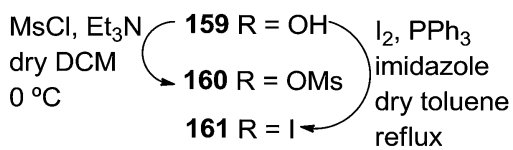


enantiomerically pure 2,3,4-trisubstituted THF scaffolds (159ad). ${ }^{35}$ To the best of our knowledge, examples for the synthesis of enantiomerically pure furanoid glycals $(\mathbf{1 6 2 a}, \mathbf{b})$ and functionalized 2,5-dihydrofurans $\left(\mathbf{1 6 3 a} \mathbf{a}\right.$ b) had not been reported. ${ }^{35 a}$
The synthetic protocol to obtain a family of furanoid glycals (162a-c, 139) of different configurations at the 3-, 4- and 5positions and functionalized 2,5-dihydrofurans $(163 \mathbf{a}, \mathbf{b})$ of different configurations at the 2- and $1^{\prime}$-positions from enantiopure THF scaffolds (159a-d) is shown in Scheme 28. These

Table 5 Synthesis of furanoid glycals (162a-c, 139) and functionalized 2,5-dihydrofurans (163a, b) from mesyl derivatives (160a-d)

\begin{tabular}{|c|c|c|c|c|}
\hline Entry & THF domains (159a-d) & Mesyl derivatives (160a-d) & Major products & Minor products \\
\hline 1 & $\mathrm{HO}{ }_{159}$ & $\mathrm{MsO}$ & $162 a(52 \%)$ & - \\
\hline 2 & $\mathrm{HO}=\mathrm{OBn}$ & MsO & OBn & OBn \\
\hline 3 & $\begin{array}{r}\mathrm{HO} O \\
159 \mathrm{c}\end{array}$ & $\begin{array}{r}\mathrm{MsO} O \\
160 \mathrm{c}\end{array}$ & $162 c(52 \%)$ & - \\
\hline 4 & $\begin{array}{l}\mathrm{HO} \text { O } \\
159 \mathrm{~d}\end{array}$ & $\begin{array}{l}\mathrm{MsO} O \\
160 \mathrm{~d}\end{array}$ & $163 b(61 \%)$ & $\begin{array}{l}139 \\
\text { inseparable mix } \\
139: 162 c=1: 0.2\end{array}$ \\
\hline
\end{tabular}

Table 6 Synthesis of furanoid glycals (162a-c, 139) and functionalized 2,5-dihydrofurans (163a, b) from lodo derivatives (161a-d)

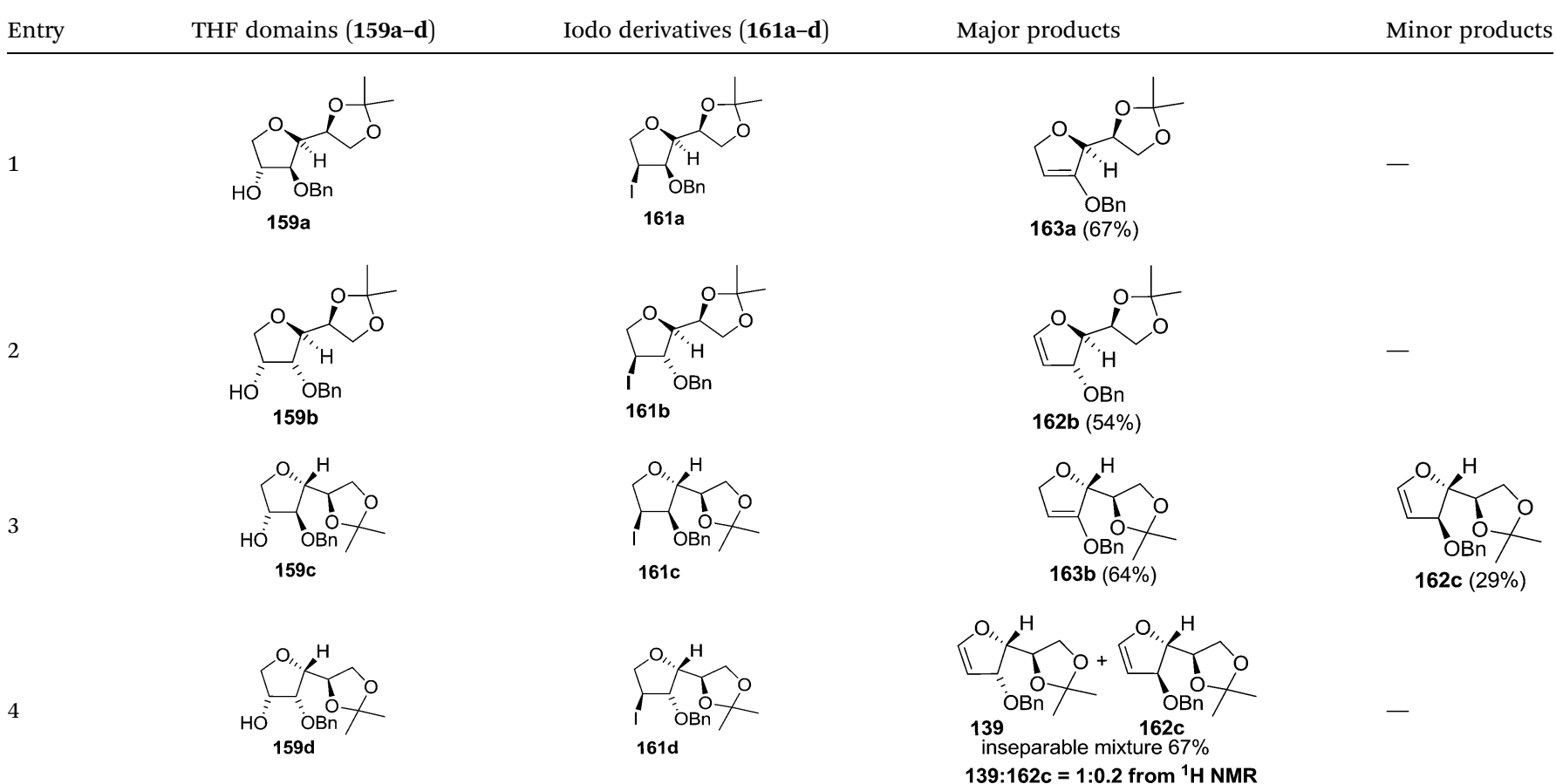


THF scaffolds (159a-d) were prepared from Pyranoid glycals (157) (3,4,6-tri-O-benzyl-D-galactal (A) and 3,4,6-tri-O-benzyl-Dglucal (B)) derived allylic alcohols (158) involving the intramolecular asymmetric ring opening (ARO) of the enantiomerically pure 2,3-epoxy alcohols using Sharpless asymmetric epoxidation (SAE) conditions followed by subsequent isopropylidene protection of the diol. The free hydroxyl group in 159 was protected with $\mathrm{MsCl}$ in the presence of $\mathrm{Et}_{3} \mathrm{~N}$ to afford the corresponding mesyl derivative 160. The OMs protected THF 160 in dry DMF was subjected to thermal elimination reaction for $8 \mathrm{~h}$ in the presence of DBU to furnish the furanoid glycals (162a-c, 139) and 2,5-dihydrofurans (163a, b). These furanoid glycals and 2,5-dihydrofurans were obtained in good yields when the stereochemically inverted iodides 161, prepared by Garegg-Samuelsson reaction $\left(\mathrm{I}_{2} / \mathrm{PPh}_{3} /\right.$ imidazole) from 159 , were heated at reflux with DBU in dry DMF for $5 \mathrm{~h}$ (Scheme 28, Tables 5 and 6). ${ }^{35 a}$

The construction of the double bonds was accomplished here by carrying out a base-induced E2 elimination of enantiomerically pure $\mathrm{C} 4$ mesylate or iodo THF scaffolds (160 or 161) by utilizing inexpensive reagents with a simple experimental and workup procedure. In the formation of either glycal or olefin, the E2 elimination took place most readily when the hydrogen atom and the leaving group were in an antiperiplanar arrangement. Further, it can be argued that E2 elimination of $\mathrm{MsOH}$ from 160b leading to the formation of two products in which furanoid glycal 162b (Hofmann product) was formed predominantly over Saytzeff product 163a (more substituted olefin) may be attributed to the involvement of a conformation in which the leaving group, 4-OMs, and one of the hydrogen atoms at C5 adopted a relatively higher degree of antiperiplanar arrangement relative to the antiperiplanar arrangement of 4OMs and H3. In contrast, the formation of Saytzeff product 163b as the major product and a mixture of glycals $(\mathbf{1 6 2 c}, 139)$ as the minor product, both from 160d, could be attributed to the comparable torsion angles subtended by the OMs group and the $\mathrm{H}$ atom across the $\mathrm{C} 4-\mathrm{C} 3$ and $\mathrm{C} 4-\mathrm{C} 5$ bond, respectively. Similarly, E2 elimination of HI from 161c gave expected Saytzeff product 163b as the major product over furanoid glycal 162c as a result of the same reason described in the case of E2 elimination of $\mathrm{MsOH}$ from 160d. We also showed that furanoid glycals 162a and 162c or functionalized 2,5-dihydrofurans 163a and 163b can be synthesized exclusively or in major quantity from the same 2,3,4-trisubstituted THF scaffolds 159a and 159c, respectively, by changing the leaving group at $\mathrm{C} 4$. Furthermore, this report provided two pairs of enantiomeric furanoid glycals (4,5-dihydrofurans) (162a, 139) and (162b, 162c) and one pair of enantiomeric 2,5-dihydrofurans (163a, 163b) (Fig. 3).

In 2010, Haraguchi and group described electrophilic glycosidation of erythro-furanoid glycal 164 with nucleobases followed by removal of the substituent $X$ at the $2^{\prime}$-position of the resulting product 165 to give a mixture of $\beta$-and $\alpha$-2'-deoxynucleosides $(\mathbf{1 6 6}, 167)$ (Scheme 29). ${ }^{38}$

To improve the $\beta$-selectivity, for the first time they reported the synthesis of erythro-furanoid glycals $(\mathbf{1 7 1}, \mathbf{1 7 3})$ by means of sulfoxide syn-elimination (Scheme 30). 2-Deoxy-D-ribose 67 on treatment with $\mathrm{PhSH} / \mathrm{H}_{2} \mathrm{SO}_{4}$ in DMF afforded phenyl-2-deoxy-1thio-D-erythro-pentofuranoside 168 in 97\% yield. The free hydroxyl groups of 168 were silylated with TIPDSCl to give 169 in $84 \%$ yield. Its oxidation with $m$-CPBA led to the formation of the

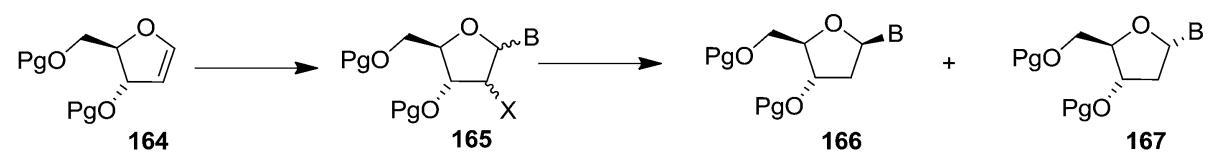

Scheme 29

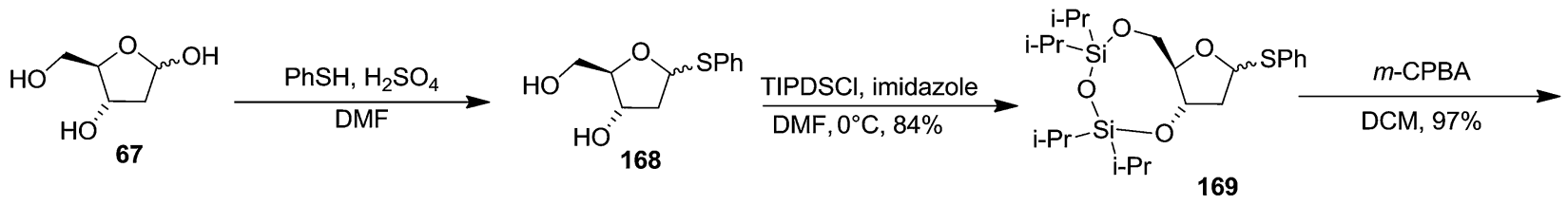

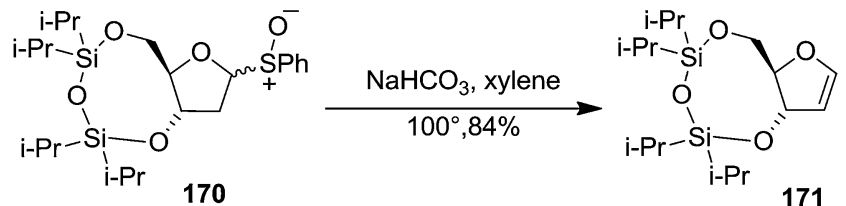

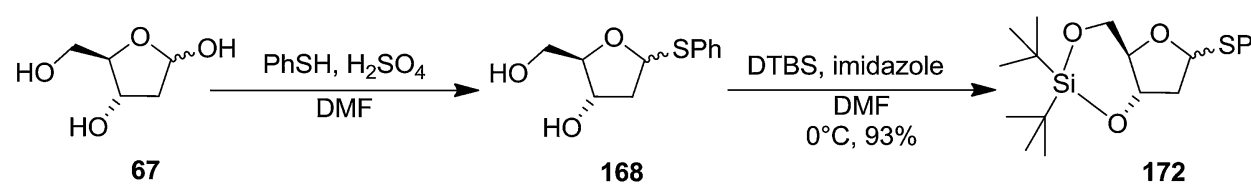

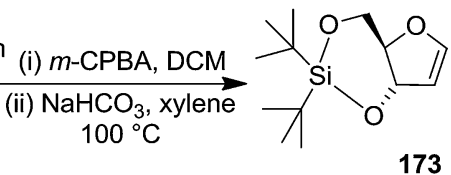

Scheme 30 
sulfoxide 170 in $96 \%$ yield. The sulfoxide 170 on treatment with solid $\mathrm{NaHCO}_{3}$ in refluxing xylene underwent sulfoxide synelimination to furnish glycal 171 in $84 \%$ yield. Likewise, 168 was protected with the DTBS group to give 172 (93\% yield), which was then converted to the 3,5-O-DTBS-protected glycal 173 in $83 \%$ yield by adopting the reaction sequence similar to that employed for the synthesis of glycal 171. The synthesis of nucleosides utilizing these furanoid glycals $(\mathbf{1 7 1}, \mathbf{1 7 3})$ has been delineated in Schemes 128 and 129.

\section{Applications of furanoid glycals}

\subsection{Synthesis of natural products and related compounds}

Nowadays, for the synthesis and utilization of chiral building blocks (CBBs) for the synthesis of target molecules for drug design and enantiomerically pure simple and complex natural products are in great demand. This approach of synthesis utilizing the stereochemistry of the starting material is customarily known as the 'chiron' approach synthesis ${ }^{39}$ and it becomes very cost effective if starting material is derived from inexpensive carbohydrate or amino acid.

The furanoid glycals derived from different starting materials have been utilized as chiral pool material by various groups for synthesis of variety of natural products and important target molecules, which are discussed below.

Ireland and group reported the total synthesis of Lasalocid A (X537A) 174 and analogues. For the synthesis of Lasalocid A (X537A)174, they described the construction of both the aldehyde 175 and ketone 176 available from the reverse aldol reaction of lasalocid A (X537A) 174 (Scheme 31). ${ }^{\mathbf{4 0 , 4 1}}$

On the basis of a retrosynthetic strategy using the IrelandClaisen rearrangement to form the two C-glycosides bearing chiral centres at the $\mathrm{C}-\alpha$ positions, they utilized carbohydrate precursors as the source of the furanoid and pyranoid subunits for the construction of ketone 176 (Scheme 32).

First they tried the synthesis of $\mathbf{1 7 6}$ from furanoid glycal $\mathbf{4 5}$ which was converted to protected furanoid glycal 49 which is described in Scheme $8,{ }^{4}$ from which the isomeric mixture of acid 180 was prepared by [3,3] sigmatropic rearrangement at $35{ }^{\circ} \mathrm{C} .{ }^{4}$ This acid mixture 180 was converted to $\alpha$-epoxides 182 in $90 \%$ overall yield through the intermediate iodolactone $\mathbf{1 8 1}$. Treatment of 182 with lithiated 1,3-dithiane followed by desulfurization of the resulting products provided 183 in moderate yield. It was converted to acid 186 (epimer of 177) via the intermediates 184 and 185 (Scheme 33).

They chose $\alpha$-D-glucosaccharino-1,4-lactone 187 as the starting material for the purpose to synthesize 177. It was converted to the mixture of unsaturated isomeric esters 190. Hydrogenation of 190 yielded 191 and 192, which were separated by column chromatography. After LAH reduction of 191 and 192, both the resulting alcohols $(193,194)$ were readily transformed to the acids 177 and 186 respectively (Scheme 34).

The construction of Pyranoid glycal 178 started with 6-deoxyL-gulose 195 as shown in Scheme 35. The hydroxyl groups were differentiated as benzyl glycoside, $O$-isopropylidene, and methoxymethyl ether in compound 196. Removal of the benzyl

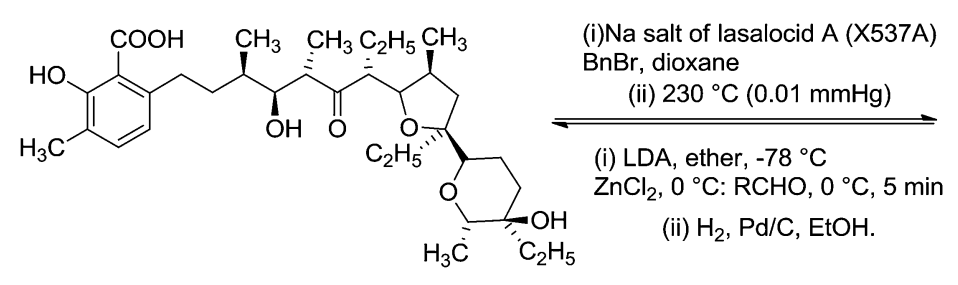

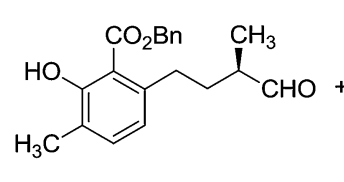

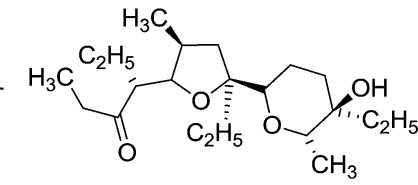

(ii) $\mathrm{H}_{2}, \mathrm{Pd} / \mathrm{C}$, EtOH

174 LASALOCID A (X537A)

Scheme 31

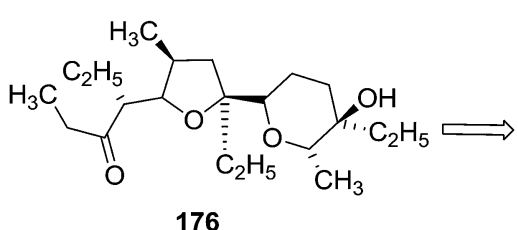<smiles>CCCC(COc1ccccc1)C1OC(C(=O)O)CC1C</smiles><smiles>CO[C@H]1[C@@H](O)C=CO[C@H]1C</smiles>

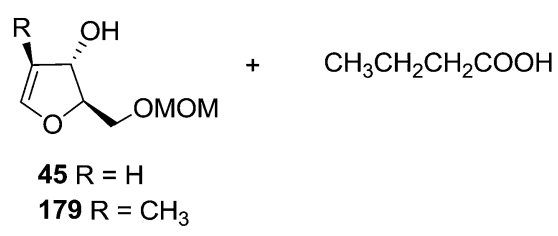

Scheme 32 Retro synthetic strategy for synthesis of ketone 176 

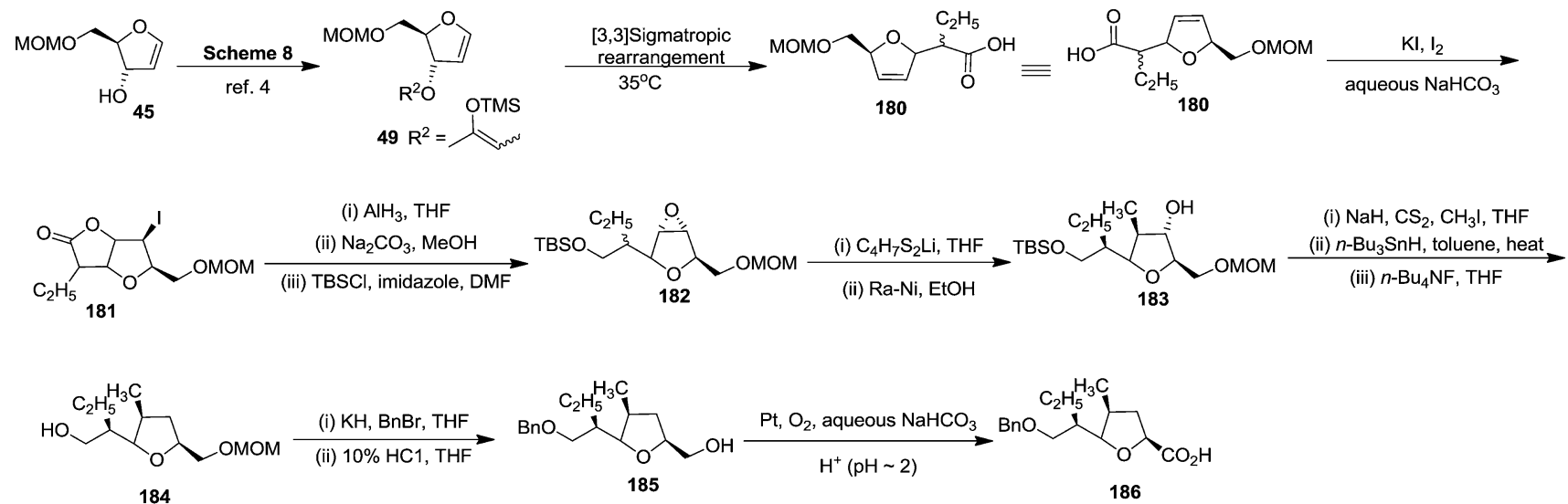

Scheme 33
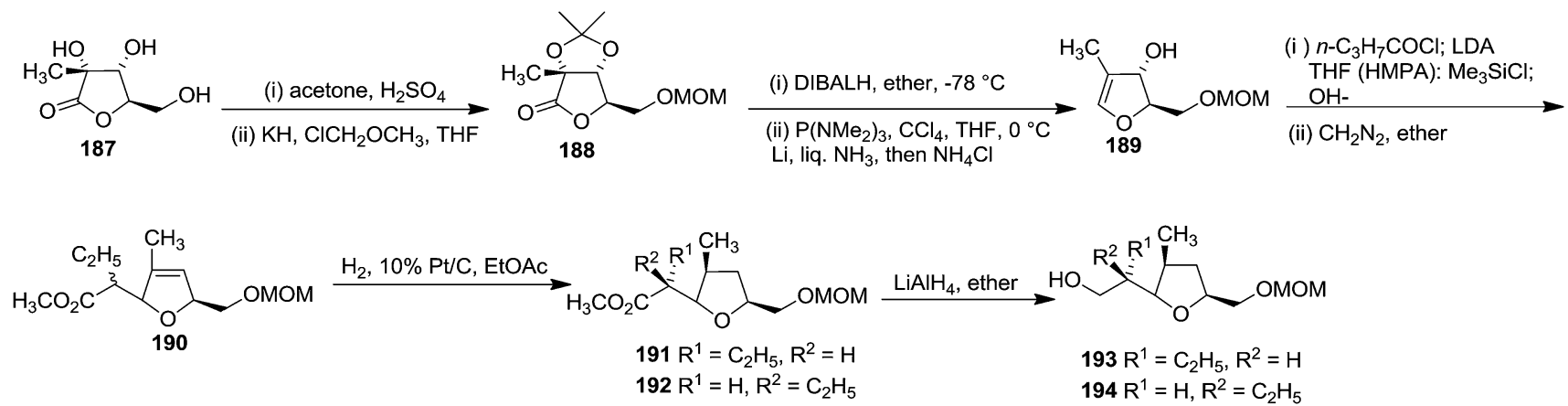

(i) $\mathrm{KH}, \mathrm{BnBr}$, THF

(ii) $10 \% \mathrm{HCl}$, THF

(iii) $\mathrm{Pt}, \mathrm{O}_{2}$, aqueous $\mathrm{NaHCO}_{3}$ $\mathrm{H}+,(\mathrm{pH} \sim 2)$

$$
\begin{aligned}
& 177 \mathrm{R}^{1}=\mathrm{C}_{2} \mathrm{H}_{5}, \mathrm{R}^{2}=\mathrm{H} \\
& 186 \mathrm{R}^{1}=\mathrm{H}, \mathrm{R}^{2}=\mathrm{C}_{2} \mathrm{H}_{5}
\end{aligned}
$$

Scheme 34

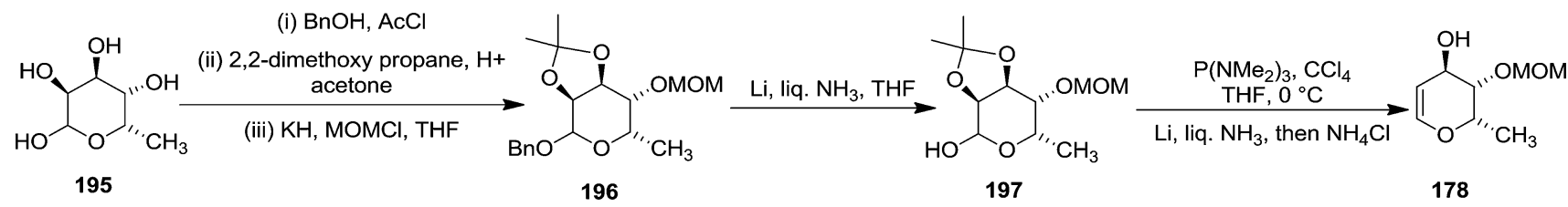

Scheme 35

ether then led to the lactol 197 which was converted to the desired glycal 178 by their optimised procedure (Scheme 35).

The connection of the pyranoid subunit 178 to acid 177 resulted in readily separable isomeric esters 198 and 199, while the epimer 186 afforded the isomeric esters 200 and 201. Subsequent transformation of these esters individually to alcohols 206-209 proceeded in excellent yields via 202-205 (Scheme 36).

Alcohol 207 was transformed into ketone 210, which was converted to the exo methylene olefin followed by oxidation with $m$-CPBA afforded a mixture of epoxides in which the $\beta$-epoxide
211 was the major component. Subsequent reductive cleavage of this isomer then led to the tertiary alcohol 212 which was transformed into the aldehyde $\mathbf{2 1 3}$ involving sequence of reactions like debenzylation and oxidation of the resulting primary alcohol. Finally its Grignard reaction furnished the ketone $\mathbf{1 7 6}$ (Scheme 37). The aldol condensation between the aldehyde 175 and the zinc enolate of the ketone $\mathbf{1 7 6}$ completed the total synthesis of Lasalocid A (X537A) 174 (Scheme 31).

In 1980 Corey et al. synthesized 6-epi-leukotriene C or 6-epiLTC 225 and 6-epi-leukotriene D or 6-epi-LTD 226 from Dmannose derived furanoid glycal 26. First it was converted to 

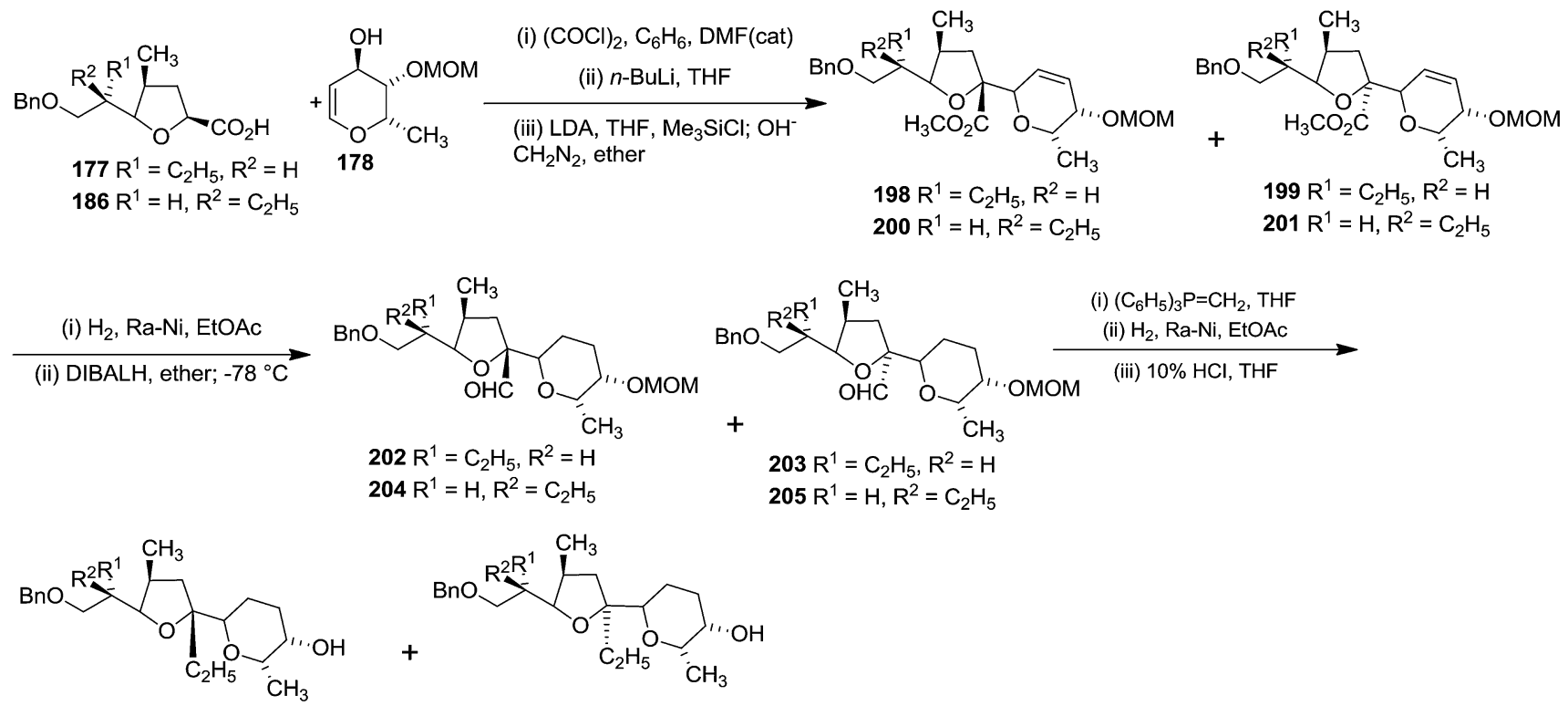

$$
\begin{array}{ll}
206 R^{1}=C_{2} H_{5}, R^{2}=H & 207 R^{1}=C_{2} H_{5}, R^{2}=H \\
208 R^{1}=H, R^{2}=C_{2} H_{5} & 209 R^{1}=H, R^{2}=C_{2} H_{5}
\end{array}
$$

Scheme 36
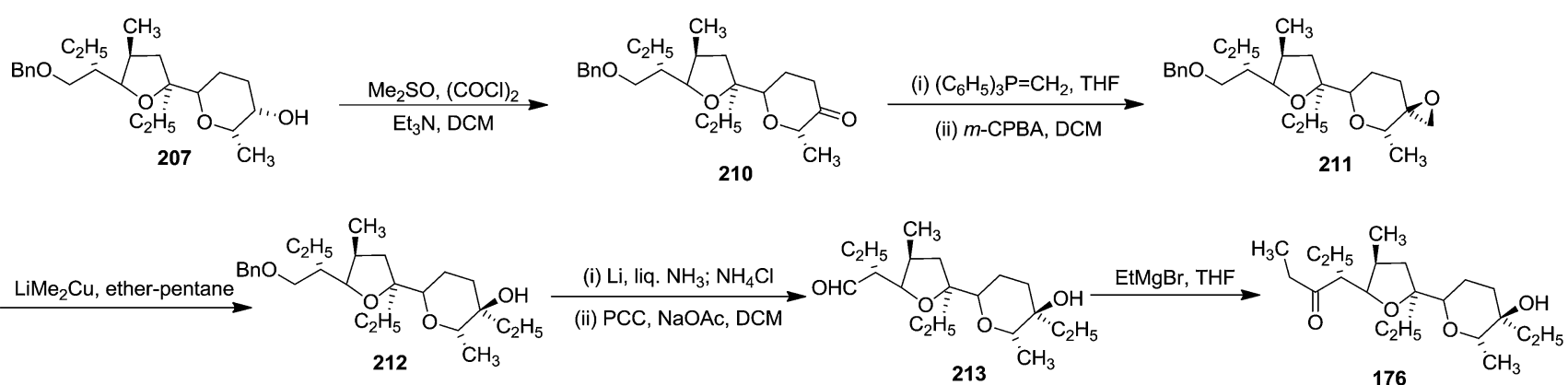

\section{Scheme 37}
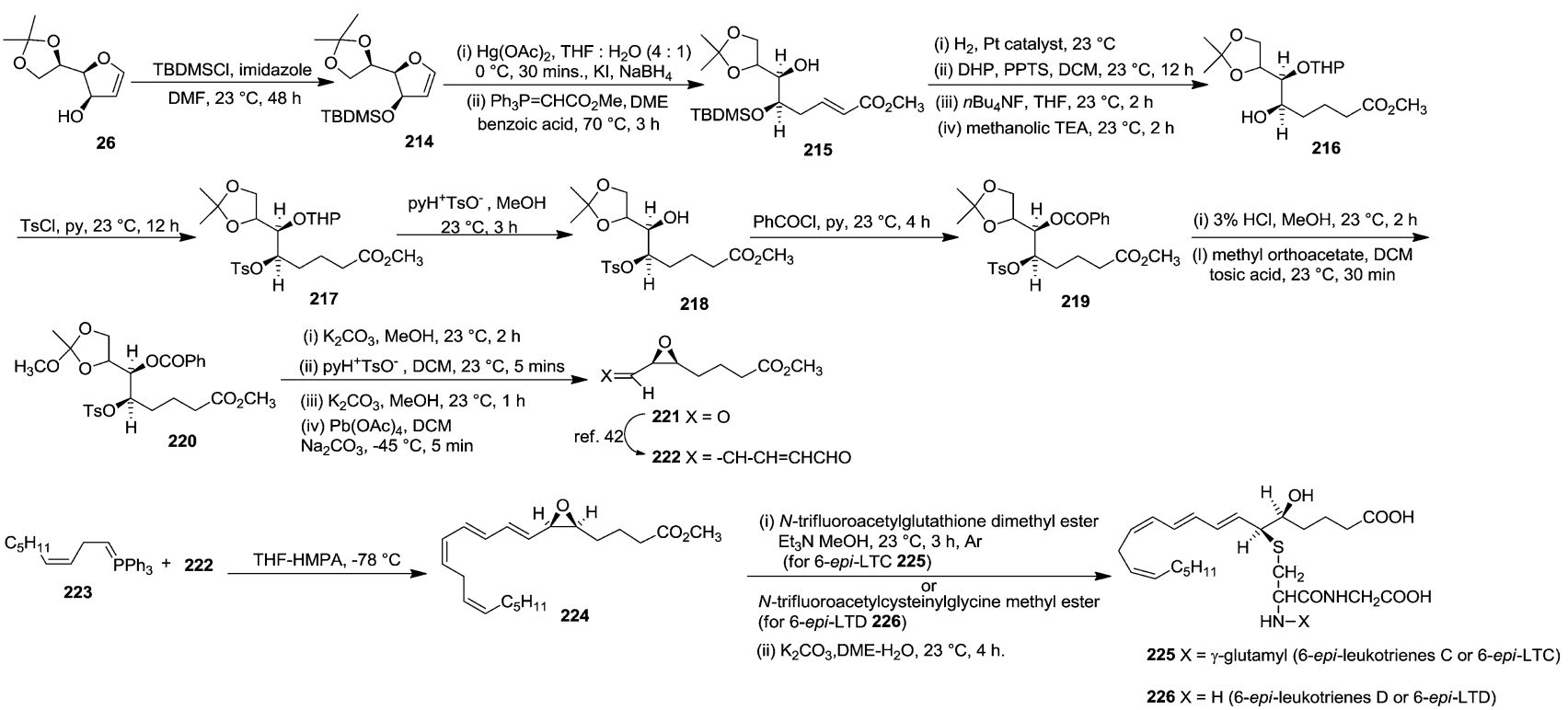
TBDMS ether derivative $\mathbf{2 1 4}$ by treatment with TBDMSCl, imidazole in dry DMF at $23{ }^{\circ} \mathrm{C}$ for $48 \mathrm{~h}$ (Scheme 38). ${ }^{5,42}$ Its successive oxymercuration-demercuration reactions followed by esterification of the resulting hemiacetal with methoxycarbonylmethylenetriphenylphosphorane in DME containing a trace of benzoic acid at $70{ }^{\circ} \mathrm{C}$ for $3 \mathrm{~h}$ gave unsaturated ester 215 in $96 \%$ yield. Its sequential hydrogenation followed by tetrahydropyranylation and desilylation formed an intermediate $\delta$ lactone which on treatment with methanolic triethylamine at $23{ }^{\circ} \mathrm{C}$ for $2 \mathrm{~h}$ provided hydroxy ester $\mathbf{2 1 6}$ (99\% yield). Tosylation of $\mathbf{2 1 6}$ gave 217 in $97 \%$ yield. Deprenylation of $\mathbf{2 1 7}$ and benzoylation of the resulting $\mathbf{2 1 8}$ (92\% yield) gave 219. Acetonide deprotection followed by reaction of the corresponding 1,2-diol with 5 equiv. of methyl orthoacetate in DCM containing a trace of tosic acid $\left(23{ }^{\circ} \mathrm{C}, 30 \mathrm{~min}\right.$ ) furnished 220 in $99 \%$ yield.

The protected benzoate tosylate $\mathbf{2 2 0}$ was transformed into the cis-epoxy aldehyde $\mathbf{2 2 1}$ in 98\% yield by the sequential (i) cisepoxididation with $\mathrm{K}_{2} \mathrm{CO}_{3}$ in $\mathrm{MeOH}\left(2 \mathrm{~h}, 23{ }^{\circ} \mathrm{C}, 96 \%\right.$ yield) (ii) conversion of the cyclic orthoacetate to mono acetate by exposure to wet DCM containing a trace of $\mathrm{pyH}^{+} \mathrm{TsO}^{-}\left(5 \mathrm{~min}, 23{ }^{\circ} \mathrm{C}\right.$, $98 \%$ yield) to (iii) deacetylation by $\mathrm{K}_{2} \mathrm{CO}_{3}$ in $\mathrm{MeOH}\left(1 \mathrm{~h}, 23{ }^{\circ} \mathrm{C}\right.$, $99 \%$ yield) to form 1,2-glycol and finally (iv) 1,2-glycol cleavage with 1.05 equiv. of $\mathrm{Pb}(\mathrm{OAc})_{4}$ in DCM containing finely powdered sodium carbonate $\left(-45^{\circ} \mathrm{C}, 5 \mathrm{~min}\right)$. Its chain extension followed by Wittig reaction of resulting dienal 222 with ylide 223 in THFHMPA gave epoxy methyl ester 224 (methyl ester of the $5 S, 6 R$ isomer of leukotriene A). ${ }^{42}$ It was converted to 6-epi-LTC 225 in two stages: (i) reaction with 2 equiv. of $\mathrm{N}$-trifluoroacetylglutathione dimethyl ester and 3 equiv. of $\mathrm{Et}_{3} \mathrm{~N}$ in a minimum quantity of methanol at $23{ }^{\circ} \mathrm{C}$ for $3 \mathrm{~h}$ under $\mathrm{Ar}$ atmosphere and (ii) deprotection with $\mathrm{K}_{2} \mathrm{CO}_{3}$ in $4: 1$ dimethyoxyethane-water at $23{ }^{\circ} \mathrm{C}$ for $4 \mathrm{~h}$ to afford 225 .

Under the identical reaction condition 6-epi-LTD 226 was prepared from $\mathbf{2 2 4}$ by using $N$-trifluoroacetylcysteinylglycine methyl ester, and the deprotection step was reported to perform at $23{ }^{\circ} \mathrm{C}$ for $18 \mathrm{~h}$ (Scheme 38).

Schlosser and coworkers described the synthesis of threofuranoid glycal 63 (Scheme 11), erythro furanoid glycal 54a (Scheme 10) ${ }^{\mathbf{2 0 a}}$ and utilized them as key intermediates for synthesis of erythro-(2S,3R)-sphingosine 232 (Scheme 39) and threo-(2S,3S)-sphingosine 238 (Scheme 40). ${ }^{21}$

In 1999, Theodorakis et al. described a short, efficient, and enantioselective synthesis of Norrisane side chain from furanoid glycal 139 as key intermediate (Scheme 23). ${ }^{31}$ Furanoid glycal 139 was converted into cyclopropanated ester 239 by treatment with ethyl diazoacetate $(0.1 \mathrm{M}$ in $\mathrm{DCM})$ and $\mathrm{Rh}_{2}(\mathrm{OAc})_{4}$ at $25{ }^{\circ} \mathrm{C}$ which on treatment with dilute ethanolic solution of sulfuric acid afforded 240. After its oxidative cleavage in the presence of $\mathrm{NaIO}_{4}$, the resulting aldehyde was methylated to produce 241 in $63 \%$ combined yield. Its Swern oxidation produced ketone 242 in 79\% yield, which on $\mathrm{MeSO}_{3} \mathrm{H}$ mediated cyclization at $0{ }^{\circ} \mathrm{C}$ furnished bicycle 243 as a single isomer in $67 \%$ yield. Its Baeyer-Villiger oxidation in presence of ureahydrogen peroxide and trifluoroacetic anhydride yielded $\mathbf{2 4 4}$ in $69 \%$ yield (Scheme 41 ).

In 2001, Chida and co-worker also utilized furanoid glycal 139 as key intermediate for synthesis of (+)-myriocine 262 (Schemes 42 and 43). ${ }^{37} \alpha$-Methyl furanoside 245 was obtained from furanoid glycal 139 in $81 \%$ yield by oxymercurationreduction followed by acid treatment. The primary hydroxyl

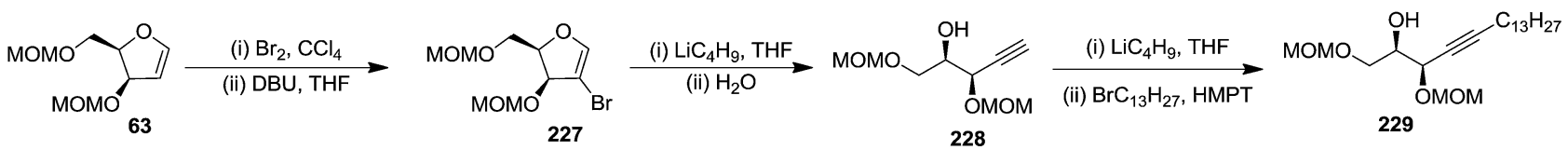

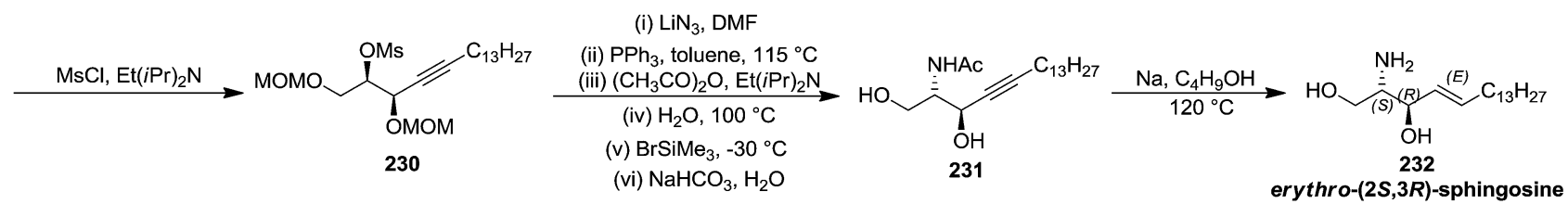

Scheme 39

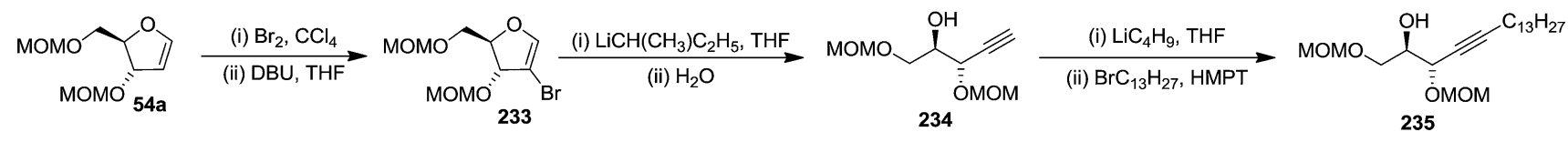

(i) $\mathrm{LiN}_{3}, \mathrm{DMF}$

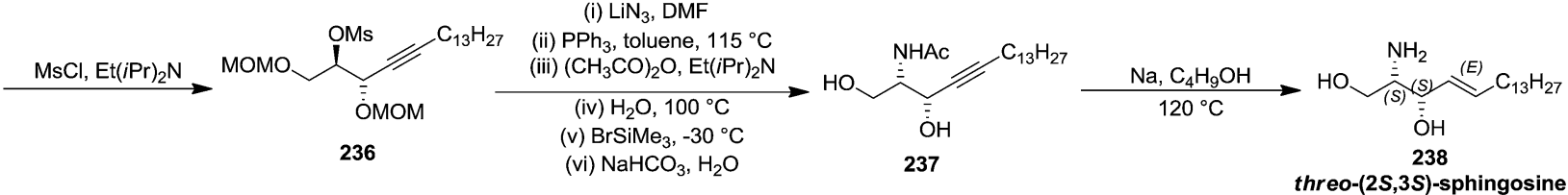

Scheme 40 


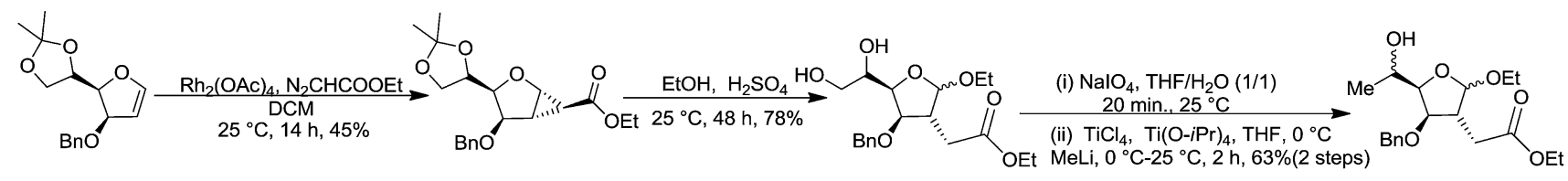

139

239

240

241

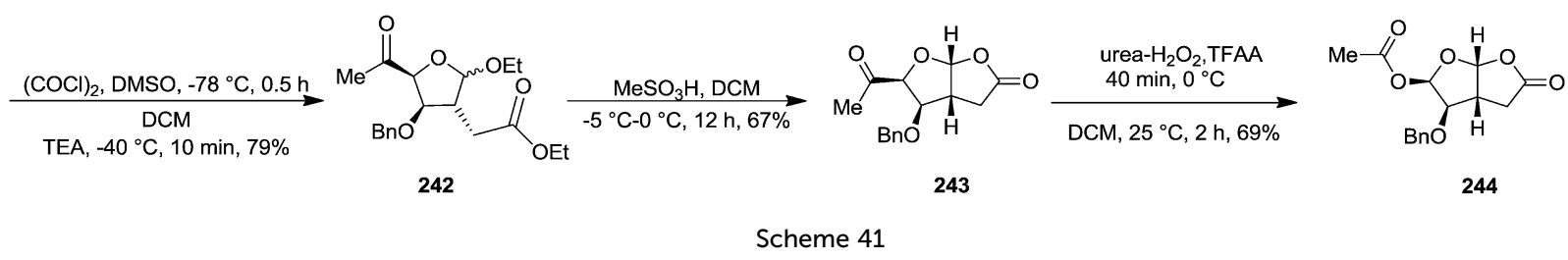

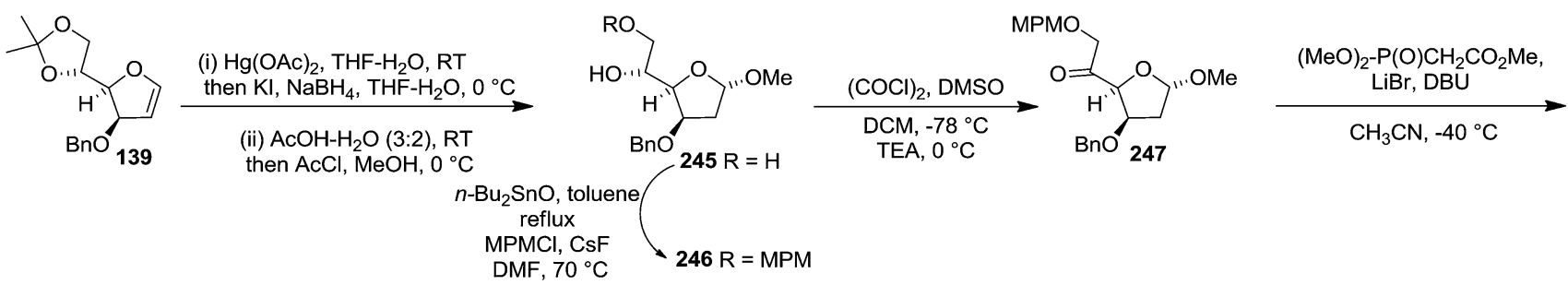
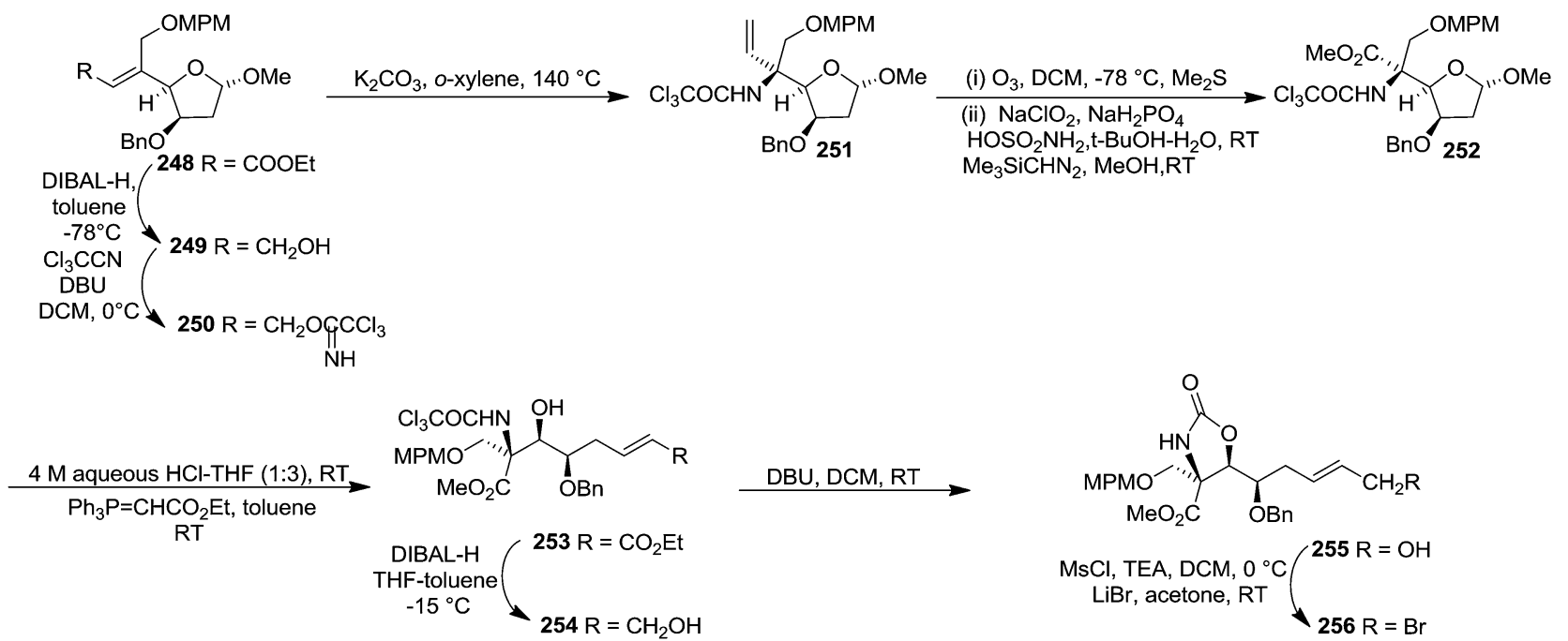

Scheme 42

group in $\mathbf{2 4 5}$ was selectively $p$-methoxybenzylated to afford $\mathbf{2 4 6}$ ( $95 \%$ yield), which on Swern oxidation generated ketone 247. Its Horner-Emmons reaction provided an inseparable mixture of $(E)$-alkene 248 and its $(Z)$-isomer $(15: 1)$ in $90 \%$ yield. DIBAL-H reduction of the mixture afforded column purified $(E)$-allyl alcohol 249 and its $(Z)$-isomer in $93 \%$ and $6 \%$ isolated yields respectively. The allyl alcohol 249 was converted into trichloroacetimidate $\mathbf{2 5 0}$ which, without further purification, was subjected to Overman rearrangement to yield an inseparable mixture of rearranged products 251 and its epimer in a ratio of $7: 1$ in $90 \%$ yield from 249. Ozonolysis of 251 followed by oxidation and esterification in succession afforded $252(82 \%$ yield). Its acid hydrolysis provided an anomeric mixture of lactol which was then treated with $\mathrm{Ph}_{3} \mathrm{P}=\mathrm{CHCO}_{2}$ Et to give $(E)$-alkene
253 in $71 \%$ yield. Its DIBAL-H reduction in THF-toluene at $215^{\circ} \mathrm{C}$ afforded allyl alcohol 254 (75\% yield), which on treatment with DBU in DCM was transformed into cyclic carbamate 255 in $86 \%$ yield. The primary hydroxyl group in $\mathbf{2 5 5}$ was converted into corresponding allyl bromide 256 in $92 \%$ yield (Scheme 42 ).

The hydrophobic part of myriocin, sulfone 258, was prepared by treatment of 1-bromododecan-6-one 257 with $\mathrm{PhSO}_{2} \mathrm{Na}$, followed by ketalization ( $82 \%$ yield) (Scheme 43 ). Sulfone 258 on treatment with $n \mathrm{BuLi}$, and allyl bromide 256 afforded the coupling product 259 in $80 \%$ yield. Saponification of 259 and subsequent Birch reduction gave crude carboxylic acid 260. Removal of the ketal group and carbamate function in $\mathbf{2 6 0}$ followed by conventional acetylation provided 261. Finally, saponification of 261 
<smiles>CCCCCCC(=O)CCCCCBr</smiles>

1-Bromododecane-6-one

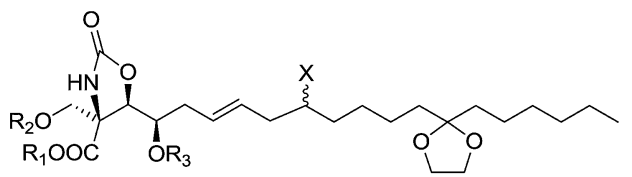

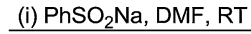

(ii) $\left(\mathrm{TMSOCH}_{2}\right)_{2}, \mathrm{TMSOTf}, \mathrm{DCM}, \mathrm{RT}$

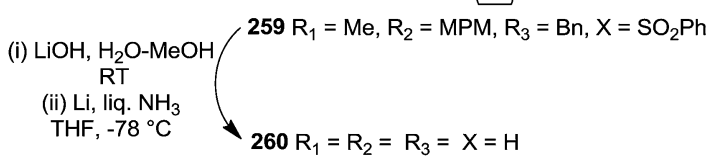

$\frac{10 \% \text { aqueous } \mathrm{NaOH}-\mathrm{MeOH}(1: 3)}{\text { Reflux }}$

261
$\mathrm{SO}_{2} \mathrm{Ph}$<smiles>CCCCCCC1(CCCCC)CC[13CH2]CO1</smiles>

$n$-BuLi, THF, $-78^{\circ} \mathrm{C}$

compd. $256,-78-0^{\circ} \mathrm{C}$

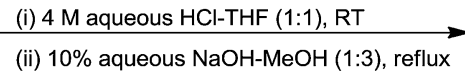

(iii) $\mathrm{Ac}_{2} \mathrm{O}$, pyridine, $\mathrm{RT}$

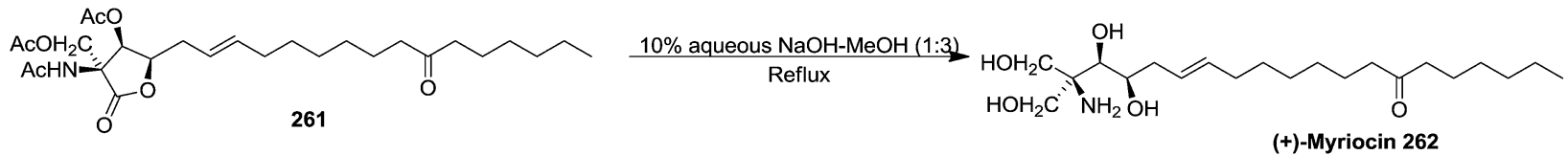

Scheme 43

followed by neutralization with weak acidic resin (Amberlite IRC$76, \mathrm{H}^{+}$form) furnished (+)-myriocin 262 in $82 \%$ yield.

In 2007, Chandrasekharan and coworker developed a methodology for the construction of fused perhydrofuro[2,3-b]pyran/ furan by using NIS mediated ring opening and cyclization of 1,2-cyclopropanated sugar derivatives, derived from pyranoid and furanoid glycals. They successfully applied this methodology to the synthesis of fused perhydrofuro[2,3- $b]$ pyrano/furano- $\gamma$-butyrolactone derivatives using sugar derived 1,2cyclopropane carboxylic acids. ${ }^{43}$

The furanoid glycal 139 on treatment with methyl diazoacetate in the presence of $\mathrm{Rh}_{2}(\mathrm{OAc})_{4}$ gave the cyclopropanated ester 263 as a major product, which on LAH reduction delivered alcohol 264 in 98\% yield. It was subjected to NIS mediated ring opening and cyclization reaction to furnish perhydrofuro[2,3- $b$ ] furan derivative $\mathbf{2 6 5}$ in $65 \%$ yield as a mixture of diastereomers $(9: 1)$. The mixture was subjected to dehydrohalogenation with DBU (THF, reflux, $12 \mathrm{~h}$ ) to obtain the corresponding furofuryl glycal 266 in $78 \%$ yield (Scheme 44 ).

The hydrolysis of the 1,2-cyclopropane carboxylate 263 under the basic medium produced 1,2-cyclopropane carboxylic acid 267 (Scheme 45). Its cyclopropane ring opening with NIS in presence of $\mathrm{CH}_{3} \mathrm{CN}$ and $4 \AA \mathrm{MS}$ for $10 \mathrm{~h}$ furnished the corresponding 3-iodoperhydrofuro[2,3- $b]$ furano- $\gamma$-butyrolactone derivative 268 in excellent yield (83\%) (Scheme 45).

In 2007, Correia and co-workers achieved the synthesis of (-)-isoaltholactone 277 in seven steps with an overall yield of $\sim 25 \%$ from $\mathrm{L}$-glutamic acid 269 derived furanoid glycal $\mathbf{2 7 0}$ (ref.

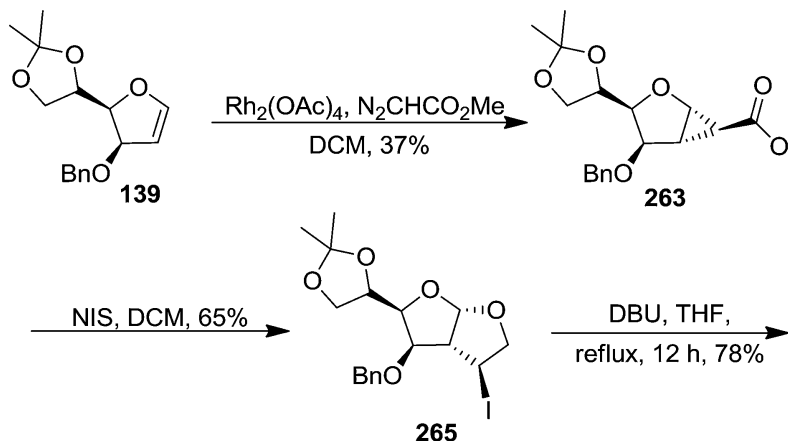

265

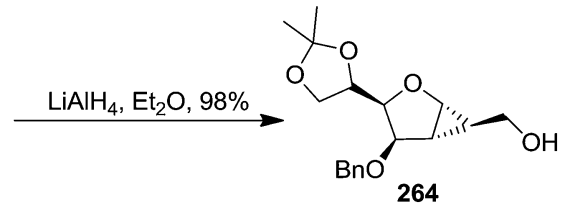<smiles></smiles>

266

Scheme 44<smiles>COC(=O)C1OC2C1OC(C1COC(C)(C)O1)C2OC(=O)c1ccccc1</smiles>
$\underline{\mathrm{LiOH}, \mathrm{THF}: \mathrm{MeOH}, 99 \%}$<smiles>CC1(C)OCC(C2OC(C(=O)O)C2C(=O)OCc2ccccc2)O1</smiles>

NIS, $\mathrm{CH}_{3} \mathrm{CN}, 4 \AA \mathrm{MS}$

$10 \mathrm{~h}, 94 \%$<smiles>CC1(C)OCC(C2OC(C(I)C(=O)O)C(C(O)C(=O)O)C2O)O1</smiles>

Scheme 45 
44) by utilizing Heck-Matsuda arylation with benzenediazonium tetrafluoroborates as the key step. ${ }^{45}$ After performing several trial and error experiments, they achieved the best condition for Heck-Matsuda arylation of enolether 270 with benzenediazonium tetrafluoroborates 271 in the presence of 4 mol\% of $\mathrm{Pd}_{2}(\mathrm{dba})_{3}$, to afford the phenyldihydrofurans 272a and 272b in 90\% yield as a 94:06 inseparable diasteromeric mixture. Though the diastereomeric mixture was inseparable by column chromatography, the desilylated Heck adducts were separated. The silyl ether deprotection of $\mathbf{2 7 2}$ followed by column purification resulted 273a and $273 \mathbf{b}$. Treatment of $273 \mathbf{a}$ with potassium osmate and $N$-methylmorpholine $\mathrm{N}$-oxide (NMO) afforded the triol $\mathbf{2 7 4}$ which, without further purification, was treated with 2,2-dimethoxypropane and PTSA to give acetonide 275 in good yields (Scheme 46). Swern oxidation of free hydroxyl group of $\mathbf{2 7 5}$ gave an unstable aldehyde which was immediately subjected to a Wittig olefination with ethoxycarbonylmethylene phosphorane in methanol to furnish the cis-enoate 276 in $75 \%$ yield (over 2 steps). It was then treated with catalytic PTSA in methanol followed by sonication to obtain (-)-isoaltholactone $\mathbf{2 7 7}$ in $70 \%$ yield (2 steps). However, when cis-enoate $\mathbf{2 7 6}$ was treated with an aqueous solution of trifluoroacetic acid for $48 \mathrm{~h}$ at room temperature, the (-)-isoaltholactone 277 was obtained in $80 \%$ yield (Scheme 46 ).

After reporting an efficient protocol for the synthesis of stereochemically pure four different furanoid glycals (162a-c, 139) (Fig. 3) from our laboratory, in the year 2011, we were further interested to demonstrate the synthetic utility of these furanoid glycals. In this endeavour, we identified and synthesized four aggregation pheromones brevicomins (285a-d), styryllactones (+)-cardiobutanolide 290a, (-)-cardiobutanolide $290 \mathrm{~b}$ and $(+)$-goniofufurone 295a from the above mentioned furanoid glycals (162a-c, 139). ${ }^{2 h}$

The total synthesis of (+)-exo-brevicomin 285a was initiated from furanoid glycal 139 (1,4-anhydro-2-deoxy-5,6-O-isopropylidene-3-O-benzyl-D-arabino-hex-1-enitol) (Scheme 47), which was converted into 278 a by oxymercuration-demercuration sequence in $98 \%$ yield. The anomeric $\mathrm{OH}$ was oxidized with

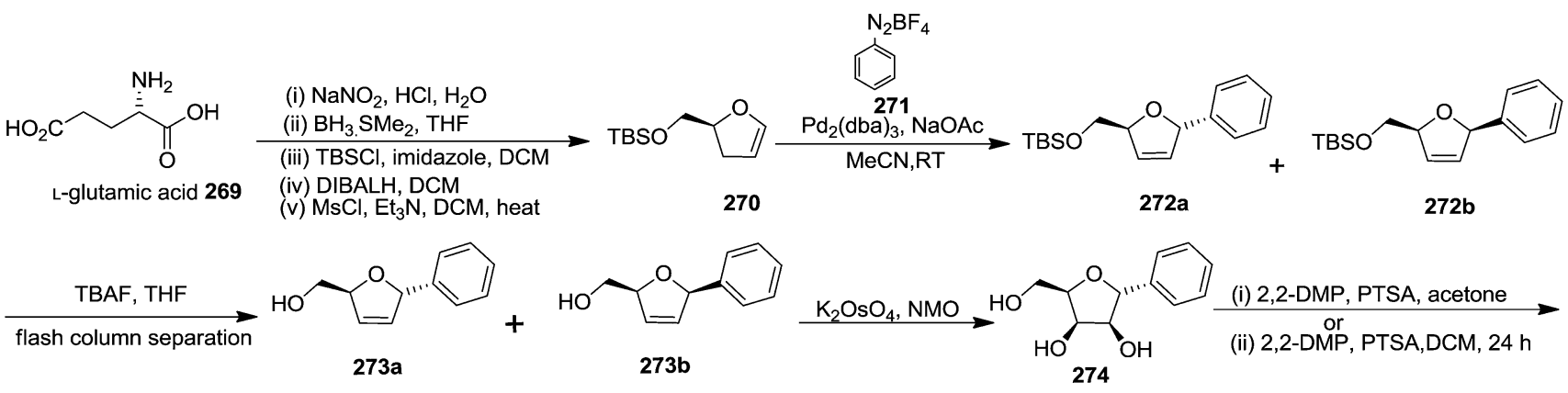<smiles>[Z6]C1([18F])O[C@H](c2ccccc2)[C@@H](O)[C@@H]1CO</smiles>

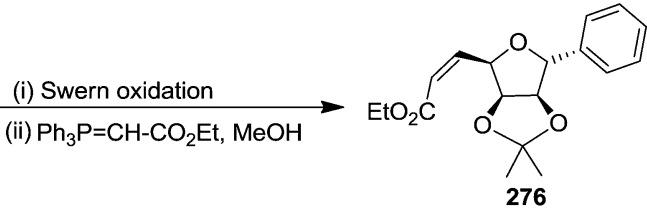

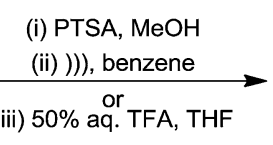

$\mathrm{RT}, 48 \mathrm{~h}$

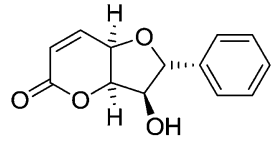

(-)-Isoaltholactone $\mathbf{2 7 7}$

Scheme 46<smiles>CC1(C)OC[C@H]([C@H]2CC=CO2)O1</smiles>
$139 \mathrm{OBn}$<smiles>[R]OCC([R])[C@H]1OC(=O)C[C@@H]1OCc1ccccc1</smiles>

$\mathrm{MsCl}$, py $280 \mathrm{a} \mathrm{R}=\mathrm{H}$

$0^{\circ} \mathrm{C}, 3 \mathrm{~h} \downarrow_{281 \mathrm{a} R}=\mathrm{Ms}$<smiles>CC=C[C@@H](O)C(O)CC=CC(C)=O</smiles>

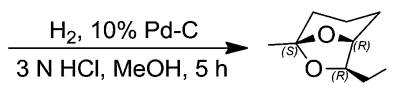

(+)-exo-Brevicomin 285a

Scheme 47 


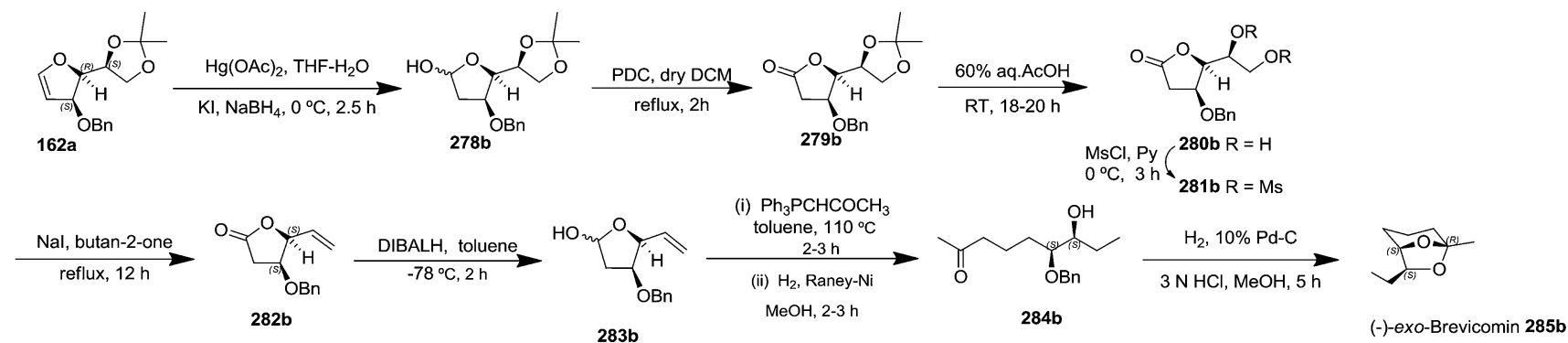

Scheme 48

PDC in dry DCM at refluxing temperature for $2 \mathrm{~h}$ to obtain lactone 279a as a white solid in $75 \%$ yield. Deprotection of the acetonide in 279a was carried out with $60 \%$ aqueous $\mathrm{AcOH}$ at room temperature for 18-20 h to give diol 280a as a white solid, which was without further purification, mesylated with $\mathrm{MsCl}$ in pyridine at $0{ }^{\circ} \mathrm{C}$ for $3 \mathrm{~h}$ to afford dimesyl derivative 281a. The reductive elimination of diester $281 \mathrm{a}$ with $\mathrm{NaI}$ in butan-2-one at reflux temperature for $12 \mathrm{~h}$ yielded vinylbutyrolactone derivative 282a in $71 \%$ yield for three steps. Its reduction with DIBALH at $-78{ }^{\circ} \mathrm{C}$ in dry toluene yielded lactol 283a in $86 \%$ yield. Its Wittig olefination with $\mathrm{Ph}_{3} \mathrm{PCHCOCH}_{3}$ in dry toluene followed by RANEY® hydrogenation of the resulting product 283a' with two double bonds afforded column purified ketone 284a in 52\% yield in two steps. Finally, the simultaneous hydrogenolysis of $\mathrm{OBn}$ in 284a in presence of $\mathrm{Pd} / \mathrm{C}$ in $\mathrm{MeOH}$ and intramolecular acetalization with a trace of $3 \mathrm{~N} \mathrm{HCl}$ delivered the target (+)-exobrevicomin $285 \mathrm{a}$ in $44 \%$ yield (Scheme 47 ).

After having completed the total synthesis of (+)-exo-brevicomin 285a from furanoid glycal 139, the similar reaction sequence was successfully followed for the synthesis of (-)-exobrevicomin 285b from 162a (1,4-anhydro-2-deoxy-5,6-O-isopropylidene-3-O-benzyl-L-arabino-hex-1-enitol) (Scheme 48), (+)-endo-brevicomin 285c from 162b (1,4-anhydro-2-deoxy-5,6-Oisopropylidene-3-O-benzyl-L-ribo-hex-1-enitol) (Scheme 49) and (-)-endo-brevicomin 285d from 162c (1,4-anhydro-2-deoxy-5,6$O$-isopropylidene-3-O-benzyl-D-ribo-hex-1-enitol) (Scheme 50).

The key intermediates 282a and 282b (Schemes 47 and 48) were utilized for the synthesis of styryllactones (+)-cardiobutanolide 290a, (-)-cardiobutanolide 290b. The olefin cross metathesis reaction between 282a and (S)-1-phenyl-2propene-1-ol with Grubb's II $^{\text {nd }}$ generation catalyst $(2.8 \mathrm{~mol} \%$ ) in refluxing DCM furnished allylic alcohol 286a in 74\% yield. It was silylated with TBSCl in dry DCM at $0{ }^{\circ} \mathrm{C}$ to afford silyl ether 287a in 93\% yield. Its asymmetric dihydroxylation with AD-mix$\beta$ in $1: 1 \mathrm{tBuOH}: \mathrm{H}_{2} \mathrm{O}$ afforded $288 \mathrm{a}$ in $67 \%$ yield which on silyl ether deprotection with amberlyst 15 resin in dry acetonitrile produced 289a in 94\% yield. Finally, its $O$-benzyl deprotection by $\mathrm{Pd}(\mathrm{OH})_{2}$ catalyzed hydrogenolysis in dry $\mathrm{MeOH}$ furnished the
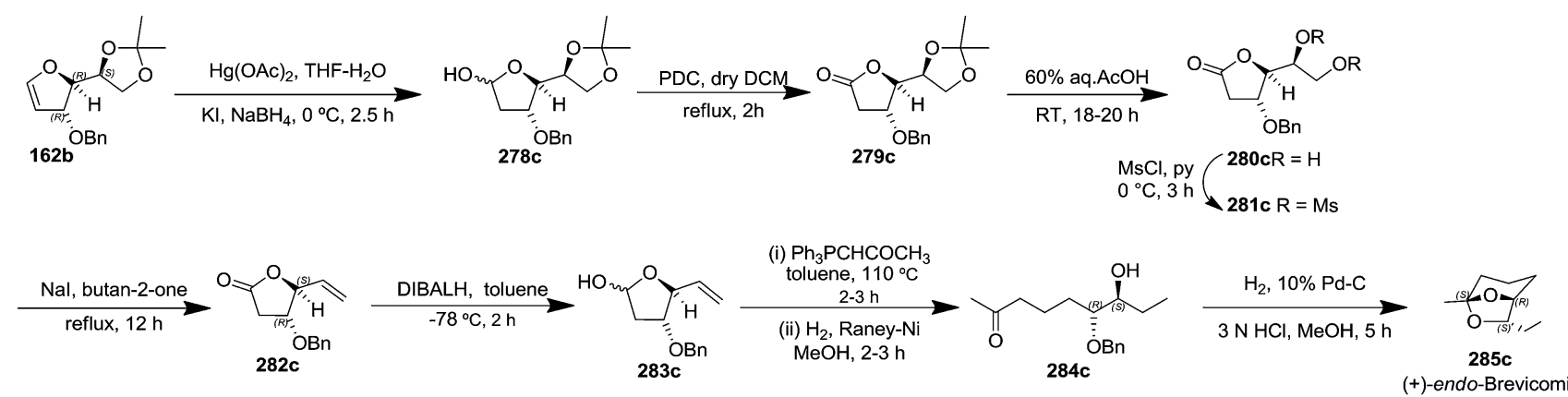

Scheme 49

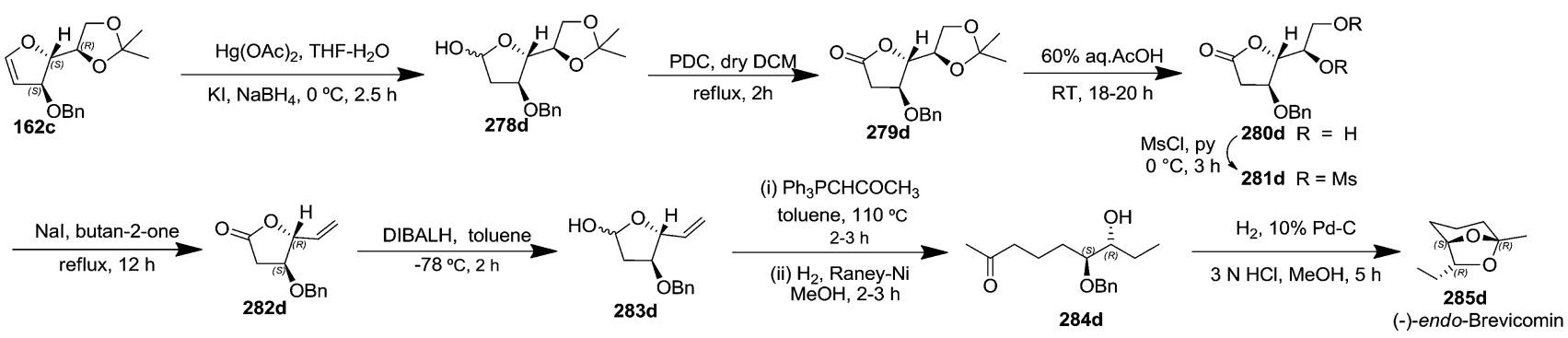

Scheme 50 
<smiles>C=C[C@H]1OC(=O)C[C@H]1OCc1ccccc1</smiles>

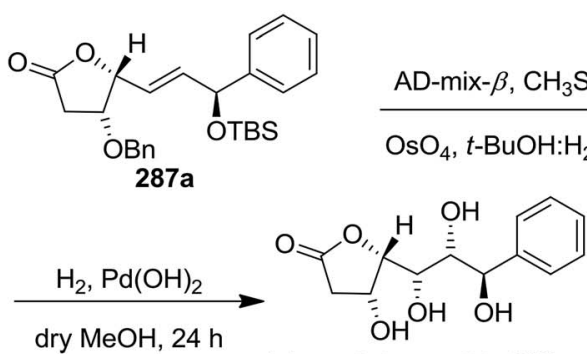

(+) cardiobutanolide 290a<smiles>O=C1C[C@H](O)[C@H]([C@H](O)[C@H](O)[C@H]([OH2+])c2ccccc2)O1</smiles>

288a

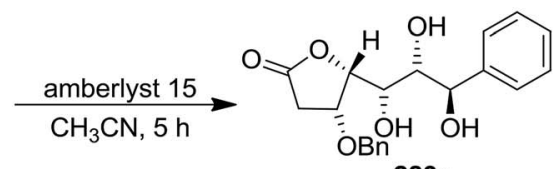

289a

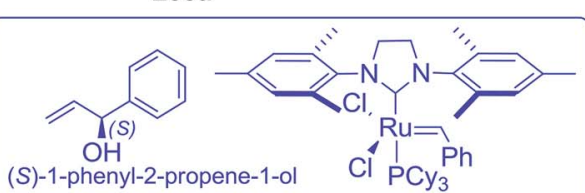

Grubbs' IInd generation catalyst

Scheme 51
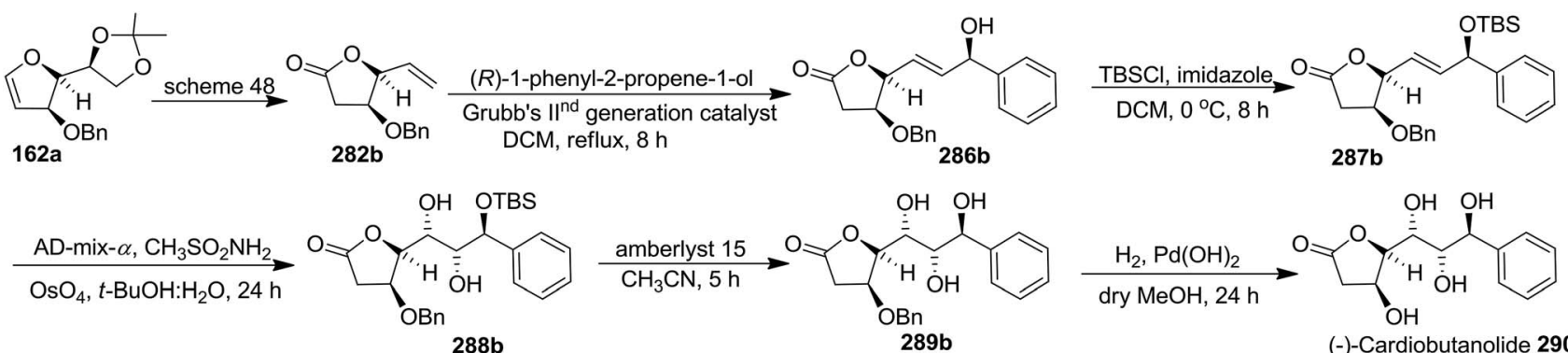

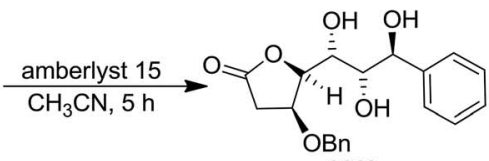

$289 b$

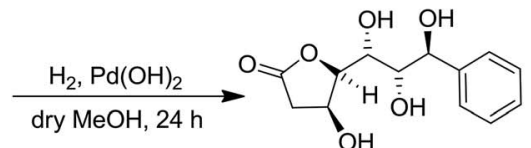

(-)-Cardiobutanolide 290b

Scheme 52<smiles>CC1(C)OC[C@H]([C@H]2CC=CO2)O1</smiles>
OBn

139

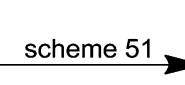<smiles>O=C1C[C@H]2O[C@H]([C@H](O)[C@H](O[Sb](=O)(=O)c3ccccc3)[C@H](O)c3ccccc3)[C@H]2O1</smiles>
三OH OTBS

288a

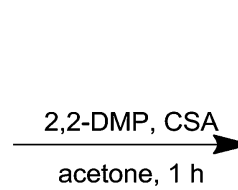

acetone, $1 \mathrm{~h}$

acetone, 1 h

\author{
(1)
}<smiles>CC1(C)C[C@H](OCc2ccccc2)[C@H]([C@H](O[SbH3])c2ccccc2)OC(C)(C)C1</smiles>

291a

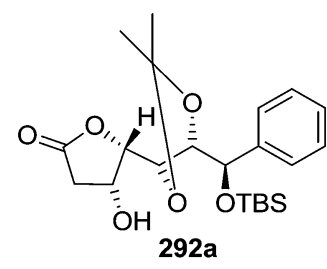

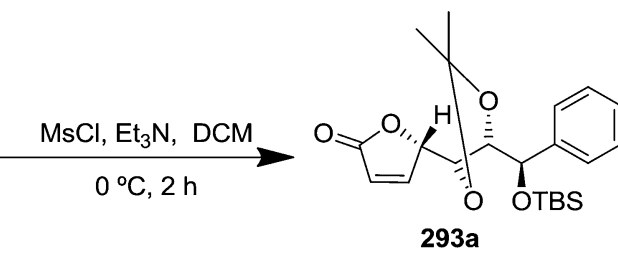

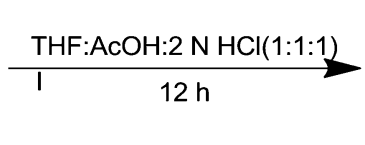<smiles>CC(C)(C)O[C@@H]([C@H]1C=CC(=O)O1)[C@H](O)[C@H](O)c1ccccc1</smiles>

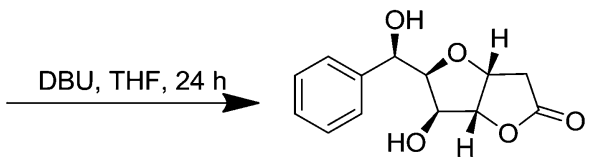

(+)-Goniofufurone 295a

Scheme 53 
desired natural product (+)-cardiobutanolide 290a in 67\% yield (Scheme 51).

Similarly, the (-)-cardiobutanolide 290b was synthesized from 162a, an optical antipode of 139 by adopting the reaction sequence similar to that employed for the synthesis of its enantiomer 290a. The olefin cross metathesis reaction between compound 282b derived from 162a (Scheme 48) and (R)-1phenyl-2-propene-1-ol with Grubb's $\mathrm{II}^{\text {nd }}$ generation catalyst $(2.8$ mol\%) furnished allylic alcohol $286 \mathrm{~b}$ in $\mathbf{7 4 \%}$ yield. Its silylated derivative $\mathbf{2 8 7 \mathrm { b }}$ on asymmetric dihydroxylation with AD-mix$\alpha$ in $1: 1 \mathrm{tBuOH}: \mathrm{H}_{2} \mathrm{O}$ afforded 288b. After having $\mathbf{2 8 8 b}$ in hand, the remaining two synthetic steps similar to that employed for the synthesis of (+)-cardiobutanolide 290a (vide supra) were followed to complete the synthesis of (-)-cardiobutanolide 290b (Scheme 52).

The acetonide protection of two free $\mathrm{OH}$ in 288a (obtained from furanoid glycal 139, Scheme 51) afforded globally OH protected derivative 291a in $83 \%$ yield. Its hydrogenolysis in the presence of $\mathrm{Pd}(\mathrm{OH})_{2}$ in dry EtOAc gave $O$-benzyl deprotected derivative 292a in $87 \%$ yield which on mesylation with $\mathrm{MsCl}^{-\mathrm{Et}_{3} \mathrm{~N}}$ at $0{ }^{\circ} \mathrm{C}$ in dry DCM for $2 \mathrm{~h}$ followed by elimination of $\mathrm{MsOH}$ under basic condition furnished the $\alpha, \beta$-unsaturated lactone 293a in $92 \%$ yield. Its treatment with $\mathrm{THF} / \mathrm{AcOH} / 2 \mathrm{~N} \mathrm{HCl}(1: 1: 1)$ at room temperature delivered the triol $294 \mathrm{a}$ in $56 \%$ yield. Finally, it was subjected to DBU catalyzed bicyclic ring formation by the participation of its $6-\mathrm{OH}$ to furnish the title natural product (+)-goniofufurone $295 \mathrm{a}$ as a white solid in $64 \%$ yield (Scheme 53 ).

\section{Some reactions of furanoid glycals}

\subsection{Peroxidation, osmylation, mercuration and bromination}

After describing the synthesis of furanoid glycal 24, 26 and 30 (Scheme 4), ${ }^{16 a}$ Bischofberger et al. in 1979 discussed some important reactions on furanoid glycals (1,4-anhydro-2-deoxy-3$O$-(2,3:5,6-di-O-isopropylidene- $\alpha$-D-mannofuranosyl)-5,6-O-isopropylidene-D-arabino-hex-1-enitol 24 and 1,4-anhydro-2-deoxy5,6-O-isopropylidene-D-arabino-hex-1-enitol $26 .{ }^{46}$ Oxidation of 26 with $m$-CPBA in absolute ethanol gave hex-2-enofuranosides 296 ( $26 \%$ yield), and also two ethyl furanosides 297 ( $7 \%$ yield) and 298 (15\% yield) by trans-ring opening of 1,2-epoxide intermediates. Under the identical reaction condition, furanoid glycal 24 afforded $\beta$-D-glucoside 299 as major product in $62 \%$ yield. Here the oxidant preferentially attacked from the $\alpha$-side to form 1,2-epoxide intermediate due to the $\beta-C$-3 bulky group (Scheme 54).

They further described that osmylation of 26 with $\mathrm{OsO}_{4}$ in pyridine, followed by cleavage of osmate ester and acetylation gave column purified $\beta$-D- and $\alpha$-D-glucofuranoses, $300(30 \%$ yield) and 301 (17\% yield), respectively, indicating that attack by the oxidant took place mainly from the $\alpha$-face. Similarly, osmylation reaction of the glycal $\mathbf{2 4}$, followed the same reaction sequence to form isolated anomeric gluco-furanoses $302(14 \%$ yield) and 303 (26\% yield) and a mixture of manno-furanoses 304 (gluco : manno, $7: 1$ ).

Methoxymercuration of 26 with $\mathrm{Hg}(\mathrm{OAc})_{2}$ in dry methanol, followed by demercuration with $\mathrm{NaBH}_{4}$ and acetylation yielded 2- deoxy derivatives 305 and 306 respectively. Methoxymercurationdemercuration of $\mathbf{2 4}$ furnished only one product $\mathbf{3 0 7}$ having the anomeric methoxy group in $\beta$-configuration.

Ethoxybromination of $\mathbf{2 6}$ with $\mathrm{N}$-bromosuccinimide (NBS) in acetonitrile-ethanol, followed by acetylation produced mainly the ethyl- $\beta$-D-glucoside 308 (28\% yield), with the $\alpha$-D-glucoside 309 (3\% yield) with other minor side products ( $6 \%$ yield). Debromination of 308 and 309 with $n \mathrm{Bu}_{3} \mathrm{SnH}$ in the presence of AIBN in benzene afforded 2-deoxy derivatives $\mathbf{3 1 0}$ and $\mathbf{3 1 1}$ respectively. Ethoxybromination of $\mathbf{2 4}$ furnished a mixture of ethyl-2-bromo-2-deoxy-furanosides $\mathbf{3 1 2}$ (19\% yield) and an anomeric mixture of a 2-bromo-2-deoxy-furanose 313. Acetylation of $\mathbf{3 1 3}$ gave separable anomeric acetates having $\beta$-D-gluco configuration 314 and $\alpha$-D-gluco configuration 315 respectively, whose debromination formed $\mathbf{3 1 6}$ and $\mathbf{3 1 7}$ respectively and debromination of $\mathbf{3 1 2}$ yielded 318 (Scheme 54).

In 1987, Dax et al. demonstrated the reaction of acetyl hypofluorite $\left(\mathrm{CH}_{3} \mathrm{CO}_{2} \mathrm{~F}\right)$ with pyranoid and furanoid glycals and they observed that more stereospecific reactions took place with furanoid glycals. Treatment of 1,4-anhydro-2-deoxy-5,6-O-isopropylidene-D-arabino-hex-1-enitol ${ }^{16,19} 26$ or 1,4-anhydro-2-deoxy5-O-methoxymethyl-D-erythro-pent-1-enitol ${ }^{4} 45$ with gaseous acetyl hypofluorite in DCM-hexane at room temperature gave a complex mixture of compounds. Among them 1-O-acetyl-2-deoxy-2-fluoro5,6-O-isopropylidene- $\beta$-D-mannofuranose 319 was obtained from 26 in $47 \%$ yield and 1-O-acetyl-2-deoxy-2-fluoro-5-O-methoxymethyl- $\alpha$-D-ribofuranose $\mathbf{3 2 2}$ from $\mathbf{4 5}$ in $30 \%$ yield as major products (Scheme 55). ${ }^{47}$

On the other hand, while 3-O-benzyl derivative 139 (ref. 31 and 35-37) (derived from glycal 26), on treatment with gaseous acetyl hypofluorite led to the formation of only 1-O-acetyl-3-O-benzyl-2deoxy-2-fluoro-5,6-O-isopropylidene- $\alpha$-D-glucofuranose 320 , and 323 from the glycal 45 , under the identical reaction conditions formed two fluorinated products viz. 1-O-acetyl-3-O-benzyl-2deoxy-2-fluoro-5-O-methoxymethyl- $\beta$-D-arabinofuranose 324 and its analogue 325. Compounds $\mathbf{3 2 0}$ and $\mathbf{3 2 4}$ were debenzylated to afford 1-O-acetyl-2-deoxy-2-fluoro-5,6-O-isopropylidene- $\alpha$-D-glucofuranose 321 and 1-O-acetyl-2-deoxy-2-fluoro-5-O-methoxymethyl- $\beta$-D-arabinofuranose 326, respectively (Scheme 55 ). They concluded from this study that free 3-OH of $\mathbf{2 6}$ and $\mathbf{4 5}$ induced the exclusive syn addition of acetyl hypofluorite across the double bond to afford their respective compounds 319 and 322, whereas benzyloxy derivatives $\mathbf{1 3 9}$ and $\mathbf{3 2 3}$ caused attack from the lesshindered opposite face of the double bond to afford 320 and 324 respectively.

\subsection{Cycloaddition reaction}

4.2.1. Diels-Alder reaction. In 1987, Leblanc et al. discussed a new and efficient method for the preparation of 2deoxy-2-aminoglycosides in high yields by stereoselective [4+2] cycloaddition reaction of dibenzyl azodicarboxylate $\left(\mathrm{BnO}_{2} \mathrm{C}-\right.$ $\mathrm{N}=\mathrm{N}-\mathrm{CO}_{2} \mathrm{Bn}$ ) on the appropriate glycals (Scheme 56, Table 7). ${ }^{48}$ Irradiation of glycals (327, 66f, 214 and 336) with dibenzyl azodicarboxylate (DBAD) in cyclohexane at $350 \mathrm{~nm}$ for $18 \mathrm{~h}$ gave single [4+2] cycloadduct $(\mathbf{3 2 8}, \mathbf{3 3 1}, 333$ and 337) respectively. Treatment of these cyclo adducts with a catalytic amount of 


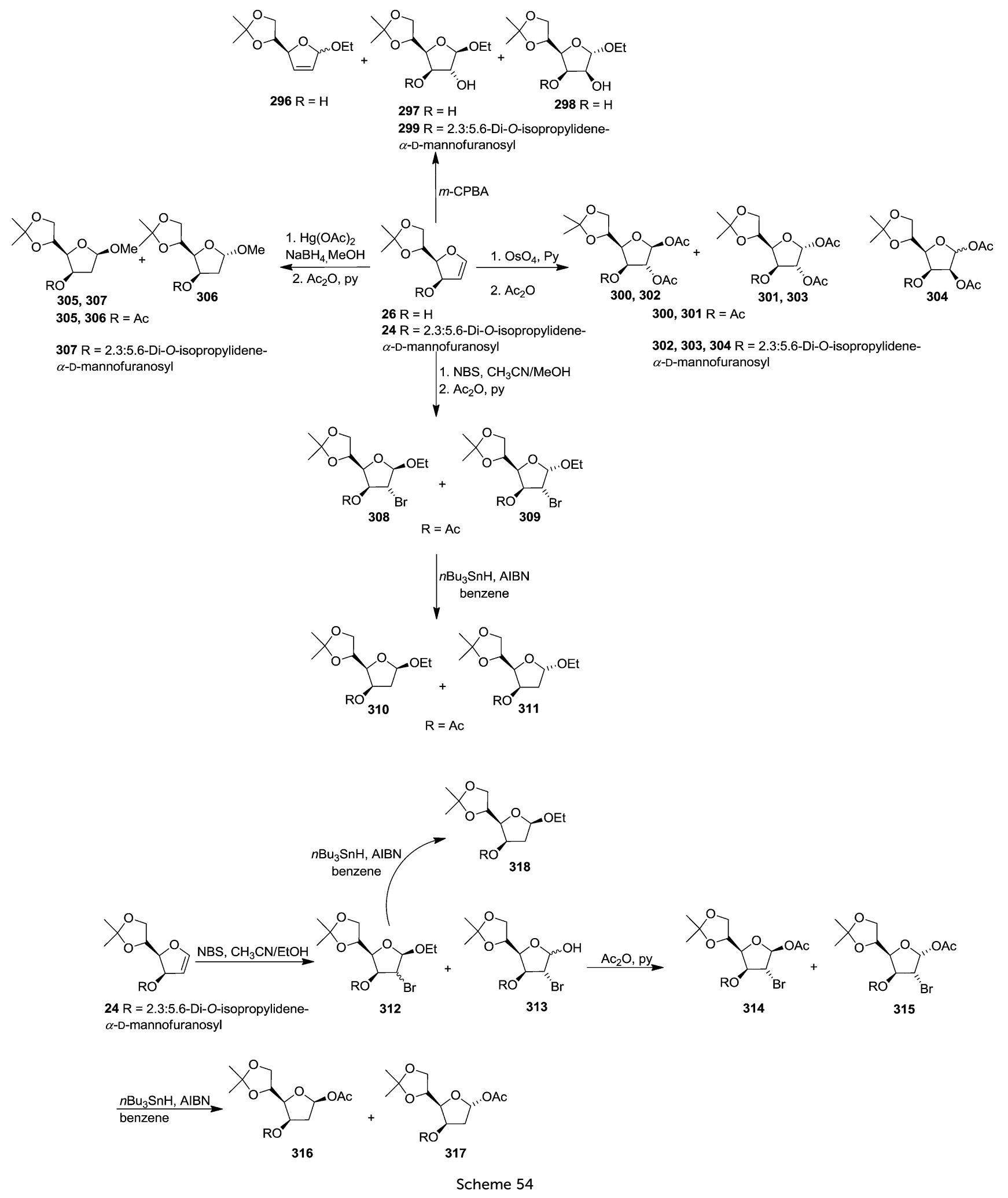

PTSA in $\mathrm{MeOH}$ led to opening at C-1 with inversion of stereochemistry to afford the corresponding methyl glycosides (329, $332,334,338)$ in quantitative yield. Hydrogenolysis of the protected hydrazines gave the 2 -amino glycosides $(330,335,339)$ in high yields (Scheme 56).
Since amino sugars present in natural products are usually in the pyranoside form, that's why they also showed the conversion of furanoside 342 into pyranoside 343 (Scheme 57). ${ }^{48}$ Later they reported similar reactions with several pyranoid glycals to obtain 2 -amino pyranosides. ${ }^{49}$ 

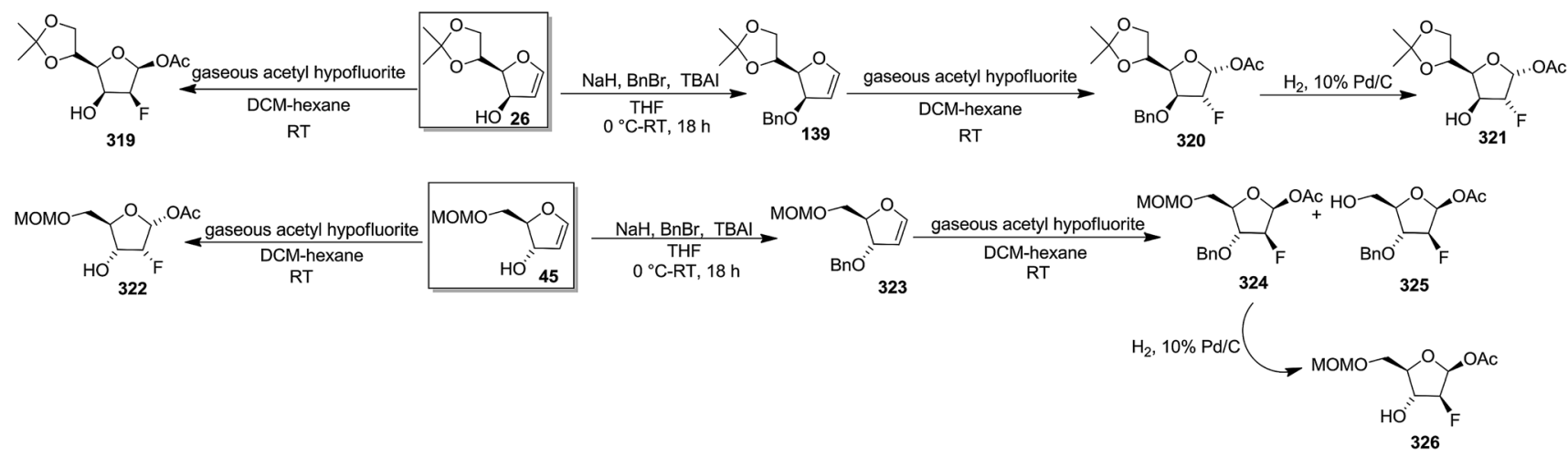

Scheme 55

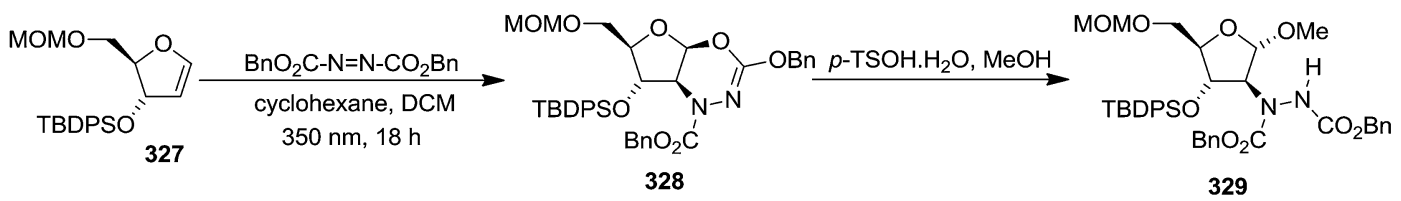
(i) Raney Ni, W-2, $\mathrm{H}_{2} 40 \mathrm{PSI}$ $\mathrm{MeOH}-\mathrm{AcOH}$ (60:1) (ii)TBAF, THF<smiles>NCCO</smiles>
(iii) $\mathrm{AcCl}, \mathrm{MeOH}(4 \mathrm{~N} \mathrm{HCl})$

330

Scheme 56

Table 7 Preparation of 2-deoxy-2-aminoglycosides

(1)

${ }^{a}$ The hydrogenolysis was performed on the free diol obtained by desilylation of compound $332\left(n-\mathrm{Bu}_{4} \mathrm{NF} 10\right.$ equiv, AcOH 3 equiv, THF, $\left.90 \%\right)$.

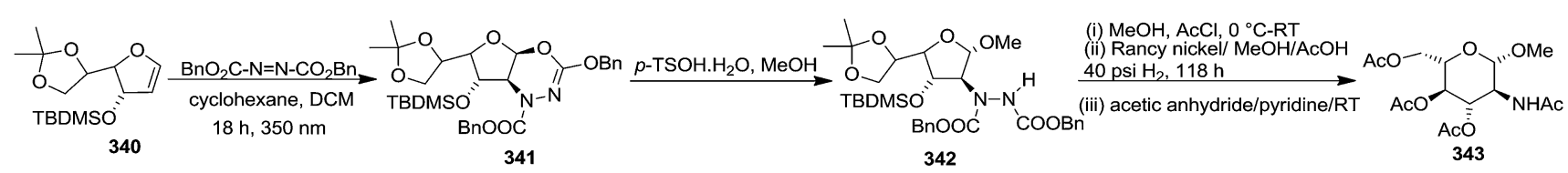

Scheme 57 
In 1993, Chmielewski et al. showed [2+2] cycloaddition of trichloroacetyl isocyanate to furanoid glycals. Here, the preferential attacked of the reagent to the substrate was governed by the stereochemistry of the C-3 substituent. They selected furanoid glycals 139, 65a and 89 which on treatment with trichloroacetyl isocyanate in acetonitrile at room temperature afforded a mixture of [2+2] cycloadducts (344-346) and [4+2] cycloadducts (347-349) in a $1: 1$ ratio in each case. Deprotection of the nitrogen atom in (344-346) produced stable bicyclic $\beta$-lactams (350-352). The $\alpha$-D-gluco configuration for 350 and $\beta$-D-arabino configuration for 351 and 352 confirmed cycloaddition proceeded exclusively anti to the C-3 substituent (Scheme 58)..$^{50}$

4.2.2. Radical cyclization. Sharma and coworkers described a protocol involving intramolecular radical cyclization of furanoid glycal derived $\alpha$-halogeno acetal derivatives. ${ }^{36}$ Furanoid glycal 26 was silylated with TBSCl or TBDMSCl in the presence of imidazole in DMF yielded 214 in 83\%. Treatment of 214 with NBS in the presence of respective propargylic and allylic alcohols viz. 2-propyn-1-ol, 2-methyl-3-butyn-2-ol, 2-propen-1-ol, and 2-methyl-2-propen-1-ol resulted in stereoselective formation of 1,2-trans- $\beta$-D-glycosides, 353, 355, 357 and 359 respectively as major products and 354, 356, 358 and 360 as minor products. The crucial regio- and stereo-selective intramolecular $\mathrm{C}-\mathrm{C}$ bond formation on 353, 355, 357 and 359 was efficiently achieved by treating each with a catalytic amount of $n \mathrm{Bu}_{3} \mathrm{SnCl}$ and AIBN in the presence of $\mathrm{NaBH}_{3} \mathrm{CN}$ in refluxing $t \mathrm{BuOH}$ to afford the respective cis-fused bicyclic acetals (361364) in 30-72\% yield by a preferred 5-exo mode of cyclization. During the radical cyclisations, the propargylic glycosides 353 and 355 gave 361 and 362 as exclusive products, while the allylic glycosides 357 and 359 gave the expected cyclized products 363 and 364 along with the 2-deoxy compounds 365 and 366 respectively (Scheme 59).

\subsection{Wittig rearrangement}

Gesson et al. studied ${ }^{51}$ the [2,3]-Wittig rearrangement of 369, 375,379 derived from furanoid glycals 26, 367, 53b which were easily derived from D-mannose, L-gulonic- $\gamma$-lactone and $\mathrm{D}^{-}$ ribonic- $\gamma$-lactone respectively. ${ }^{19,20 a}$ The C-3 free hydroxyl group of these furanoid glycals $(\mathbf{2 6}, \mathbf{3 6 7}, \mathbf{5 3 b})$ was alkylated with propargyl bromide in the presence of NaH in THF to form 368 , 374, 378 which on treatment with $n \mathrm{BuLi}$ (1.1 eq.) in THF at
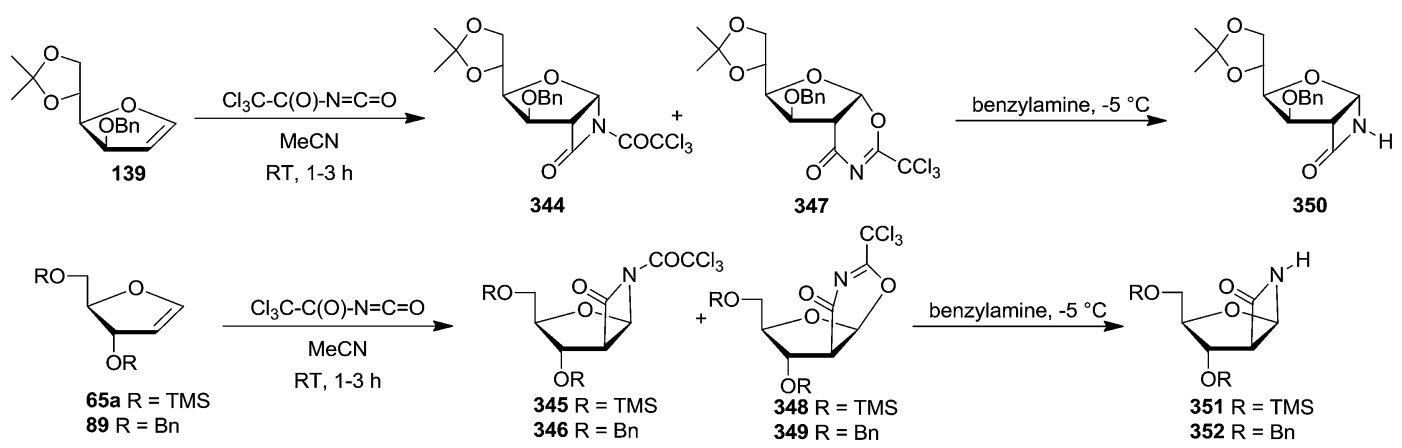

Scheme 58
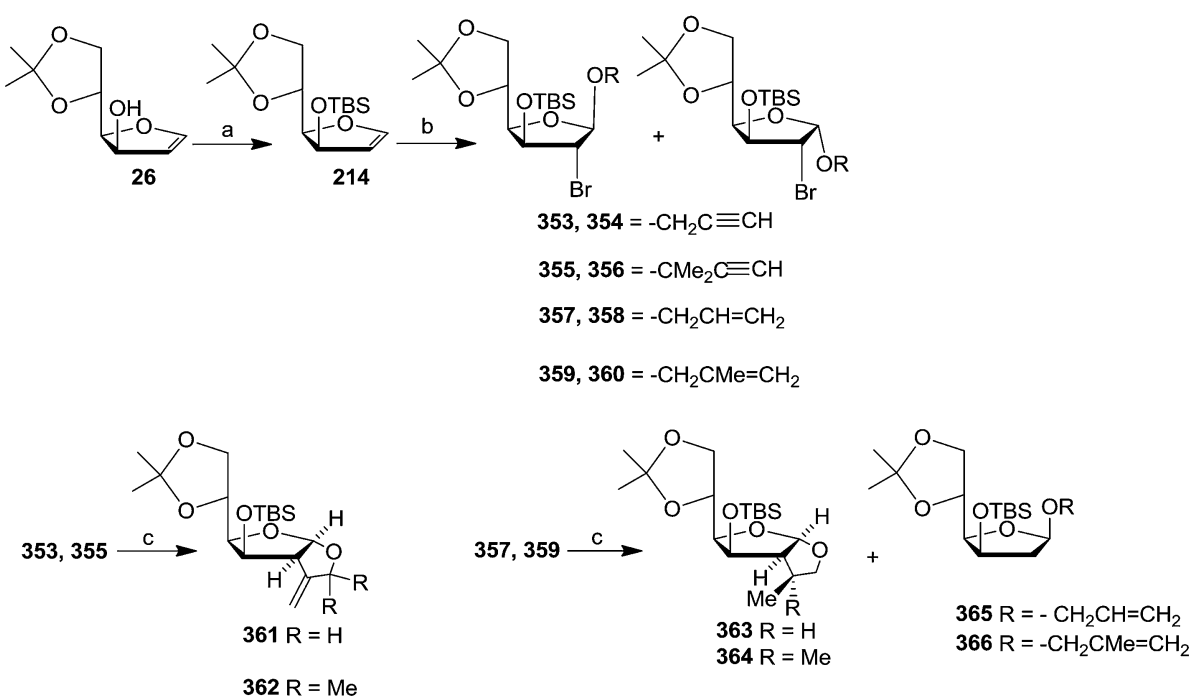

Scheme 59 Reagents and conditions: (a) TBSCl, imidazole, DMF, 83\%; (b) NBS, 10 equiv. 2-propyn-1-ol (for 353, 354), 2-methyl-3-butyn-2-ol (for 355,356 ), 2-propen-1-ol (for 357, 358), and 2-methyl-2-propen-1-ol (for 359, 360) respectively; (c) $n \mathrm{Bu}_{3} \mathrm{SnCl}_{1} \mathrm{AlBN}_{1} \mathrm{NaBH} \mathrm{CNN}_{3}, \mathrm{BuOH}, \mathrm{reflux}$. 
$-78{ }^{\circ} \mathrm{C}$ followed by addition of TMSCl $\left(1.1\right.$ eq., $-78{ }^{\circ} \mathrm{C}$ to $\left.-5{ }^{\circ} \mathrm{C}\right)$ afforded 369, 375, 379 respectively. These trimethylsilylpropargyl ethers of furanoid glycals 369, 375, 379 were used in a one-pot [2,3]-Wittig rearrangement by addition of a further 1.1 eq. of $n \mathrm{BuLi}$ at $-5{ }^{\circ} \mathrm{C}$. The glycal derivative 369 , under the identical reaction condition produced easily separable mixture of 370 and 371 in a $7: 3$ ratio with $61 \%$ overall isolated yield from 26. The formation of the major isomer with erythro configuration was confirmed by converting 370 and 371 into 372 and 373 respectively through sequence of reactions involving desilylation, benzoylation followed by hydrogenation. The rearrangement of 375 afforded 376 and 377 with higher selectivity in $9: 1$ ratio but in lower overall yield (40\%) from 367. Under the same conditions, $\mathbf{3 7 9}$ gave an inseparable mixture of 380 and 381 in a $2: 1$ ratio (Scheme 60).

\subsection{Reverse polarity strategy}

Parker and Su, utilized "Reverse Polarity" strategy for the synthesis of C-aryl furanosides from furanoid glycals. ${ }^{52}$ They started with furanoid glycal 66e for the synthesis of C-1 aryl arabino-furanosides $(385 \mathrm{a}-\mathbf{c})$. Lithiation of $66 \mathrm{e}$ with $t \mathrm{BuLi}$ and addition of the resulting reagent to quinone ketal 382 gave quinol ketal 383, which without further purification was treated with sodium dithionite to afford C-aryl glycal. But instead of that, quinol 384a, the hydrolysis product, was obtained in 53\% yield. However, the reductive aromatization and antiMarkovnikov hydration was made possible by treating crude 383 with borane-THF followed by stirring with $\mathrm{NaOH} / \mathrm{H}_{2} \mathrm{O}_{2}$ and acylation to obtain $2^{\prime}$-acetate 385 a in an $40 \%$ overall yield from glycal 66e (Scheme 61).

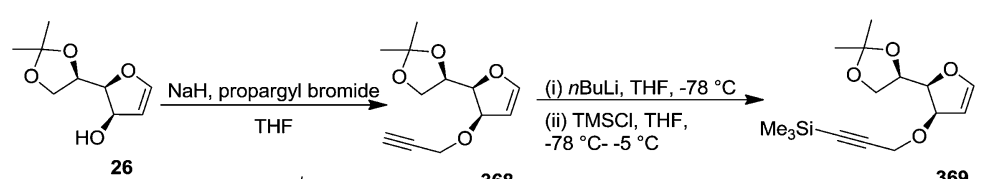

26

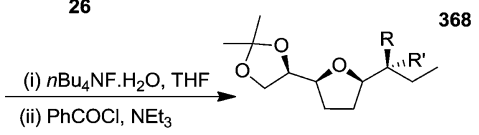

(iii) $\mathrm{H}, \mathrm{Pd} / \mathrm{C}$, benzent

$372 \mathrm{R}=\mathrm{OCOPh}, \mathrm{R}^{\prime}=\mathrm{H}$
$373 \mathrm{R}=\mathrm{H}, \mathrm{R}^{\prime}=$ OCOPh

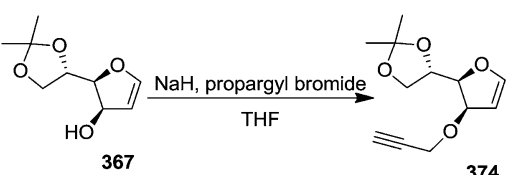

374

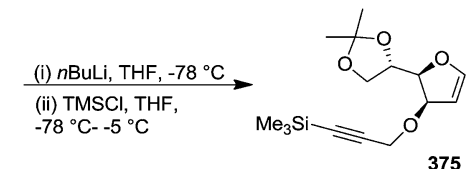

375

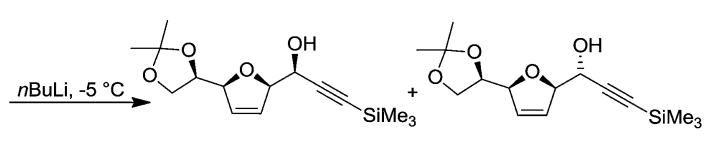

370

371

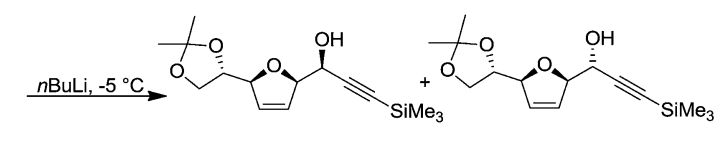

377

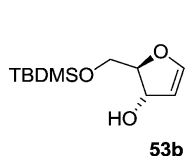

$\frac{\mathrm{NaH}, \text { propargy }}{\mathrm{THF}}$

$53 b$

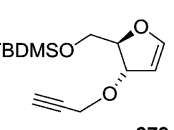

378

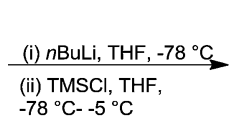
(ii) TMSCl, THF,
$-78{ }^{\circ} \mathrm{C}--5^{\circ} \mathrm{C}$

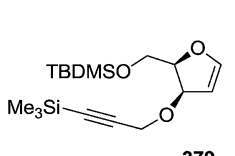

379

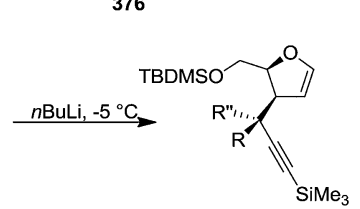

$380 \mathrm{R}=\mathrm{H}, \mathrm{R}^{\prime \prime}=\mathrm{OH}$ $381 \mathrm{R}=\mathrm{OH}, \mathrm{R}^{\prime \prime}=\mathrm{H}$

Scheme 60

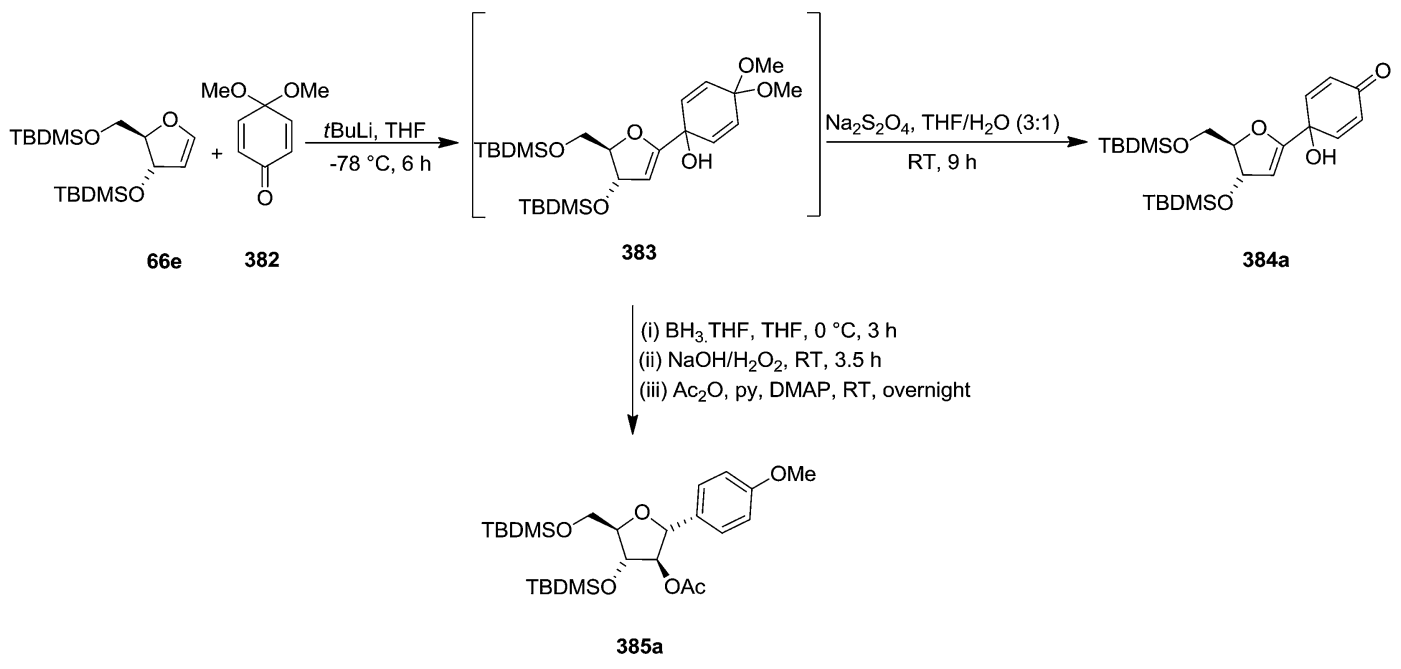

Scheme 61 

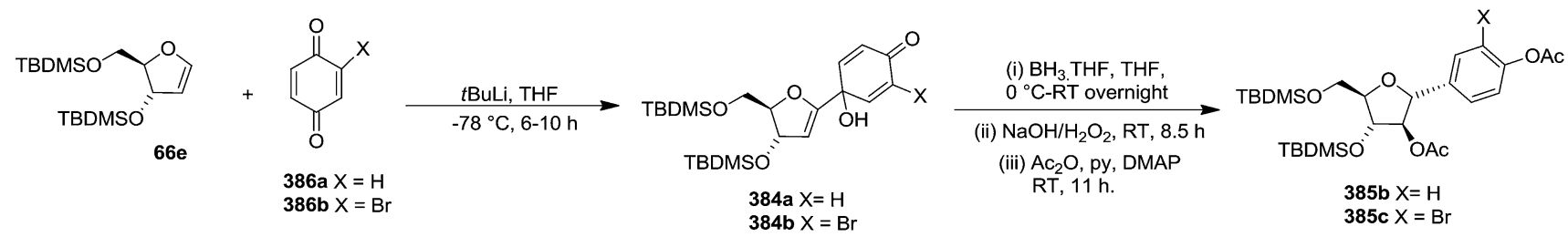

Scheme 62

By utilizing same reaction sequence, they synthesized C-aryl furanosides 385b and 385c in good yields starting from furanoid glycal 66e, via intermediates (384a-b) (Scheme 62).

They have also reported the synthesis of C-1 aryl glucofuranosides 389, 390, 391 in good yields from furanoid glycal 214, by utilizing same reaction sequence (Schemes 63 and 64).

\subsection{Metal mediated amination}

Carrier and group have synthesized stereoselectively 2-amino saccharides through metal-mediated amination of glycal substrates. They studied this reaction on differently protected pyranoid and furanoid glycals by utilizing (saltmen)Mn(N) and TFAA to transfer $\mathrm{CF}_{3} \mathrm{CON}$ unit to electron rich silyl enol ethers. The oxazoline 393 was isolated on treatment of furanoid glycal<smiles>COC1(OC)C=CC(=O)C=C1</smiles>

(i) $\mathrm{BH}_{3} \mathrm{THF}, \mathrm{THF}, 0^{\circ} \mathrm{C}, 3 \mathrm{~h}$

(ii) $\mathrm{NaOH} / \mathrm{H}_{2} \mathrm{O}_{2}$, r.t, $3.5 \mathrm{~h}$

(iii) $\mathrm{Ac}_{2} \mathrm{O}$, py, DMAP, r.t, overnight.<smiles>COc1ccc([C@H]2O[C@H](C3COC(C)(C)O3)[C@H](OC(C)=O)[C@H]2OC(C)(C)C)cc1</smiles>

Scheme 63<smiles>[Z10]OC1CCOC1[C@H]1COC(C)(C)O1</smiles>

$+$ 214 $386 b X=$

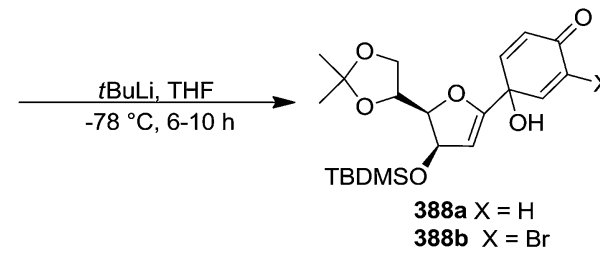

(i) $\mathrm{BH}_{3} \mathrm{THF}, \mathrm{THF}$ (ii) $\mathrm{NaOH} / \mathrm{H}_{2} \mathrm{O}_{2}, \mathrm{RT}, 8.5 \mathrm{~h}$ (iii) $\mathrm{Ac}_{2} \mathrm{O}$, py, DMAP, RT,11 h.

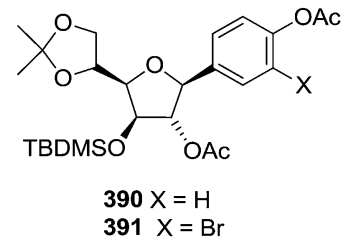

Scheme 64

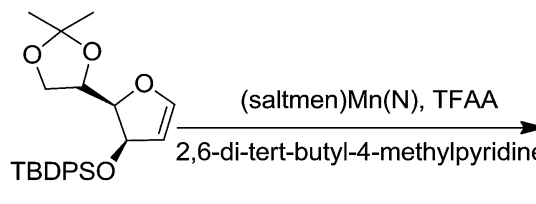

392<smiles>[3H]C1=N[C@@H]2C(O[R5]C(C)C)C([C@H]3COC(C)(C)O3)O[C@@H]2O1</smiles>

393<smiles>CC(C)CO[C@H]1C([C@H]2COC(C)(C)O2)O[C@@H](O)[C@H]1NC(=O)C(F)(F)F</smiles>

394

Scheme 65 


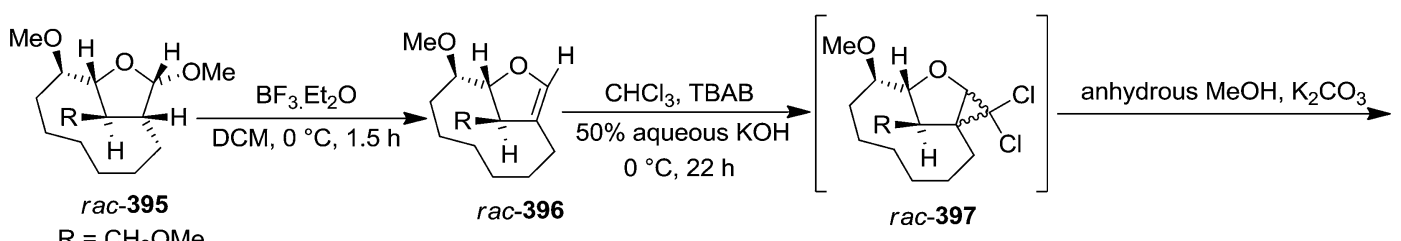

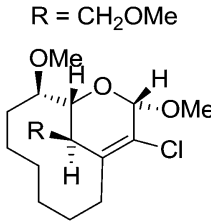

rac-398

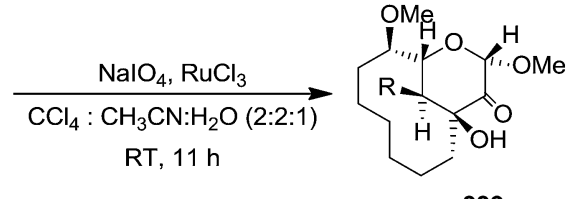

rac-399

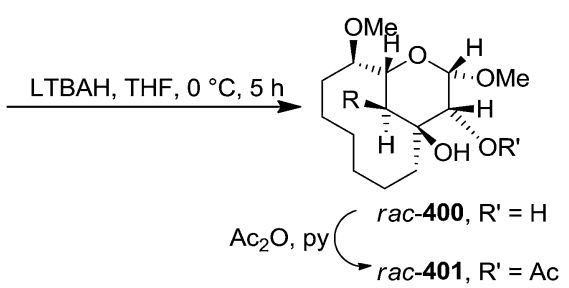

Scheme 66

392 with (saltmen)Mn(N) and TFAA, which, under mild acidic conditions furnished the N-protected amino alcohol 394. Its structure was confirmed by converting it back to the oxazoline 393 upon treatment with $\mathrm{MsCl}, \mathrm{Et}_{3} \mathrm{~N}$, DCM (Scheme 65). ${ }^{53}$

\subsection{Ring expansion}

In 2000 Totchtermann et al. reported the formation of heptanobridged pyranosides by ring enlargement of the glycal rac-396, ${ }^{54}$ which was prepared from heptano bridge methyl furanoside rac395 by treatment with $\mathrm{BF}_{3} \cdot \mathrm{Et}_{2} \mathrm{O}$ in $\mathrm{DCM}$ in $95 \%$ isolated yield. Treatment of $r a c-396$ with $50 \%$ aq. $\mathrm{KOH}$ in the presence of catalytic amounts of $n \mathrm{Bu}_{4} \mathrm{NBr}$ in $\mathrm{CHCl}_{3}$ for $22 \mathrm{~h}$ at $0{ }^{\circ} \mathrm{C}$ afforded dichloro intermediate derivative $\mathrm{rac}$-397, which was without further purification refluxed in anhydrous methanol with a large excess of $\mathrm{K}_{2} \mathrm{CO}_{3}$ to give chloro- $2 \mathrm{H}$-pyran $\mathrm{rac}-398$ in $60 \%$ isolated yield over two steps. Oxidation of $r a c-398$ with $\mathrm{RuO}_{4}$ yielded $r a c-399$ in $67 \%$. The stereoselective reduction of rac-399 with LTBAH provided the methyl pyranoside rac-400 in 71\% isolated yield, which was transformed into corresponding acetate rac-401 in 90\% yield (Scheme 66).

\section{Synthesis of $C$-nucleosides}

The synthesis of nucleoside analogues having modified sugar and/ or nucleobases moieties has received much attention because of their general biological activities ${ }^{55}$ and potential use as antiviral ${ }^{56,57}$ and antineoplastic ${ }^{58}$ therapeutic agents. Over the last few decades, deoxynucleosides have attracted the attention of many research groups due to their antiviral and antitumor activities. They are also important components of antisense oligonucleotides.

The $2^{\prime}$-deoxynucleosides such as $3^{\prime}$-azido- $2^{\prime}, 3^{\prime}$-dideoxythymidine (AZT), 2', $3^{\prime}$-dideoxyinosine (ddI), 2',3'-didehydro$2^{\prime}, 3^{\prime}$-dideoxythymidine ( $\left.\mathrm{d} 4 \mathrm{~T}\right)$ and related analogues have shown potent antiviral activity, particularly against human immunodeficiency virus (HIV) (Fig. 4), which is the causative agent for acquired immune deficiency syndrome (AIDS). ${ }^{59}$

Nucleosides are generally considered to be compounds which contain a heterocyclic aglycon and a carbohydrate moiety that are joined together by a carbon-nitrogen bond. However, $C$-nucleosides differ from the more common nucleosides in that the sugar and heterocyclic aglycon are connected by a $\mathrm{C}-\mathrm{C}$, rather than a $\mathrm{C}-$ $\mathrm{N}$, bond.$^{60}$ From the last few years synthesis of $\mathrm{C}$ or $\mathrm{N}$-nucleosides and nucleoside analogues by utilizing furanoid glycals as the key intermediates has also received much attention in research. In this overview we have discussed as one of the important application of furanoid glycals for synthesis of $\mathrm{C}$ and $\mathrm{N}$-nucleosides.

To synthesize different $C$-nucleosides Daves Jr and his group contributed a lot in the field of nucleoside chemistry by utilizing differently substituted furanoid glycal.<smiles>Cc1cn([C@H]2C[C@H](N)[C@@H](CO)O2)c(=O)[nH]c1=O</smiles>

AZT<smiles>Nc1ccn([C@H]2C[C@H](N)[C@@H](CO)O2)c(=O)n1</smiles>

3'-Amino-2', 3'-dideoxycytidine<smiles>Cc1cn([C@H]2C=C[C@@H](CO)O2)c(=O)[nH]c1=O</smiles>

d4T<smiles>Nc1ncn([C@H]2C[C@H](O)[C@@H](CO)O2)c(=O)n1</smiles><smiles>O=c1nc[nH]c2c1ncn2[C@H]1C[C@H](CO)O[C@H]1CCl</smiles><smiles></smiles>

Telbivudine

Fig. 4 Structures of some $2^{\prime}$-deoxynucleosides have potent antiviral activity, particularly against human immunodeficiency virus (HIV). 
In 1983 Daves Jr and Hacksell showed Heck coupling reactions of furanoid glycals 404-407, 45, 54a, 54b with (1,3-dimethyl-2,4-dioxo1,2,3,4-tetrahydrimidin-5-yl)mercuric acetate $\mathbf{4 0 2}$ in the presence of a stoichiometric quantity of $\mathrm{Pd}(\mathrm{OAc})_{2}$ resulted in regio- and stereospecific formation of $\alpha$ or $\beta$ - $C$-nucleosides (408-414) through an initial transmetalation leading to an organopalladium reagent which subsequently adds to the olefinic double bond in a syn fashion to form adducts (409A-414A) (Scheme 67). ${ }^{6}$ These are reasonably stable and decomposed to $\alpha$ or $\beta$ - $C$-nucleosides (409-414) via syn elimination of hydropalladium. The more stable adduct $\mathbf{4 1 2 A}$ among them on treatment with hydrogen for $8 \mathrm{~h}$ was resulted in $2^{\prime}$-deoxy $\mathrm{C}$ nucleoside 412B. In this report, they demonstrated the direction of addition of organopalladium reagent to transsubstituted furanoid glycals $(\mathbf{4 5}, \mathbf{5 4 a}, \mathbf{5 4 b})$ which was depended

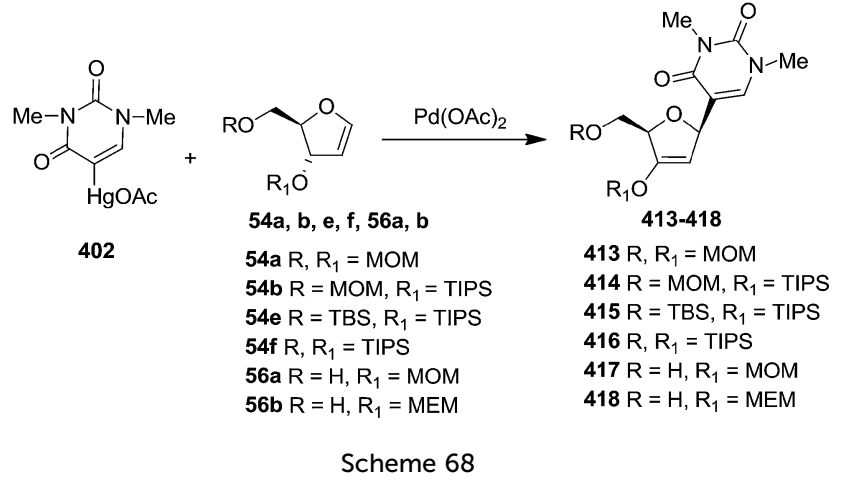

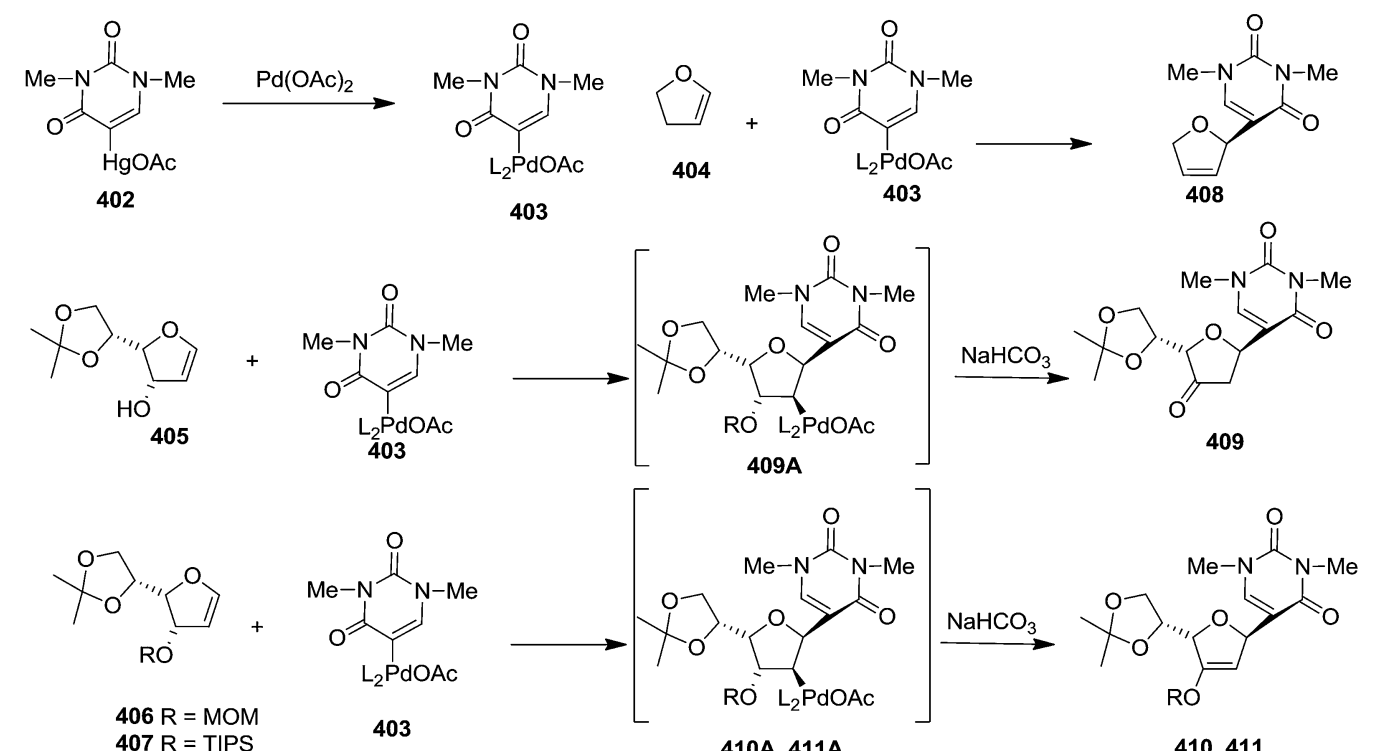

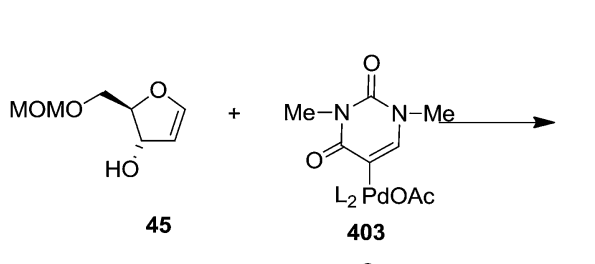

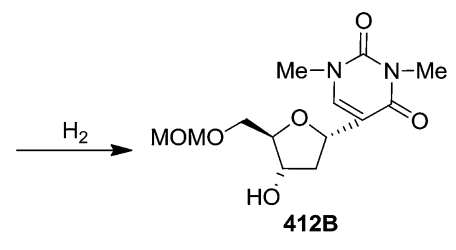

410A, 411A

410, 411<smiles>COC[C@H]1O[C@@H](c2cn(C)c(=O)n(C)c2=O)[C@H](O)[C@@H]1OC(C)=O</smiles><smiles>COC[C@H]1O[C@@H]2O[C@H](c3cn(C)c(=O)n(C)c3=O)[C@H]12</smiles>

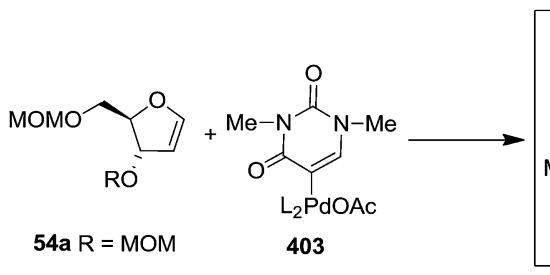

54b $R=$ TIPS<smiles>[R20][C@H]1[C@@H](c2cn(C)c(=O)n(C)c2=O)O[C@H](COC)[C@H]1OC(C)=O</smiles>

413A, 414A
$\mathrm{NaHCO}_{3}$ or DIPEA or $\mathrm{K}_{2} \mathrm{CO}_{3}$<smiles>COC[C@H]1C=C[C@H](c2cn(C)c(=O)n(C)c2=O)[C@H]1CNC(=O)[O-]</smiles>

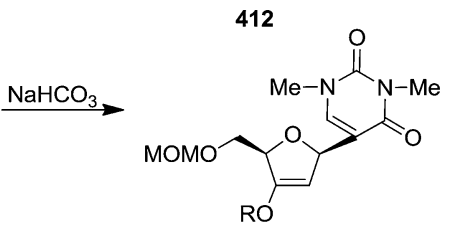

413, 414 
on the steric bulk of C3 and C4 substituents of the corresponding trans-furanoid glycals to form $C$-nucleosides (412414). Organopalladium reagent always attacked from less sterically hindered site of the furanoid glycals. With cissubstituted glycals (405-407), the attack occured on the unsubstituted face of the ring to form $C$-nucleosides (409-411).

This research group after reported the synthesis of differently substituted furanoid glycals ${ }^{20 a}$ and $\alpha$-or $\beta$ - $C$-nucleosides, they further extended their study to show that when both the 3and 5-hydroxyls are identically substituted e.g. 54a and 54f, the organopalladium reagent attacked from $\beta$-face to form $\mathbf{4 1 3}$ and $\mathbf{4 1 6}$ respectively. Thus, it indicated that the reaction was more sensitive to the steric bulk of the substituent at the allylic position (C3) than to that at position $\mathrm{C} 5$ of the furanoid glycal. Use of very bulky group at $\mathrm{C} 3$ for $\mathbf{5 4 b}, \mathbf{5 4 e}$ also yielded $\beta$ - $C$ nucleoside 414, 415 respectively. The furanoid glycals 56a and 56b whose $3-\mathrm{OH}$ was substituted and $5-\mathrm{OH}$ was free led only to $\beta$ - $C$-nucleosides 417 and 418 respectively (Scheme 68). ${ }^{61}$

The methoxymethyl group of $C$-nucleoside of 413 was removed under acidic condition to form 419a and/or 420. $O$ trialkylsilyl $\beta$ - $C$-nucleosides 414 and 416 on treatment with TBAF in the presence of $\mathrm{AcOH}$ in $\mathrm{THF}$ at $-78{ }^{\circ} \mathrm{C}$ yielded $419 \mathrm{a}$ and $419 \mathrm{~b}$ and/or 421 respectively. The removal of $(\beta-$ methoxyethoxy)methyl group in $\mathbf{4 1 8}$ by using zinc bromide ${ }^{\mathbf{1 4}}$ resulted in migration of the ( $\beta$-methoxyethoxy)methyl group from the $3^{\prime}-O$ to the $5^{\prime}-O$ to form $419 \mathrm{c}$ along with 421 .

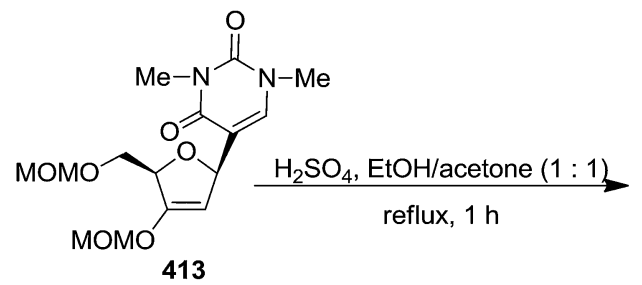<smiles>COCC(O)C(=O)/C=C/c1cn(C)c(=O)n(C)c1=O</smiles>

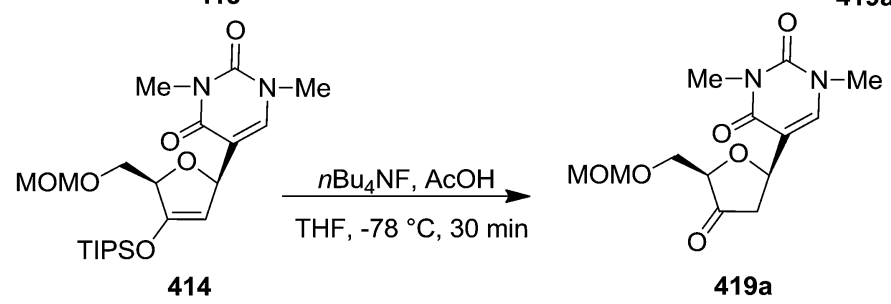

420

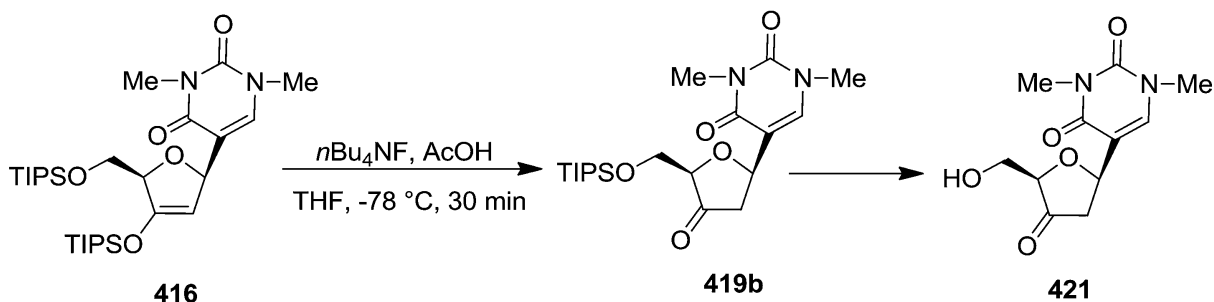

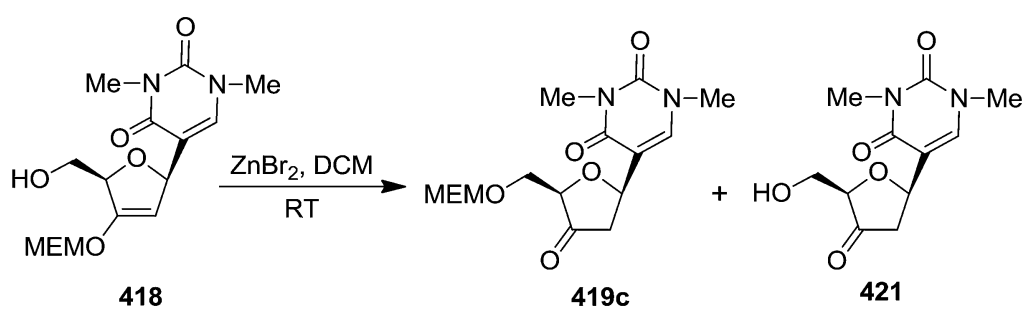

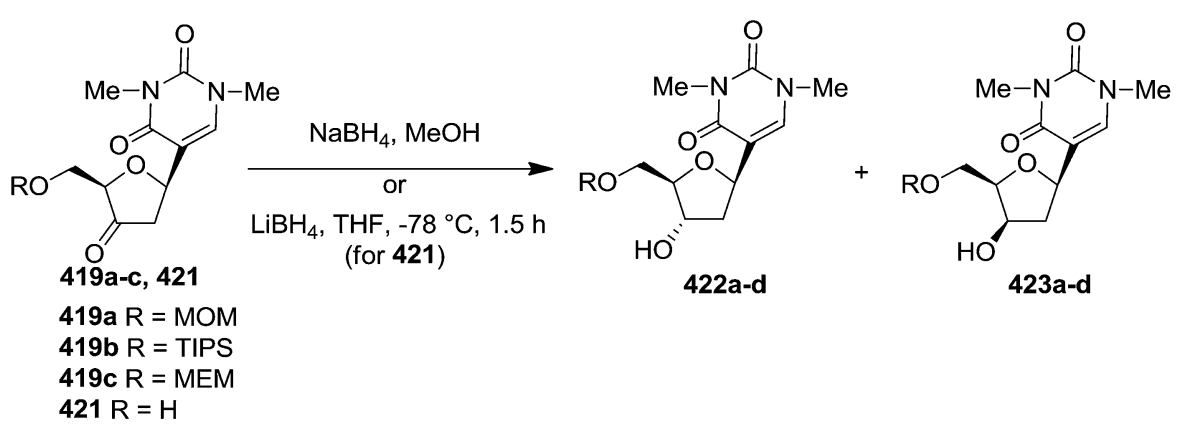


Table 8 Borohydride reduction of $(419 a-c, 421)$

\begin{tabular}{|c|c|c|c|c|c|c|c|}
\hline Entry & $3^{\prime}$-Keto- $C$-nucleoside & $\mathrm{R}$ & Reducing agents & Temperature ${ }^{\circ} \mathrm{C}$ & Yield $^{a_{\%}} \%$ & $3^{\prime}-\mathrm{OH}_{\alpha} / 3^{\prime}-\mathrm{OH}_{\beta}{ }^{b}$ & Products \\
\hline 1 & $419 a$ & MOM & $\mathrm{NaBH}_{4}$ & $0^{\circ} \mathrm{C}$ & 73 & $1: 3$ & $422 a / 423 a$ \\
\hline 2 & 419b & TIPS & $\mathrm{NaBH}_{4}$ & $0^{\circ} \mathrm{C}$ & 88 & $1: 2$ & $422 b / 423 b$ \\
\hline 4 & 421 & $\mathrm{H}$ & $\mathrm{LiBH}_{4}$ & $-78{ }^{\circ} \mathrm{C}$ & 60 & $1: 2$ & $422 d / 423 d$ \\
\hline
\end{tabular}

${ }^{a}$ Isolated yield. ${ }^{b}$ Determined by high-pressure liquid chromatography.

The borohydride reduction of (419a-c, 421) gave separable $\alpha$ $3^{\prime}$-hydroxyl (422a-d) and $\beta$-3'-hydroxyl derivatives (423a-d) (Scheme 69, Table 8).

The furanoid glycal 54d on Pd-mediated coupling reaction with 402 yielded a $3^{\prime}$-keto- $\beta-C$-nucleoside $419 \mathrm{c}$ which indicated that the trimethylsilyloxy substituent effectively directed organopalladium adduct formation even though trimethylsilyl was lost during reaction (Scheme 70).

Coupling of 402 with 3,5-O-unsubstituted glycal (1,4-anhydro-2-deoxy-D-erythro-pent-1-enitol) $\mathbf{5 5}$ produced a mixture of the $\alpha$ - and $\beta$ - $C$-nucleosides $\mathbf{4 2 1}$ and $\mathbf{4 2 4}$ in $45 \%$ and $29 \%$ yields, respectively. Coupling of $\mathbf{4 0 2}$ with 5-O-substituted glycal 53c gave $\alpha$ - $C$-nucleoside $\mathbf{4 2 4}$ as the sole product via formation of $\mathbf{4 2 5}$ followed by desilylation (Scheme 71).

Daves Jr and Outten further utilized their developed methodology for coupling of furanoid glycals with 1-methoxy-4-(tri- $n$ butylstannyl)benzo[ $d]$ naphtho[1,2-b]pyran-6-one for synthesis of benzo[ $[d]$ naphtho[ $[1,2,-b]$-pyran-6-one- $C$-glycosides related to antibiotics ravidomycin, gilvocarcins (toromycin), and chrysomycin A and B (virenomycin) for the very first time. 1Methoxybenzo $[d]$-naphtho[1,2-b]pyran-6-one $\quad \mathbf{4 2 6}$ was

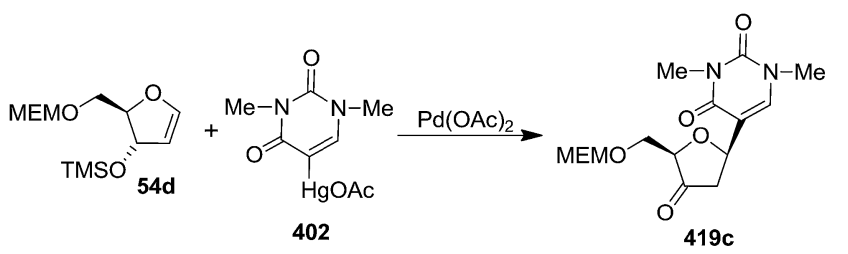

Scheme 70 brominated at para position to -OMe with NBS in DMF at room temperature for $30 \mathrm{~min}$ to give $\mathbf{4 2 7}$ in $\mathbf{8 1 \%}$ yield, which on treatment with hexa- $n$-butylditin $\left(n \mathrm{Bu}_{3} \mathrm{Sn}\right)_{2}$ in the presence of $2.0 \mathrm{~mol} \%$ of $\mathrm{Pd}\left(\mathrm{PPh}_{3}\right)_{4}$ in toluene $\left(\mathrm{N}_{2}, 115{ }^{\circ} \mathrm{C}, 12 \mathrm{~h}\right)$ produced stannane 428 in $65 \%$ yield. Its coupling with furanoid glycal 54b in the presence of stoichiometric $\mathrm{Pd}(\mathrm{OAc})_{2}$ in $\mathrm{CH}_{3} \mathrm{CN}$ at room temperature for $24 \mathrm{~h}$ furnished $C$-glycoside 429 in $66 \%$ yield. Similar coupling of $\mathbf{4 2 8}$ with glycal $\mathbf{5 4 f}$ formed the corresponding $C$-glycoside 430 in a $28 \%$ yield. Silyl ether deprotection of $\mathbf{4 2 9}$ and $\mathbf{4 3 0}$ by $n \mathrm{Bu}_{4} \mathrm{NF}$ in the presence of acetic acid in $\mathrm{THF}$ at room temperature for $2 \mathrm{~h}$ yielded the corresponding $3^{\prime}$-keto- $C$-glycosides 431 (94\%) and 432 (92\%) respectively. Reduction of the ketones $\mathbf{4 3 1}$ and $\mathbf{4 3 2}$ with $\mathrm{NaBH}_{4}, \mathrm{H}_{2} \mathrm{O}$ in tetrahydrofuran afforded the corresponding $2^{\prime}$-deoxy- $C$-glycosides 433 and $\mathbf{4 3 4}$ respectively (Scheme 72).62

Daves Jr discussed coupling reaction of iodo derivatives of anthracycline aglycons with furanoid and pyranoid glycals in stoichiometric amounts in the presence of catalytic amounts of palladium(II) acetate and a tertiary amine in DMF at room temperature to get regio and stereospecific aryl $C$-glycosides. ${ }^{63}$ After several trial and error, they treated anthracycline iodo derivative $\mathbf{4 3 5}$ with furanoid glycal $\mathbf{5 4 b}$ in the presence of 10 mol\% $\mathrm{Pd}(\mathrm{OAc})_{2}, 2$ equiv. of $n \mathrm{Bu}_{3} \mathrm{~N}$, and 1 equiv. of $\mathrm{NaOAc}$ in DMF at room temperature for $48 \mathrm{~h}$ to furnish $C$-glycoside 436, which was in situ desilylated under the reaction condition to afford $3^{\prime}$-keto- $\beta$ - $C$-glycoside $\mathbf{4 3 7}$ in $85 \%$ yield. This reaction was equally successful with tetra- $n$-butylammonium chloride and sodium bicarbonate (Scheme 73).

They have also synthesized $C$-glycoside $\mathbf{4 4 0}$ from furanoid glycal 660 in a one pot three step sequence. Under the identical<smiles>Cn1cc(-c2ccc(CO)cc2)c(=O)n(C)c1=O</smiles>

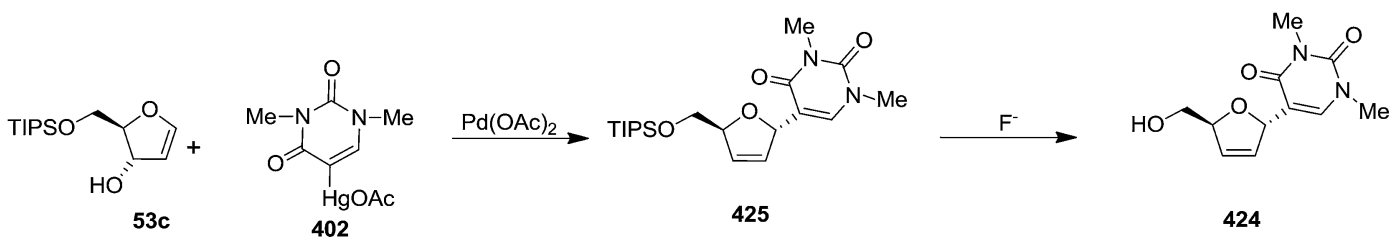

Scheme 71 


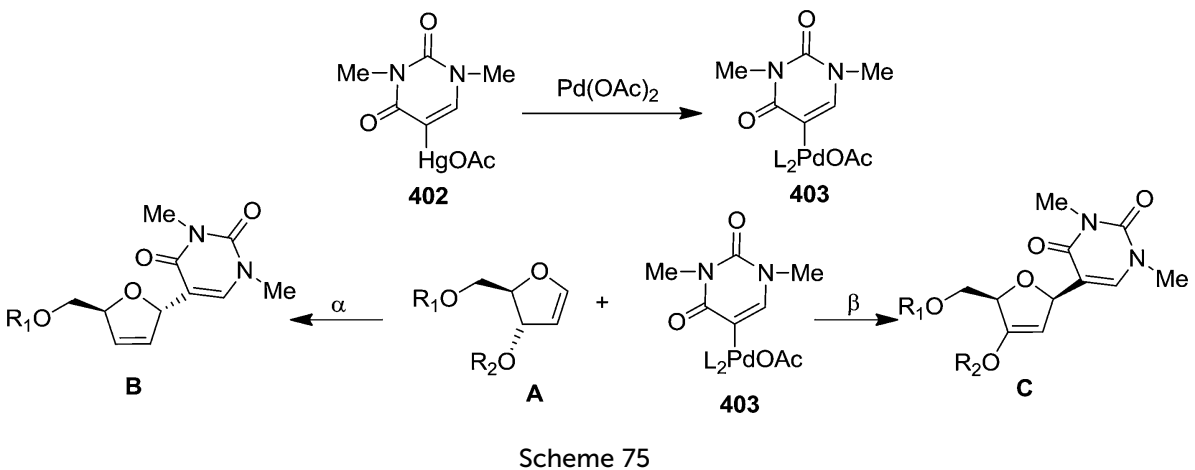

palladium-catalyzed coupling reaction condition, furanoid glycal 660 was stirred with iodo anthracycline 435 for $10 \mathrm{~h}$ at room temperature to form $\mathbf{4 3 8}$, which was then desilylated by the $n \mathrm{Bu}_{4} \mathrm{NF}$ in reaction medium to give keto derivative 439 . The free -OH group was then acetylated into the same reaction medium to furnish $C$-glycoside $\mathbf{4 4 0}$ in $\mathbf{8 9 \%}$ isolated yield by one pot three step sequence. The stereospecific reduction of a $3^{\prime}$-keto group of a furanosyl $C$-glycoside $\mathbf{4 3 9}$ with $\mathrm{NaBH}(\mathrm{OAc})_{3}$ gave $\mathbf{4 4 1}$ which was acetylated to $C$-glycoside $\mathbf{4 4 2}$ in $\mathbf{9 4 \%}$ isolated yield by onepot four-step sequence (Scheme 74).

In 1990 Daves Jr discussed the regio- and stereospecific synthesis of $C$-glycosides by palladium-mediated coupling reaction of glycals (furanoid or pyranoid glycal), with suitable aglycon (heterocyclic or anthracyclic) derivatives. ${ }^{64}$ The reaction of pyrimidine mercurial derivative $\mathbf{4 0 2}$ with $\mathrm{Pd}(\mathrm{II})$ acetate led to the formation of $\mathrm{Pd}(\mathrm{II})$ organopalladium reagent 403, which underwent stereospecific coupling reaction with furanoid glycals (55, 56a, 45, 54a, 54b, 54f, 66o) to yield single product (either a $\alpha$ - $C$ glycoside or a $\beta$-C-glycoside, Table 9$)$. They observed in the case of 56a, 45 or 660 where only one of the two glycal hydroxyls was substituted, the $\pi$-complex was formed exclusively from the face of the furanoid ring opposite to the substituted hydroxyl to give 417, 412 and 444 respectively. When both glycal hydroxyls were substituted (54a, $\mathbf{5 4 b}$, or $\mathbf{5 4 f}$ ), the organopalladium reagent attacked from the $\beta$-face of the glycal to form 413, 414, 416 respectively, indicated that the reaction was more sensitive to the steric bulk of the C3 substituent than to that at position C5 of the furanoid glycal. Only when both hydroxyls of the glycal remain unsubstituted 55 mixture of stereoisomeric $C$-glycosides 443a and 443b were obtained (Scheme 75, Table 9).

Table 9 Stereochemistry of C-glycoside formation by palladiummediated glycal aglycon coupling

\begin{tabular}{|c|c|c|c|}
\hline Entry & $\begin{array}{l}\% \text { yield of } \\
\alpha \text { - } C \text {-nucleosides } \\
\text { (B) }\end{array}$ & Substituents of (A) & $\begin{array}{l}\% \text { yield of } \\
\beta \text { - } C \text {-nucleosides } \\
\text { (C) }\end{array}$ \\
\hline 1 & $29(443 a)$ & $55 \mathrm{R}_{1}=\mathrm{R}_{2}=\mathrm{H}$ & $45(443 b)$ \\
\hline 2 & 0 & $56 a R_{1}=H, R_{2}=M O M$ & $65(417)$ \\
\hline 3 & $78(\mathbf{4 1 2})$ & $45 \mathrm{R}_{1}=\mathrm{MOM}, \mathrm{R}_{2}=\mathrm{H}$ & 0 \\
\hline 4 & 0 & $54 \mathrm{a} \mathrm{R}_{1}=\mathrm{R}_{2}=\mathrm{MOM}$ & $71(413)$ \\
\hline 5 & 0 & $54 \mathrm{~b} \mathrm{R}_{1}=\mathrm{MOM}, \mathrm{R}_{2}=\mathrm{TIPS}$ & $92(\mathbf{4 1 4})$ \\
\hline 6 & 0 & $54 f \mathrm{R}_{1}=\mathrm{R}_{2}=$ TIPS & $51(416)$ \\
\hline 7 & 0 & $660 \mathrm{R}_{1}=\mathrm{H}, \mathrm{R}_{2}=\mathrm{TBDPS}$ & $84(444)$ \\
\hline
\end{tabular}

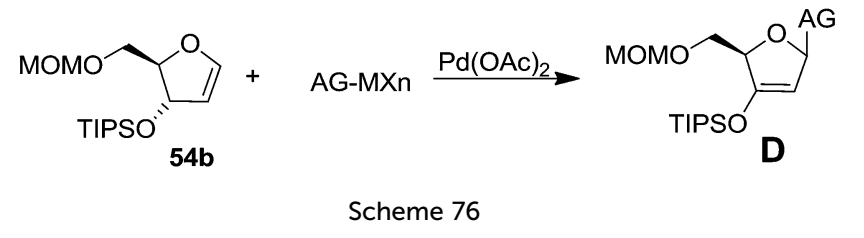

Table 10 Coupling reactions of aglycon-mercuric acetate and tri- $n$ butylstannyl derivatives with a furanoid glycal $54 \mathrm{~b}$ in the presence of stoichiometric $\mathrm{Pd}(\mathrm{OAc})_{2}$

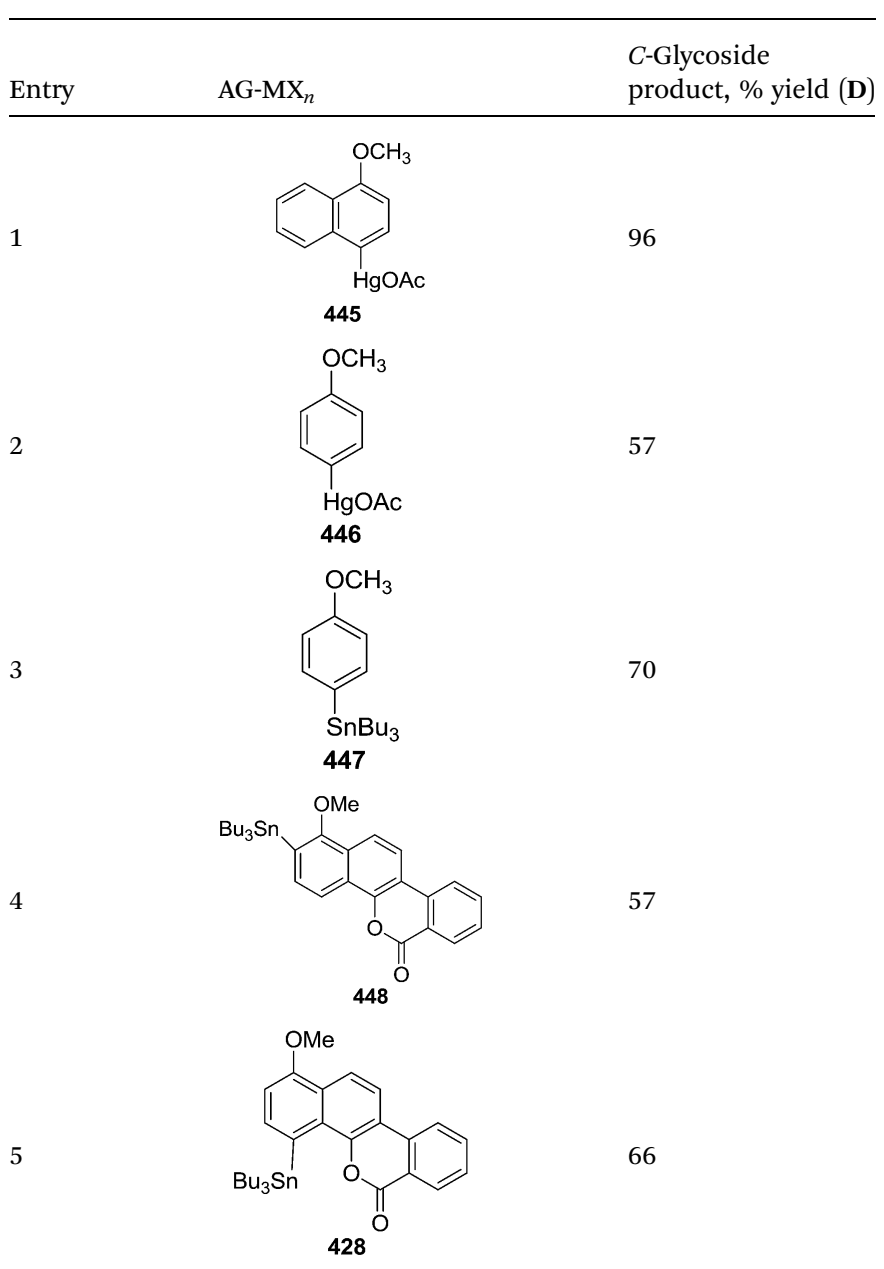


In this report, Daves Jr also showed the comparative study of coupling reaction of aglycon-mercuric acetate and tri- $n$-butylstannyl derivatives with a particular furanoid glycal 54b in the presence of stoichiometric $\mathrm{Pd}$ (II) acetate and observed there were no significant differences in the effectiveness (Scheme 76, Table 10).

In 1992, this research group further reported syntheses of synthetic $C$-glycosides 453 and $\mathbf{4 5 4}$ structurally related to the gilvocarcin, ravidomycin, and chrysomycin antibiotics which possess the aglycon substituents (hydroxyl at C-1 and ethenyl at C-8) considered critical for the photolytic nicking of DNA. They synthesized $\beta$ - $C$-glycosides 453 from triester 452 (Scheme 77) which was synthesized following the same one-pot four-step sequence from furanoid glycal 660 and pivaloyl protected aglycon derivative $449 .^{65}$

They further extended their study and showed the utility of regio- and stereospecific $C$-glycosyl bonds formation by the synthesis of $C$-nucleoside analogs. They synthesized 2 -deoxypseudouridin $\mathbf{4 5 8}$ in three steps by utilizing the palladiummediated coupling of 5-iodouracil 455 with glycal 66o, as the key step in the presence of either triphenylphosphine or triphenylarsine ligands. The coupling reaction formed $\beta$ - $C$-nucleoside 456 which, without isolation, was desilylated with fluoride ion to form the $2^{\prime}$-deoxy- $3^{\prime}$-keto- $C$-nucleoside 457. Finally, stereospecific reduction of the 3 -keto group with $\mathrm{NaBH}(\mathrm{OAc})_{3}$ formed 2'-deoxypseudouridine $\mathbf{4 5 8}$ (Scheme 78). ${ }^{\mathbf{6}}$

In a similar way, they synthesized $2^{\prime}$-deoxyformycin B 463, $2^{\prime}, 3^{\prime}$-dideoxyformycin B 468 by palladium-mediated glycalaglycon coupling reaction as the key step. Ribofuranoid glycal
660 and bis(tetrahydropyranyl) protected iodo aglycon derivative 459 underwent regio and stereospecific coupling reaction in the presence of $\operatorname{Pd}(\mathrm{dba})_{2}$ as catalyst and triphenylarsine as ligand in acetonitrile to give $C$-nucleoside 460 in $62 \%$ isolated yield. Following the similar reaction sequence desilylation followed by stereospecific keto group reduction, $C$-nucleoside 460 was converted to 462 via 461 which on treatment with pyridinium $p$-toluenesulfonate yielded 2 -deoxyformycin B 463 in $83 \%$ yield (Scheme 79). ${ }^{66}$

$2^{\prime}$-Deoxy- $C$-nucleoside 462 was transformed into $2^{\prime}, 3^{\prime}$ dideoxyformycin B 468 in five steps in 52\% overall yield. The primary hydroxyl at $\mathrm{C}-5^{\prime}$ was selectively silylated to form 464 followed by protection of the $\mathrm{C}-3^{\prime}$ hydroxyl using $O$-phenyl chlorothionoformate to give intermediate 465 which on deoxygination with $n \mathrm{Bu}_{3} \mathrm{SnH} / \mathrm{AIBN}$ produced $2^{\prime}, 3^{\prime}$-dideoxy $C$-nucleoside 466. Its silyl ether deprotection with fluoride ion furnished 467 which on removal of tetrahydropyranyl groups with pyridinium $p$-toluenesulfonate afforded $2^{\prime}, 3^{\prime}$-dideoxyformycin B 468 (Scheme 80). ${ }^{66}$

Daves Jr have reported the synthesis of 1-(tri- $n$-butylstannyl) furanoid glycals for the first time by lithiation of the corresponding 3-O-unsubstituted glycals $(\mathbf{4 0 4}, 469,55,53 \mathrm{~b})$ followed by reaction with $n \mathrm{Bu}_{3} \mathrm{SnCl}$. They also discussed the tri- $n$-butylstannaylation of 3-O-substituted hydroxy glycal $66 \mathbf{h}$, which underwent elimination to yield the corresponding furan in the presence of $t$ BuLi. Finally, they succeeded to prepare 3-O-benzyl furanoid glycal $\mathbf{4 7 8}$ from phenylthioglycoside 475, which was oxidized with $m$-CPBA to phenyl sulfone 476. Treatment of 476 with $n \mathrm{BuLi}$ furnished unsaturated sulfone 477, which was

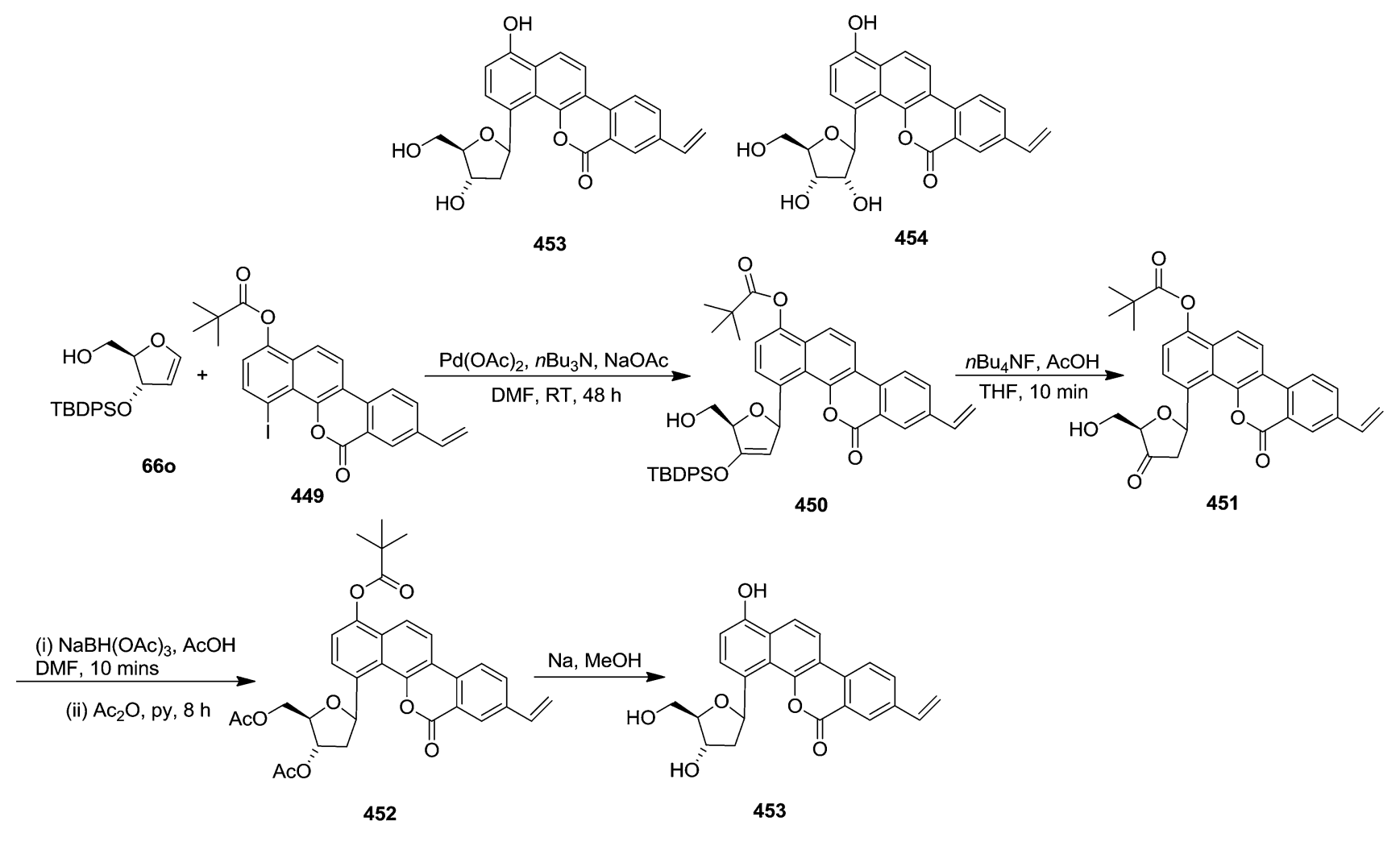

Scheme 77 


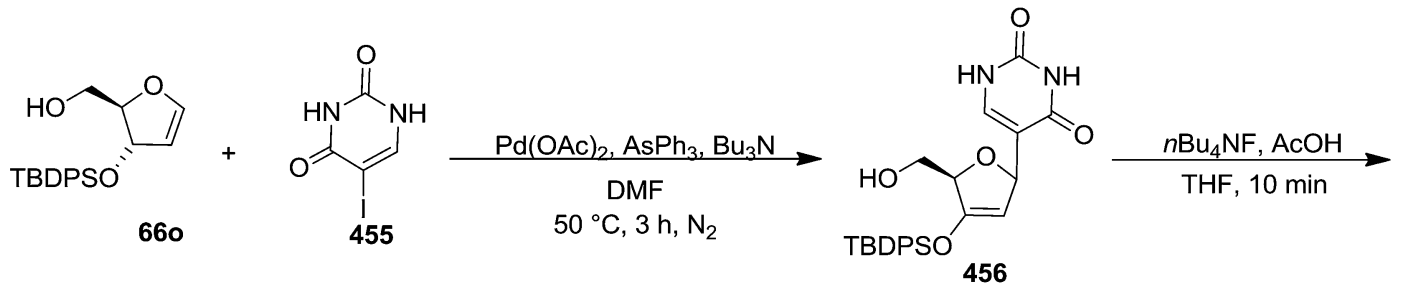

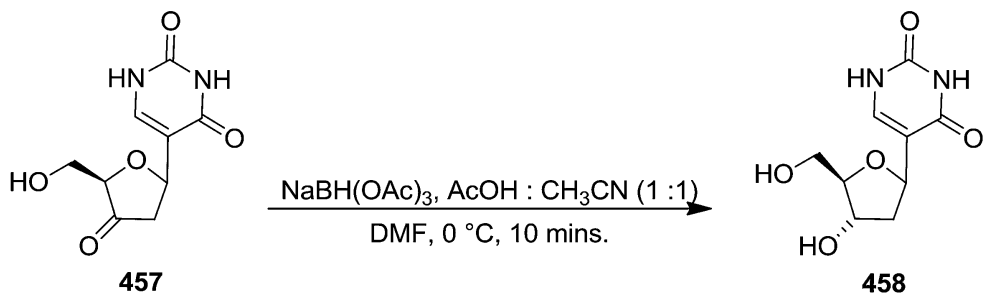

Scheme 78<smiles>C[18O][C@@H]1C=CO[C@@H]1CO</smiles>

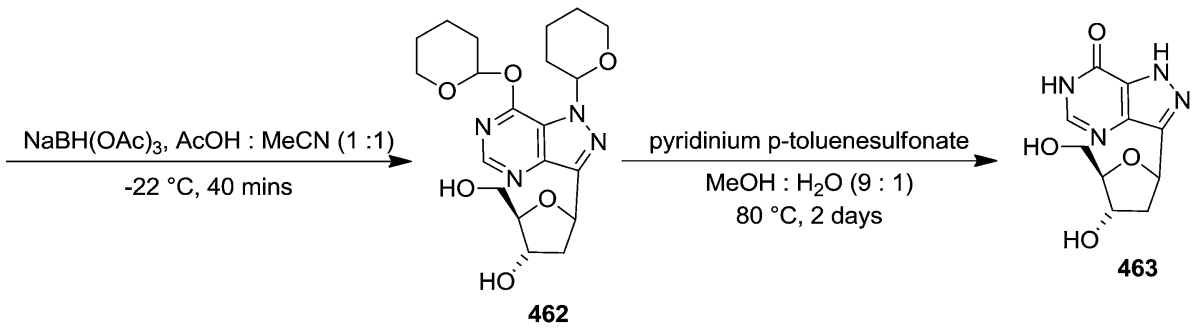

Scheme 79

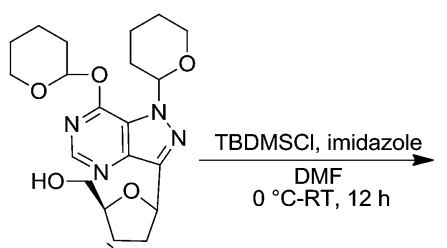

HO

462
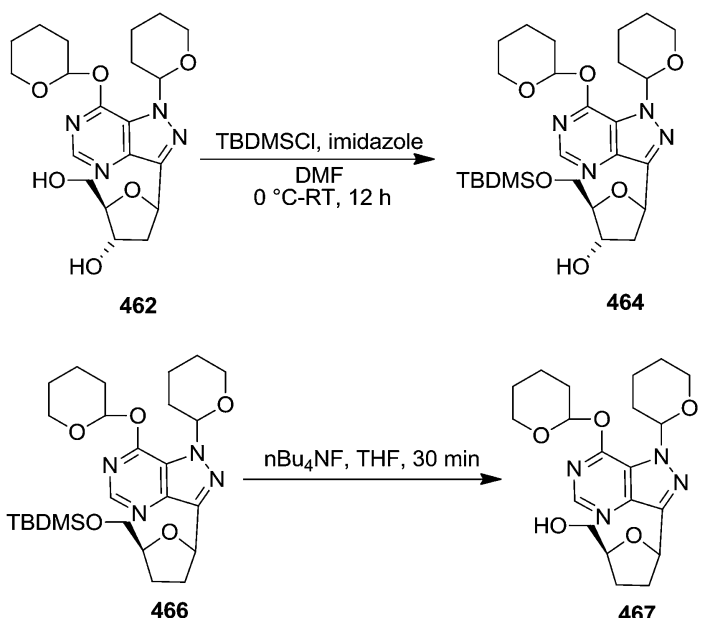

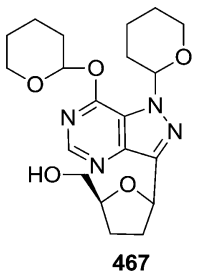

pyridinium p-toluenesulfonate,

$\mathrm{MeOH}: \mathrm{H}_{2} \mathrm{O}(9: 1)$ $50^{\circ} \mathrm{C}, 2$ days. $\underset{\text { Toluene }}{\stackrel{n \mathrm{Bu}_{3} \mathrm{SnH}, \mathrm{AlBN}}{\longrightarrow}}$

$80^{\circ} \mathrm{C}, 15 \mathrm{~h}$

Scheme 80 
treated with $n \mathrm{Bu}_{3} \mathrm{SnH}$ in the presence of AIBN formed stannylated 3-O-benzyl furanoid glycal 478. Palladium mediated coupling reaction of these stannylated furanoid glycals (470473,478 ) with iodoaglycon derivatives yielded the corresponding 1-substituted furanoid glycals in good to excellent yields (Scheme 81). ${ }^{67}$

This group further extended their studies on Pd-mediated regio- and stereospecific coupling reaction of 483 with furanoid glycal 56a to obtain $C$-nucleosides $484 .^{68}$ The coupling of iodoaglycon derivative $\mathbf{4 8 3}$ with furanoid glycal $\mathbf{6 6 0}$ followed by desilylation of 485 with TBAF and stereospecific hydroxyactivated reduction of the $3^{\prime}$-keto group of intermediate 486 using $\mathrm{NaBH}(\mathrm{OAc})_{3}$ yielded the $2^{\prime}$-deoxyribofuranosyl $C$-nucleoside 487 in $65 \%$ yield for the three steps (Scheme 82).

Similarly, they synthesized palladium-mediated coupling of 8-iodo-4-methoxypyrazolo[1,5- $a]$-1,3,5-triazine 488 and furanoid glycal 660 efficiently produced $C$-nucleoside intermediate 489 which was desilylated to form $3^{\prime}$-keto $C$-nucleoside 490 (Scheme 83).

They also tried Pd-mediated coupling of iodoaglycon 491 and 492 with furanoid glycal 660 but it was futile. As a result, they prepared aglycon bis-carbamate derivative 494 by reaction of 493 with isobutyloxycarbonyl chloride in the presence of pyridine. Aglycon derivative 494, was successfully coupled with glycal 660 in the presence of catalytic $\mathrm{Pd}(\mathrm{dba})_{2}$ and $\mathrm{AsPh}_{3}$ to give, after desilylation of the initially formed silyl enol ether with fluoride ion, $3^{\prime}$-keto $C$-nucleoside 495 (2 steps, 50\% yield) (Scheme 84).

In the same year, Townsend and group reported an efficient and stereospecific synthesis of pyrazine $C$-nucleosides by $\operatorname{Pd}(0)$ mediated cross-coupling reaction between ribofuranoid glycals 66e, 66f and 65b and iodoaglycon 496. ${ }^{69}$ The cross-coupling reaction between aglycon 496 and ribofuranoid glycal 66e resulted silyl enolether derivative 497a which was gradually converted to 498a. Pd-mediated cross-coupling reaction between iodoaglycon 496 and ribofuranoid glycal $66 \mathbf{f}$ furnished $C$-nucleoside $\mathbf{4 9 7 b}$ whereas under identical reaction condition furanoid glycal $\mathbf{6 5} \mathbf{b}$ only resulted in the isolation of the $2^{\prime}$-deoxy$3^{\prime}$-keto- $C$-nucleoside $\mathbf{4 9 8 b}$ instead of the silyl enol ether derivative 497c. They selectively deprotected the $3^{\prime}$-silyl group of the silyl enol ethers $497 \mathbf{a}$ and $\mathbf{4 9 7}$ b by the fluoride ion at low temperature to give $\mathbf{4 9 8 a}$ and $\mathbf{4 9 8 b}$, respectively. $2^{\prime}$-Deoxy- $\beta$-Dribofuranoside $\mathbf{5 0 0}$ was prepared from the complete deprotection of 497a, b or 498a, b with TBAF via 499, followed by a stereospecific reduction by $\mathrm{NaBH}(\mathrm{OAc})_{3}$. They confirmed the $\beta$-configuration of $C$-nucleoside $\mathbf{5 0 0}$ by NOE analysis and also converted it to $5,5^{\prime}$-anhydro nucleoside $\mathbf{5 0 1}$ by diazotization reaction with iso-amyl nitrite (Scheme 85).

Motivated by the work of Daves et al., in 1995, McLaughlin and coworkers reported the synthesis of two pyridine $C$ -

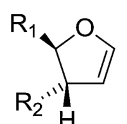

$404 \mathrm{R}_{1}=\mathrm{R}_{2}=\mathrm{H}$

$469 \mathrm{R}_{1}=\mathrm{CH}_{2} \mathrm{OCPh}_{3}, \mathrm{R}_{2}=\mathrm{H}$

$55 \mathrm{R}_{1}=\mathrm{CH}_{2} \mathrm{OH}, \mathrm{R}_{2}=\mathrm{OH}$

53b R $\mathrm{R}_{1}=\mathrm{CH}_{2} \mathrm{OTBDMS}, \mathrm{R}_{2}=\mathrm{OH}$

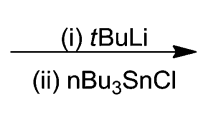

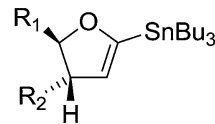

$470 \mathrm{R}_{1}=\mathrm{R}_{2}=\mathrm{H}$

$471 \mathrm{R}_{1}=\mathrm{CH}_{2} \mathrm{OCPh}_{3}, \mathrm{R}_{2}=\mathrm{H}$

$472 \mathrm{R}_{1}=\mathrm{CH}_{2} \mathrm{OH}, \mathrm{R}_{2}=\mathrm{OH}$

$473 \mathrm{R}_{1}=\mathrm{CH}_{2} \mathrm{OTBDMS}, \mathrm{R}_{2}=\mathrm{OH}$

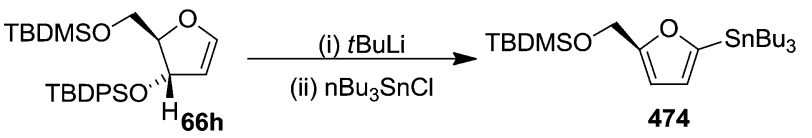

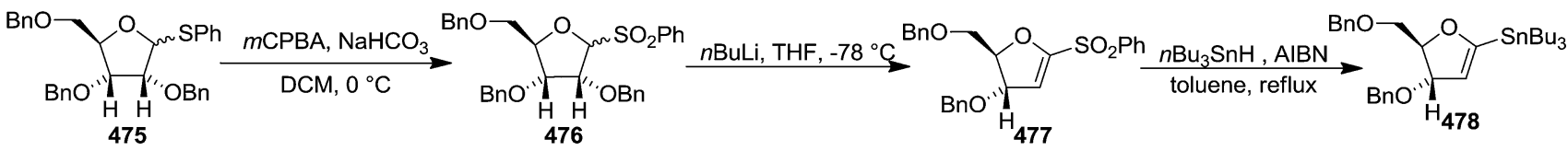

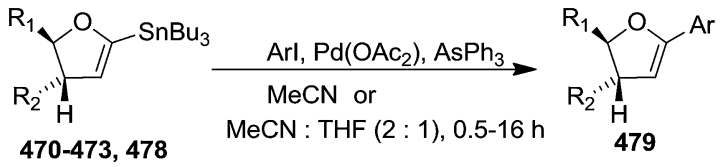

$470 R_{1}=R_{2}=H$

$471 \mathrm{R}_{1}=\mathrm{CH}_{2} \mathrm{OCPh}_{3}, \mathrm{R}_{2}=\mathrm{H}$

$472 \mathrm{R}_{1}=\mathrm{CH}_{2} \mathrm{OH}, \mathrm{R}_{2}=\mathrm{OH}$

$473 \mathrm{R}_{1}=\mathrm{CH}_{2} \mathrm{OTBDMS}, \mathrm{R}_{2}=\mathrm{OH}$

$478 \mathrm{R}_{1}=\mathrm{CH}_{2} \mathrm{OBn}, \mathrm{R}_{2}=\mathrm{OBn}$

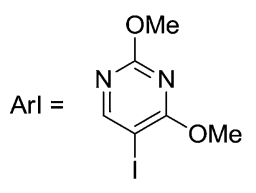

480<smiles>CS(=O)(=O)c1ncnc(OC2CCCCO2)c1N1CCCCO1</smiles>

cheme 81<smiles>COc1ccc(Br)cc1</smiles><smiles>CCc1ccc2c(c1)c(=O)oc1c(I)ccc(OC(C)(C)C)c12</smiles><smiles>Ic1cnn2c(OC3CCCCO3)ncnc12</smiles>

483 
nucleosides 507 and 512, "deletion modified" analogues of dT and $\mathrm{dC}^{70}$ After several trial and error, they prepared 2(benzyloxy)-3-methyl-5-iodopyridine 505 from 502 in three steps. Pd-mediated coupling reaction of glycal 660 and 2(benzyloxy)-3-methyl-5-iodopyridine $\mathbf{5 0 5}$ in the presence of ancillary ligand 1,3-bis(diphenylphosphino)propane resulted $C$ nucleoside 506 in 90\% yield. $C$-Nucleoside 506 was then converted into 507 by three steps sequential reactions, silyl ether deprotection, followed by stereoselectively keto group reduction<smiles>CO[C@H]1C=CO[C@H]1CO</smiles><smiles>COc1ncnc2c(I)c(C[13CH3])nn12</smiles><smiles></smiles>

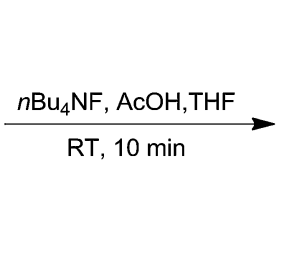<smiles>COc1ncnc2c3c(cn12)C1CC(=O)C(O)[C@@H](C1)O3</smiles>

Scheme 83

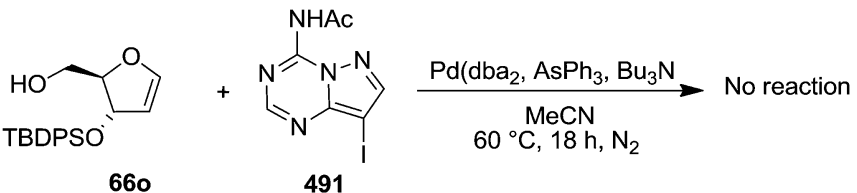

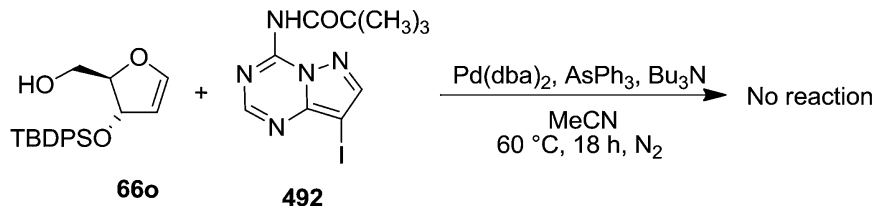<smiles>CC(C)COC(=O)Cl</smiles>

493<smiles>CC(C)COC(=O)N(C(=O)OCC(C)C)c1ncnc2c(I)cnn12</smiles>

494 (i) $\mathrm{Pd}(\mathrm{dba})_{2}, \mathrm{AsPh}_{3}, \mathrm{Bu}_{3} \mathrm{~N}$ $\mathrm{MeCN}, 60^{\circ} \mathrm{C}, 18 \mathrm{~h}, \mathrm{~N}_{2}$

(ii) $n \mathrm{Bu}_{4} \mathrm{NF}, \mathrm{THF}, \mathrm{RT}, 10 \mathrm{~min}$<smiles>CC(C)COC(=O)Nc1ncnc2c(C3CC(=O)[C@@H](CO)O3)cnn12</smiles>

Scheme 84 


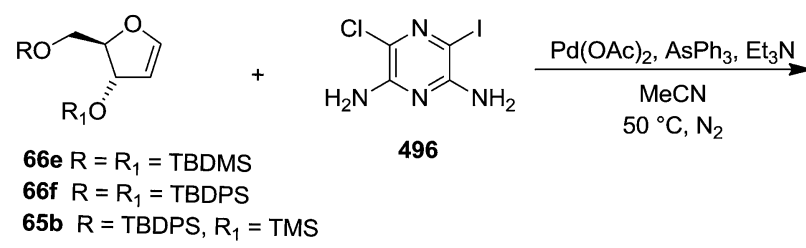

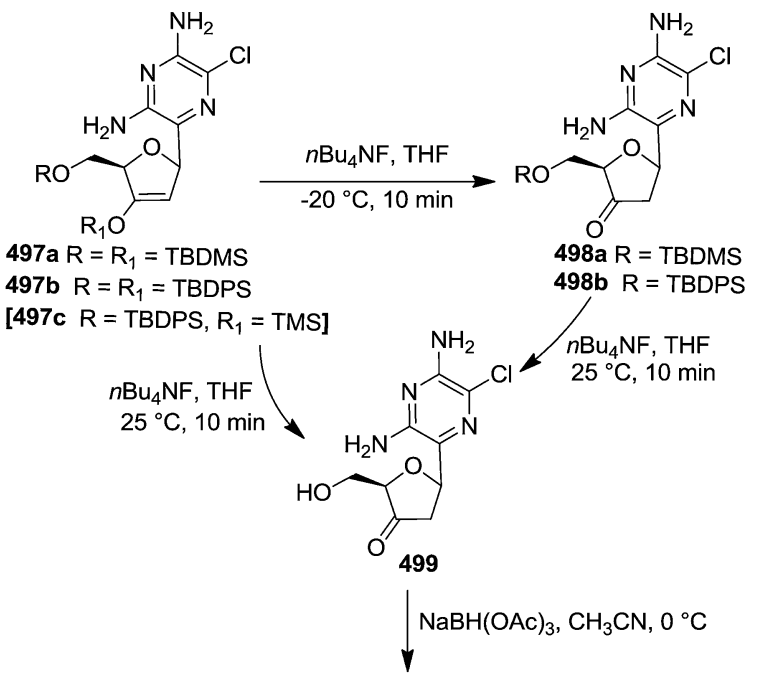

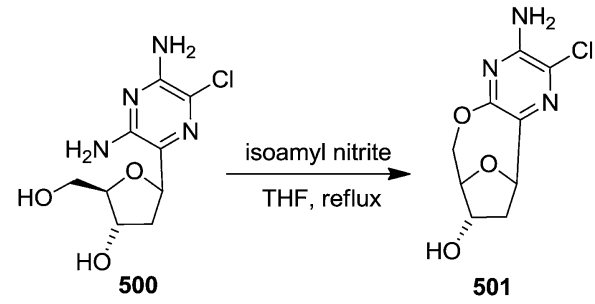

Scheme 85

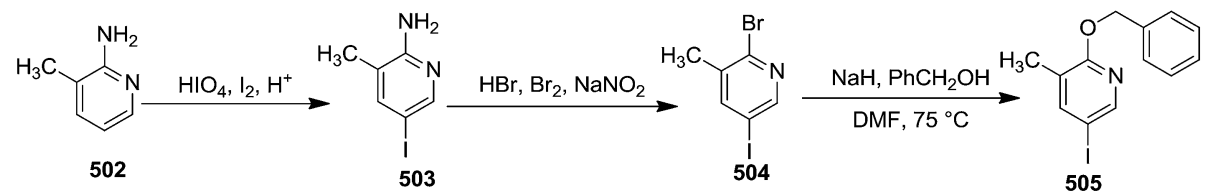

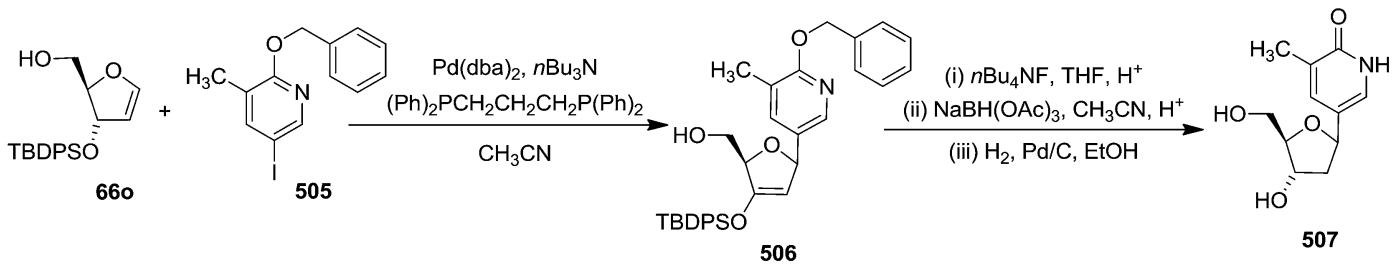

Scheme 86

and finally benzyloxy group deprotection by catalytic hydrogenation (Scheme 86).

In a similar fashion, they prepared the $C$-nucleoside analogue of dC 512 from 2-aminopyridine 508. They prepared 510 from 508 by its iodination followed by amino group protection with $\mathrm{BzCl}$ of the resulting iodo derivative 509. The coupling reaction of glycal $\mathbf{6 6 0}$ with $\mathbf{5 1 0}$ in the presence of $\mathrm{Pd}$ and an ancillary ligand $\mathrm{P}\left(\mathrm{C}_{6} \mathrm{~F}_{5}\right)_{3}$ resulted in moderate yields of product 511 (36\% yield). The remaining steps to generate $\mathbf{5 1 2}$ were strictly analogous to those described in Scheme 86 for the synthesis of $\mathbf{5 0 7}$ (Scheme 87).

In 1998, Coleman and Madaras followed Daves Jr strategy for synthesis of coumarin $\beta$ - $C$-riboside 522. For this, they synthesized furanoid glycal $660,{ }^{23} 56 a^{20 a}$ and $66 \mathbf{n}^{23}$ in the ususal procedure. $^{71}$
Coumarin $515(\mathrm{X}=\mathrm{OH})$ was prepared from 8-hydroxyjulolidine 513. Reaction of 513 with bis(2,4,6-trichlorophenyl) malonate $\mathbf{5 1 4}$ in refluxing toluene effected annulation of the $\alpha$-pyrone ring system to afford 515 in excellent yields (94\%). Its hydroxyl functionality could be transformed to the iodide by treating it with a preformed complex of triphenylphosphine and iodine $\left(\mathrm{Ph}_{3} \mathrm{P}, \mathrm{I}_{2}, \mathrm{CH}_{3} \mathrm{CN}, 82{ }^{\circ} \mathrm{C}\right)$ to form 516. Alternatively, the hydroxyl group could be acylated with trifluoromethanesulfonic anhydride $\left(\mathrm{Tf}_{2} \mathrm{O}, \mathrm{Et}_{3} \mathrm{~N}, \mathrm{DCM}, 0{ }^{\circ} \mathrm{C}\right)$ to afford triflate 517 in $87 \%$ yield (Scheme 88). These systems were examined in the Heck coupling reaction with glycals 66o, 56a and 66n (Schemes 89 and 90).

Pd-catalyzed coupling of $\mathbf{5 1 6}$ with glycal 660 was unsuccessful in providing any of the coupled product $\mathbf{5 1 8}$ (Scheme 89). 


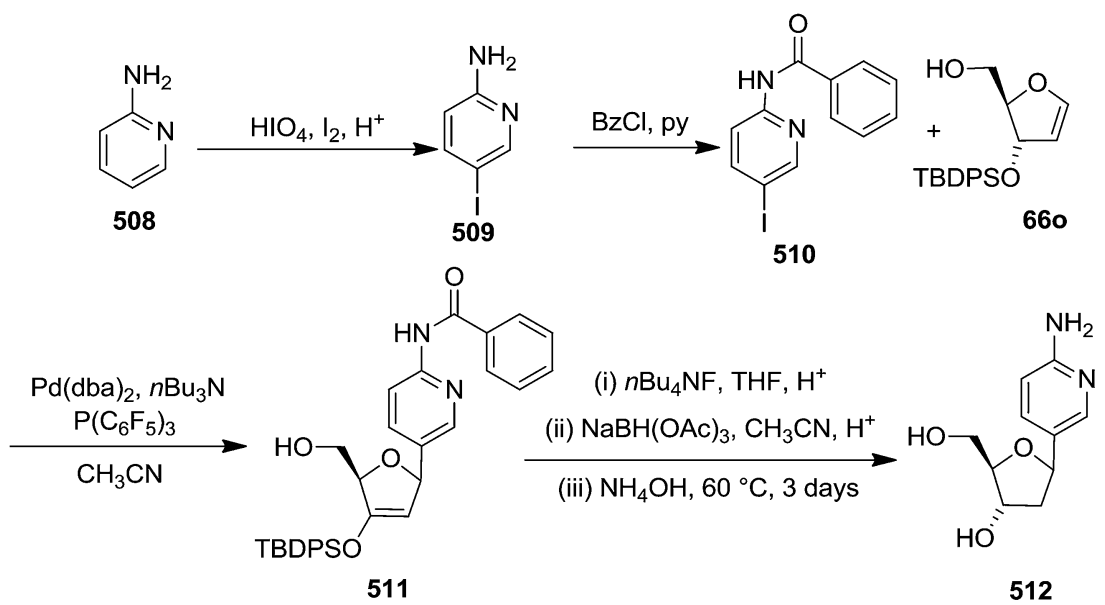

Scheme 87

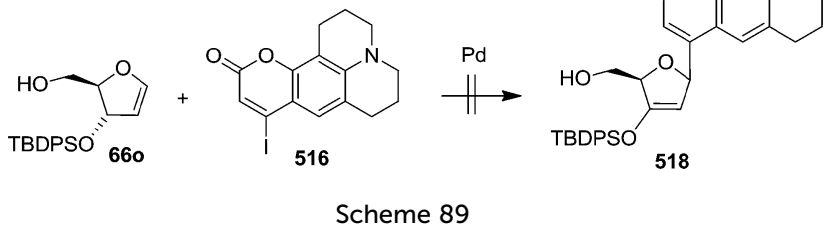

After getting unsuccessful results, they proceeded for Pdcatalyzed coupling reaction of triflate 517 with glycal 56a and 66n in the presence of $40 \mathrm{~mol} \% \mathrm{Pd}(\mathrm{OAc})_{2}, 5 \mathrm{~mol} \% \mathrm{dppp}$, and 3 equiv. $\mathrm{NaHCO}_{3}$ in $\mathrm{CH}_{3} \mathrm{CN}$ under refluxing condition to obtain Heck product 519 (75\% yield) and 520 (79\% yield) respectively. Hydrolysis of 519 under acidic conditions $\left(\mathrm{HCl}, \mathrm{CH}_{3} \mathrm{OH}, 25{ }^{\circ} \mathrm{C}\right.$ ) afforded ketone 521. Fluoride-promoted cleavage (HF/pyridine) of the silyl ether $\mathbf{5 2 0}$ afforded ketone $\mathbf{5 2 1}$ in excellent yields. The carbonyl group of $\mathbf{5 2 1}$ was reduced stereoselectively to the riboglycoside 522 with $\mathrm{NaBH}(\mathrm{OAc})_{3}$ (Scheme 90).

In 1999, Tingoli et al. showed the reaction of aromatic Grignard reagents with furanoid and pyranoid glycals in the presence of low valent Ni catalyst at low temperature. Treatment of furanoid glycal $\mathbf{9 0}$ with aryl magnesium bromide in the presence of $\mathrm{Ni}(0)$ catalyst in dry toluene at $-10{ }^{\circ} \mathrm{C}$ for $5 \mathrm{~h}$ afforded column purified 2,3-unsaturated products $(\mathbf{5 2 3}, \mathbf{5 2 4})$ in good yields. They further confirmed the 1,4-trans relationship between $\mathrm{H}-1$ and $\mathrm{H}-4$ by NOESY experiment (Scheme 91). ${ }^{72}$

Knaus et al. synthesized furanoid glycals (146a, b) (Scheme 24), used as key intermediate for the synthesis of unnatural $C$-aryl $2^{\prime}$ deoxy- $\beta$-L-cytidine mimics (529a, b) (Scheme 92). ${ }^{32}$ The Heck coupling reaction of 2,5-difluoro-4-iodoaniline 525a or 3-fluoro-4iodoaniline 525b with glycal $146 \mathrm{a}$ or $146 \mathrm{~b}$ in the presence of $\mathrm{Pd}(\mathrm{OAc})_{2}, \mathrm{Ph}_{3} \mathrm{As}$, and $\mathrm{Et}_{3} \mathrm{~N}$ in dry $\mathrm{CH}_{3} \mathrm{CN}$ at $70{ }^{\circ} \mathrm{C},{ }^{32}$ afforded 526a (71\% yield) or $\mathbf{5 2 6 b}$ ( $57 \%$ yield). After several trial and errors, 526b was subjected to $\mathrm{Pd} / \mathrm{C}$ catalyzed hydrogenation in anhydrous

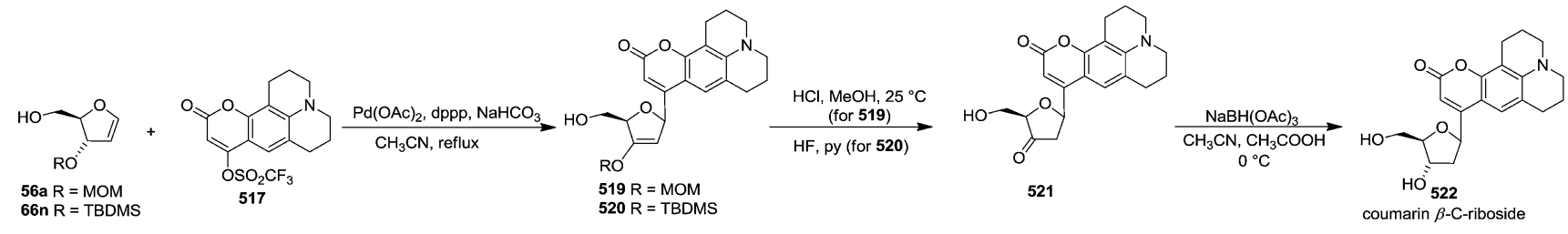

Scheme 90 


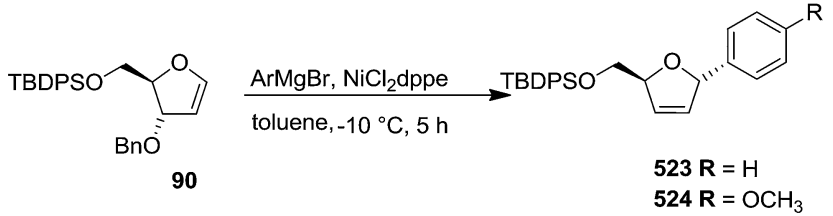

Scheme 91
EtOH containing several drops of $\mathrm{Et}_{3} \mathrm{~N}$ at $60{ }^{\circ} \mathrm{C}$ to afford the hydroxyl ketone 527b in $61 \%$ yield. The 5 -( $p$-chlorobenzoyl) group deprotection of 526a on treatment with $\mathrm{NaOMe}$ in $\mathrm{MeOH}$ resulted benzyl enol ether 528, which was converted to the hydroxy ketone 527a upon $\mathrm{Pd} / \mathrm{C}$ catalyzed hydrogenation in anhydrous EtOH in the presence of several drops of $\mathrm{Et}_{3} \mathrm{~N}$ at $60{ }^{\circ} \mathrm{C}$. Subsequent reduction of the hydroxy ketones $(\mathbf{5 2 7} \mathbf{a}, \mathbf{b})$ with $\mathrm{NaBH}(\mathrm{AcO})_{3}$ in dry

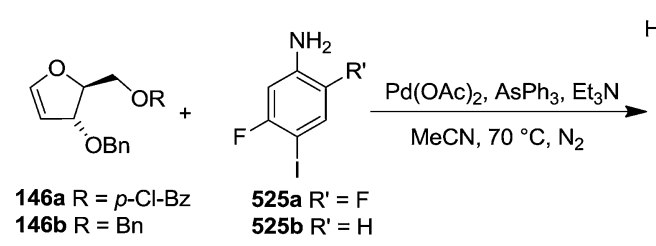<smiles>[R]CC1OC(c2cc([R])c(N)cc2F)C=C1OCc1ccccc1</smiles><smiles>Nc1cc(F)c([C@H]2C=C(OCc3ccccc3)C(CO)O2)cc1F</smiles>

526a $\mathrm{R}=p-\mathrm{Cl}-\mathrm{Bz}, \mathrm{R}^{\prime}=\mathrm{F}$ 526b $\mathrm{R}=\mathrm{Bn}, \mathrm{R}^{\prime}=\mathrm{H}$

528

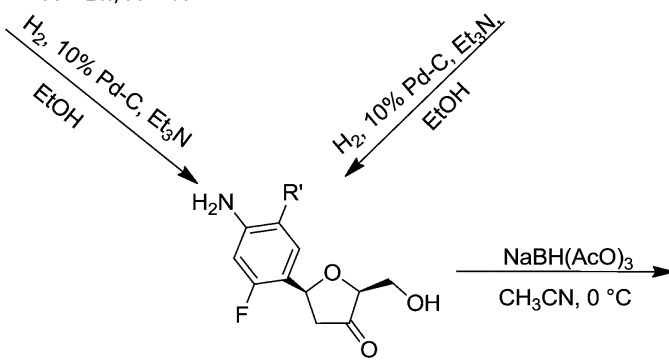<smiles>[R]c1cc([C@H]2C[C@H](O)[C@@H](CO)O2)c(F)cc1N</smiles>

\section{$527 a R^{\prime}=F$}

527b $R^{\prime}=H$

Scheme 92<smiles>Cc1nc(N)ccc1C1C[C@H](O)[C@H](CO)O1</smiles>

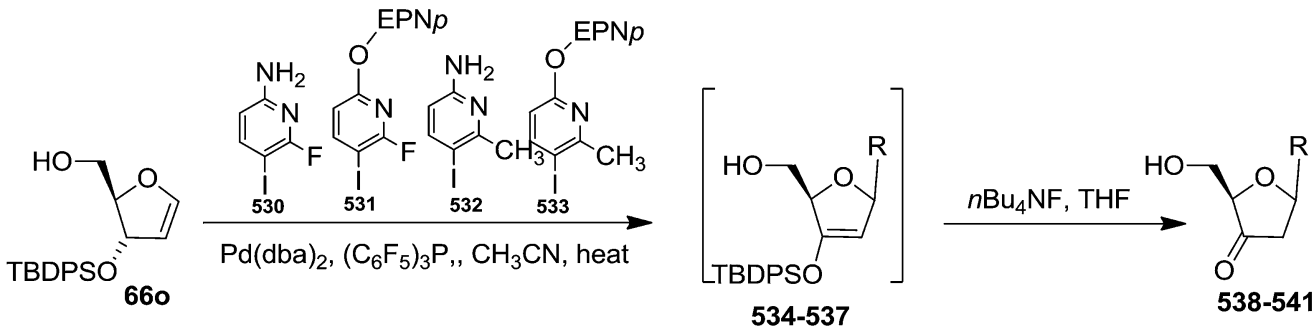

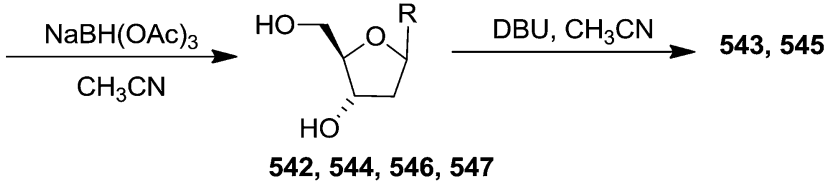

$\mathrm{R}=$ pyridine heterocycles corresponding to structure $\mathbf{5 3 0 - 5 3 3}$<smiles>Cc1nc(C(=O)N=[W])ccc1C1C[C@@H](O)[C@@H](CO)[C@@H]1CO</smiles>

Scheme 93 
$\mathrm{CH}_{3} \mathrm{CN}$ afforded the target deoxy- $\beta$-L-cytidine $C$-nucleoside mimics (529a, b) (Scheme 92).

McLaughlin et al. described the synthesis of four pyrimidine $C$-nucleoside analogues (542-545) of natural nucleosides dC and dU. ${ }^{73}$ They synthesized desired pyridine heterocycles (530533) necessary for the syntheses of (542-545) from the readily available differently 2,6-substituted pyridines. ${ }^{73}$ Furanoid glycal 660 and pyridine heterocycles (530-533) underwent regio and stereospecific Heck-type coupling reaction in the presence of $\mathrm{Pd}(\mathrm{dba})_{2}$ and $\left(\mathrm{C}_{6} \mathrm{~F}_{5}\right)_{3} \mathrm{P}$ in acetonitrile to give $\beta$ - $C$-nucleoside intermediates (534-537), which, without isolation, were desilylated with $n \mathrm{Bu}_{4} \mathrm{NF}$ to form $2^{\prime}$-deoxy-3'-keto- $C$-nucleosides (538541). Stereospecific reduction of (538-541) and removal of the $p$ NPE protecting group of $\mathbf{5 4 6}$ and 547 resulted in the target compounds (542-545) (Scheme 93).

Seitz and Singh diastereoselectively synthesized $\beta$-aryl- $C-2$ deoxynucleosides from furanoid glycal derived glycal epoxides. $^{74}$ The glycal $66 f$ on treatment with DMDO in DCM at $0{ }^{\circ} \mathrm{C}$ was converted to epoxide 548. Its reaction with trinaphthylaluminum 549 yielded 1-naphthyl- $\beta$ - $C$-arabinonucleoside $\mathbf{5 5 0}$ by cis opening of the epoxide ring. It was transformed into methyl xanthate 553 via phenylthionocarbonate 551 and thiocarbonylimidazole 552. They failed to reduce 553 to 554 by treatment with $n \mathrm{Bu}_{3} \mathrm{SnH}$ or (TMS) $)_{3} \mathrm{SiH}$ in presence of AIBN due to the bulkiness of the two TBDPS groups (Scheme 94).

Then they selected TBDMS-protected glycal 66e. ${ }^{23}$ The required epoxide 555 was obtained from the known glycal 66e by treating it with dimethyldioxirane (DMDO). The cis opening of epoxide 555 was performed by treatment with trinaphthylaluminum to afford 1-naphthyl- $\beta$ - $C$-arabinonucleoside 556a (method 1) in 50\% yield from 66e. The nucleoside 556a was allowed to react with thiocarbonyldiimidazole to form $557 \mathbf{a}$, which on reduction with (TMS) ${ }_{3} \mathrm{SiH}$ and AIBN furnished $2^{\prime}$ deoxynucleoside $\mathbf{5 5 8 a}$ in $82 \%$ yield. Finally, the silyl ether deprotection was performed by treatment with $n \mathrm{Bu}_{4} \mathrm{NF}$ in THF to afford fully deprotected 2 -deoxy-1'- $\beta$-naphthyl nucleoside
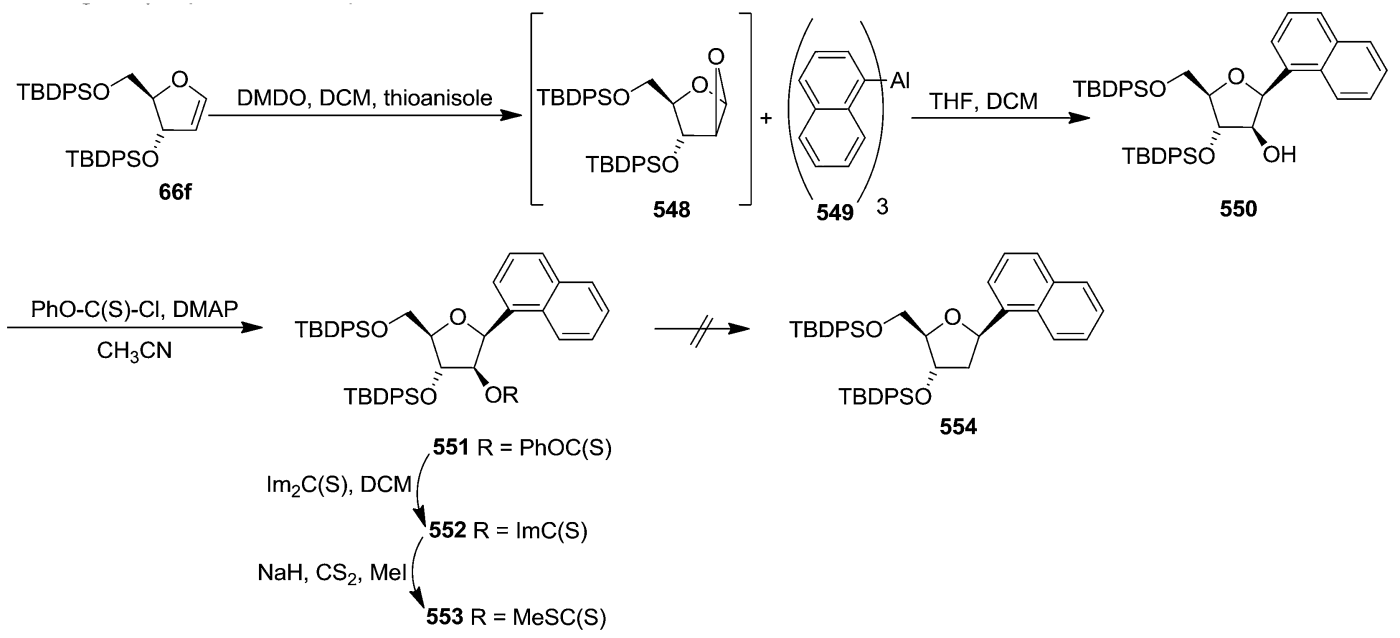

Scheme 94
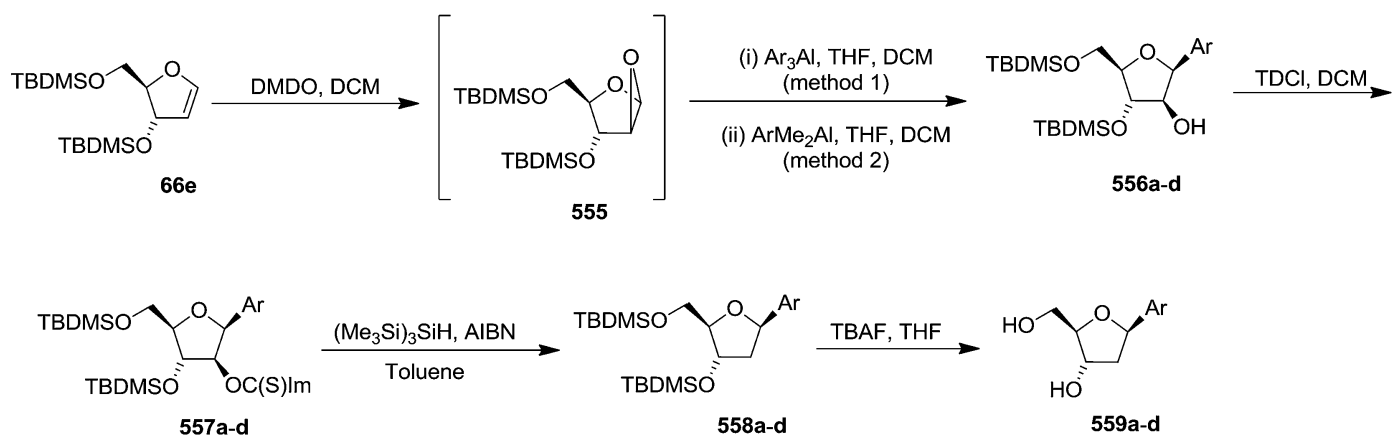
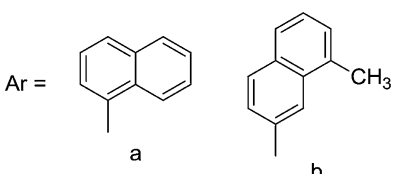

b<smiles>Cc1cccc2c(C)cccc12</smiles><smiles>Cc1cccc2c(-c3ccccc3)cccc12</smiles>

Scheme 95 


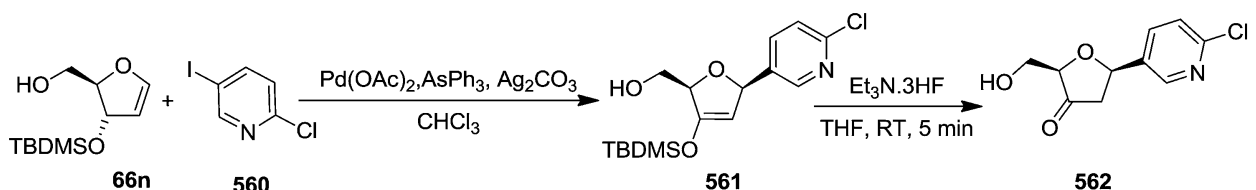

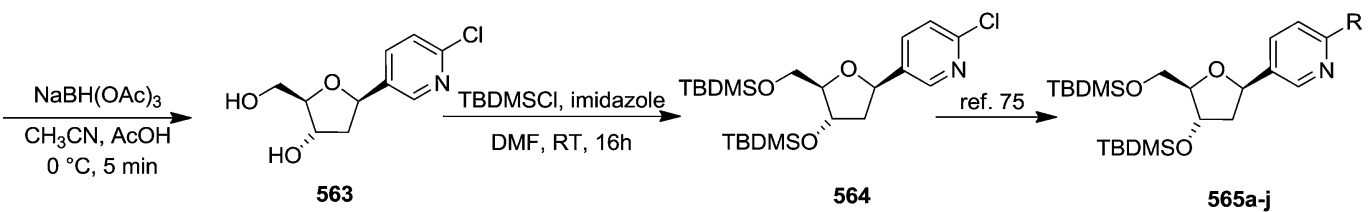<smiles>[R]O[C@H]1C[C@H](c2ccc([R])nc2)O[C@H]1CO</smiles>

Scheme 96

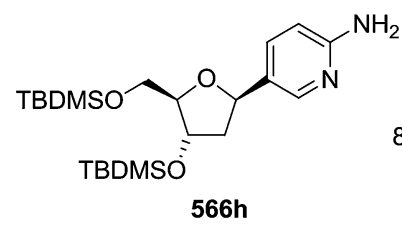

$566 \mathrm{~h}$

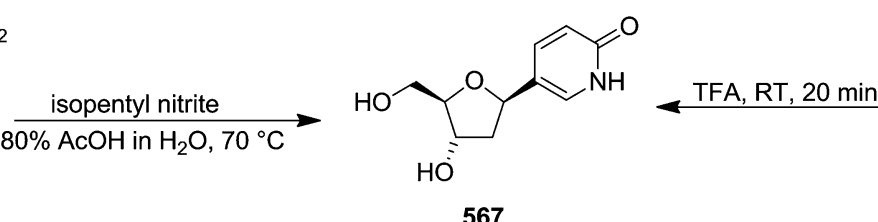

567<smiles>CCCCOC[C@H]1O[C@H](c2ccc(OCCCC)nc2)C[C@@H]1OCCCC</smiles>

$566 j$

Scheme 97

559a in $98 \%$ yield. They further studied the reaction sequence by changing triarylaluminum reagent for cis opening of the glycal epoxide to dimethylarylaluminum reagent (method 2). They synthesized a series of $2^{\prime}$-deoxy-1'- $\beta$-naphthyl nucleoside 559a-d by employing both the two methods (Scheme 95).

In 2007, Hocek and co-worker have developed a novel methodology for the synthesis of 6-substituted pyridin-3-yl $C$ nucleosides. ${ }^{75}$ After several trial experiments, they optimized the Heck reaction of 2-chloro-5-iodopyridine 560 with glycal $\mathbf{6 6 n}$ in the presence of $\mathrm{Pd}(\mathrm{OAc})_{2} / \mathrm{AsPh}_{3}$ and $\mathrm{Ag}_{2} \mathrm{CO}_{3}$ in chloroform to give the desired $C$-nucleoside precursor 561 in acceptable 65\% yield. Desilylation followed by reduction of the corresponding keto 562 with $\mathrm{NaBH}(\mathrm{OAc})_{3}$ in a mixture of acetonitrile and acetic acid afforded 563 in a good yield of $70 \%$ for the two steps. The free hydroxyl group of nucleoside $\mathbf{5 6 3}$ was then protected with TBDMSCl with imidazole in DMF to afford the fully protected key intermediate $\beta$ - $C$-nucleoside $\mathbf{5 6 4}$ in $87 \%$ yield (39\% overall yield over four steps from glycal 66n), (Scheme 96). They prepared 6-unsubstituted pyridine nucleoside $\mathbf{5 6 5 a}$ by catalytic hydrogenation of $\mathbf{5 6 4}$ with $\mathrm{H}_{2}$ over Pd/C for $3 \mathrm{~h}$, in a mixture of $\mathrm{EtOH}$, THF, and $\mathrm{H}_{2} \mathrm{O}$, in presence of $\mathrm{Et}_{3} \mathrm{~N}$. This key intermediate
564 was then subjected to a series of palladium catalyzed crosscoupling reactions to form new pyridine $C$-nucleosides $565 \mathrm{~b}-\mathrm{g}$ bearing diverse C (6-alkyl, 6-aryl, or 6-hetaryl) groups. They performed Hartwig-Buchwald aminations, and alkoxylations on 564 to give a series of protected $1 \beta$-(6-amino-, and 6-tert-butoxypyridin-3-yl)-2'-deoxyribonucleosides $565 \mathbf{h}-\mathbf{j}$ in good yields. All the silylated nucleosides 565a-i were deprotected using $\mathrm{Et}_{3}$ $\mathrm{N} \cdot 3 \mathrm{HF}$ in THF to give the free 6-substituted pyridine $C$-nucleosides 566a-i in good yields (Scheme 96).

6-Oxopyridine $C$-nucleoside $\mathbf{5 6 7}$ was synthesized in $84 \%$ yield by this research group from 6-(tert-butoxy)pyridine derivative 566j on treatment with TFA for $20 \mathrm{~min}$. They also synthesized $C$-nucleoside $\mathbf{5 6 7}$ from aminopyridine $C$-nucleoside $\mathbf{5 6 6 h}$ by reacting it with isopentyl nitrite in $80 \%$ aqueous $\mathrm{AcOH}$ at $70{ }^{\circ} \mathrm{C}$ for $100 \mathrm{~min}$. However, here $\mathbf{5 6 7}$ was isolated along with some inseparable impurities (Scheme 97). ${ }^{75}$

\section{Synthesis of $N$-nucleosides}

In 1990 Danishefsky and Chow proposed the epoxidation of furanoid glycals and showed their application towards the 
synthesis of nucleosides. ${ }^{8}$ The epoxidation of furanoid glycal 65b with DMDO (dimethyldioxirane) was highly face selective to give 568. The treatment of the epoxide 568 with (TMS) $)_{2}$ thymine provided a mixture of 569 (52\% yield) and 570 (30\% yield). The mixture was deprotected with TBAF in THF to afford 571. Its acetylation with $\mathrm{Ac}_{2} \mathrm{O}$-DMAP afforded C1-epi-arabinonucleoside triacetate 572 in $94 \%$ yield. On the other hand, reaction of furanoid glycal 66b (having free hydroxyl group at C-3) with DMDO in acetone with a minimal amount of DCM afforded $1: 1$ mixture of anhydro sugars 573 and 574. They further investigated reaction of $66 \mathbf{b}$ with a mixture of acetone/DCM in $6: 1$ ratio to furnish mixture of epoxides 573 and 574 in $9: 1$ ratio. Treatment of the mixture with (TMS) $)_{2}$ thymine in acetonitrile followed by desilylation with TBAF in THF and acetylation with acetic anhydride/DMAP resulted in a mixture of 575 and 572 in $4: 1$ ratio with $36 \%$ yield (Scheme 98 ).

In $1991 \mathrm{Kim}$ et al. prepared phosphonate isosteres of $\mathbf{5 7 7}$ (d4T), 578 (d4A), and 579 (ddA) (Fig. 5) monophosphates using regiospecific and highly stereoselective electrophilic addition to furanoid glycals as the key step. ${ }^{76}$ The starting material for this study was the glycal $\mathbf{5 8 2}$, which was readily prepared from thymidine 64a via thymidine-5'-carboxylic acid 581 in two steps by adopting the reported procedure of Horwitz and coworkers. ${ }^{77}$ Glycal 582 was treated with $\mathrm{PhSeCl}$ at $-70{ }^{\circ} \mathrm{C}$, to give a $12: 1$ mixture of $\mathbf{5 8 3}$ and $\mathbf{5 8 4}$ in high yield. This mixture was allowed to react with silver perchlorate in the presence of dimethyl(hydroxymethyl)phosphonate to afford the phosphonate 585 in
$41 \%$ overall yield. It was then transformed into the $\mathrm{d} 4 \mathrm{~T}$ phosphonate analogue $\mathbf{5 8 7}$ by the sequential oxidation with sodium periodate in methanol followed by phosphonate ester removal of the resulting $\mathbf{5 8 6}$ with TMSBr in DMF and finally by neutralization with $\mathrm{NaHCO}_{3}$ in overall $52 \%$ yield (Scheme 99). They also showed phosphonates $\mathbf{5 8 6}$ exhibited a potent antiviral activity comparable to that of $\mathbf{5 7 7}(\mathrm{d} 4 \mathrm{~T})$.

They also described the synthesis of glycal 591 from 2'deoxyadenosine $\mathbf{5 8 8}$ by following the same reaction sequence described for glycal 582. Glycal 591 on treatment with dimethyl(hydroxymethyl)phosphonate in the presence of $N$-(phenylseleno)phthalimide or IBr afforded 592 (65\% yield) or 593 (95\% yield) in a regiospecific and a highly stereoselective manner. Oxidative elimination of the phenylselenyl group in 592 or base (DBU) promoted elimination of hydrogen iodide in 593 gave olefin 594 in high yield, which on deprotection was converted to 595, phosphonate isostere of $\mathrm{d} 4 \mathrm{~A}$ (578) monophosphate, by following the same reaction sequence for the conversion of $\mathbf{5 8 6}$ to 587. The tetrahydrofuranyl derivative 596, a phosphonate isostere of ddA (579) monophosphate was also prepared by catalytic hydrogenation of the olefin 595. Dihydroxylation of the double bond in $\mathbf{5 9 4}$ with catalytic $\mathrm{OsO}_{4}$ and $\mathrm{NMO}$ as the oxidant gave diol 597 as a single isomer in high yield. The deblocking of the protecting groups in $\mathbf{5 9 7}$ led to $\mathbf{5 9 8}$, which is a phosphonate isostere of adenosine monophosphate. These $\mathrm{d} 4 \mathrm{~T}$ and $\mathrm{d} 4 \mathrm{~A}$ phosphonate analogues 587 and 595 exhibited potent anti HIV activity (Scheme 100).
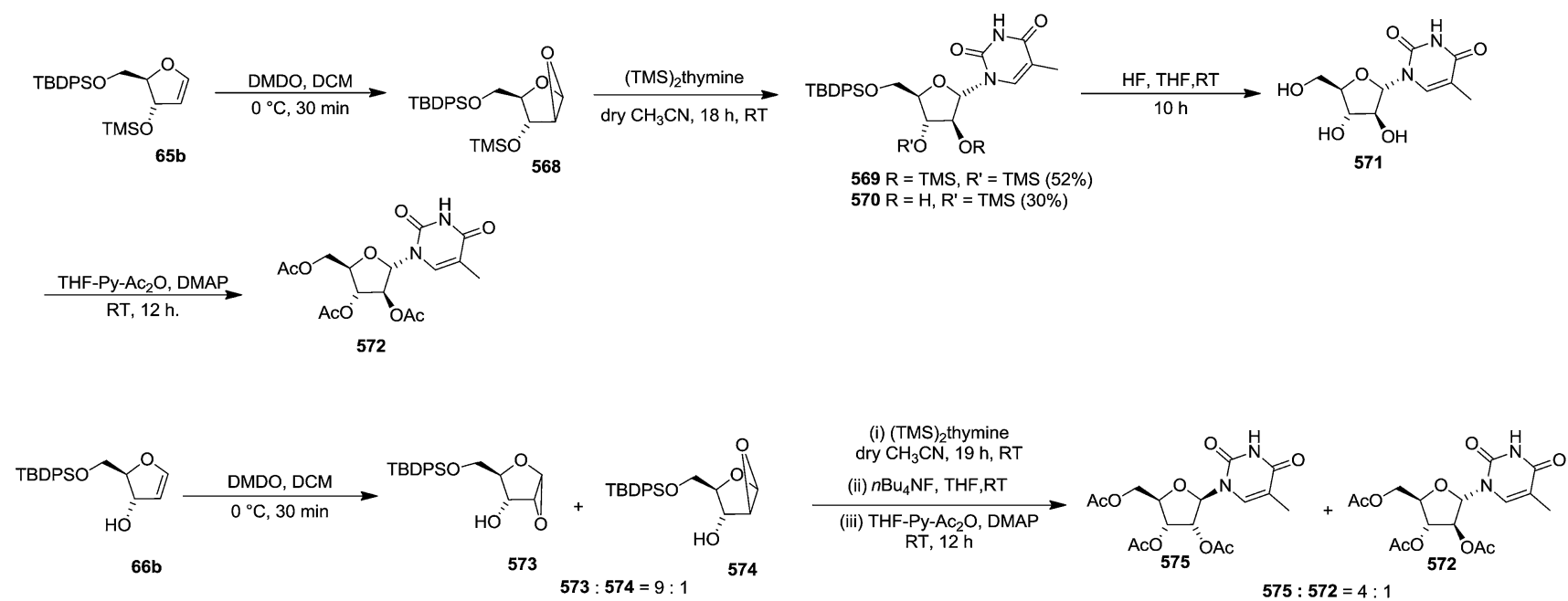

Scheme 98
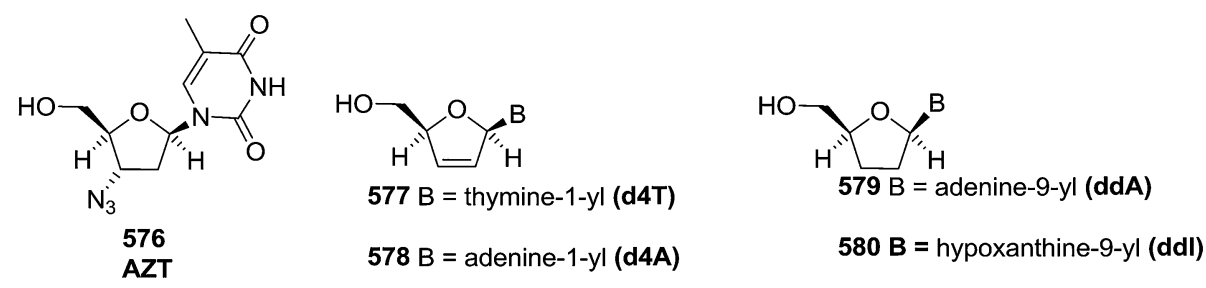

Fig. 5 Structures of AZT 576, d4T 577, d4A 578, ddA 579 and ddl 580. 


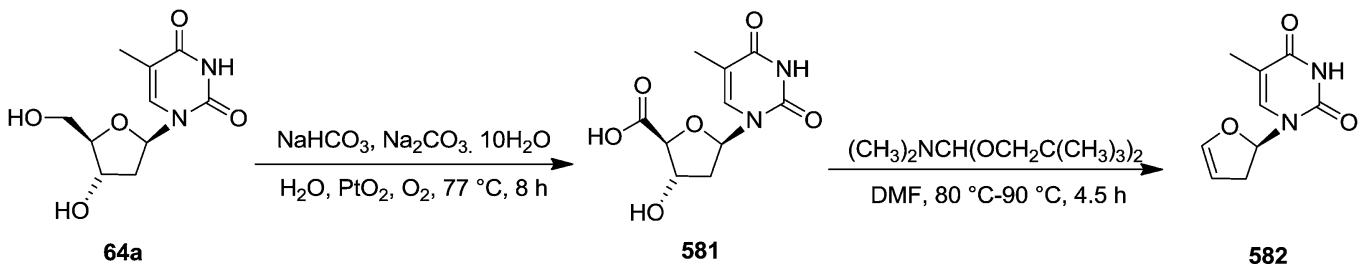<smiles>Cc1cn(C2C[C@H]([SeH]c3ccccc3)[C@H](Cl)O2)c(=O)[nH]c1=O</smiles>

583<smiles>Cc1cn(C2C[C@H]([PbH])[C@@H](Cl)O2)c(=O)[nH]c1=O</smiles>

584
$\mathrm{AgClO}_{4},\left(\mathrm{CH}_{3} \mathrm{O}\right)_{2} \mathrm{P}(\mathrm{O}) \mathrm{CH}_{2} \mathrm{OH}$ DCM, $-70{ }^{\circ} \mathrm{C}-0{ }^{\circ} \mathrm{C}$

$$
\left(\mathrm{H}_{3}\right.
$$<smiles>COP(=O)(COC1O[C@@H](n2cc(C)c(=O)[nH]c2=O)C[C@@H]1[Se]c1ccccc1)OC</smiles>

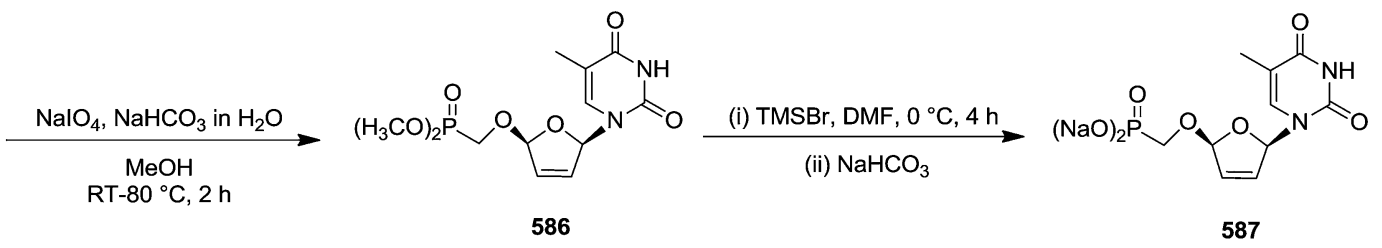

Scheme 99

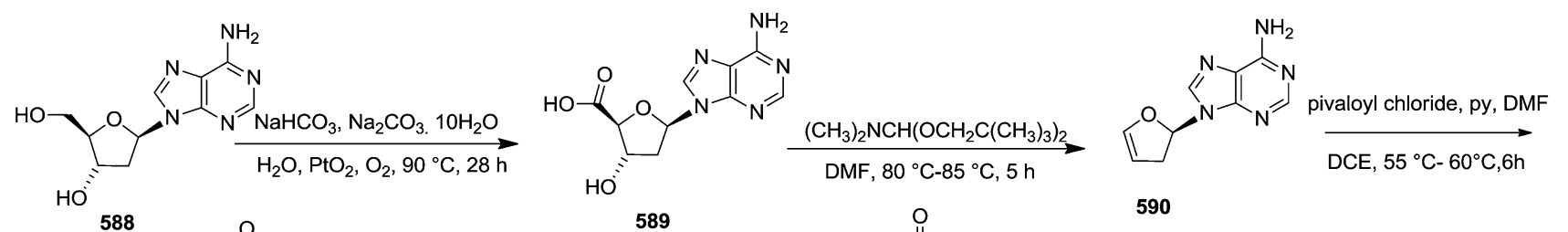

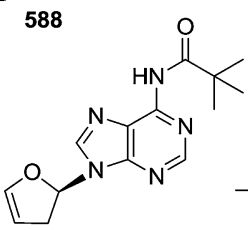

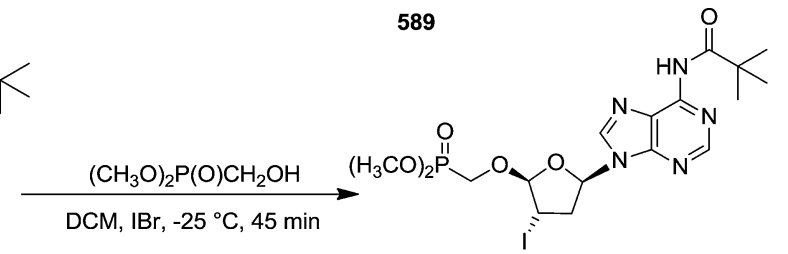

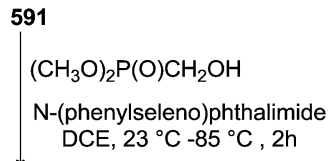<smiles>COP(=O)(O)OC[C@H]1OC(n2cnc3c(NC(=O)C(C)(C)C)ncnc32)C[C@@H]1[18OH]</smiles>
592<smiles>Nc1ncnc2c1ncn2[C@@H]1O[C@H](OCP([NH3+])(=O)O)[C@@H](O)[C@H]1O</smiles>
(ii) $\mathrm{TMSBr}, \mathrm{DMF}$, $0^{\circ} \mathrm{C}-25^{\circ} \mathrm{C}, 3 \mathrm{~h}$ (iii) $\mathrm{NH}_{4} \mathrm{OH}$

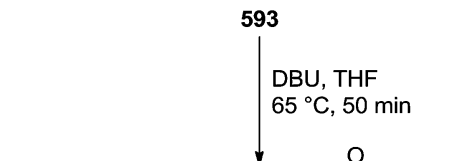

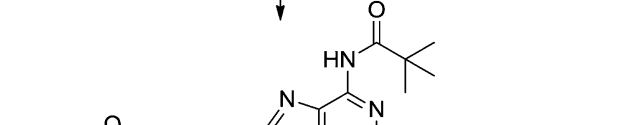

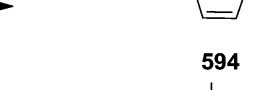
$\mathrm{OsO}_{4}, \mathrm{NMO}$ (ii) $\mathrm{TMSBr}, \mathrm{DMF}$, $0{ }^{\circ} \mathrm{C}-25^{\circ} \mathrm{C}, 3 \mathrm{~h}$ (iii) $\mathrm{NH}_{4} \mathrm{OH}$ DCM $23^{\circ} \mathrm{C}, 2 \mathrm{~h}$

$\checkmark$<smiles>COP(=O)(OCc1ccccc1)OC1O[C@@H](n2cnc3c(NC(=O)C(C)(C)C)ncnc32)[C@H](O)[C@@H]1O</smiles>

Scheme 100 
In 1992, Kim and Misco, demonstrated highly stereoselective synthesis of d4T 577 and ddA 579, antiviral nucleosides, from L-glutamic acid 269 via furanoid glycal intermediate. ${ }^{9}$ The synthesis of the requisite furanoid glycal 106 was derived from the known lactone $\mathbf{5 9 9}$ which was in turn, readily available by the diazotation-lactonization of L-glutamic acid 269. ${ }^{78}$ Pivaloyl group protection of the free hydroxyl group of $\mathbf{5 9 9}$ with pivaloyl chloride gave 600, which on DIBALH reduction afforded 601. Its chlorination with $\mathrm{SOCl}_{2}$ followed by elimination of chloride $\mathbf{6 0 2}$ with $\mathrm{KO} t \mathrm{Bu}$ gave the glycal 106 (overall 52\% yield). Addition of acetic acid to glycal $\mathbf{1 0 6}$ in the presence of NIS produced a mixture of 603 and 604 in a ratio of $14: 1$. This mixture without further purification was coupled with silylated N6benzoyladenine in the presence of $\mathrm{SnCl}_{4}$ to give the adenosine analogue 605 (45\% yield over 2 steps) after chromatographic purification. Hydrogenolysis of iodide $\mathbf{6 0 5}$ followed by removal of the pivaloyl group by saponification gave ddA 579 in 75\% yield (Scheme 101).
Then they repeated this reaction sequences with pyrimidine series. But in this case, they directly coupled the pyrimidine base and the furanoid glycal in the presence of NIS. When NIS was added to a mixture of glycal 106 and silylated thymine in DCM, the desired thymidine analogue 606 was formed as a major product (Scheme 102), which without purification, on treatment with DBU furnished the anhydro intermediate 607 in $52 \%$ overall yield. Its treatment with $\mathrm{KO} t \mathrm{Bu}$ in THF produced olefin 608 (82\% yield) which on acyl deprotection with NaOMe yielded 577 (d4T) in 95\% yield.

Liotta et al. described the synthesis of nucleosides via regionand stereoselective electrophilic addition to furanoid glycals 610 which was prepared from lactone 609 in a straightforward fashion. ${ }^{79}$ The DIBAL-H reduction of 609 followed by addition of $\mathrm{SOCl}_{2}$ and $\mathrm{Et}_{3} \mathrm{~N}$ to the corresponding lactol afforded furanoid glycal 610. Its exposure to an appropriate source of electrophilic sulfur in the presence of a silylated nucleoside base and Lewis acids produced the pyrimidine and purine derivatives 611 in
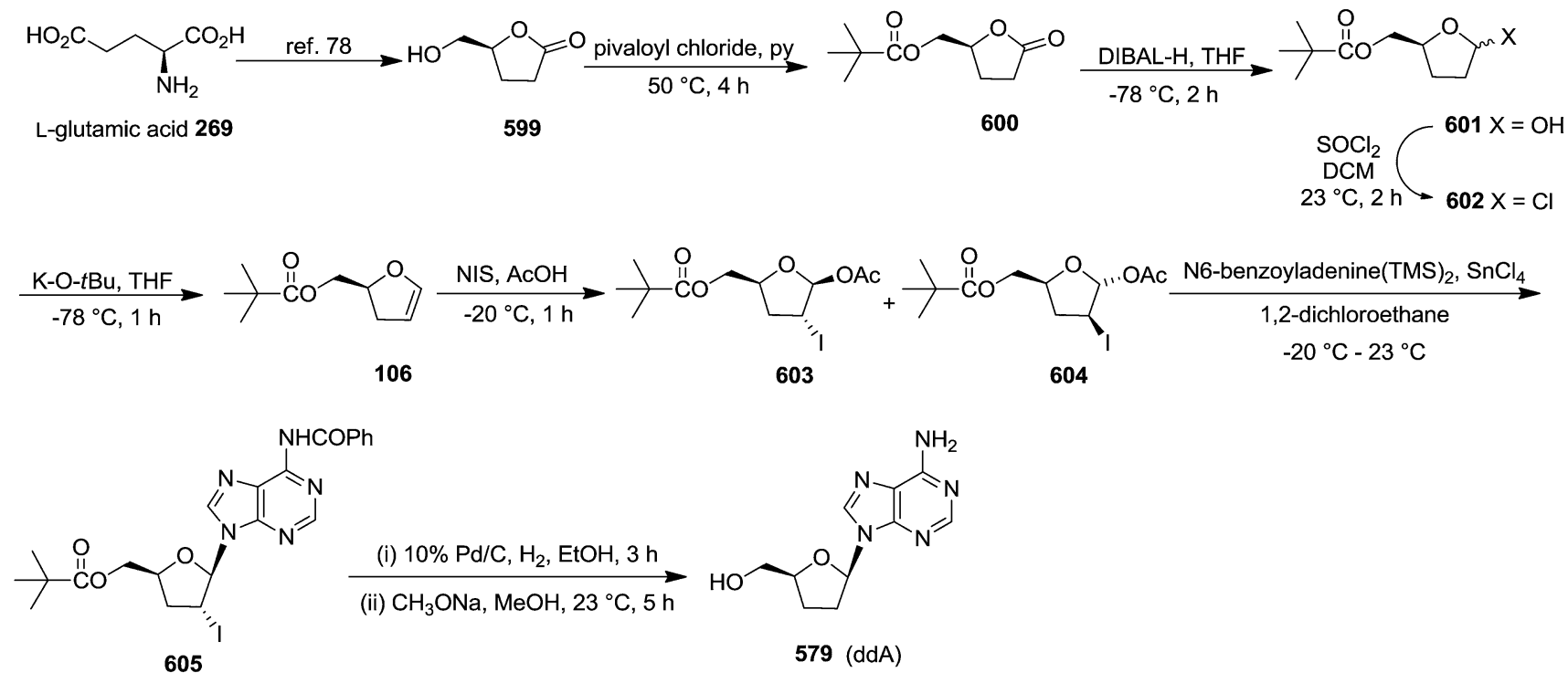

Scheme 101

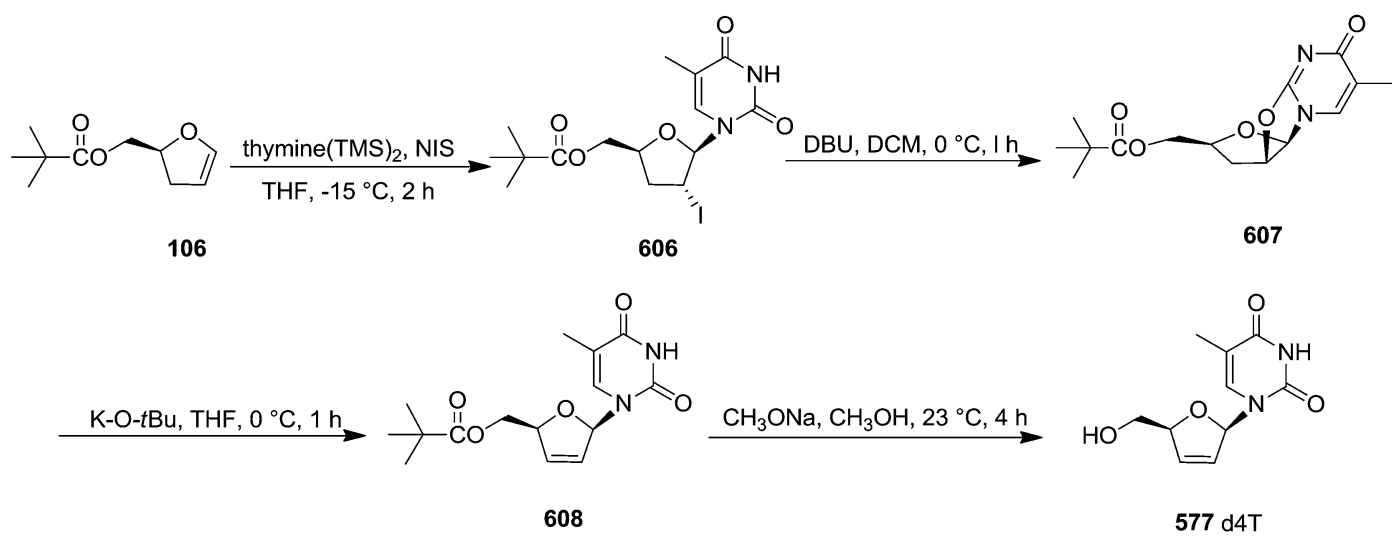

Scheme 102 


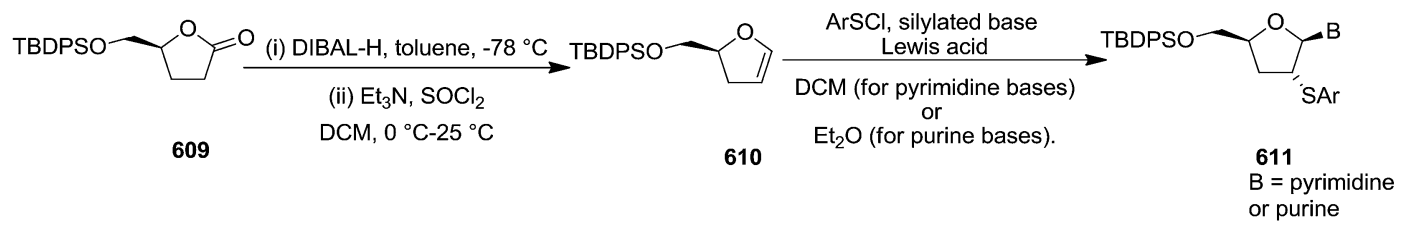

Scheme 103

Table 11 Additions of arylsulfenyl chlorides/silylated bases to glycals

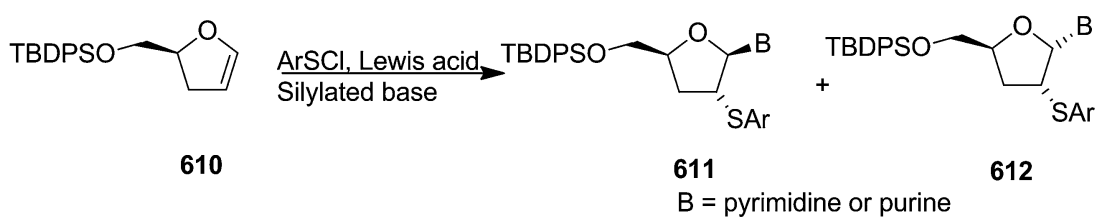

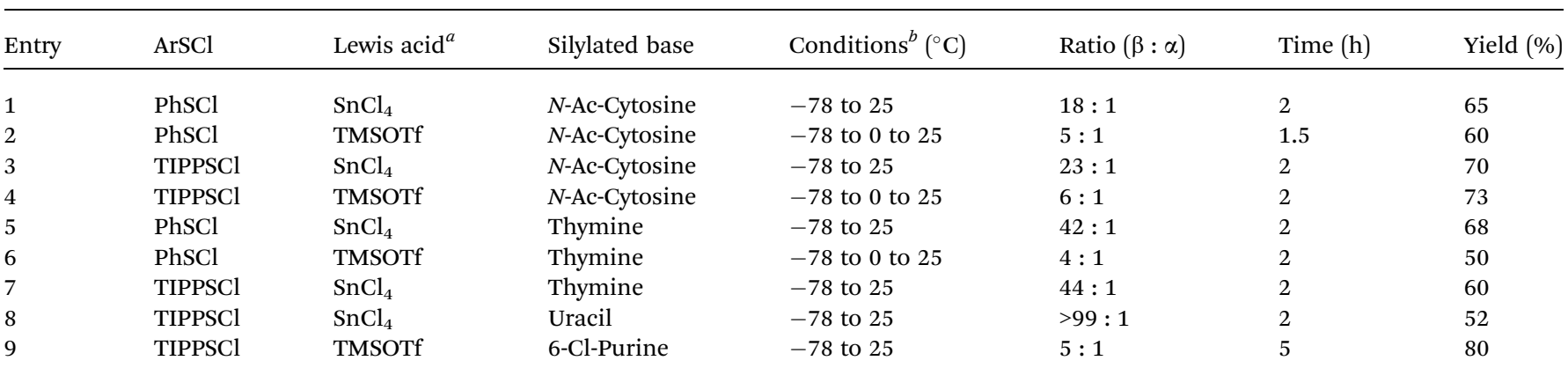

${ }^{a}$ The reaction utilized 1.15 eq. of Lewis acid. ${ }^{b}$ (i) -78 to 0 to $25^{\circ} \mathrm{C}$ : after addition of the sulfenyl chloride, the reaction was kept at $-78{ }^{\circ} \mathrm{C}$ for 30 min and then warmed to $0{ }^{\circ} \mathrm{C}$. The silylated base and Lewis acid were then introduced, and the reaction was allowed to warm to room temperature $(25$ ${ }^{\circ} \mathrm{C}$ ). (ii) -78 to $25^{\circ} \mathrm{C}$ : after addition of the sulfenyl chloride, the reaction was kept at $-78{ }^{\circ} \mathrm{C}$ for $30 \mathrm{~min}$. The silylated base and Lewis acid were then introduced and the reaction was allowed to warm to room temperature. (iii) The solvent of choice for pyrimidine bases was DCM and diethyl ether for purine bases. TIPP = 2,4,6-triisopropylphenyl.

a stereo- and regioselective fashion by judicious choice of the Lewis acid, solvent and temperature (Scheme 103, Table 11).

In 1993, Castillón and co workers showed selenium controlled stereoselective synthesis of a series of $2^{\prime}$-deoxy nucleosides and a formal synthesis of $3^{\prime}$-azido-3'-deoxythymidine (AZT, 576) and $3^{\prime}$-fluoro- $3^{\prime}$-deoxythymidine (FDT, 621), a powerful anti HIV agent, starting from furanoid glycals. Furanoid glycals 139 and 132c were derived from 2,3:5,6-di-O-

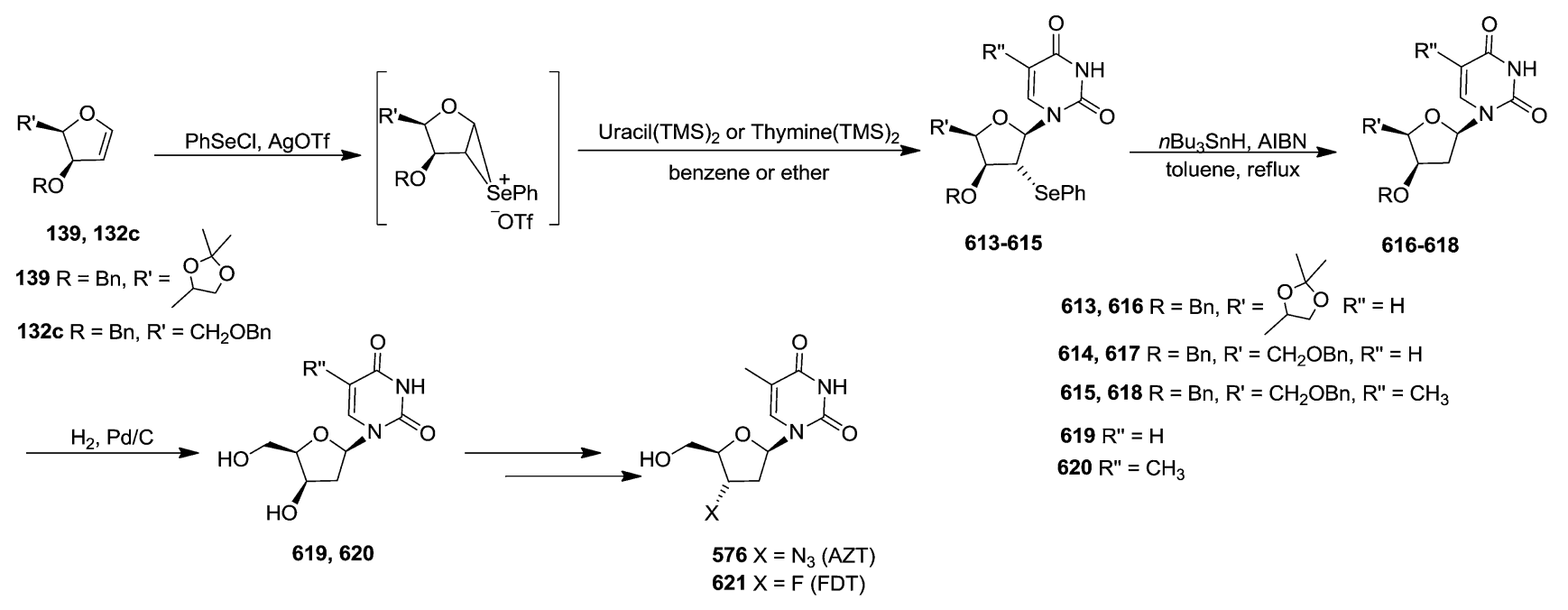

Scheme 104 


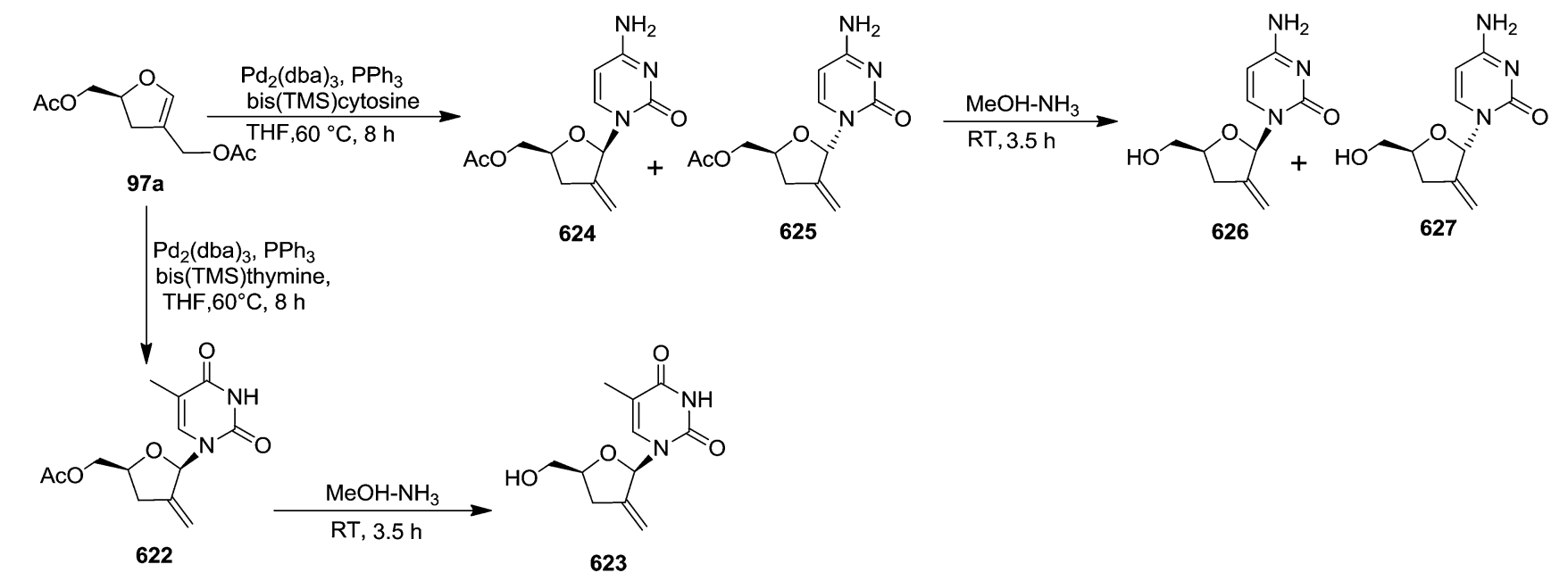

Scheme 105

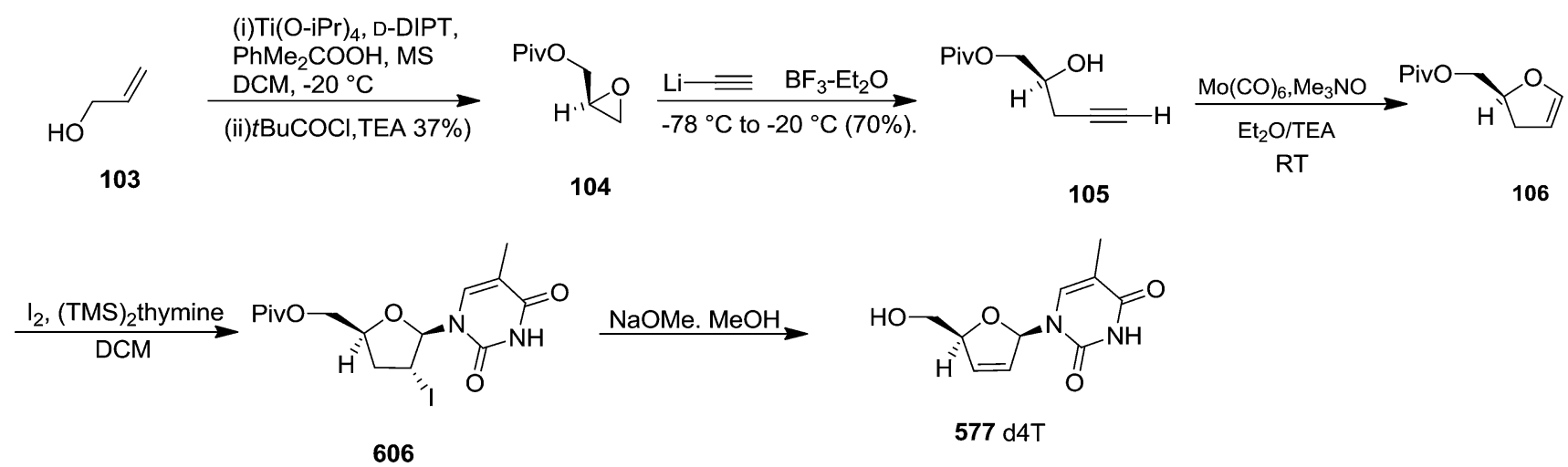

Scheme 106

isopropyliden-manno furanose $\mathrm{f}^{31}$ and 2,3-O-isopropylidene-lyxofuranose $^{30}$ respectively. $^{10}$ These glycals (139 and 132c) on treatment with $\mathrm{PhSeCl}$ in presence of AgOTf followed by glycosylation with pyrimidine bases in non polar solvents accomplished 2'-deoxy-2'-phenylselenenyl nucleosides 613-615. In all cases, removal of the phenylselenenyl group was carried out by reaction with $n \mathrm{Bu}_{3} \mathrm{SnH}$ in refluxing toluene to afford 2 -deoxynucleosides 616-618 in 80-90\% overall yields from the glycal.
Hydrogenolysis of compounds 617 and 618 using $\mathrm{Pd} / \mathrm{C}$ as the catalyst gave the unprotected nucleosides 619 and 620 in quantitative yield (Scheme 104).

In 1995, Florent and coworkers also showed the utilization of furanoid glycal 97a (synthesized from $\alpha$-D-isosaccharino-1,4lactone 93, Scheme 16) for the synthesis of $2^{\prime}, 3^{\prime}$-dideoxy-2'-Cmethylidene-5-methyl uridine 623, 3'-deoxy analog of DMDC 626 and $627 . .^{27}$ The glycosylation of bis-(trimethylsilyl)thymine

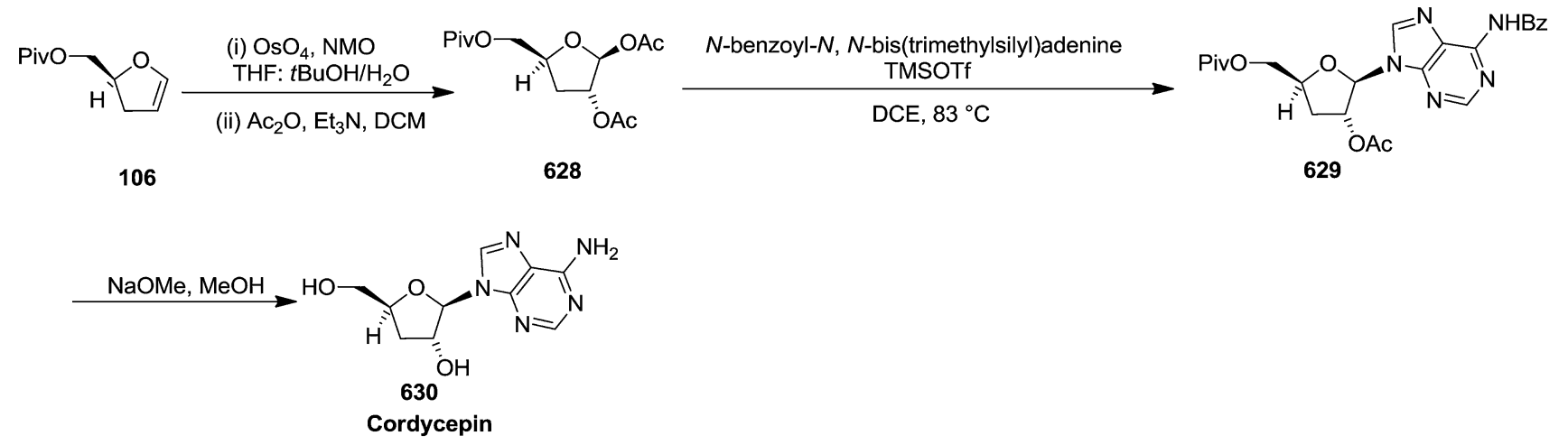




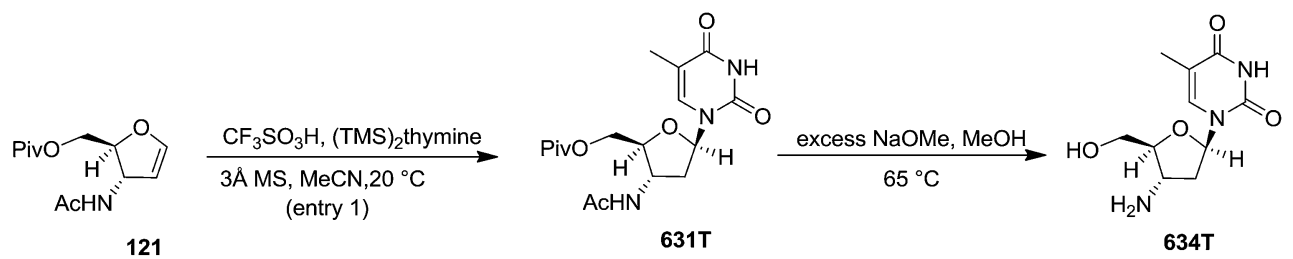

121

$631 \mathrm{~T}$

$634 \mathrm{~T}$

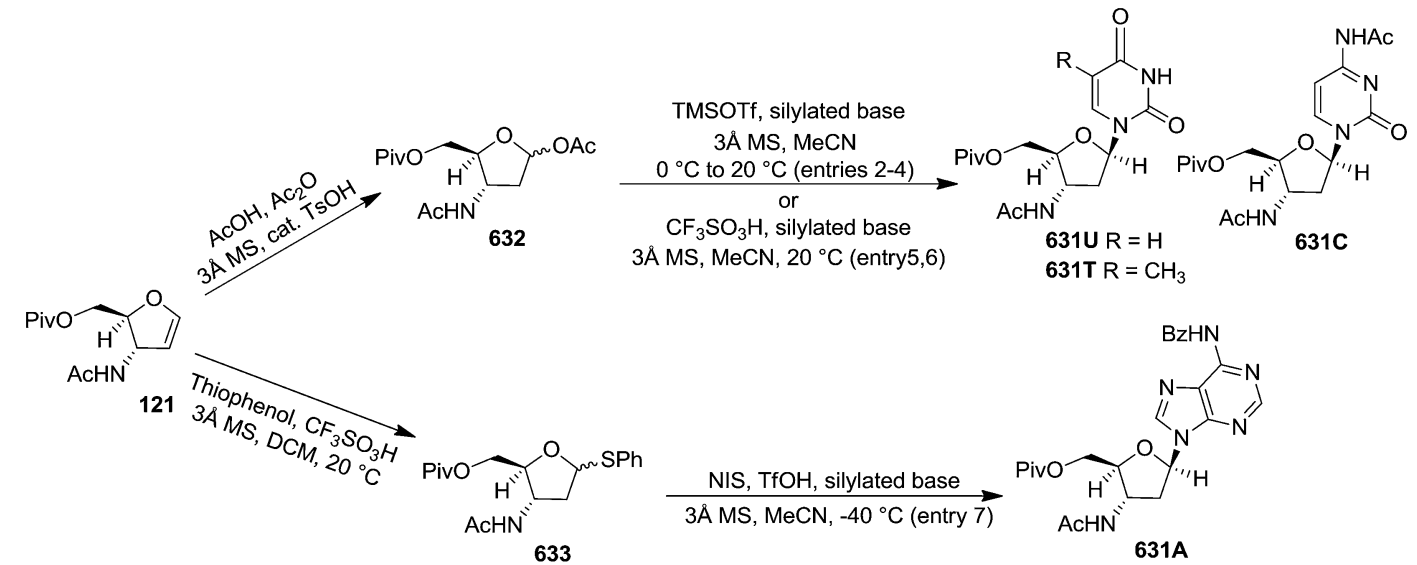

Scheme 108

with crude furanoid glycal in the presence of $\operatorname{Pd}_{2}(\mathrm{dba})_{3}$ and $\mathrm{PPh}_{3}$ gave nucleoside $\mathbf{6 2 2}$ in $25 \%$ overall yield. Deprotection by ammonolysis led to the $2^{\prime}, 3^{\prime}$-dideoxy-2'-C-methylidene-5-methyl uridine $\mathbf{6 2 3}$ ( $80 \%$ yield). Glycosylation of silylated cytosine with 97a under the identical reaction conditions afforded $\beta$-nucleoside $\mathbf{6 2 4}$ along with the corresponding $\alpha$-anomer $\mathbf{6 2 5}(40 \%$ overall yield and ratio $\beta: \alpha=8: 2$ ) after column purification of the crude product mixture. Removal of the acetyl group produced 3'-deoxy analog of DMDC 626 and 627 (Scheme 105).

McDonald and coworkers synthesized Stavudine (d4T, 577), an anti-AIDS compound, ${ }^{80}$ from allyl alcohol 103 derived furanoid glycal key intermediate 106, whose synthesis already described in Scheme 18. ${ }^{29,80}$ Iodine-mediated addition of (TMS) $)_{2}$ thymine to 106 gave iodonucleoside 606 which on without further purification treated with freshly prepared NaOMe to accomplish stavudine 577 (d4T) (Scheme 106).

Dihydroxylation of 106 with $\mathrm{OsO}_{4}$ in presence of NMO followed by acylation of the crude diol provided a $13: 4: 3: 1$ mixture of diacetylated products favouring 628 (Scheme 107). This mixture was subjected to Lewis acid catalyzed adenine glycosylation to give a 9:1 mixture of stereoisomers favouring 629. Methanolysis of acyl groups followed by column purification produced the synthetic cordycepin 630 (Scheme 107).

After reporting the synthesis of d4T $\mathbf{5 7 7}$ and cordycepin $\mathbf{6 3 0}$ from 106, McDonald and Gleason then optimized the glycosylation of 3-amidofuranose glycal $\mathbf{1 2 1}$ or $\mathbf{1 2 2}$ (whose synthesis already discussed in Scheme 19, Table 4) with pyrimidine and purine bases and found that reaction of 121 with $\mathrm{CF}_{3} \mathrm{SO}_{3} \mathrm{H}$ and silylated thymine at room temperature with acetonitrile as solvent afforded predominantly the $\beta$-nucleoside 631T (Scheme 108, Table 12, entry 1). ${ }^{29}$ Treatment of $\mathbf{1 2 1}$ with acetic acid gave a more highly reactive glycosyl donor $\mathbf{6 3 2}$, which underwent highyielding TMSOTf-induced glycosylation with silylated pyrimidine bases in the presence of acetonitrile to afford the desired $\beta$ - nucleoside 631T, U, C (Table 12, entries 2-4). They obtained similar results by using $\mathrm{CF}_{3} \mathrm{SO}_{3} \mathrm{H}$ as the activating agent (Table 12, entries 5 and 6); possibly $\mathrm{CF}_{3} \mathrm{SO}_{3} \mathrm{H}$ was also generated by in situ hydrolysis of trimethylsilyl trifluoromethanesulfonate.

For the addition of purine bases, they treated the more reactive thioglycoside donor 633 obtained from 121 with NIS and $\mathrm{CF}_{3} \mathrm{SO}_{3} \mathrm{H}$ at significantly lower temperature giving the purine $\beta$-nucleoside $631 \mathrm{~A}$ with high stereoselectivity (Table 12, entry 7). The deblocking of ester and amide protective groups of 631T with $\mathrm{NaOMe}$ in $\mathrm{MeOH}$ gave the $3^{\prime}$-amino- $2^{\prime}, 3^{\prime}$-dideoxythymidine 634T.

In the case of guanine glycosylations, the reaction of 633 under kinetic conditions gave primarily the N-7 regioisomer 631G* as the major nucleoside product (Scheme 109, Table 13,

Table 12 Glycosylation of 121 to $3^{\prime}$-amido-2', $3^{\prime}$-dideoxynucleosides ${ }^{a}$

\begin{tabular}{|c|c|c|c|c|}
\hline Entry & Silylated base & $\begin{array}{l}\text { Glycosyl } \\
\text { donar }\end{array}$ & Conditions & $\begin{array}{l}\text { Nucleoside, } \\
\text { isolated yield } \\
(\beta: \alpha \text { ratio })\end{array}$ \\
\hline 1 & $(\mathrm{TMS})_{2}$-thymine & 121 & a & 631T, $50 \%(>20: 1)$ \\
\hline 2 & $(\mathrm{TMS})_{2}$-thymine & 632 & $\mathrm{~b}$ & 631T, $85 \%(4.7: 1)$ \\
\hline 3 & $(\mathrm{TMS})_{2}$-uracil & 632 & $\mathrm{~b}$ & 631U, $85 \%(21: 1)$ \\
\hline 4 & $\begin{array}{l}N-\mathrm{Ac}(\mathrm{TMS})_{2^{-}} \\
\text {cytosine }\end{array}$ & 632 & $\mathrm{~b}$ & 631C, $77 \%(8.7: 1)$ \\
\hline 5 & $(\mathrm{TMS})_{2}$-thymine & 632 & $\mathrm{c}$ & 631T, $87 \%(8.4: 1)$ \\
\hline 6 & $\begin{array}{l}N-\mathrm{Ac}(\mathrm{TMS})_{2^{-}} \\
\text {cytosine }\end{array}$ & 632 & $\mathrm{c}$ & 631C, $84 \%(3.3: 1)$ \\
\hline 7 & $\begin{array}{l}N-\mathrm{Bz}(\mathrm{TMS})_{2^{-}} \\
\text {adenine }\end{array}$ & 633 & $\mathrm{~d}$ & 631A, $42 \%(>10: 1)$ \\
\hline
\end{tabular}

${ }^{a}$ (Method a) $\mathrm{CF}_{3} \mathrm{SO}_{3} \mathrm{H}$, silylated base, $3 \AA$ MS, MeCN, $20{ }^{\circ} \mathrm{C}$ (entry 1); (Method b) TMSOTf, silylated base, $3 \AA \mathrm{MS}$, MeCN, $0{ }^{\circ} \mathrm{C}$ to $20{ }^{\circ} \mathrm{C}$ (entries 2-4); (Method c) $\mathrm{CF}_{3} \mathrm{SO}_{3} \mathrm{H}$, silylated base, $3 \AA$ MS, MeCN, $20{ }^{\circ} \mathrm{C}$ (entries 5, 6); (Method d) NIS, TfOH, silylated base, $3 \AA$ MS, $\mathrm{MeCN},-40{ }^{\circ} \mathrm{C}$ (entry 7 ). 

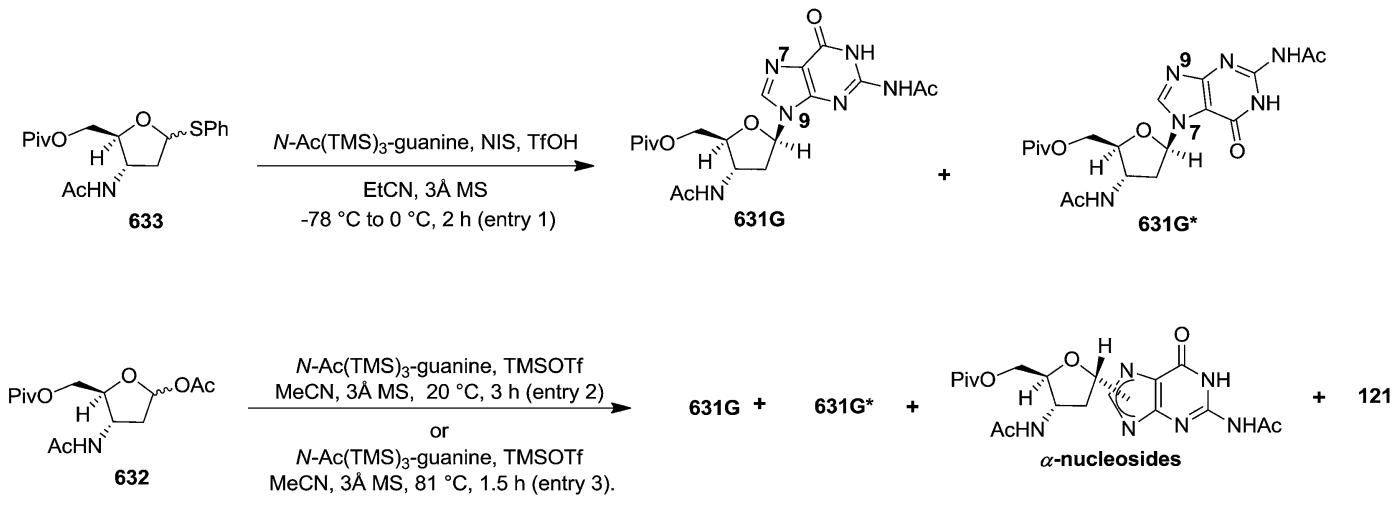

Scheme 109

Table 13 Glycosylation of 632 and 633 with silylated guanine base ${ }^{a}$

\begin{tabular}{|c|c|c|c|c|}
\hline Entry & $\begin{array}{l}\text { Glycosyl } \\
\text { donar }\end{array}$ & Condition & $\begin{array}{l}\text { Nucleosides, } \\
\text { combined yield }\end{array}$ & $\begin{array}{l}\text { Relative ratio of } \\
\text { products } 631 \mathrm{G}: \mathbf{6 3 1 G}^{*}: \\
\alpha \text {-nucleosides }: \mathbf{1 2 1}\end{array}$ \\
\hline 1 & 633 & $\mathrm{a}$ & $35 \%$ & $1.0: 7.3: 0: 0$ \\
\hline 2 & 632 & b & $38 \%$ & $3.4: 1.4: 1.0: 0$ \\
\hline 3 & 632 & $\mathrm{c}$ & $50 \%$ & $2.2: 1.0: 12: 3.2$ \\
\hline
\end{tabular}

entry 1). They observed that when glycosylation of guanine with 632 was carried out at room temperature, the proportion of $\mathrm{N}-9$ regioisomer 631G increased along with $\alpha$-nucleoside isomers (entry 2) and were the major product when the glycosylation was conducted in refluxing acetonitrile (entry 3 ).

Epoxidation of 121 with peroxyacids gave 635 (Scheme 110). Acylation of free hydroxyl group yielded 636 which permitted trans-glycosylation under Lewis acid conditions to give purine $\beta$ nucleosides including 637. Basic methanolysis of 637 yielded the deprotected puromycin aminonucleoside 638.

Peroxyacetic acid epoxidation followed by acetylation of 3trifluoroacetamide glycal 122 furnished diacetate 640 via 639 (Scheme 111). Under the thermodynamic conditions of these glycosylations, the naturally occurring $\mathrm{N}-9$ regioisomers 641A, 641G, and 641A' were the major products (Table 14, entries 1-3).
DMDO epoxidation of $\mathbf{1 2 2}$ was also directed by the amide when epoxidation was conducted in solvent DCM. The crude glycal epoxide 642 reacted stereospecifically with silylated pyrimidine bases to give 641T, U, C in good yields (Scheme 111, Table 14, entries 4-6), whereas in the case of pyrimidine bases, benzoyladenine gave 641A in a very low isolated yield (Table 14, entry 7).

In 1997, Castillón et al. also reported the formation of $2^{\prime}, 3^{\prime}$ dideoxy nucleosides by electrophilic addition of selenium to furanoid glycal 610, which was synthesized from 2-deoxyribose $67{ }^{81}$ They further discussed the synthesis of d4T 577 via precursor 656 through selenium-mediated glycosylation and selenoxide elimination.

Thus, 2-deoxyribose 67 was converted into the phenyl-1seleno-glycoside 645 (mixture $\alpha / \beta=1.9: 1$ ) in four steps involving methyl glycoside synthesis, selective $5-\mathrm{OH}$ protection, Barton deoxygenation, and treatment with $\mathrm{PhSeH}$ in the presence of $\mathrm{BF}_{3} \cdot \mathrm{OEt}_{2}$. Oxidation of $\mathbf{6 4 5}$ gave glycal $\mathbf{6 1 0}$ with a yield of $52 \%$. The reaction of glycal 610 with (TMS) $)_{2}$ uracil, $\mathrm{PhSeCl}$, and AgOTf at room temperature in ether led to a mixture of $2^{\prime}$ phenylselenenyl nucleosides 648 and 649 in a $99: 1$ ratio in good yield. Similarly, they treated glycal 610 with $(\mathrm{TMS})_{2^{-}}$ thymine to obtain $2^{\prime}$-phenylselenenyl nucleosides 650 and 651 with a ratio of $90: 10$ in excellent yields.

Under identical reaction condition, the reaction of glycal $\mathbf{6 1 0}$ with silylated 6-chloropurine showed a lower stereoselectivity (ratio 652/653, $3: 1$ ). In order to increase the $\beta$-stereoselectivity of the glycosylation step, they synthesized glycal 647 in a similar way the glycal 610 was synthesised. In this case a mixture of 654/ $655(\beta / \alpha=89: 11)$ was obtained in a yield of $78 \%$ (Scheme 112).
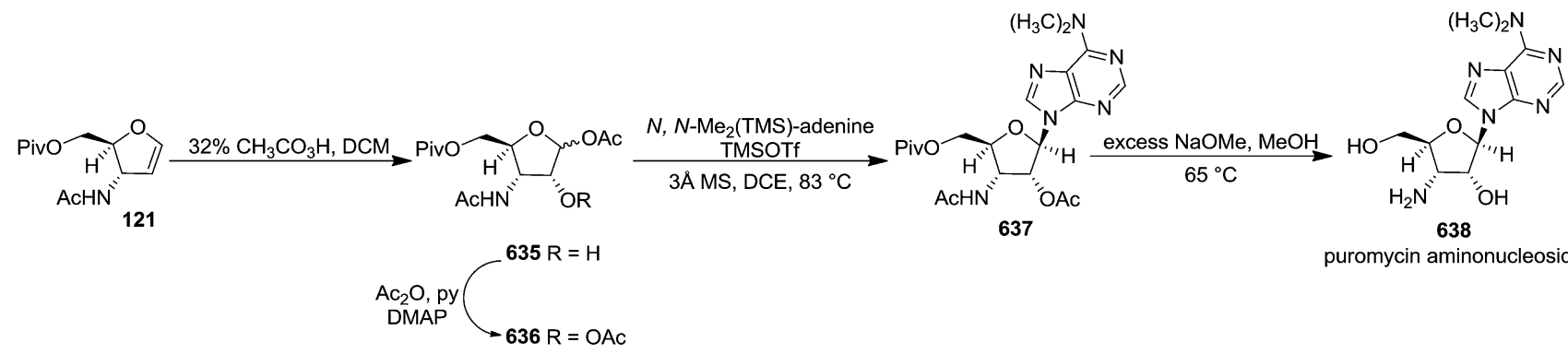

puromycin aminonucleoside

Scheme 110 


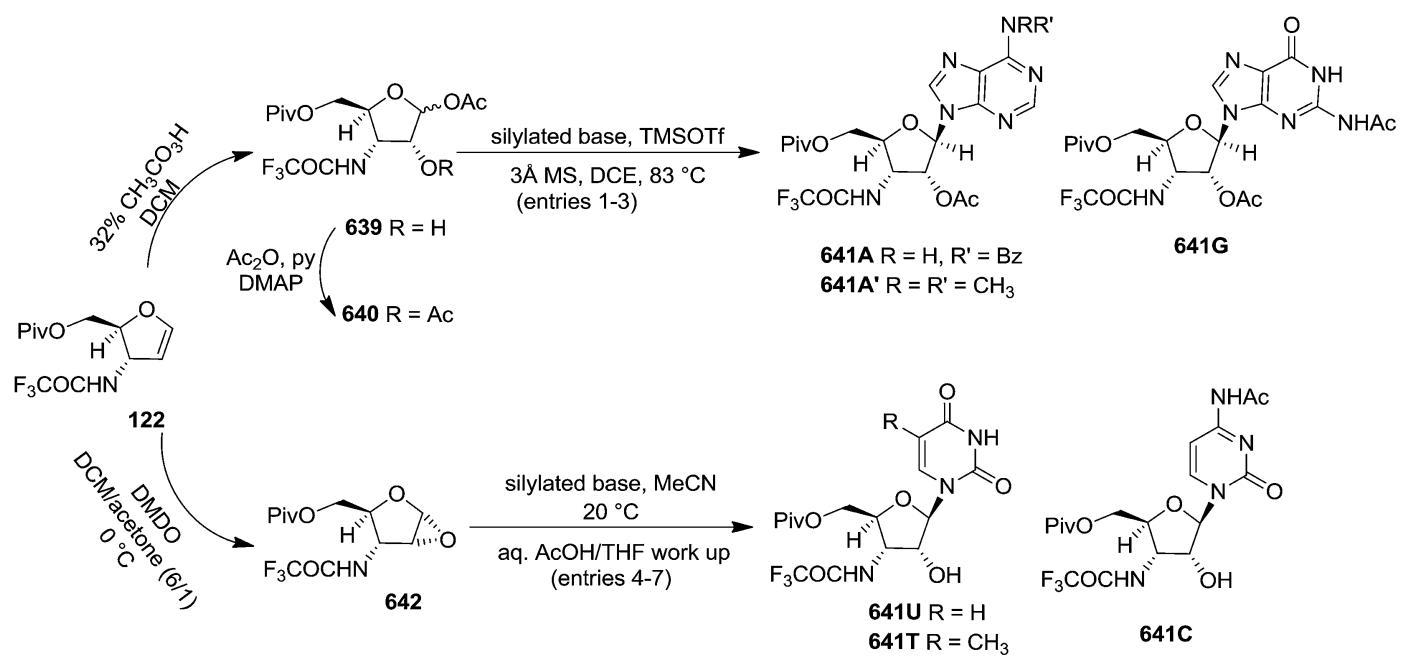

Scheme 111

Table 14 Epoxidation/glycosylation of 122 to $3^{\prime}$-amido-3'deoxynucleosides ${ }^{a}$

\begin{tabular}{|c|c|c|c|c|}
\hline Entry & Silylated base & $\begin{array}{l}\text { Glycosyl } \\
\text { donar }\end{array}$ & Conditions & $\begin{array}{l}\text { Nucleoside, } \\
\text { isolated yield }\end{array}$ \\
\hline 1 & $N$-Bz(TMS) $)_{2}$-adenine & 640 & a & 641A, 90\% \\
\hline 2 & $N$-Ac(TMS) $)_{3}$-guanine & 640 & a & 641G, $77 \%(10: 1)$ \\
\hline 3 & $N, N-\mathrm{Me}_{2}(\mathrm{TMS})$-adenine & 640 & a & 641A', $71 \%$ \\
\hline 4 & $(\mathrm{TMS})_{2}$-uracil & 642 & $\mathrm{~b}$ & 641U, $80 \%$ \\
\hline 5 & $(\mathrm{TMS})_{2}$-thymine & 642 & b & 641T, 86\% \\
\hline 6 & $N$-Ac(TMS $)_{2}$-cytosine & 642 & b & 641C, $71 \%$ \\
\hline 7 & $N$-Bz(TMS $)_{2}$-adenine & 642 & $\mathrm{~b}$ & 641A, $16 \%$ \\
\hline
\end{tabular}

${ }^{a}$ (a) silylated base, TMSOTf, $3 \AA$ A MS, DCE, $83{ }^{\circ} \mathrm{C}$, (entries 1-3); (b) silylated base, MeCN, $20^{\circ} \mathrm{C}$, aq. AcOH/THF work up (entries 4-7).

Compound 650 on oxidative elimination afforded the corresponding didehydro derivative 656 in $85 \%$ yield by using $t \mathrm{BuOOH} / \mathrm{Ti}\left(\mathrm{O}^{\mathrm{i}} \mathrm{Pr}\right)_{4}$ as an oxidative system; the deprotection of the TBDPS group gave d4T 577 (Scheme 113).

In the same year, this group also reported stereoselective synthesis of $2^{\prime}$-deoxy-2'-phenylselenenyl nucleosides from furanoid glycals in a "one pot" reaction and efficiently converted them into $2^{\prime}$-deoxy nucleosides. ${ }^{83}$ They also showed the stereoselectivity of the reaction was affected by some of the factors such as stereochemistry at position 3 , the nature of the protecting groups, the phenylselenenyl reagent and the solvent. For this purpose they synthesized a series of furanoid glycals. Glycal 139 and 214 (ref. 5) from D-mannose derived furanoid glycal 26. The glycal 132c was prepared from D-mannose by degradation of the side chain, in a similar way to $26,{ }^{21}$ or from 2-deoxyribose $67 .{ }^{24}$

Treatment of 139 with $\mathrm{PhSeCl}$ and (TMS) $)_{2}$ uracil in the presence of AgOTf in ether at room temperature yielded $\beta$-gluco nucleoside 613 and $\alpha$-gluco nucleoside 657 in $81 \%$ yield (ratio $613 / 657=90: 10)($ Scheme 114, Table 15, entry 1).

Under the identical reaction condition treatment of glycal 214 and 132c afforded $2^{\prime}$-deoxy- $2^{\prime}$-phenylselenenyl nucleosides $\beta$-gluco 658/ $\alpha$-gluco 659 (86 : 14) in 95\% yield and $\beta$-xylo 614/ $\alpha$ xylo 660 (91:9) in 91\% yield respectively (Table 15, entries 2 and 3).

To show the stereoselectivity in the formation of $2^{\prime}$-deoxy-2'phenylselenenyl nucleosides derived from erythro configured furanoid glycals, they synthesized glycals 661, 662, 66e and 665 (Table 16) from D-ribonic- $\gamma$-lactone ${ }^{18}$ and 71a, 90, 663, 664 and 66j from 2-deoxyribose. ${ }^{24,28}$ For the glycals $(661,662,66 e, 71 a$,

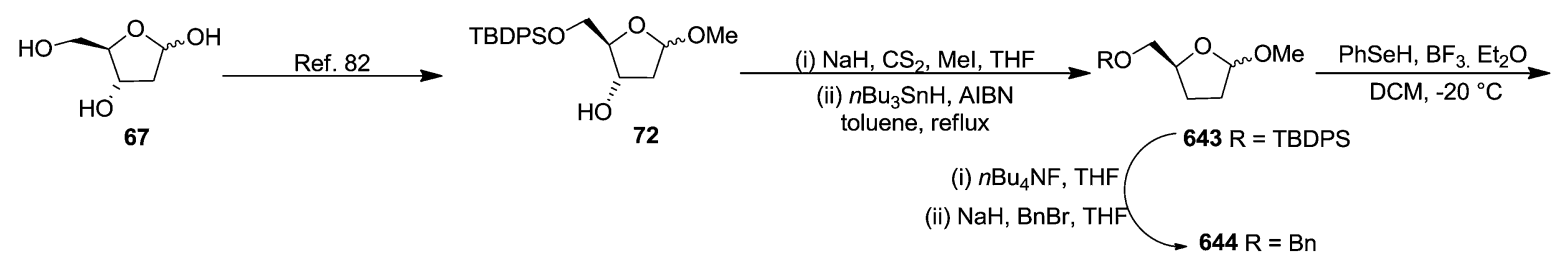

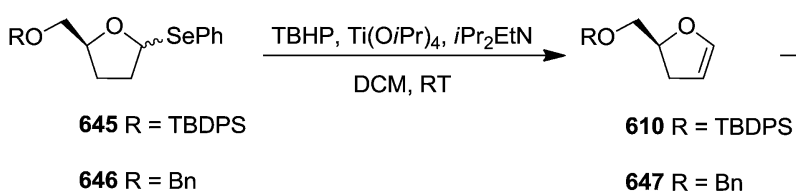

$647 \mathrm{R}=\mathrm{Bn}$

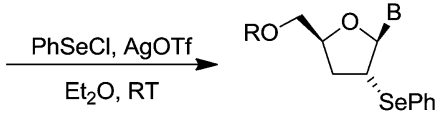

$648 \mathrm{R}=$ TBDPS, $\mathrm{B}=$ Uracil $650 \mathrm{R}=$ TBDPS, $\mathrm{B}=$ Thymine $652 \mathrm{R}=$ TBDPS, $\mathrm{B}=6-\mathrm{Cl}$-purine $654 \mathrm{R}=\mathrm{Bn}, \mathrm{B}=6-\mathrm{Cl}$-purine

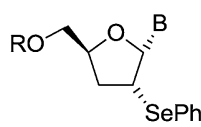

$649 \mathrm{R}=$ TBDPS, $\mathrm{B}=$ Uracil $651 R=$ TBDPS,$B=$ Thymine $653 \mathrm{R}=$ TBDPS, $\mathrm{B}=6$-Cl-purine $655 \mathrm{R}=\mathrm{Bn}, \mathrm{B}=6-\mathrm{Cl}$-purine 


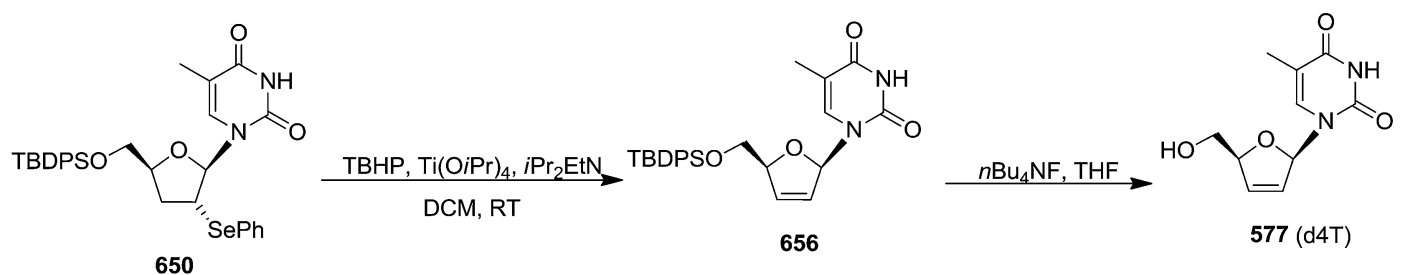

Scheme 113

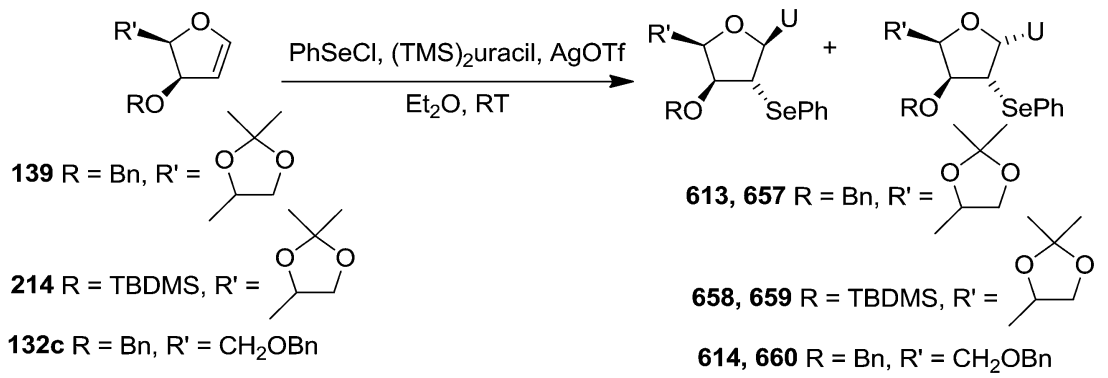

Scheme 114

Table 15 Stereoselectivity in the synthesis of $2^{\prime}$ - phenylselenenyl nucleosides derived from threo glycals ${ }^{a}$

\begin{tabular}{|c|c|c|c|c|}
\hline & Starting glycals & Time (h) & Yield $^{b}(\%)$ & $2^{\prime}$-Selenenyl nucleosides ${ }^{c}$ (diastereomeric ratio) \\
\hline 139 & $\mathrm{R}=\mathrm{Bn}, \mathrm{R}^{\prime}=$ & 1 & 81 & $\beta$-Gluco $613: \alpha$-Gluco $657(90: 10)$ \\
\hline 214 & $R=T B D M S, R$ & 1 & 95 & $\beta$-Gluco 658 : $\alpha$-Gluco $659(86: 14)$ \\
\hline $132 \mathrm{c}$ & $\mathrm{R}=\mathrm{Bn}, \mathrm{R}^{\prime}=\mathrm{Br}$ & 0.5 & 90 & $\beta$-xylo $614: \alpha$-xylo $660(91: 9)$ \\
\hline
\end{tabular}

${ }^{a}$ Reactions were carried out using the molar ratio glycal/PhSeCl/AgOTf/Uracil(TMS $)_{2}=1 / 1.5 / 1.7 / 2 .{ }^{b}$ Expressed as a percentage of recovered mixture of products after chromatography. ${ }^{c}$ Determined by integration of the $\mathrm{H}-1^{\prime}$ protons in the ${ }^{1} \mathrm{H}$ NMR spectrum of the reaction mixture.

90, 663, 664, 665 and 66j) with an erythro configuration, stereoselectivity was seen to depend on the protecting groups at positions 3 and 5 (Scheme 115, Table 16).

They further synthesized 2 -deoxy nucleosides from 2 '-deoxy$2^{\prime}$-phenylselenenyl nucleosides viz. $\beta$-gluco nucleoside 613, $\beta$ xylo 614, and $\alpha$-arabino 669 and $\beta$-ribo 672 by their treatment with $n \mathrm{Bu}_{3} \mathrm{SnH}$ and AIBN in refluxing benzene to give $2^{\prime}$-deoxy nucleosides 616, 617 and 675, 676 respectively (Scheme 116).

In 1997, Robles and coworkers have shown synthesis of a series of $2^{\prime}$-deoxy-2'-iodo nucleosides (678-684), from furanoid glycals (133c, 76b, 132c and 136c), which were synthesized from differently $O$-protected D-xylo 133a, 677, 132a and Dgluco 136a configured furanoid 1,2-diols respectively on treatment with $\mathrm{I}_{2} / \mathrm{PPh}_{3} /$ imidazole. NIS-mediated glycosylation of furanoid glycals $(\mathbf{1 3 3 c}, \mathbf{7 6 b}, \mathbf{1 3 2 c}$ and 136c) with pyrimidine bases afforded 2'-deoxy-2'-iodo nucleosides (678-684) (Scheme 117)..$^{84}$

In 1999, Kim and coworker described stereoselective synthesis of $1^{\prime}-\beta-2^{\prime}, 3^{\prime}$-dideoxy-2'-bis(ethoxycarbonyl)methyluridine nucleosides (687a-e) and (688a-e) in good yields from furanoid glycals 404 and 610. Cyclopropanation of furanoid glycals 404, 610 with diethyl diazomalonate and dirhodium tetraacetate $\left(\mathrm{N}_{2} \mathrm{C}\left(\mathrm{CO}_{2} \mathrm{Et}\right)_{2}: \mathrm{Rh}_{2}(\mathrm{OAc})_{4}:\right.$ glycal $\left.=2: 0.01: 1\right)$ afforded stereoselectively cyclopropanated sugars 685 and 686 respectively. Lewis acid mediated glycosylations of 685 and 686 with 5-substituted uracils afforded $1^{\prime} \beta-2^{\prime}, 3^{\prime}$-dideoxy- $2^{\prime}$ -

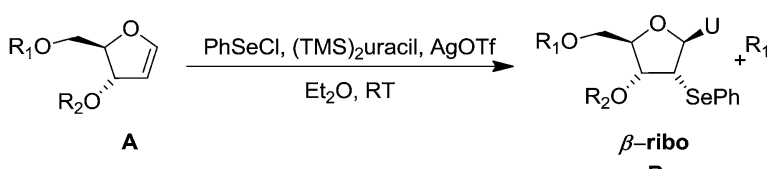

B

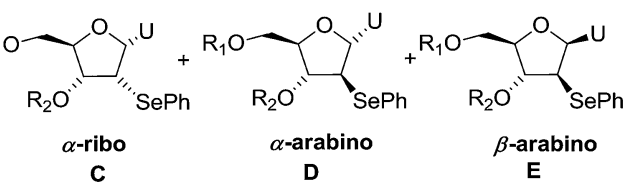

C
D
E

Scheme 115 
Table 16 Stereoselectivity in the synthesis of $2^{\prime}$-phenylselenenyl nucleosides derived from erythro glycals ${ }^{a}$

(Diastereomeric ratio) $(\beta-$ ribo : $\alpha$-ribo $: \alpha$-arabino $: \beta$ Starting glycals Time (h) Yield (\%) 2'-Selenenyl nucleosides arabino) B : C : D : E

\begin{tabular}{|c|c|c|c|c|c|c|c|}
\hline \multirow[t]{2}{*}{$661 \mathrm{R}_{1}=\mathrm{MEM}, \mathrm{R}_{2}=\mathrm{Bn}$} & 2 & 82 & $666 \mathrm{R}_{1}=\mathrm{MEM}, \mathrm{R}_{2}=\mathrm{Bn}$ & 14 & - & 49 & - \\
\hline & & & 666a $\mathrm{R}_{1}=\mathrm{OH}, \mathrm{R}_{2}=\mathrm{Bn}$ & - & - & 37 & - \\
\hline \multirow[t]{2}{*}{$662 \mathrm{R}_{1}=\mathrm{TBDMS}, \mathrm{R}_{2}=\mathrm{Bn}$} & 1.5 & 87 & $667 \mathrm{R}_{1}=\mathrm{TBDMS}, \mathrm{R}_{2}=\mathrm{Bn}$ & 32 & 16 & 16 & 一 \\
\hline & & & 667a $\mathrm{R}_{1}=\mathrm{OH}, \mathrm{R}_{2}=\mathrm{Bn}$ & 18 & 5 & 13 & - \\
\hline \multirow[t]{2}{*}{ 66e $\mathrm{R}_{1}=\mathrm{TBDMS}, \mathrm{R}_{2}=\mathrm{TBDMS}$} & 1.5 & 88 & $668 \mathrm{R}_{1}=\mathrm{TBDMS}, \mathrm{R}_{2}=\mathrm{TBDMS}$ & 28 & 21 & 15 & - \\
\hline & & & 668a $\mathrm{R}_{1}=\mathrm{OH}, \mathrm{R}_{2}=\mathrm{TBDMS}$ & 22 & 8 & 6 & - \\
\hline 71a $R_{1}=B n, R_{2}=B n$ & 1 & 89 & $669 \mathrm{R}_{1}=\mathrm{Bn}, \mathrm{R}_{2}=\mathrm{Bn}$ & 30 & - & 70 & - \\
\hline \multirow{2}{*}{$90 \mathrm{R}_{1}=\mathrm{TBDPS}, \mathrm{R}_{2}=\mathrm{Bn}$} & 2 & 58 & $670 \mathrm{R}_{1}=\mathrm{TBDPS}, \mathrm{R}_{2}=\mathrm{Bn}$ & 44 & 9 & - & - \\
\hline & & & 670a $\mathrm{R}_{1}=\mathrm{TBDPS}, \mathrm{R}_{2}=\mathrm{Bn}, \mathrm{R}=\mathrm{SePh}^{b}$ & 19 & 8 & 6 & 14 \\
\hline $663 \mathrm{R}_{1}=\mathrm{Bn}, \mathrm{R}_{2}=$ TBDPS & 2 & 85 & $671 \mathrm{R}_{1}=\mathrm{Bn}, \mathrm{R}_{2}=\mathrm{TBDPS}$ & 43 & 11 & 32 & 14 \\
\hline \multirow[t]{2}{*}{$664 \mathrm{R}_{1}=$ TBDPS, $\mathrm{R}_{2}=\mathrm{MEM}$} & 2 & 83 & $672 \mathrm{R}_{1}=$ TBDPS, $\mathrm{R}_{2}=\mathrm{MEM}$ & 54 & 18 & 15 & 4 \\
\hline & & & 672a $\mathrm{R}_{1}=\mathrm{TBDPS}, \mathrm{R}_{2}=\mathrm{MEM}, \mathrm{R}=\mathrm{SePh}^{b}$ & 9 & - & - & - \\
\hline \multirow[t]{2}{*}{$665 \mathrm{R}_{1}=\mathrm{Ac}, \mathrm{R}_{2}=$ TBDPS } & 2 & 84 & $673 \mathrm{R}_{1}=\mathrm{Ac}, \mathrm{R}_{2}=$ TBDPS & 23 & 14 & 16 & 6 \\
\hline & & & 673a R $\mathrm{R}_{1}=\mathrm{Ac}, \mathrm{R}_{2}=$ TBDPS, $\mathrm{R}=\mathrm{SePh}^{b}$ & 26 & 5 & 5 & 5 \\
\hline 66j $\mathrm{R}_{1}=\mathrm{TBDPS}, \mathrm{R}_{2}=\mathrm{TBDMS}$ & 2 & 87 & $674 \mathrm{R}_{1}=$ TBDPS, $\mathrm{R}_{2}=$ TBDMS & 66 & 20 & 14 & - \\
\hline
\end{tabular}

${ }^{a}$ Reactions were carried out at room temperature using the molar ratio glycal/PhSeCl/AgOTf/Uracil(TMS) $)_{2}=1 / 1.5 / 1.7 / 2 .{ }^{b} \mathrm{R}=\mathrm{SePh}$ stands for selenenylation of nucleosides at position 5 .

bis(ethoxycarbonyl)methyluridine nucleosides (687a-e) and $(\mathbf{6 8 8 a}-\mathbf{e})$ respectively in good yields (Scheme 118)..$^{\mathbf{5}}$

In 1999, Paquette and group showed furanoid glycals which are amenable to C-5 metalation in the presence of $t \mathrm{BuLi}$, were readily coupled to $\mathrm{N}$-protected 2,3-azetidinediones. ${ }^{86}$ L-Glutamic acid derived ${ }^{79}(S)$-(+)-dihydro-5-(hydroxymethyl)-2-(3,4)-furanone 599 was converted to 689 and 690 by TrCl and TBDMSCl respectively. Their DIBALH reduction followed by acetylation of the resulting lactols yielded 691 and 692 respectively whose vacuum pyrolysis in a Kugelrohr apparatus afforded 693 and 270 respectively (Scheme 119). Also, exposure of the lithium derivative of 693 to excess $n \mathrm{Bu}_{3} \mathrm{SnCl}$ afforded 694 in $60 \%$ yield. They also treated 270 with $\mathrm{KO}^{t} \mathrm{Bu}$ in the presence of $\mathrm{PhSCl}$ and $\mathrm{PhSeCl}$ to afford 695 and 696 respectively.

These furanoid glycals $(693,270,404,695,696$ and 610) in the presence of $t \mathrm{BuLi}$ were readily coupled to N-protected 2,3-azetidinediones (697 and 698) at low temperature in THF containing $\mathrm{BF}_{3} \cdot \mathrm{Et}_{2} \mathrm{O}$ to give the desired epimeric mixture of carbinols, i.e.

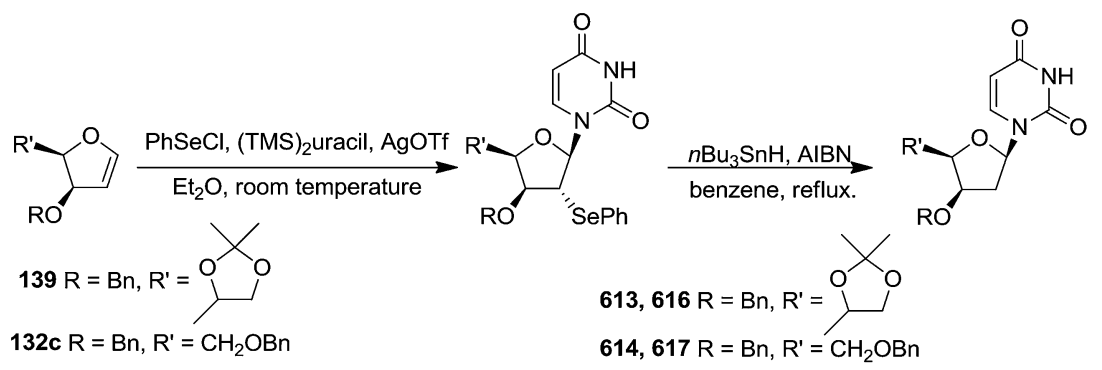

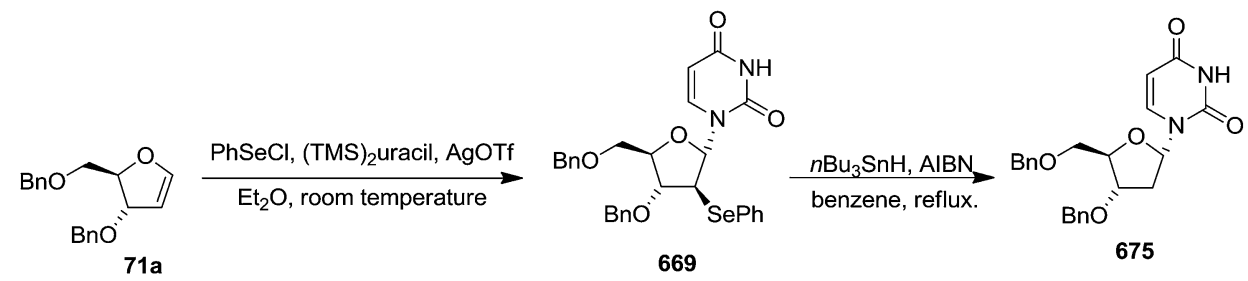

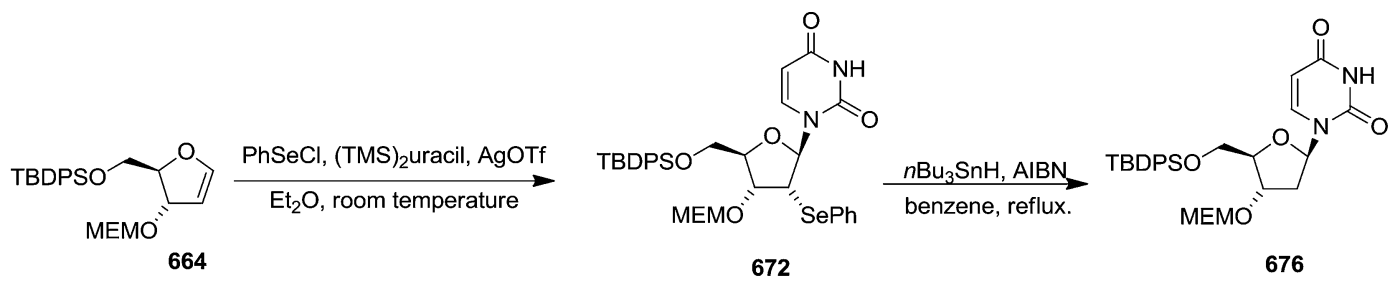




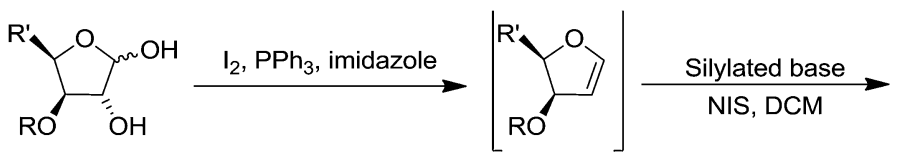

133a, 133c $\mathrm{R}=\mathrm{Bz}, \mathrm{R}^{\prime}=\mathrm{CH}_{2} \mathrm{OBz}$

$677,76 b \mathrm{R}=\mathrm{Ac}, \mathrm{R}^{\prime}=\mathrm{CH}_{2} \mathrm{OAc}$

132a, 132c R = Bn, $\mathrm{R}^{\prime}=\mathrm{CH}_{2} \mathrm{OBn}$

136a, 136c $R=B z, R^{\prime}={ }_{B z O}{ }^{B z O}-$

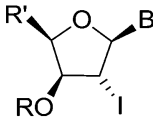

$678 \mathrm{R}=\mathrm{Bz}, \mathrm{R}^{\prime}=\mathrm{CH}_{2} \mathrm{OBz}, \mathrm{B}=$ Thymine

$679 \mathrm{R}=\mathrm{Bz}, \mathrm{R}^{\prime}=\mathrm{CH}_{2} \mathrm{OBz}, \mathrm{B}=$ Uracil

$680 \mathrm{R}=\mathrm{Bz}, \mathrm{R}^{\prime}=\mathrm{CH}_{2} \mathrm{OBz}, \mathrm{B}=5$-F-Uracil

$681 \mathrm{R}=\mathrm{Bz}, \mathrm{R}^{\prime}=\mathrm{CH}_{2} \mathrm{OBz}, \mathrm{B}=$ Cytosine

$682 \mathrm{R}=\mathrm{Ac}, \mathrm{R}^{\prime}=\mathrm{CH}_{2} \mathrm{OAc}, \mathrm{B}=$ Thymine

$683 \mathrm{R}=\mathrm{Bn}, \mathrm{R}^{\prime}=\mathrm{CH}_{2} \mathrm{OBn}, \mathrm{B}=$ Thymine

$684 \mathrm{R}=\mathrm{Bz}, \mathrm{R}^{\prime}=$

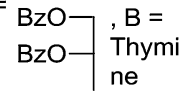

Scheme 117

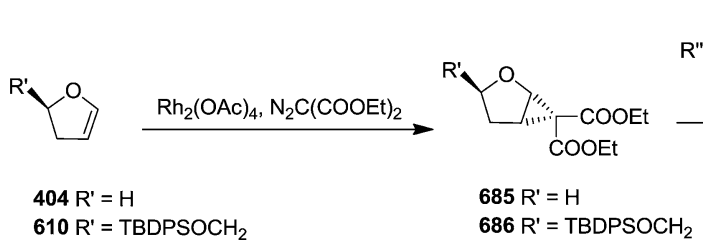

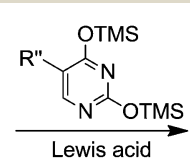

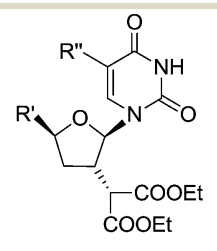

$687 \mathrm{R}^{\prime}=\mathrm{H}$

a R" = H, b R" $=\mathrm{CH}_{3}, \mathbf{c} \mathrm{R}^{\prime \prime}=\mathrm{F}, \mathbf{d} \mathrm{R}^{\prime \prime}=\mathrm{Br}$, e R" $=$ । $688 \mathrm{R}^{\prime}=\mathrm{TBDPSOCH}_{2}$

a R" = H, b R" = $\mathrm{CH}_{3}$, c R" = F, d R" = $\mathrm{Br}$, e R" = ।

Scheme 118

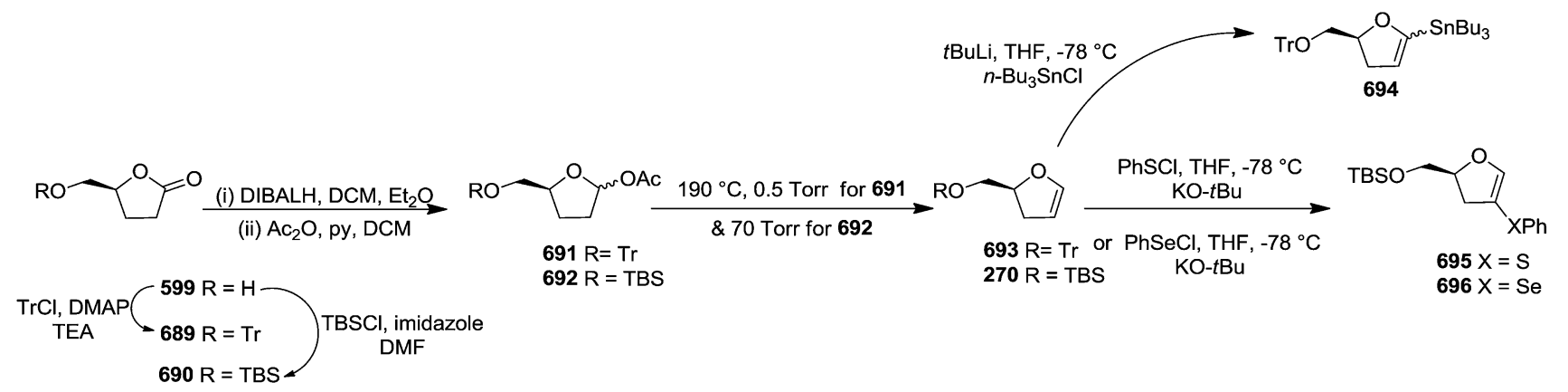

Scheme 119

(699-704) respectively. Treatment of (699-703) with pyridinium $p$ toluenesulfonate (PPTS) in benzene afforded spirocyclic keto amides (705, 706, 707, 708, 709, 710, 711) respectively (Scheme 120).

In 2001 Quirion and group reported the synthesis of $2^{\prime}$ deoxy-2'-difluoromethyluridine $\mathbf{7 1 6} .^{87}$

They described two methods A and B for its synthesis. One of them was started from thymidine 64a which was converted into benzylated furanoid glycal 71a (56\% overall yield) in two steps involving the treatment of 64a with an excess of HMDS in the presence of $\left(\mathrm{NH}_{4}\right)_{2} \mathrm{SO}_{4}$ followed by benzylation with $\mathrm{BnBr}$ of the resulting 65a. Then they applied Miethchen method ${ }^{88}$ on 71a to obtain $\mathbf{7 1 2}$ which was acetylated to $\mathbf{7 1 3}$ (47\% yield from $\mathbf{7 1 a}$ ). It was then converted to $\mathbf{7 1 4}$ via a radical reductive process $\left(n \mathrm{Bu}_{3} \mathrm{SnH}\right.$, AIBN). Addition of (TMS) ${ }_{2}$ uracil to $\mathbf{7 1 4}$ in the presence of TMSOTf furnished a $4: 1$ mixture of isomeric nucleosides in $76 \%$ yield. The major one was $\mathbf{7 1 5} \alpha$ (NMR) whose hydrogenolysis afforded 2'deoxy-2'-difluoromethyluridine 716 $\alpha$ (Scheme 121, method A).
In order to change the $\alpha / \beta$ ratio in favour of $\beta$, they synthesized $\alpha$-halodeoxyarabinose $\mathbf{7 1 7}$ from $\mathbf{7 1 4}$ on treatment with $\mathrm{HCl}$. The condensation of 717 in DCM with (TMS) $)_{2}$ uracil gave a 57 : 43 mixture of $\mathbf{7 1 5} \boldsymbol{\beta}$ and $\mathbf{7 1 5} \boldsymbol{\alpha}$ isomers (NMR), respectively, via a $\mathrm{S}_{\mathrm{N}} 2$ type reaction. Finally, the deprotection of the benzyl groups was easily achieved by hydrogenolysis of $715 \beta$ and $715 \alpha$ to give the two desired nucleosides $716 \beta$ and $716 \alpha$ with good yields (Scheme 122, method B).

In 2005, Choudhury and Pierce et al. synthesized D-D4FC 724 from an aromatization prone xylo-furanoid glycal 721, by development of a palladium mediated Ferrier rearrangementtype glycosidation. ${ }^{89}$ For the synthesis of xylo-furanoid glycal 721, they chose commercially available 1,2-isopropylidine $\mathrm{D}^{-}$ (+)-xylofuranose $\mathbf{7 1 8}$, as the starting material. The free hydroxyl groups of $\mathbf{7 1 8}$ were then protected with $p$-anisoyl chloride in pyridine to afford 719. The acetonide deprotection followed by treatment of the diols 720 with $\mathrm{I}_{2} /$ resin bound $\mathrm{Ph}_{3} \mathrm{P} /$ imidazole afforded xylo-furanoid glycal $\mathbf{7 2 1}$ in more than $90 \%$ yield. After several trial and error for the choice of solvent, base and 

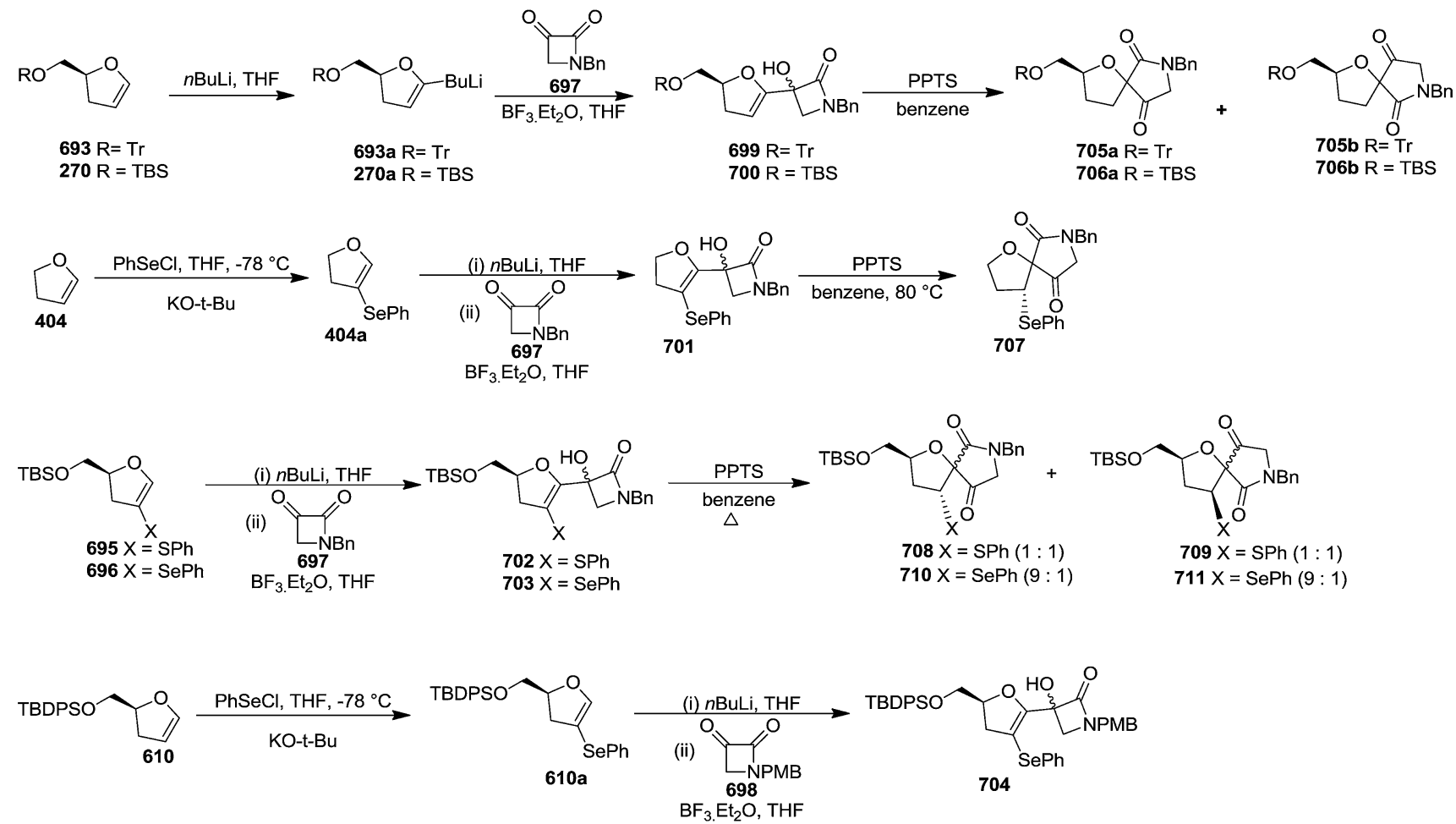

Scheme 120

different mol\% of $\operatorname{Pd}\left(\mathrm{Ph}_{3} \mathrm{P}\right)_{4}$, the glycosylation reaction of glycal 721 with an unprotected nucleoside base fluoro cytosine $\mathbf{7 2 2}$ was optimized with DBU as the base, NMP as the solvent with 3 mol\% of $\mathrm{Pd}\left(\mathrm{Ph}_{3} \mathrm{P}\right)_{4}$ as the catalyst at $33^{\circ} \mathrm{C}$ for 2 days to afford $5^{\prime}$ anisoyl-D-D4FC 723 in good isolated yield. Deprotection of 723 provided the D-D4FC 724 in 82\% yield (Scheme 123).
In 2006, Lequeux and group reported an alternative strategy based on group transfer reaction of $S$-alkyl dithiocarbonates (xanthates) followed by substitution reactions to prepare 2,3trans disubstituted tetrahydrofuran derivatives. ${ }^{90}$ They described the additions of alkyl radicals to 2,3-dihydrofuran derivatives using $S$-alkyl dithiocarbonates and the nucleophilic
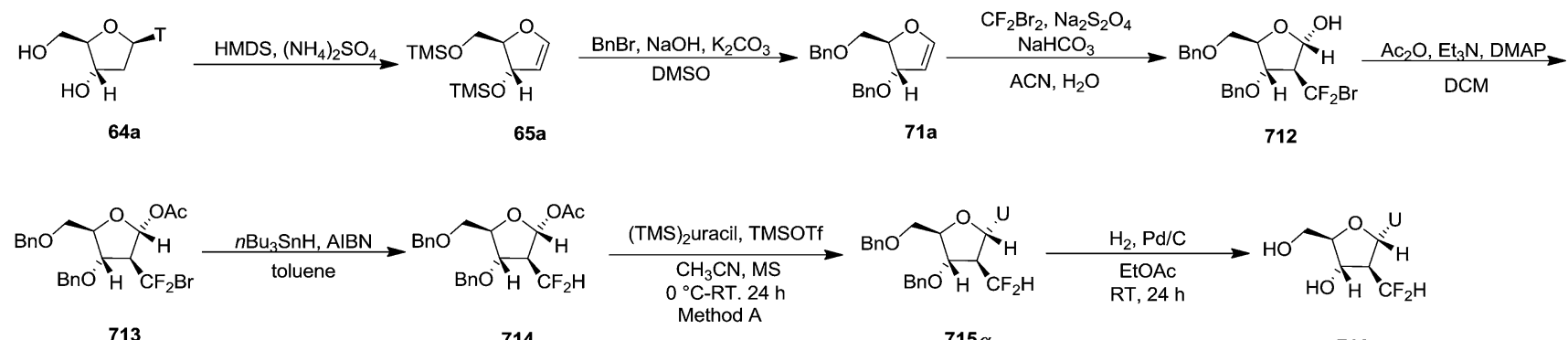

Scheme 121

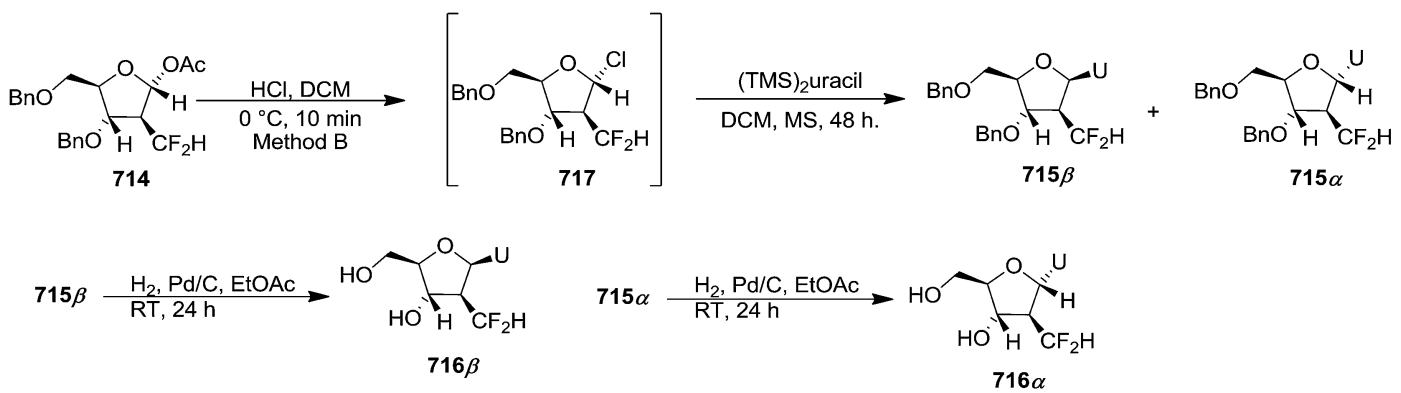

Scheme 122 

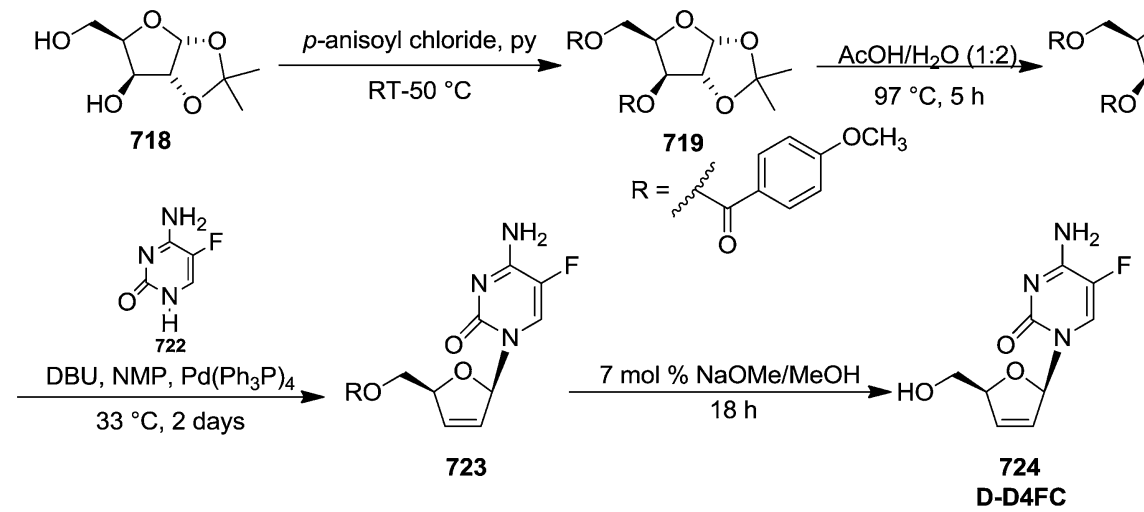
$33{ }^{\circ} \mathrm{C}, 2$ days

723

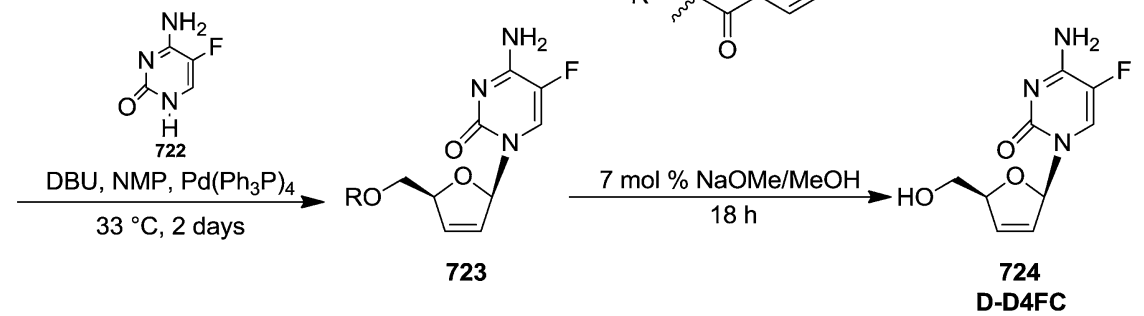<smiles>[R20]C1[C@H](CC)O[C@@H]2OC(C)(CC(=O)O)O[C@H]12</smiles><smiles>[R20]C[C@H]1O[C@H](O)[C@@H](O)[C@H]1[R20]</smiles>

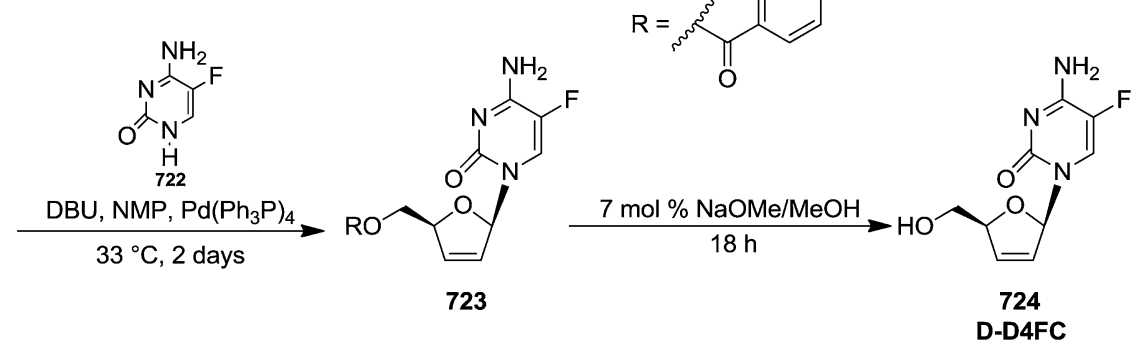

Scheme 123

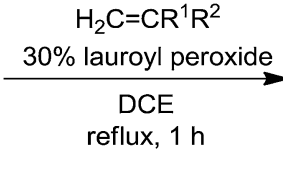

$$
\begin{aligned}
& \text { a }(67 \%) \mathrm{R}^{1}=\mathrm{OBu}, \mathrm{R}^{2}=\mathrm{H} \\
& \text { b }(65 \%) \mathrm{R}^{1}=n-\mathrm{C}_{6} \mathrm{H}_{13}, \mathrm{R}^{2}=\mathrm{H} \\
& \text { c }(80 \%) \mathrm{R}^{1}=t \mathrm{Bu}, \mathrm{R}^{2}=\mathrm{H} \\
& \text { d }(74 \%) \mathrm{R}^{1}=\mathrm{R}^{2}=\left(\mathrm{CH}_{2}\right)_{4}
\end{aligned}
$$

Scheme 124

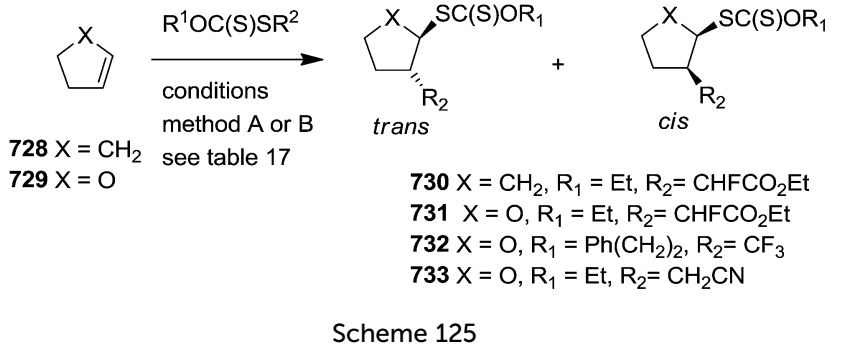

displacements of the resulting anomeric $S$-alkyl dithiocarbonate function by various nucleophiles in the presence of Lewis acid to form a new carbon-carbon or carbon-heteroatom bond which presented a new route for the preparation of modified 2 - $\beta$ - $C$-branched nucleoside analogues.
To achieve the goal, first they synthesized xanthate $\mathbf{7 2 6}$ following known procedure from commercially available ethyl bromofluoroacetate 725 (Scheme 124) by a nucleophilic substitution of its bromine atom with $O$-ethyl potassium dithiocarbonate. ${ }^{91}$

Then they studied the ethyl fluoroacetate group transfer reaction with the slow addition of lauroyl peroxide $(30 \%)$ over $1 \mathrm{~h}$ in the mixture of different terminal alkenes (1.1 equiv.) and xanthate 726 in refluxing DCM (Scheme 124) to form fluoroesters $(727 \mathbf{a}-\mathbf{d})$ in fair to good yields as a mixture of diastereomers ( $1: 1$ ratio).

They further repeated the same reaction (described for Scheme 124) with cyclopentene 728 and 2,3-dihydrofuran 729 in the presence of lauroyl peroxide. The best results were obtained from these alkenes $(\mathbf{7 2 8}, \mathbf{7 2 9})$ and the fluoroxanthate $\mathbf{7 2 6}$ (Scheme 125, Table 17, entries 1 and 2, method A) when lauroyl

Table 17 Group transfer reaction from cyclic alkenes ${ }^{a}$

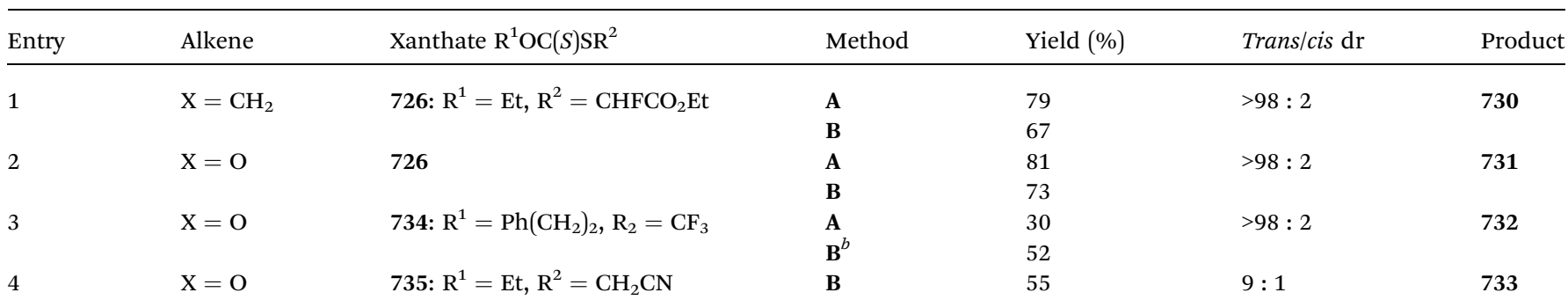

${ }^{a}$ Method (A): slow addition of 0.3 equiv. of lauroyl peroxide, refluxed DCE, 1-2 h. Method (B): addition of $3 \times 0.1$ equiv. of Et ${ }_{3} \mathrm{~B}$, DCM, room temperature, $1-2$ h. ${ }^{b}$ Stirring was maintained overnight at room temperature. 


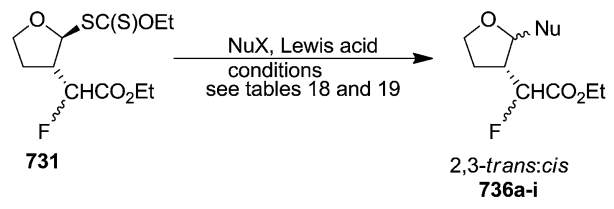

Scheme 126

peroxide was added slowly to a mixture of alkene and xanthate (method A). In case of cyclopentene $\left(\mathrm{X}=\mathrm{CH}_{2}\right) \mathbf{7 2 8}$, only two diastereomers were detected in a $1: 1$ ratio, and purification of the crude product afforded 2,3-trans disubstituted cyclopentane derivatives $\mathbf{7 3 0}$ in $79 \%$ yield. Similar results were observed from the 2,3-dihydrofuran ( $\mathrm{X}=\mathrm{O}) 729$ and xanthate 726, and a mixture of two trans diastereomers of 731 (2,3-trans disubstituted tetrahydrofuran derivatives, ${ }^{1} \mathrm{H}\left\{{ }^{19} \mathrm{~F}\right\}$ HOESY) was obtained in $81 \%$ yield. These two isomers of 731 differed only by the relative configuration of the third stereogenic center bearing the fluorine atom. The cis products were not reported in both cases (cyclopentene and 2,3-dihydrofuran). 2,3-trans Isomers 732 were obtained from 729 in the case of xanthate 734 in $30 \%$ isolated yield (Scheme 125, Table 17, entry 3, method A).

They also repeated the reaction with $\mathrm{Et}_{3} \mathrm{~B}$, as an alternative free radical initiator of lauroyl peroxide, in deoxygenated DCM under $\mathrm{N}_{2}$ atmosphere (method B) to afford 2,3-trans products 730 in $67 \%$ isolated yield from 728 and xanthate 726 (Table 17, entry 1, method B). While 2,3-trans disubstituted furans 731 were isolated in $73 \%$ yield from 2,3-dihydrofuran 729 and xanthate 726 (Table 17 , entry 2 , method $\mathrm{B})$, the reaction between 729 and the trifluoromethylxanthate $\mathbf{7 3 4}$ afforded the trans adduct $\mathbf{7 3 2}$ in $\mathbf{5 2 \%}$ yield (Table 17, entry 3 , method $\mathrm{B}$ ). The reaction proceeded smoothly with xanthate 735 and afforded the 2,3-trans isomers 733 as major products in 55\% yield (Table 17, entry 4, method B).

Afterward, they explored the formation of a new carboncarbon or carbon-heteroatom bond by displacement of dithiocarbonate function of $\mathbf{7 3 1}$ by a variety of nucleophiles in the presence of Lewis acid (Scheme 126, Tables 18 and 19).

By following this strategy, they have synthesized 2 '-deoxy-2'$C$ - $\beta$-alkyl nucleoside analogues 739 from furanoid glycal 71a and xanthate $\mathbf{7 2 6}$ (Scheme 127). Lauroyl peroxide was added slowly in the reaction mixture of furanoid glycal 71a and xanthate 726 in DCE and the reaction mixture was refluxed for $5 \mathrm{~h}$ to obtain a diastereomeric mixture of 2,3-trans addition products $737(1: 1)$ in $57 \%$ isolated yield. Treatment of (TMS) ${ }_{2}$ thymine with 737 in the presence of AgOTf at $0{ }^{\circ} \mathrm{C}$ for $3 \mathrm{~h}$ afforded a mixture of protected $2^{\prime}$-deoxy- $2^{\prime}$ - $C$ - $\beta$-alkyl nucleoside analogues 738 in $61 \%$ yield (only trans products). These were subjected to hydrogenation to give the corresponding diol 739 .

The synthesis of furanoid glycals $(\mathbf{1 7 1}, \mathbf{1 7 3})$ proposed by Haraguchi and group has been already discussed in Scheme $30 .^{38}$ Now, the utilization of their synthesized furanoid glycals (66e, 171 and 173) is being discussed here for the synthesis of $2^{\prime}$ deoxynucleosides and its $1^{\prime}$-branched analogues. They performed NIS-mediated electrophilic glycosidation between protected erythro-furanoid glycals (66e, 171 and 173) and silylated thymine in $\mathrm{CH}_{3} \mathrm{CN} / \mathrm{DCM}$ at room temperature and observed that only the glycal 173 selectively furnished $\beta$-anomer $\mathbf{7 4 2}$ exclusively in $76 \%$ yield. Whereas, under identical reaction condition formation of the $\alpha$-anomer $(740 \alpha, 62 \%$ yield)

Table 18 Carbon-oxygen and carbon-carbon bond formation

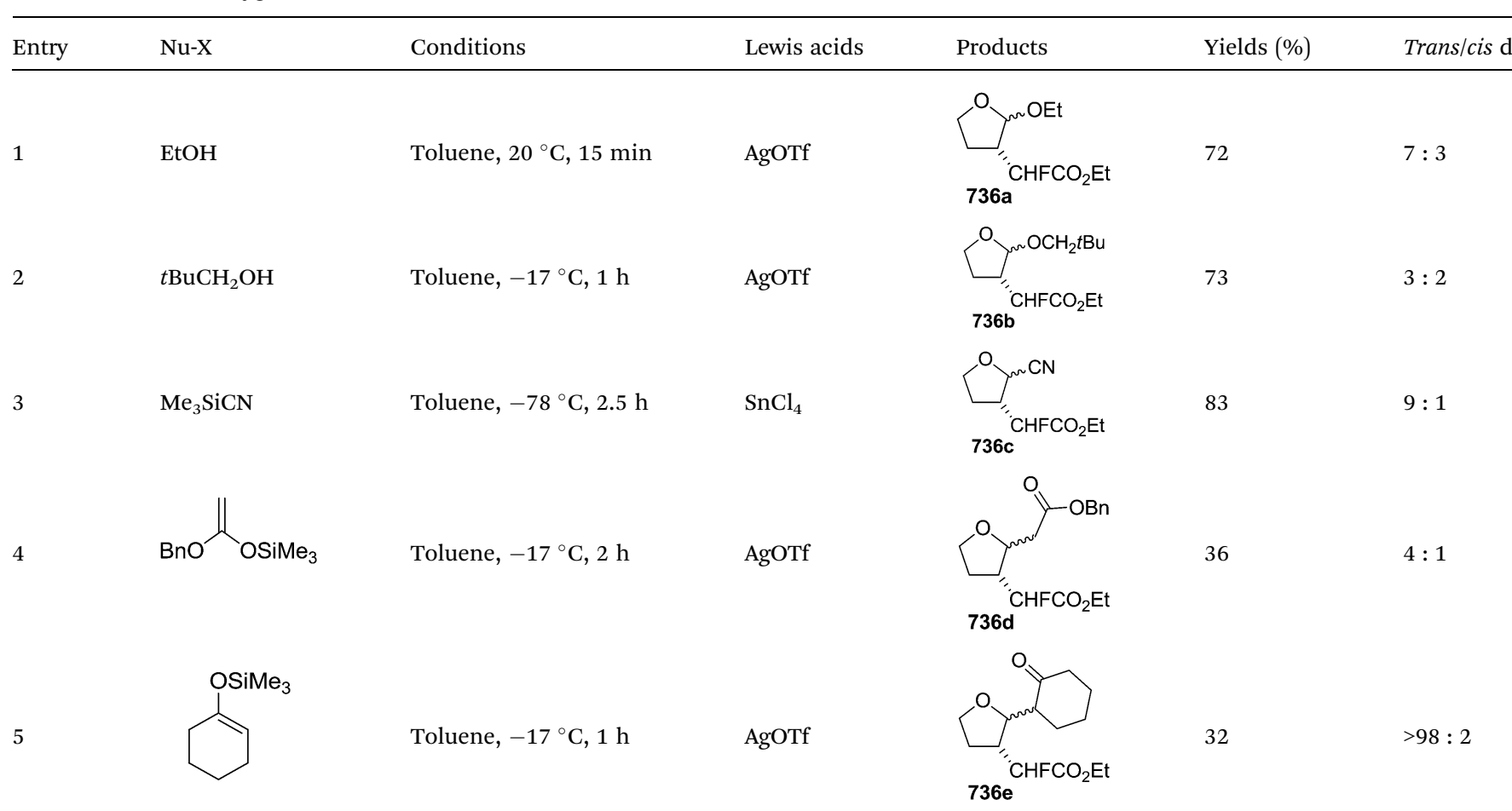


Table 19 Carbon-nitrogen bond formation

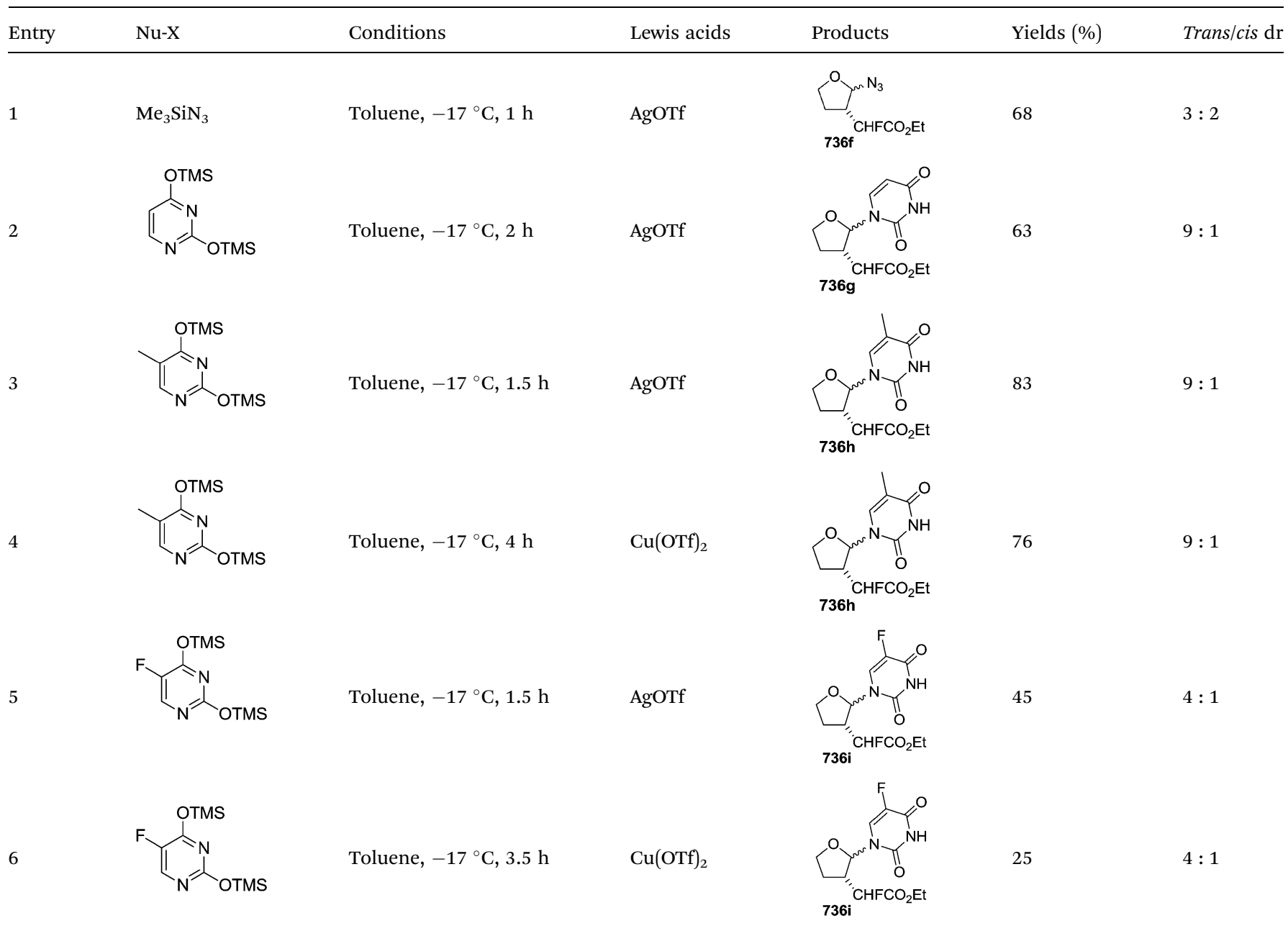




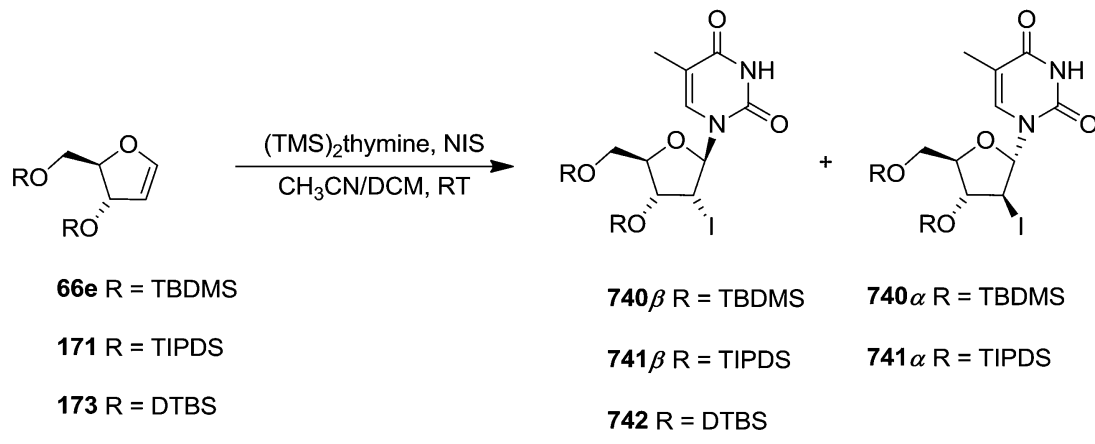

Scheme 128

Table 20 NIS-initiated electrophilic glycosidation of silylated thymine by using (66e, 171 and 173$)^{a}$

\begin{tabular}{llll}
\hline Entry & Glycal & Products (isolated yield) & Ratio of $\beta$-anomer/ $\alpha$-anomer \\
\hline 1 & $66 e$ & $740 \beta$ and $740 \alpha(77 \%)$ & $1: 4$ \\
2 & 171 & $741 \beta(35 \%)$ and $741 \alpha(35 \%)$ & $1: 1$ \\
3 & 173 & $742(76 \%)$ & - \\
${ }^{a}$ All reactions were carried out in $\mathrm{CH}_{3} \mathrm{CN} / \mathrm{DCM}$ at rt for $12 \mathrm{~h}$ by using (TMS) $)_{2}$ thymine (3.0 equiv.) and NIS (1.5 equiv.).
\end{tabular}

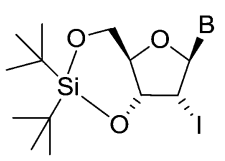

$743 \mathrm{~B}=$ Uracil-1-yl

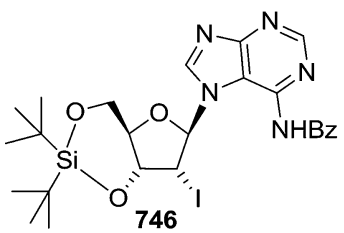

$744 \mathrm{~B}=\mathrm{N}^{4}-($ acetyl $)$ cytosine-1-yl

$745 \mathrm{~B}=\mathrm{N}^{6}-($ benzoyl)adenine-9-yl

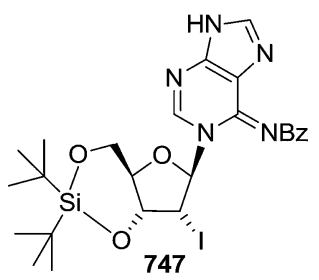

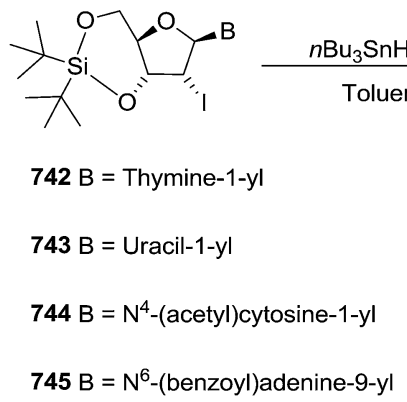

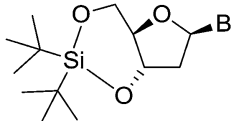

748 B = Thymine-1-yl (84\%)

$749 \mathrm{~B}=$ Uracil-1-yl $(100 \%)$

$750 \mathrm{~B}=\mathrm{N}^{4}-($ acetyl $)$ cytosine $-1-\mathrm{yl}(79 \%)$

$751 \mathrm{~B}=\mathrm{N}^{6}$-(benzoyl)adenine-9-yl (94\%)

Scheme 129

furanoid glycals (754-759). To obtain derivatives suitable for glycosidation, 1-( $\omega$-hydroxy)alkyl erythro-furanoid glycals (754759) were converted to their $O$-triethylsilyl derivatives (760-765) respectively on silylation (Scheme 130).

NIS-initiated electrophilic glycosidation of silylated thymine with these glycals (752, 753, and 760-765) formed exclusively the $\beta$-anomers of $1^{\prime}$-branched 2 -iodothymidine derivatives (766-773) respectively. Compounds (766-773) were transformed to 1'-branched thymidines (774-781) in good yields (Scheme 131, yields are given in parentheses) by reacting them with $n \mathrm{Bu}_{3} \mathrm{SnH}, \mathrm{Et}_{3} \mathrm{~B} / \mathrm{O}_{2}$, in toluene at room temperature.

Pal and Shaw have already reported the synthesis of four stereochemically different enantiomerically pure, furanoid glycal building blocks (162a-c, 139) (Scheme 28) (Fig. 3) ${ }^{35}$ and also shown their synthetic utility to obtain some natural products 


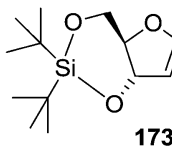

173 (i) tBuLi, THF, below $-70^{\circ} \mathrm{C}$

(ii) electrophile as shown in table 21

(iii) $\mathrm{Et}_{3} \mathrm{SiCl}$, imidazole, DMF for 754-759<smiles>CC(C)(C)[Si]1(C(C)(C)C)OC[C@H]2OC(P)=C[C@H]2O1</smiles>

752: $\mathrm{R}=\mathrm{Me}$

753: $\mathrm{R}=\mathrm{CH}_{2} \mathrm{Ph}$

754: $\mathrm{R}=\mathrm{CH}_{2} \mathrm{OH}$

755: $\mathrm{R}=\mathrm{CH}(\mathrm{OH}) \mathrm{Ph}$

$756 \mathrm{R}=\mathrm{CH}(\mathrm{OH}) \mathrm{Me}$

757: $\mathrm{R}=\mathrm{CH}(\mathrm{OH}) \mathrm{Me}_{2}$

758: $\mathrm{R}=\mathrm{CH}_{2} \mathrm{CH}_{2} \mathrm{OH}$

759: $\mathrm{R}=\mathrm{CH}_{2} \mathrm{CH}_{2} \mathrm{CH}_{2} \mathrm{OH}$
760: $\mathrm{R}=\mathrm{CH}_{2} \mathrm{OSiEt}_{3}(86 \%)$

761: $\mathrm{R}=\mathrm{CH}\left(\mathrm{OSiEt}_{3}\right) \mathrm{Ph}(85 \%)$

762: $\mathrm{R}=\mathrm{CH}\left(\mathrm{OSiEt}_{3}\right) \mathrm{Me}(93 \%)$

763: $\mathrm{R}=\mathrm{C}\left(\mathrm{OSiEt}_{3}\right) \mathrm{Me}_{2}(95 \%)$

$764 \mathrm{R}=\mathrm{CH}_{2} \mathrm{CH}_{2} \mathrm{OSiEt}_{3}(85 \%)$

765: $\mathrm{R}=\mathrm{CH}_{2} \mathrm{CH}_{2} \mathrm{CH}_{2} \mathrm{OSiEt}_{3}(63 \%)$

Scheme 130

Table 21 Preparation of 1-alkyl and 1-( $\omega$-hydroxy)alkyl glycals based on lithiation of $173^{a}$

\begin{tabular}{llll}
\hline Entry & Electrophile (equiv.) & $\mathrm{R}$ & $\begin{array}{l}\text { Product } \\
\text { (isolated yield) }\end{array}$ \\
\hline 1 & MeI (10)/HMPA (5) & $\mathrm{Me}$ & $\mathbf{7 5 2}(56 \%)$ \\
2 & $\mathrm{PhCH}_{2} \mathrm{Br}(5) / \mathrm{HMPA}(10)^{b}$ & $\mathrm{CH}_{2} \mathrm{Ph}$ & $\mathbf{7 5 3}(56 \%)$ \\
3 & $\mathrm{DMF}(5)$ then $\mathrm{NaBH}_{4}(1.5)$ & $\mathrm{CH}_{2} \mathrm{OH}$ & $\mathbf{7 5 4}(82 \%)$ \\
4 & $\mathrm{PhCHO}(3)$ & $\mathrm{CH}(\mathrm{OH}) \mathrm{Ph}$ & $\mathbf{7 5 5}(93 \%)^{c}$ \\
5 & $\mathrm{MeCHO}(5)^{c}$ & $\mathrm{CH}(\mathrm{OH}) \mathrm{Me}$ & $\mathbf{7 5 6}(90 \%)^{c}$ \\
6 & $\mathrm{CH}_{3} \mathrm{COCH}(5)$ & $\mathrm{C}(\mathrm{OH}) \mathrm{Me}_{2}$ & $\mathbf{7 5 7}(19 \%)^{d}$ \\
7 & Ethylene oxide (5) $^{d}$ & $\mathrm{CH}_{2} \mathrm{CH}_{2} \mathrm{OH}$ & $\mathbf{7 5 8}(62 \%)$ \\
8 & $\& \mathrm{BF}_{3} \cdot \mathrm{OEt}_{2}(5)$ & & \\
& Trimethylene oxide (5) $_{2}$ & $\mathrm{CH}_{2} \mathrm{CH}_{2} \mathrm{CH}_{2} \mathrm{OH}$ & $\mathbf{7 5 9}(65 \%)$
\end{tabular}

${ }^{a}$ After addition of the respective electrophile, the reaction mixture was stirred below $-70{ }^{\circ} \mathrm{C}$ for $0.5 \mathrm{~h}$, except entry $2 .{ }^{b}$ After addition of the electrophile,the reaction mixture was stirred at $-40{ }^{\circ} \mathrm{C}$ for $11 \mathrm{~h} .{ }^{c}$ The product was obtained as a mixture of diastereomers. ${ }^{d}$ The starting material (173) was recovered in $78 \%$ yield.

such as the aggregation pheromones brevicomins (285a-d) (Schemes 47-50) and styryllactones (+)-cardiobutanolide (290a, Scheme 51), (-)-cardiobutanolide (290b, Scheme 52) and (+)-goniofufurone (295a, Scheme 53). ${ }^{2 h}$ Thus, inspired by literature reports on the interesting and important biological activities of 2'-deoxynucleosides we decided to undertake the synthesis of six $2^{\prime}$-deoxynucleoside analogue building blocks (Fig. 7) from the stereochemically different furanoid glycals (162a-c, 139) by adopting a methodology reported earlier by Kim and Misco. ${ }^{9}$ We have synthesized three pairs of enantiomeric $2^{\prime}$-deoxynucleoside analogues (783a, 783b), (783c, 783e) and (783d, 783f) respectively as building blocks from furanoid glycals (162a-c, 139) by involving the similar synthetic strategy. ${ }^{2 i}$

Furanoid glycal 139 on treatment with (TMS) $)_{2}$ thymine (2.0 equiv.) in the presence of NIS (2.5 equiv.) in dry DCM at $-30{ }^{\circ} \mathrm{C}$ $\rightarrow$ rt for overnight afforded glycosylated product 782a, which, without purification, was directly converted into $2^{2}$-deoxynucleoside analogue 783a in $26 \%$ yield (over two steps) in the presence of $n \mathrm{Bu}_{3} \mathrm{SnH}$ and a radical initiator ABCN $\left(1,1^{\prime}\right.$-Azobis-(cyclohexanecarbonitrile)) (Scheme 132). The stereochemistry of compound 783a was determined on the basis of its NOE spectrum.

Having this result in hand, we further extended our study on furanoid glycal 162a which was an optical antipode of 139. Thus 2'-deoxynucleoside analogue 783b (Scheme 133) was obtained from 162a following the identical reaction pathway

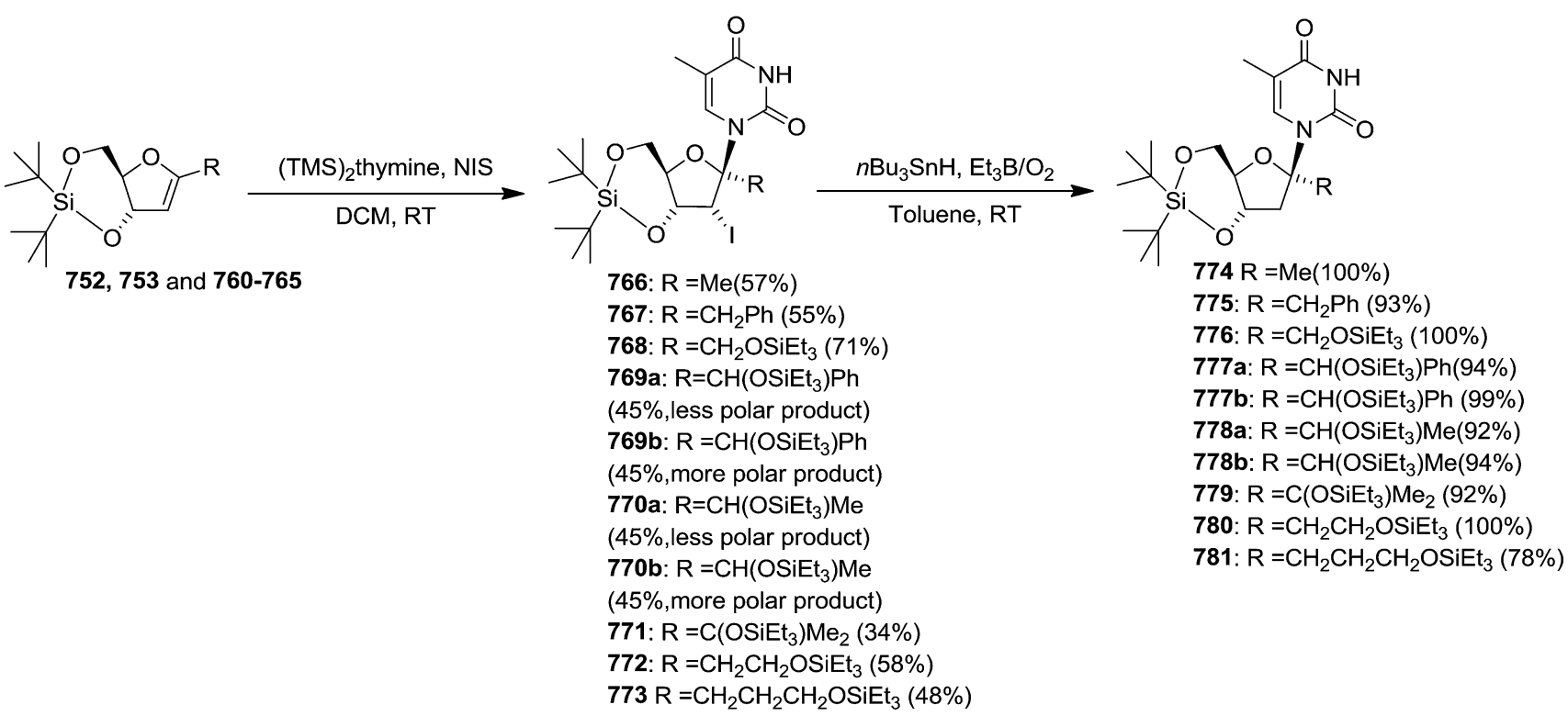

Scheme 131 

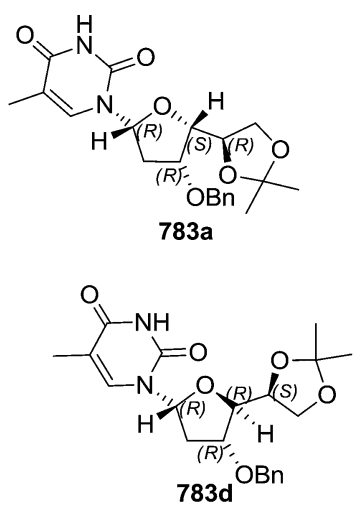

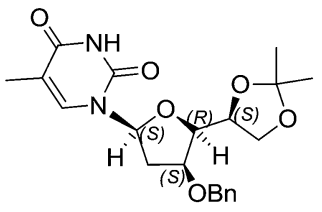

$783 b$

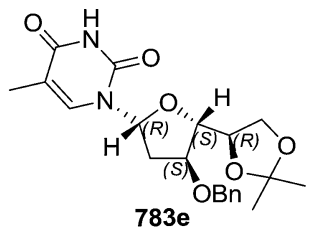

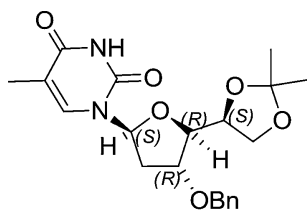

783c

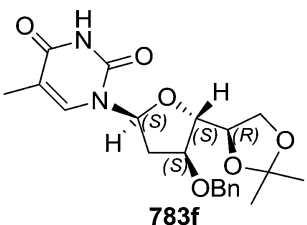

Fig. 7 Structures of $2^{\prime}$-deoxynucleoside analogues (783a-f).

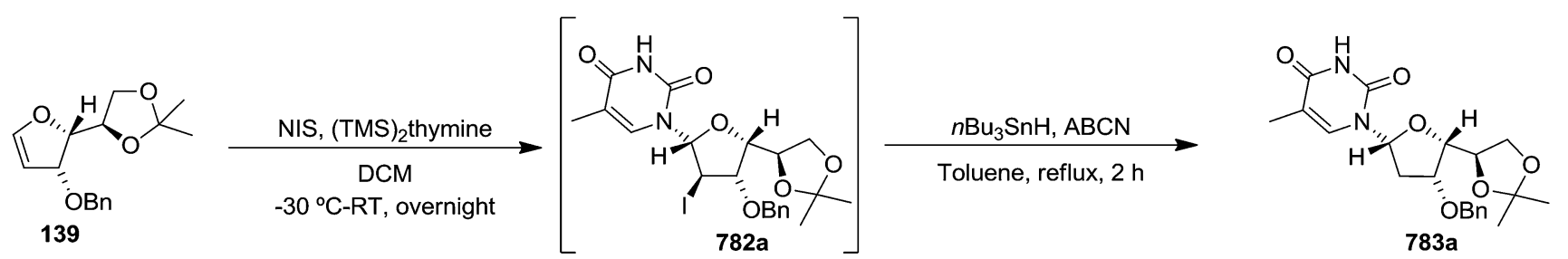

Scheme 132

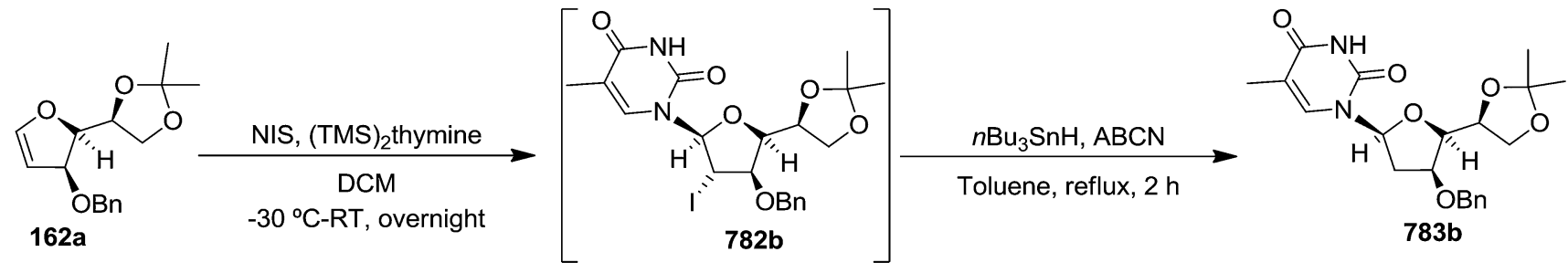

Scheme 133
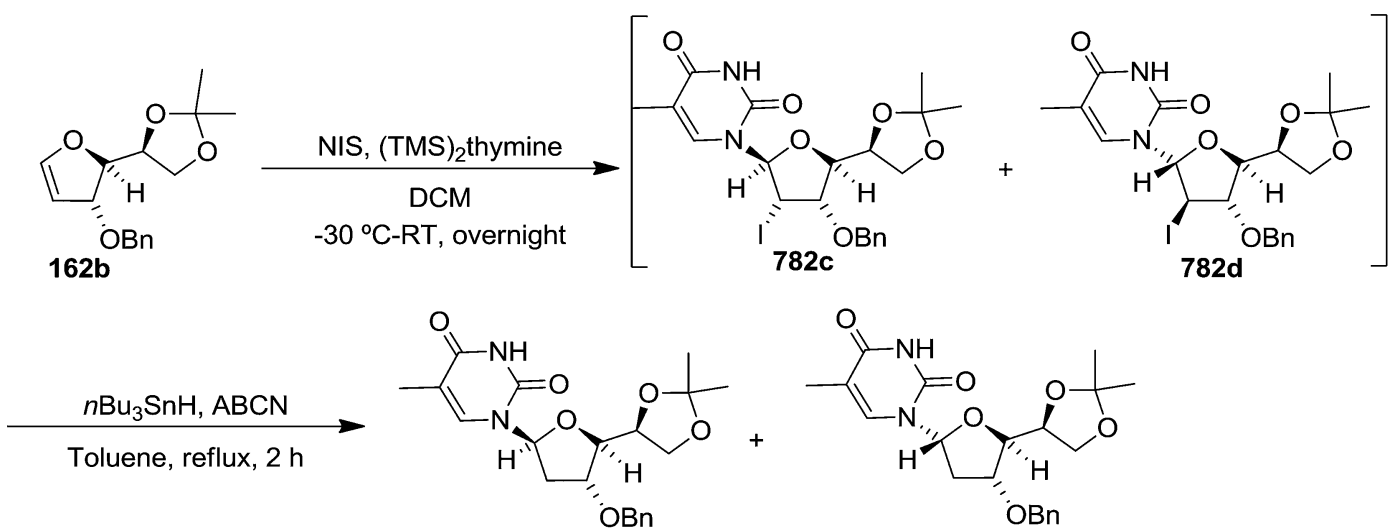

783c<smiles>Cc1cn([C@H]2C[C@H](C)[C@H]([C@H]3COC(C)(C)O3)O2)c(=O)[nH]c1=O</smiles>

783d

Scheme 134

as it was shown in the case of 783a (Scheme 132). The $[\alpha]_{\mathrm{D}}$ of $2^{\prime}$-deoxynucleoside analogue 783b $\left[[\alpha]_{\mathrm{D}}^{25}+17.7\right.$ (c 0.27 , $\mathrm{MeOH})]$ was just opposite to that of 783a $\left[[\alpha]_{\mathrm{D}}^{25}-23.4(c 1.67\right.$, $\mathrm{MeOH})]$.
Our further study on erythro-furanoid glycal $\mathbf{1 6 2 b}$, under the identical reaction conditions furnished a mixture of two compounds. Column chromatographic purification of the mixture led to the isolation of $\mathbf{7 8 3 c}$ and $\mathbf{7 8 3 d}$ in $8 \%$ and $32 \%$ 

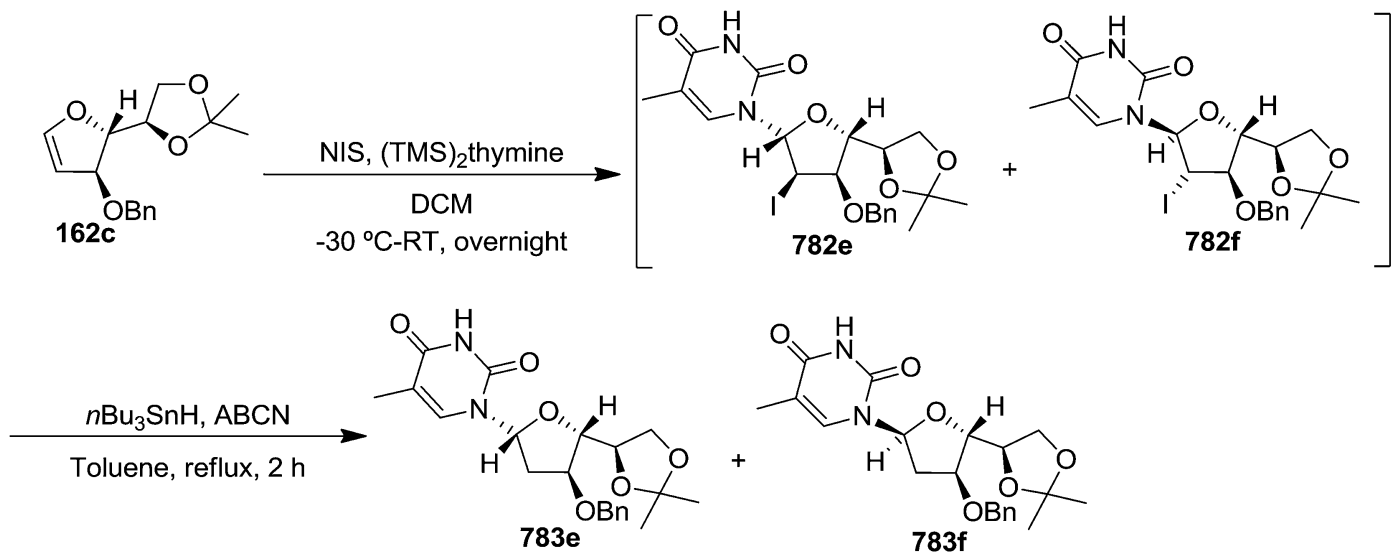

Scheme 135

yields respectively (over two steps, Scheme 134). The NOE experiment was also carried out for the complete characterization of $2^{\prime}$-deoxy- $\beta$-nucleoside analogue $783 \mathrm{c}\left[[\alpha]_{\mathrm{D}}^{25}-1.91(c 0.10\right.$, $\mathrm{MeOH})]$ and $2^{\prime}$-deoxy- $\alpha$-nucleoside analogue 783d $\left[[\alpha]_{\mathrm{D}}^{26}-10.2\right.$ (c $0.40, \mathrm{MeOH})]$ in a $1: 4$ ratio.

Under the identical reaction conditions formation of mixture of nucleosides was quite obvious from erythro-furanoid glycal 162c having two anti bulky groups at $\mathrm{C}-3^{\prime}$ and $\mathrm{C}-4^{\prime}$ which was enantiomeric to $\mathbf{1 6 2} \mathbf{b}$. The chromatographic purification of the mixture containing the isomeric nucleoside analogues led to the isolation of 2 -deoxynucleoside analogues $783 f\left[[\alpha]_{\mathrm{D}}^{26}+12.1\right.$ (c $0.57, \mathrm{MeOH})]$ as the major product in $27 \%$ yield (over two steps) and 783e $\left[[\alpha]_{\mathrm{D}}^{25}+1.42(c 0.37, \mathrm{MeOH})\right]$ as minor product in $9 \%$ yield (over two steps) (Scheme 135) which were the enantiomers of 783d and 783c respectively.

\section{Conclusion}

In summary, this review is an attempt to describe the various synthetic approaches to obtain both erythro and threo furanoid glycals since their discovery. Emphasis has also been given to their synthetic applications towards the syntheses of natural products, natural product like molecules, important "building blocks" and C-and N-nucleosides. One of the purposes, of this review is to attract the attention of the synthetic community to develop new approaches for furanoid glycals syntheses and to exploit this inexpensive and widely available chiral building blocks for broader applications both in synthetic as well as medicinal chemistry. We hope that this review will be useful to those who have an interest in furanoid glycals.

\section{Acknowledgements}

Dr Pinki Pal is highly grateful to CSIR, New Delhi, for fellowships in the form of junior research fellow and senior research fellow.

\section{Notes and references}

1 Z. J. Witczak, Curr. Med. Chem., 1999, 6, 165.
2 (a) M. Saquib, M. K. Gupta, R. Sagar, Y. S. Prabhakar, A. K. Shaw, R. Kumar, P. R. Maulik, A. N. Gaikwad, S. Sinha, A. K. Srivastava, V. Chaturvedi, R. Srivastava and B. S. Srivastava, J. Med. Chem., 2007, 50, 2942; (b) L. V. R. Reddy, P. V. Reddy and A. K. Shaw, Tetrahedron: Asymmetry, 2007, 18, 542; (c) P. V. Reddy, L. V. R. Reddy, B. Kumar, R. Kumar, P. R. Maulik and A. K. Shaw, Tetrahedron, 2008, 64, 2153; (d) L. V. R. Reddy, G. N. Swamy and A. K. Shaw, Tetrahedron: Asymmetry, 2008, 19, 1372; (e) M. Saquib, I. Hussain, B. Kumar and A. K. Shaw, Chem.-Eur. J., 2009, 15, 6041; (f) L. V. R. Reddy, P. V. Reddy, N. N. Mishra, P. K. Shukla, G. Yadav, R. Srivastava and A. K. Shaw, Carbohydr. Res., 2010, 345, 1515; (g) P. V. Reddy, B. Bajpai, B. Kumar and A. K. Shaw, Eur. J. Org. Chem., 2011, 1575; (h) P. Pal and A. K. Shaw, Tetrahedron, 2011, 67, 4036; (i) P. Pal, P. Singh, B. Kumar, H. M. Gauniyal and A. K. Shaw, Tetrahedron: Asymmetry, 2011, 22, 992.

3 (a) L. V. R. Reddy, V. Kumar, R. Sagar and A. K. Shaw, Chem. Rev., 2013, 113, 3605; (b) S. J. Danishefsky and M. T. Bilodeau, Angew. Chem., Int. Ed., 1996, 35, 1380; (c) R. J. Ferrier and O. A. Zubkov, Org. React., 2003, 62, 569.

4 R. E. Ireland, S. Thaisrivongs, N. Vanier and C. S. Wilcox, J. Org. Chem., 1980, 45, 48 and references cited therein.

5 E. J. Corey and G. Goto, Tetrahedron Lett., 1980, 21, 3463. 6 U. Hacksell and G. D. Daves Jr, J. Org. Chem., 1983, 48, 2870. 7 U. Hacksell and G. D. Daves Jr, Prog. Med. Chem., 1985, 22, 1. 8 K. Chow and S. Danishefsky, J. Org. Chem., 1990, 55, 4211.

9 C. U. Kim and P. F. Misco, Tetrahedron Lett., 1992, 33, 5733. 10 A. El-Laghdach, Y. Diáz and S. Castillón, Tetrahedron Lett., 1993, 34, 2821.

11 E. Fischer and K. Zach, Sitzber Kgl Preuss Akad Wiss, 1913, 16, 311.

12 R. K. Ness and H. G. Fletcher Jr, J. Am. Chem. Soc., 1958, 80, 2007.

13 R. K. Ness and H. G. Fletcher Jr, J. Org. Chem., 1963, 28, 435. 14 M. Haga and R. K. Ness, J. Org. Chem., 1965, 30, 158.

15 (a) K. Bischofberger and R. H. Hall, Carbohydr. Res., 1975, 42, 175; (b) A. K. M. Anisuzzaman and R. L. Whistler, J. Org. Chem., 1972, 37, 3187; (c) B. Iselin and T. Reichstein, Helv. 
Chim. Acta, 1944, 27, 1146; (d) K. Bischofberger and R. H. Hall, Carbohydr. Res., 1976, 52, 223.

16 (a) S. J. Eitelman and A. Jordaan, J. Chem. Soc., Chem. Commun., 1977, 552; (b) S. Hanessian, M. M. Ponpipom and P. Lavallee, Carbohydr. Res., 1972, 24, 45.

17 (a) S. J. Eitelman, R. H. Hall and A. Jordaan, J. Chem. Soc., Perkin Trans. 1, 1978, 595; (b) J. B. Lee and T. J. Nolan, Tetrahedron, 1967, 23, 2789; (c) B. D. Kohn, P. Kohn and A. Dubin, Carbohydr. Res., 1971, 18, 349.

18 R. E. Ireland, C. S. Wilcox and S. Thaisrivongs, J. Org. Chem., 1978, 43, 786.

19 R. E. Ireland, D. W. Norbeck, G. S. Mandel and N. S. Mandel, J. Am. Chem. Soc., 1985, 107, 3285.

20 (a) J. C.-Y. Cheng, U. Hacksell and G. D. Daves Jr, J. Org. Chem., 1985, 50, 2778; (b) R. F. Cunico and L. Bedell, J. Org. Chem., 1980, 45, 4797.

21 M. Obayashi and M. Schlosser, Chem. Lett., 1985, 1715.

22 E. Larsen, P. T. Jørgensen, M. A. Sofan and E. B. Pederson, Synthesis, 1994, 1037.

23 M. A. Cameron, S. B. Cush and R. P. Hammer, J. Org. Chem., 1997, 62, 9065.

24 M. Kassou and S. Castillón, Tetrahedron Lett., 1994, 35, 5513. 25 F. Bravo, M. Kassou and S. Castillón, Tetrahedron Lett., 1999, 40, 1187.

26 F. Bravo, M. Kassou, Y. Díaz and S. Castillón, Carbohydr. Res., 2001, 336, 83.

27 R. Pontikis, J. Wolf, C. Monneret and J.-C. Florent, Tetrahedron Lett., 1995, 36, 3523.

28 J. A. Walker II, J. J. Chen, D. S. Wise and L. B. Townsend, J. Org. Chem., 1996, 61, 2219.

29 F. E. McDonald and M. M. Gleason, J. Am. Chem. Soc., 1996, 118, 6648.

30 R. R. Diaz, C. R. Melgarejo, I. I. Cubero and M. T. P. LópezEspinosa, Carbohydr. Res., 1997, 300, 375.

31 C. Kim, R. Hoang and E. A. Theodorakis, Org. Lett., 1999, 1, 1295.

32 Z.-X. Wang, L. I. Wiebe, J. Balzarini, E. D. Clercq and E. E. Knaus, J. Org. Chem., 2000, 65, 9214.

33 B. Schmidt and H. Wildemann, Eur. J. Org. Chem., 2000, 3145.

34 A. M. Gómez, M. Casillas, A. Barrio, A. Gawel and J. C. López, Eur. J. Org. Chem., 2008, 3933.

35 (a) P. Pal, B. Kumar and A. K. Shaw, Eur. J. Org. Chem., 2009, 2179; (b) F. Gonzalez, S. Lesage and A. S. Perlin, Carbohydr. Res., 1975, 42, 267; (c) R. Sagar, R. Pathak and A. K. Shaw, Carbohydr. Res., 2004, 339, 2031; (d) M. Saquib, R. Sagar and A. K. Shaw, Carbohydr. Res., 2006, 341, 1052; (e) R. Sagar, L. V. R. Reddy and A. K. Shaw, Tetrahedron: Asymmetry, 2006, 17, 1189.

36 G. V. M. Sharma and K. Krishnudu, Carbohydr. Res., 1995, 268, 287 and references cited therein.

37 T. Oishi, K. Ando and N. Chida, Chem. Commun., 2001, 1932 and references cited therein.

38 K. Haraguchi, K. Konno, K. Yamada, Y. Kitagawa, K. T. Nakamura and H. Tanaka, Tetrahedron, 2010, 66, 4587.

39 S. Hanessian, Total Synthesis of Natural Products; The 'Chiron' Approach, Oxford, Pergamon, 1983.
40 R. E. Ireland, S. Thaisrivongs and C. S. Wilcox, J. Am. Chem. Soc., 1980, 102, 1155 and references cited therein.

41 R. E. Ireland, R. C. Anderson, R. Badoud, B. J. Fitzsimmons, G. J. Mcgarvey, S. Thaisrivongs and C. S. Wilcox, J. Am. Chem. Soc., 1983, 105, 1988 and references cited therein.

42 E. J. Corey, D. A. Clark, G. Goto, A. Marfat, C. Mioskowski, B. Samuelsson and S. Hammarström, J. Am. Chem. Soc., 1980, 102, 1436.

43 S. D. Haveli, P. R. Sridhar, P. Suguna and S. Chandrasekaran, Org. Lett., 2007, 9, 1331.

44 (a) U. Ravid, R. M. Silverstein and L. R. Smith, Tetrahedron, 1978, 34, 1449; (b) A. Takle and P. Kocienski, Tetrahedron, 1990, 46, 4503.

45 P. R. R. Meira, A. V. Moro and C. R. D. Correia, Synthesis, 2007, 2279.

46 K. Bischofberger, S. J. Eitelman and A. Jordaan, Carbohydr. Res., 1979, 74, 145.

47 K. Dax, B. I. Glänzer, G. Schulz and H. Vyplel, Carbohydr. Res., 1987, 162, 13.

48 B. J. Fitzsimmons, Y. Leblanc and J. Rokach, J. Am. Chem. Soc., 1987, 109, 285.

49 Y. Leblanc, B. J. Fitzsimmons, J. P. Springer and J. Rokach, J. Am. Chem. Soc., 1989, 111, 2995.

50 W. Abramski, K. Badowska-Rosbnek and M. Chmielewski, Bioorg. Med. Chem. Lett., 1993, 3, 2403.

51 P. Bertrand, J.-P. Gesson, B. Renoux and I. Tranoy, Tetrahedron Lett., 1995, 36, 4073.

52 K. A. Parker and D.-S. Su, J. Org. Chem., 1996, 61, 2191.

53 J. D. Bois, C. S. Tomooka, J. Hong and E. M. Carreira, J. Am. Chem. Soc., 1997, 119, 3179.

54 V. Kirsch, C. Wolff, C. Näther and W. Tochtermann, Eur. J. Org. Chem., 2000, 1741.

55 V. Y. Mizuno, The Organic Chemistry of Nucleic Acids, Elsevier, Amsterdam, 1986.

56 (a) H. Mitsuya, R. Yarchoan and S. Broder, Science, 1990, 249, 1533; (b) E. DeClercq, Design of anti-AIDS Drugs, Elsevier, New York, 1990; (c) S. Broder, AIDS: Modern Concepts and Therapeutic Challenges, Marcel Dekker, New York, 1987.

57 P. Herdewijn, J. Balzarini, E. De Clercq, R. Pauwels, M. Baba, S. Broder and H. Vanderhaeghe, J. Med. Chem., 1987, 30, 1270.

58 J. A. Montgomery, T. P. Johnston and Y. F. Shealy, in Burger's Medicinal Chemistry, ed. M. E. Wolff, Wiley, New York, 4th edn, 1980, Part 2.

59 M. I. Johnston and D. F. Hoth, Science, 1993, 260, 1286.

60 Q. Wu and C. Simons, Synthesis, 2004, 1533.

61 J. C.-Y. Cheng, U. Hacksell and G. D. Daves Jr, J. Org. Chem., 1986, 51, 3093.

62 R. A. Outten and G. D. Daves Jr, J. Org. Chem., 1987, 52, 5064.

63 R. N. Farr, R. A. Outten, J. C.-Y. Cheng and G. D. Daves Jr, Organometallics, 1990, 9, 3151.

64 G. D. Daves Jr, Acc. Chem. Res., 1990, 23, 201.

65 R. N. Farr, D.-I. Kwok and G. D. Daves Jr, J. Org. Chem., 1992, 57, 2093.

66 H.-C. Zhang and G. D. Daves Jr, J. Org. Chem., 1992, 57, 4690.

67 H.-C. Zhang, M. Brakta and G. D. Daves Jr, Tetrahedron Lett., 1993, 34, 1571. 
68 H.-C. Zhang, M. Brakta and G. D. Daves Jr, Nucleosides Nucleotides, 1995, 14, 105.

69 J. J. Chen, J. A. Walker II, W. Liu, D. S. Wise and L. B. Townsend, Tetrahedron Lett., 1995, 36, 8363.

70 H.-P. Hsieh and L. W. McLaughlin, J. Org. Chem., 1995, 60, 5356.

71 R. S. Coleman and M. L. Madaras, J. Org. Chem., 1998, 63, 5700 .

72 M. Tingoli, B. Panunzi and F. Santacroce, Tetrahedron Lett., 1999, 40, 9329.

73 Z. Sun, S. Ahmed and L. W. McLaughlin, J. Org. Chem., 2006, 71, 2922 and references cited therein.

74 I. Singh and O. Seitz, Org. Lett., 2006, 8, 4319.

75 N. Joubert, R. Pohl, B. Klepetářová and M. Hocek, J. Org. Chem., 2007, 72, 6797.

76 C. U. Kim, B. Y. Luh and J. C. Martin, J. Org. Chem., 1991, 56, 2642.

77 J. Žemlička, R. Gasser, J. V. Freisler and J. P. Horwitz, J. Am. Chem. Soc., 1972, 94, 3213.

78 M. Taniguchi, K. Koga and S. Yamada, Tetrahedron, 1974, 30, 3547.

79 J. Wang, J. A. Wurster, L. J. Wilson and D. Liotta, Tetrahedron Lett., 1993, 34, 4881.

80 F. E. McDonald and M. M. Gleason, Angew. Chem., Int. Ed. Engl., 1995, 34, 350.
81 Y. Díaz, A. El-Laghdach, M. I. Matheu and S. Castillón, J. Org. Chem., 1997, 62, 1501.

82 P. Hansen and E. B. Pedersen, Acta Chem. Scand., 1990, 44, 522.

83 Y. Díaz, A. El-Laghdach and S. Castillón, Tetrahedron, 1997, 53, 10921.

84 R. Robles, C. Rodríguez, I. Izquierdo, M. T. Plaza and A. Mota, Tetrahedron: Asymmetry, 1997, 8, 2959.

85 J. Lim and Y. H. Kim, J. Chem. Soc., Perkin Trans. 1, 1999, 3239.

86 L. A. Paquette, S. Brand and C. Behrens, J. Org. Chem., 1999, 64, 2010.

87 S. Marcotte, B. Gérard, X. Pannecoucke, C. Feasson and J.-C. Quirion, Synthesis, 2001, 929.

88 (a) R. Miethchen, M. Hein and H. Reinke, Eur. J. Org. Chem., 1998, 919; (b) F. H. Wu, B. N. Huang, L. Lu and W. Y. Huang, J. Fluorine Chem., 1996, 80, 91.

89 A. Choudhury, M. E. Pierce, D. Nguyen, L. Storace and P. N. Confalone, Tetrahedron Lett., 2005, 46, 8099.

90 L. Jean-Baptiste, S. Yemets, R. Legay and T. Lequeux, J. Org. Chem., 2006, 71, 2352.

91 (a) S. Z. Zard, in Radical Reactions in Organic Synthesis, Oxford Chemistry Masters, Oxford, 2003; (b) S. Z. Zard, Angew. Chem., Int. Ed. Engl., 1997, 36, 672. 